DEC 112000

OSTI

\title{
Development of Probabilistic Design Basis Earthquake (DBE) Parameters for Moderate and High Hazard Facilities at INEEL
}

\author{
S. J. Payne, V. W. Gorman, \\ S. A. Jensen, M. E. Nitzel, \\ M. J. Russell, and R. P. Smith \\ Revision 1 \\ Final Report \\ Published March \\ Idaho National Engineering and Environmental Laboratory \\ Geosciences Department \\ Bechtel BWXT Idaho, LLC \\ Idaho Falls, Idaho 83415
}

Prepared for the U.S. Department of Energy Assistant Secretary for Environmental Management Under DOE Idaho Operations Office Contract DE-AC07-99ID13727 



\section{DISCLAIMER}

This report was prepared as an account of work sponsored by an agency of the United States Government. Neither the United States Government nor any agency thereof, nor any of their employees, make any warranty, express or implied, or assumes any legal liability or responsibility for the accuracy, completeness, or usefulness of any information, apparatus, product, or process disclosed, or represents that its use would not infringe privately owned rights. Reference herein to any specific commercial product, process, or service by trade name, trademark, manufacturer, or otherwise does not necessarily constitute or imply its endorsement, recommendation, or favoring by the United States Government or any agency thereof. The views and opinions of authors expressed herein do not necessarily state or reflect those of the United States Government or any agency thereof. 


\section{DISCLAIMER}

Portions of this document may be illegible in electronic image products. Images are produced from the best available original document. 


\section{SUMMARY}

Design Basis Earthquake (DBE) horizontal and vertical response spectra are developed for moderate and high hazard facilities or Performance Categories (PC) 3 and 4, respectively, at the Idaho National Engineering and Environmental Laboratory (INEEL). The probabilistic DBE response spectra will replace the deterministic DBE response spectra currently in the U.S. Department of Energy Idaho Operations Office (DOE-ID) Architectural Engineering Standards that govern seismic design criteria for several facility areas at the INEEL.

Probabilistic DBE response spectra are recommended to DOE Naval Reactors for use at the Naval Reactor Facility (NRF) at INEEL.

The site-specific Uniform Hazard Spectra (UHS) developed by URS Greiner Woodward Clyde Federal Services are used as the basis for developing the DBE response spectra. In 1999, the UHS for all INEEL facility areas were recomputed using more appropriate attenuation relationships for the Basin and Range province. The revised UHS have lower ground motions than those produced in the $1996 \mathrm{INEEL}$ site-wide probabilistic ground motion study. To develop the DBE response spectra, the INEEL facility areas were categorized into four groups:

1. Idaho Nuclear Technology and Engineering Center (INTEC); Test Reactor Area (TRA); Radioactive Waste Management Complex (RWMC); Power Burst Facility (PBF)

2. Test Area North (TAN)

3. Naval Reactor Facility (NRF)

4. Argonne National Laboratory - West (ANL-W)

This report documents the development of DBE response spectra for INTEC, TRA, RWMC, PBF, TAN, and NRF. DBE response spectra were developed for ANL-W in 1998.

The PC 3 and PC 4 site-specific UHS for INTEC were adjusted for higher motions at TRA and RWMC to develop a DBE applicable to INTEC, TRA, RWMC, and PBF. The PC 3 UHS was also increased by $8 \%$ to account for a 2,500-year return period in anticipation of changes to DOE regulations. The adjusted PC 3 and PC 4 UHS were then used to develop the DBE response spectra for INTEC, TRA, RWMC, and PBF. For TAN, the site-specific PC 3 UHS was developed at the 2,500-year return period and the site-specific PC 4 UHS at the 10,000 -year return period.

The DBE response spectra were developed by incorporating smoothed broadened regions of the peak accelerations, velocities, and displacements defined by the site-specific UHS. Portions of the DBE response spectra were adjusted to ensure conservatism for the structural design process. Median amplification values from Newmark and Hall (1978) and current work of the Nuclear Regulatory Commission were used to check the adequacy of the DBE 
response spectra. These median amplification values were not used to develop the DBE response spectra.

Revisions to the DOE-ID Architectural Engineering Standards include:

1. PC 3 DBE corresponding to a 2,500-year return period.

2. $\mathrm{PC} 4 \mathrm{DBE}$ corresponding to a 10,000 -year return period.

3. $\mathrm{PC} 3$ and $\mathrm{PC} 4$ horizontal and vertical rock $\mathrm{DBE}$ response spectra applicable to INTEC, TRA, RWMC, and PBF.

4. $\mathrm{PC} 3$ and $\mathrm{PC} 4$ horizontal and vertical rock $\mathrm{DBE}$ response spectra applicable to TAN.

5. $\mathrm{PC} 3$ and PC 4 horizontal and vertical soil DBE response spectra applicable to INTEC for soil thickness of 30 to $50 \mathrm{ft}$.

For other soil conditions at INTEC, TRA, RWMC, PBF, and TAN, the DOE-ID Architectural Engineering Standards will require soil response analyses using appropriate time histories developed for the $\mathrm{PC} 3$ and $\mathrm{PC} 4$ rock DBE response spectra. Because the peak soil response is sensitive to variations in soil properties and thickness, more detailed soil response analyses are needed to develop generic soil response curves for PC 3 and PC 4 that will be applicable to multiple facility areas.

PC 3 and PC 4 rock DBE response spectra were also developed for NRF using the site-specific UHS. For NRF, PC 3 is defined at the 2,000-year and PC 4 , at the 10,000-year return periods consistent with current DOE Standards. The PC 3 and PC 4 DBE parameters are recommended for use at NRF for rock surface conditions and as input to soil response analyses. 


\section{FORWARD}

The purpose of this report is to document the steps for development of PC 3 and PC 4 DBE response spectra that are based on probabilistic site-specific uniform hazard spectra. The report also suggests the changes for incorporation into the DOE-ID Architectural Engineering Standards. It is recommended that the DBE information in this report be used as background and a reference to the contents of the DOE-ID Architectural Engineering Standards. Appendix S of the DOE-ID Architectural Engineering Standards contains the specific DBE information that shall be used in seismic design and evaluation analyses for facilities at INEEL. 
Rev 1 


\section{ACKNOWLEDGMENTS}

This report is the culmination of over a decade of work to understand the seismic hazards at INEEL. We greatly appreciate the support and guidance from Bob Secondo (formerly with DOE-ID) who made this effort possible. We also appreciate the help and contributions given by many people over the years. In particular we recognize Ivan Wong (URS Greiner Woodward Clyde Federal Services), Walt Silva (Pacific Engineering and Analysis), Bob Youngs (Geomatrix Consultants), and their respective staffs for the all work they have done to help us understand the seismic hazards and to develop the design basis earthquake parameters. We also recognize and appreciate the help from Jeff Kimball (DOE-HQ) for his recommendations of the design basis earthquakes upon which much of this report is based. We appreciate the peer review by Dr. Carl Costantino (City College of New York) and his help to develop the DBE response spectra. We recognize Bob Guenzler (currently with the State of Idaho) for his contributions toward development of seismic design criteria when at INEEL and thank him for his review. We thank the many peer reviewers, especially Dr. Norm Abrahamson (consultant), Dr. Robert B. Smith (University of Utah), Brent Buescher (BBWI), Jeff Brower (BBWI), Bob Ciardi (Bechtel Bettis Naval Reactors), Brent Harris (ANL-W), Stuart Jensen (BBWI), and Greg Miller (BBWI). We also appreciate the continued support of DOE-ID and the INEEL Natural Phenomena Hazards Committee. 
Rev 1 


\section{CONTENTS}

SUMMARY

FORWARD

$\mathrm{v}$

ACKNOWLEDGMENTS

vii

ABBREVIATIONS.

xvii

1. Introduction

2. Design Basis Earthquake for Rock Conditions at INTEC, TRA, RWMC, and PBF

2.1 Selection of Horizontal Rock UHS for PC 3 and PC 4

2.2 Adjustments for Multiple Facility Areas

2.3 Adjustment to 2,500 Year Return Period for PC 3.

2.4 Development of the PC 3 and PC 4 Horizontal Rock DBE.

2.5 Development of the PC 3 and PC 4 Vertical Rock DBE.

2.6 Use of the PC 3 and PC 4 Rock DBE.

2.7 Rock DBE for Input to Soil Response and Soil Structure Interaction Analyses

3. Design Basis Earthquake For Soil Surface Conditions at INTEC

3.1 Selection of Horizontal Soil UHS for PC 3 and PC 4

3.2 Development of the PC 3 and PC 4 Horizontal Soil DBE

3.3 Development of the PC 3 and PC 4 Vertical Soil DBE.

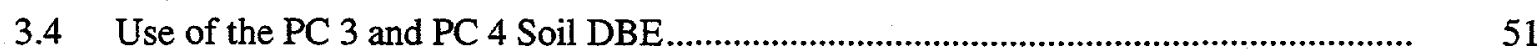

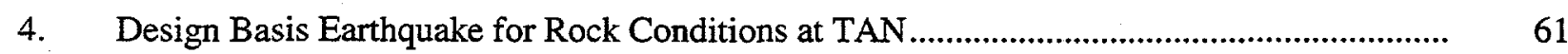

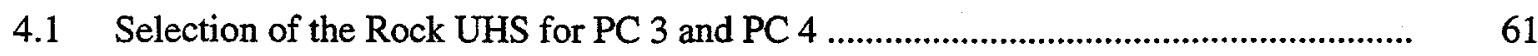

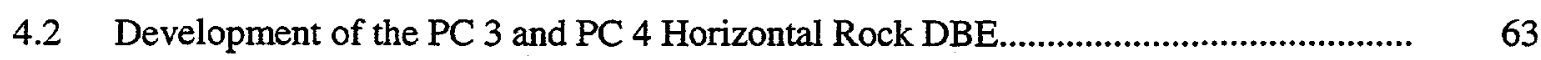

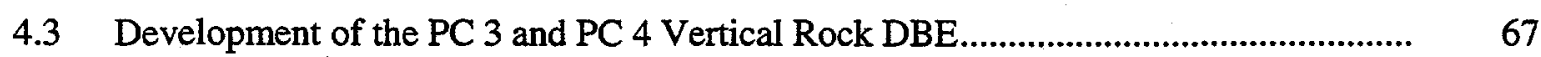

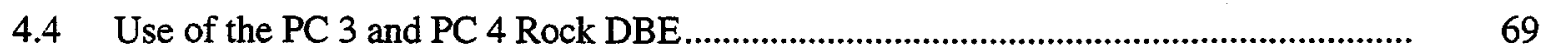

4.5 Rock DBE for Input to Soil Response and Soil Structure Interaction Analyses ........... 78 
5. Design Basis Earthquake for Rock Conditions at NRF

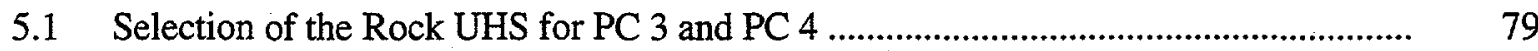

5.2 Development of the PC 3 and PC 4 Horizontal Rock DBE................................... 81

5.3 Development of the PC 3 and PC 4 Vertical Rock DBE....................................... 85

5.4 Use of the PC 3 and PC 4 Rock DBE

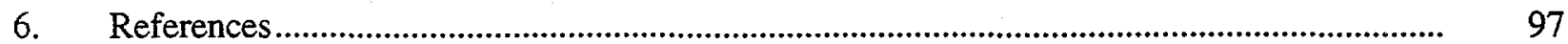




\section{FIGURES}

Figure 1. Map showing the locations of facility areas at INEEL relative to the mountain ranges located closest to INEEL within the northern Basin and Range Province.

Figure 2. Comparison of the INTEC, TRA, PBF, RWMC, NRF, TAN, and ANL-W rock mean $5 \%$ damped UHS at the 2,000-year return period.

Figure 3. Comparison of the INTEC, TRA, PBF, RWMC, NRF, TAN, and ANL-W rock mean $5 \%$ damped UHS at the 10,000-year return period.

Figure 4. Spectral ratios of the 2,000-year return period UHS for TRA, RWMC, and PBF to INTEC

Figure 5. Spectral ratios of the 10,000-year return period UHS for TRA, RWMC, and PBF to INTEC.

Figure 6. Comparison of the adjusted PC 3 (2,500 year return period) rock $5 \%$ damped UHS to the site-specific UHS at a 2,000-year return period for INTEC, TRA, RWMC, and PBF. .

Figure 7. Envelopes of the horizontal response spectra, (a) acceleration, (b) velocity, and (c) displacement, to portions of the adjusted PC 3 UHS used to develop the PC 3 (2,500 years) horizontal rock DBE response spectral shape for INTEC, TRA, RWMC, and PBF.

Figure 8. Comparison of the PC 3 (2,500 years) and PC 4 (10,000 years) horizontal rock DBE 5\% damped response spectra with the adjusted rock UHS for INTEC, TRA, RWMC, and PBF..

Figure 9. Comparison of the PC 3 (2,500 years) and PC 4 (10,000 years) horizontal rock DBE response spectra for INTEC, TRA, RWMC, and PBF with the current horizontal design criteria in the DOE-ID AE Standards for INTEC and TRA.

Figure 10. Vertical to horizontal spectral ratios developed for INEEL.

Figure 11. Envelopes of the vertical response spectra, acceleration, velocity, and displacement, to portions of the vertical rock PC 3 UHS used to develop the PC 3 (2,500 years) vertical rock DBE response spectral shape for INTEC, TRA, RWMC, and PBF.

Figure 12. Comparison of the PC 3 (2,500 years) and PC 4 (10,000 years) vertical rock DBE response spectra for INTEC, TRA, RWMC, and PBF with current vertical design criteria in the DOE-ID AE Standards for INTEC and TRA.

Figure 13. The horizontal and vertical rock DBE $5 \%$ damped response spectra for PC $3(2,500$ years) to be used for seismic design and evaluations at INTEC, TRA, RWMC and PBF.......

Figure 14. The horizontal and vertical rock DBE $5 \%$ damped response spectra for PC $4(10,000$ years) to be used for seismic design and evaluations at INTEC, TRA, RWMC, and PBF......

Figure 15. Tripartite graph of the horizontal and vertical PC 3 (2,500 years) rock DBE 5\% damped response spectra to be used for seismic design and evaluations at INTEC, TRA, RWMC, and PBF. 
Figure 16. Tripartite graph of the horizontal and vertical PC 4 (10,000 years) rock DBE 5\% damped response spectra to be used for seismic design and evaluations at INTEC, TRA, RWMC, and PBF.

Figure 17. Map showing the western boundary for the INEEL region and facility areas that the PC 3 (2,500 years) and PC 4 (10,000 years) rock DBE response spectra for INTEC, TRA, RWMC, and PBF can be used for seismic design and evaluations.

Figure 18. Plots of the acceleration, velocity, and displacement time histories for one horizontal component of the PC 3 (2,500 years) rock DBE response spectrum at INTEC, TRA, RWMC, and PBF.

Figure 19. Plots of the acceleration, velocity, and displacement time histories for the second horizontal component of the PC 3 (2,500 years) rock DBE response spectrum at INTEC, TRA, RWMC, and PBF.

Figure 20. Plots of the acceleration, velocity, and displacement time histories for the vertical component of the PC 3 (2,500 years) rock DBE response spectrum at INTEC, TRA, RWMC, and PBF.

Figure 21. Plots of the acceleration, velocity, and displacement time histories for one horizontal component of the PC 4 (10,000 years) rock DBE response spectrum at INTEC, TRA, RWMC, and PBF

Figure 22. Plots of the acceleration, velocity, and displacement time histories for the second horizontal component of the PC $4(10,000$ years) rock DBE response spectrum at INTEC, TRA, RWMC, and PBF .

Figure 23. Plots of the acceleration, velocity, and displacement time histories for the vertical component of the PC 4 (10,000 years) rock DBE response spectrum at INTEC, TRA, RWMC, and PBF.

Figure 24. Spectral accelerations of the 30 soil profiles with variations in seismic velocities and soil thicknesses ( 20 to $65 \mathrm{ft}$ ) at INTEC for the 2,000-year return period.

Figure 25. Soil amplification factors for the spectral ratios of soil to rock UHS for 20 to $65 \mathrm{ft}$ soil thickness at INTEC and for 5 to 25 soil thickness at ANL-W

Figure 26. The adjusted smoothed PC 3 (2,500 years) and the smoothed PC 4 (10,000 years) soil $5 \%$ damped UHS.

Figure 27. Comparison of the horizontal soil DBE 5\% damped response spectra and the smoothed soil UHS for INTEC.

Figure 28. Comparison of the PC 3 (2,500 years) and PC 4 (10,000 years) horizontal soil DBE $5 \%$ damped response spectra with the current design criteria for a soil thickness greater than $20 \mathrm{ft}$ at INTEC as defined by DOE-ID AE Standards.

Figure 29. Comparison of the PC 3 (2,500 years) and PC 4 (10,000 years) vertical soil DBE response spectra for INTEC with the current vertical design criteria for a soil thickness greater than $20 \mathrm{ft}$ at INTEC as defined by DOE-ID AE Standards 
Figure 30. The horizontal and vertical PC 3 (2,500 years) soil DBE 5\% damped response spectra for INTEC soil thickness between 30 to $50 \mathrm{ft}$.

Figure 31. The horizontal and vertical PC 4 (10,000 years) soil DBE 5\% damped response spectra for INTEC soil thickness between 30 to $50 \mathrm{ft}$.

Figure 32. Tripartite graph of the horizontal and vertical PC 3 (2,500 years) soil DBE 5\% damped response spectra for INTEC soil thickness between 30 to $50 \mathrm{ft}$.

Figure 33. Tripartite graph of the horizontal and vertical PC 4 (10,000 years) soil DBE 5\% damped response spectra for INTEC soil thickness between 30 to $50 \mathrm{ft}$.

Figure 34. Site-specific rock UHS for TAN at the 2,500 year return period and 10,000 year return period

Figure 35. Comparison of the PC 3 (2,500 years) and PC 4 (10,000 years) horizontal rock DBE 5\% damped response spectra with the adjusted PC 4 rock UHS at TAN.

Figure 36. Comparison of the TAN PC 3 (2,500 years) and PC 4 (10,000 years) horizontal rock DBE 5\% damped response spectra with the current design criteria in the DOE-ID AE Standards for TAN

Figure 37. Comparison of the TAN PC 3 (2,500 years) and PC 4 (10,000 years) vertical rock DBE 5\% damped response spectra with the current vertical design criteria in the DOE-ID AE Standards for TAN.

Figure 38. The horizontal and vertical rock DBE 5\% damped response spectra for PC 3 $(2,500$ years) to be used for seismic design and evaluations at TAN.

Figure 39. The horizontal and vertical rock DBE 5\% damped response spectra for PC 4 $(10,000$ years) to be used for seismic design and evaluations at TAN.

Figure 40. Tripartite graph of the horizontal and vertical PC 3 (2,500 years) rock DBE 5\% damped response spectra to be used for seismic design and evaluations at TAN

Figure 41. Tripartite graph of the horizontal and vertical PC 4 (10,000 years) rock DBE 5\% damped response spectra to be used for seismic design and evaluations at TAN

Figure 42. Comparison of the NRF rock UHS computed by WCFS (1996) using contributions from empirical California strong motion attenuation relationships and the NRF rock UHS computed by URSG-WCFS (2000a) using contributions from extensional tectonic attenuation relationships

Figure 43. Comparison of the NRF horizontal rock DBE 5\% damped response spectra and the horizontal rock UHS

Figure 44. Comparison of the NRF PC 3 (2,000 years) and PC 4 (10,000 years) horizontal rock DBE 5\% damped response spectra with design criteria developed by PCRA (1998)

Figure 45. Comparison of the NRF PC 3 (2,000 years) and PC 4 (10,000 years) vertical rock DBE $5 \%$ damped response spectra with vertical design criteria developed by PCRA (1998). 
Figure 46. The recommended PC 3 (2,000 years) horizontal and vertical rock DBE 5\% damped response spectra to be used for seismic design and evaluations at NRF.

Figure 47. The recommended PC 4 (10,000 years) horizontal and vertical rock DBE 5\% damped response spectra to be used for seismic design and evaluations at NRF

Figure 48. Tripartite graph of the horizontal and vertical PC 3 (2,000 years) rock DBE 5\% damped response spectra for NRF

Figure 49. Tripartite graph of the horizontal and vertical PC 4 (10,000 years) rock DBE 5\% damped response spectra for NRF 


\section{TABLES}

Table 1. Rock peak horizontal accelerations for INEEL facility areas.

Table 2. Spectral accelerations for the adjusted PC 3 (2,500 years) rock 5\% damped UHS at INTEC, TRA, RWMC, and PBF.

Table 3. Spectral accelerations for the adjusted PC 4 (10,000 years) rock 5\% damped UHS at INTEC, TRA, RWMC, and PBF.

Table 4. Spectral accelerations for the PC 3 (2,500 year) and PC 4 (10,000 year) horizontal rock DBE 5\% damped response spectra at INTEC, TRA, RWMC, and PBF.

Table 5. Spectral accelerations for the PC 3 (2,500 year) and PC 4 (10,000 year) vertical rock DBE 5\% damped response spectra for INTEC, TRA, RWMC, and PBF..

Table 6. Rock DBE compared to previous peak horizontal accelerations for INEEL facilities......

Table 7. Peak vertical accelerations.

Table 8. Spectral accelerations for the adjusted PC 3 (2,500 years) soil $5 \%$ damped UHS at INTEC.

Table 9. Spectral accelerations for the PC 4 (10,000 years) soil 5\% damped UHS at INTEC........

Table 10. Spectral accelerations for the PC 3 (2,500 year) and PC 4 (10,000 year) horizontal soil DBE response spectra for $5 \%$ damping at INTEC.

Table 11. Spectral accelerations for the PC 3 (2,500 year) and PC 4 (10,000 year) vertical soil DBE response spectra for $5 \%$ damping at INTEC.

Table 12. Peak horizontal and vertical accelerations for soil conditions at INTEC.

Table 13. Spectral accelerations for the PC 3 (2,500 years) rock 5\% damped UHS at TAN.

Table 14. Spectral accelerations for the PC 4 (10,000 years) rock 5\% damped UHS at TAN.......

Table 15. Spectral accelerations for the PC 3 (2,500 year) and PC 4 (10,000 year) horizontal rock DBE response spectra for $5 \%$ damping at TAN.

Table 16. Spectral accelerations for the PC 3 (2,500 year) and PC $4(10,000$ year) vertical rock DBE 5\% damped response spectra for TAN.

Table 17. Spectral accelerations for the PC 3 (2,000 years) $5 \%$ damped rock UHS at NRF.

Table 18. Spectral accelerations for the adjusted PC 4 (10,000 years) 5\% damped rock UHS at NRF.

Table 19. Spectral accelerations for the PC $3(2,000$ year) and PC $4(10,000)$ horizontal rock DBE $5 \%$ damped response spectra for NRF. 
Table 20. Spectral accelerations for the PC 3 (2,000 year) and PC $4(10,000)$ vertical rock DBE $5 \%$ damped response spectra for NRF

Table 21. Peak Accelerations for NRF 


\section{ABBREVIATIONS}

AE

ASCE

CFA

DBE

DNFSB

DOE

DOE-ID

ICPP

INTEC

ISFSI

INEEL

NEHRP

NPHC

NQA-1

NRC

NRF

PC

PCRA

PGA

PBF

RG

RWMC

SSI

SSC

TAN

Architectural Engineering

American Society of Civil Engineers

Central Facilities Area

Design Basis Earthquake

Defense Nuclear Facilities Safety Board

U.S. Department of Energy

U.S. Department of Energy Idaho Operations Office

Idaho Chemical Processing Plant

Idaho Nuclear Technology and Engineering Center

Independent Spent Fuel Storage Installation

Idaho National Engineering and Environmental Laboratory

National Earthquake Hazards Reduction Program

Natural Phenomena Hazards Committee

Nuclear Quality Assurance

Nuclear Regulatory Commission

Naval Reactor Facility

Performance Category

Paul C. Rizzo Associates, Inc.

Peak Ground (Horizontal) Acceleration

Power Burst Facility

Regulatory Guide

Radioactive Waste Management Complex

Soil Structure Interaction

Structure, System, or Component

Test Area North 
TRA

URSG-WCFS

UHS

$\mathrm{V} / \mathrm{H}$

WCFS

ZPA
Test Reactor Area

URS Greiner Woodward Clyde Federal Services

Uniform Hazard Spectra

Vertical to Horizontal Ratio

Woodward-Clyde Federal Services

Zero Period Acceleration 


\section{Development of Probabilistic Design Basis Earthquake (DBE) Parameters for Moderate and High Hazard Facilities at INEEL}

\section{INTRODUCTION}

This report documents the basis for revisions to the seismic design criteria in the DOE-ID Architectural Engineering (AE) Standards (DOE-ID, 1998) and recommendations for new seismic design criteria at NRF. Previously, the seismic design criteria in the DOE-ID AE Standards and at NRF were developed using a deterministic methodology. The seismic design criteria presented in this report have been developed using a probabilistic methodology that incorporates the most up-to-date region- and sitespecific geologic, seismologic, and geotechnical information for the Idaho National Engineering and Environmental Laboratory (INEEL). Site-specific probabilistic seismic hazard and Design Basis Earthquake (DBE) evaluations were conducted for the purpose of revising seismic design criteria at INEEL. The probabilistic and DBE evaluations were developed for seismic hazard annual probabilities of exceedance of 1,000 years, 2,000 years, and 10,000 years corresponding to Performance Categories (PC) 2, 3, and 4, respectively, as per the U.S. Department of Energy (DOE) Standards STD-DOE-102094 and STD-DOE-1023-95. These evaluations are also consistent with the requirements of the Nuclear Regulatory Commission (NRC) and NQA-1 (ASME, 1997).

In 1996, Woodward-Clyde Federal Services (WCFS) completed a site-specific probabilistic seismic hazard evaluation for all INEEL facility areas (WCFS, 1996) including: the Idaho Chemical Processing Plant (ICPP) now referred to as the Idaho Nuclear Technology and Engineering Center (INTEC); Test Reactor Area (TRA); Radioactive Waste Management Complex (RWMC); Power Burst Facility (PBF); Test Area North (TAN); Naval Reactor Facility (NRF); and Argonne National Laboratory West (ANL-W). The 1996 INEEL site-wide evaluation used region-specific earthquake source parameters, empirical California strong motion attenuation relationships, attenuation relationships based on site-specific numerical modeling, and detailed subsurface geologic profiles at each facility area. The results were in the form of mean Uniform Hazard Spectra (UHS) corresponding to the seismic hazard annual probabilities of exceedance for DOE PC 1,2,3, and 4.

Following the 1996 INEEL site-wide evaluation, WCFS developed DBE response spectra and corresponding time histories for ANL-W (WCFS, 1998). The PC 3 (2,000 years) and PC 4 (10,000 years) DBE response spectra for ANL-W were developed consistent with the current DOE Standards STDDOE-1020-94 and STD-DOE-1023-95. In 1998, the DOE Chicago Field Office concurred with the use of the DBE response spectra at ANL-W.

In 1999 WCFS, now referred to as URS Greiner Woodward-Clyde Federal Services (URSGWCFS), completed an evaluation using the site-specific UHS to develop design peak horizontal and vertical accelerations and response spectra for INTEC in support of an NRC license for the TMI-2 Independent Spent Fuel Storage Installation (ISFSI) (URSG-WCFS, 1999). Additionally, URSG-WCFS reevaluated the seismic hazard for INTEC, TRA, RWMC, PBF, TAN, and NRF using more appropriate empirical and numerical modeling attenuation relationships for the Basin and Range or extensional regime (URSG-WCFS, 2000a). The URSG-WCFS evaluations produced site-specific mean UHS that are used in this report to develop the DBE response spectra for the facility areas included in the DOE-ID AE Standards. Site-specific mean UHS are also used in this report to develop recommended DBE response spectra for NRF. 
The INEEL covers $2300 \mathrm{~km}^{2}$ of the eastern Snake River Plain that is surrounded by the northern Basin and Range Province (Figure 1). Because facility areas are located in different regions of the INEEL, they have different contributions to their seismic hazard from earthquake sources. Figures 2 and 3 show the UHS at the 2,000- and 10,000-year return periods for all INEEL facility areas. The UHS have different spectral amplitudes and shapes depending on the earthquake magnitude, distance to earthquake sources, and near-surface attenuation effects that contribute to their respective seismic hazard.

The facility areas were categorized into four groups to develop PC 3 and PC 4 seismic design criteria: 1) ANL-W; 2) INTEC, TRA, RWMC, and PBF; 3) NRF; and 4) TAN. The categorization of the facility areas into these groups was based on DOE programmatic issues and comparison of the UHS. ANL-W was not grouped with other facility areas because it's site-specific UHS has a broader peak than the other facility areas since the site has less near-surface attenuation and is located farthest from Basin and Range faults. Also, ANL-W is not contained within the DOE-ID AE Standards and is under the management of the DOE Chicago Field Office. As mentioned, DBE response spectra have been developed for ANL-W (WCFS, 1998).

TAN was not grouped with the other facility areas because it has the highest ground motions that would result in unnecessary conservative for INTEC, TRA, RWMC, PBF, and NRF. TAN is closest to Basin and Range faults that are capable of producing large earthquakes greater than moment magnitude $\left(M_{w}\right) 7.0$ and to background earthquakes of $M_{w} 5.5$ to 6.5 in the Basin and Range Province. For primarily this reason TAN was not grouped with the other facility areas (INTEC, TRA, RWMC, and PBF) contained within the DOE-ID AE Standards. TAN is under the management of DOE-ID.

Even though the NRF site-specific UHS has a similar spectral shape to INTEC, TRA, and RWMC, it was not grouped with these sites because it has higher motions since is located closer to Basin and Range faults than INTEC, TRA, and RWMC. Grouping NRF with INTEC, TRA, and RWMC would result in unnecessary conservatism for these three sites. Additionally, NRF is not contained within the DOE-ID AE Standards and is under the management of DOE Naval Reactors.

PBF was grouped with INTEC, TRA, and RWMC even though the resulting DBE response spectra will be conservative (Figures 2 and 3). PBF is at a greater distance from earthquake sources and has slightly greater near-surface attenuation effects than the other sites. Also, design criteria for INTEC, TRA, RWMC, and PBF is contained in the DOE-ID AE Standards and these four facility areas are under the management of DOE-ID.

This report provides the background information and steps taken to develop DBE response spectra for PC 3 and PC 4 for rock conditions at INTEC, TRA, RWMC, PBF, TAN, and NRF and for soil conditions at INTEC. The site-specific UHS (URSG-WCFS, 1999; 2000a) were used as a basis to develop the DBE response spectra. The approach is consistent with STD-DOE-1023-95. Standardized response spectral shapes were developed similar in the approach to that of Newmark and Hall (1978), and with consideration of ongoing work by the NRC for empirical spectral shapes (Per. Comm. J. Kimball, 1999).

The PC 3 and PC 4 rock DBE response spectra applicable to INTEC, TRA, RWMC, and PBF were developed to be inclusive of these facility areas so that the resulting DBE would be applicable to a larger region of the INEEL than to a specific facility area. The larger region includes the Central Facilities Area (CFA) even though a site-specific UHS was not developed for this area because it does not have PC 3 or PC 4 facilities. This report also includes a discussion of the appropriate rock DBE response spectra and time histories that are to be used for soil response or Soil Structure Interaction (SSI) analyses for PC 3 and PC 4 at these facility areas. DOE-ID and the INEEL Natural Phenomena Hazards Committee (NPHC) agreed that the DBE response spectra for the DOE-ID AE Standards also account for anticipated 
changes in DOE regulations that will require a 2,500-year return period for PC 3 type facilities. The current DOE Standards require a 2,000-year return period for PC 3. This report suggests the changes for incorporation of $\mathrm{DBE}$ response spectra at a return period of 2,500 years for $\mathrm{PC} 3$ and a return period of 10,000 years for PC 4 into the DOE-ID AE Standards.

PC 3 and PC 4 DBE response spectra for soil conditions having a thickness of 30 to $50 \mathrm{ft}(9.1$ to $15.2 \mathrm{~m}$ ) were developed for INTEC. A short discussion is provided about the applicability of the soil DBE response spectra to other sites. The PC 3 soil DBE response spectra were developed for a 2,500year return period. This report suggests the changes for incorporation of the INTEC PC 3 and PC 4 soil DBE into the DOE-ID AE Standards. It also recommends that additional soil response analyses be conducted to develop more appropriate DBE response spectra for various soil thicknesses and properties that could be applicable to PC 3 and PC 4 facilities at multiple sites.

PC 3 and PC 4 DBE response spectra were developed for rock surface conditions at NRF. At the request of NRF management, the PC 3 DBE response spectrum correspond to a 2,000-year return period as per the current DOE Standards, STD-DOE-1020-94. A short discussion is provided for use of the PC 3 and PC 4 rock DBE as input to soil response and SSI analyses at NRF. This report recommends that the PC 3 and PC 4 rock DBE response spectra be considered for approval by DOE Naval Reactors for use at NRF. 


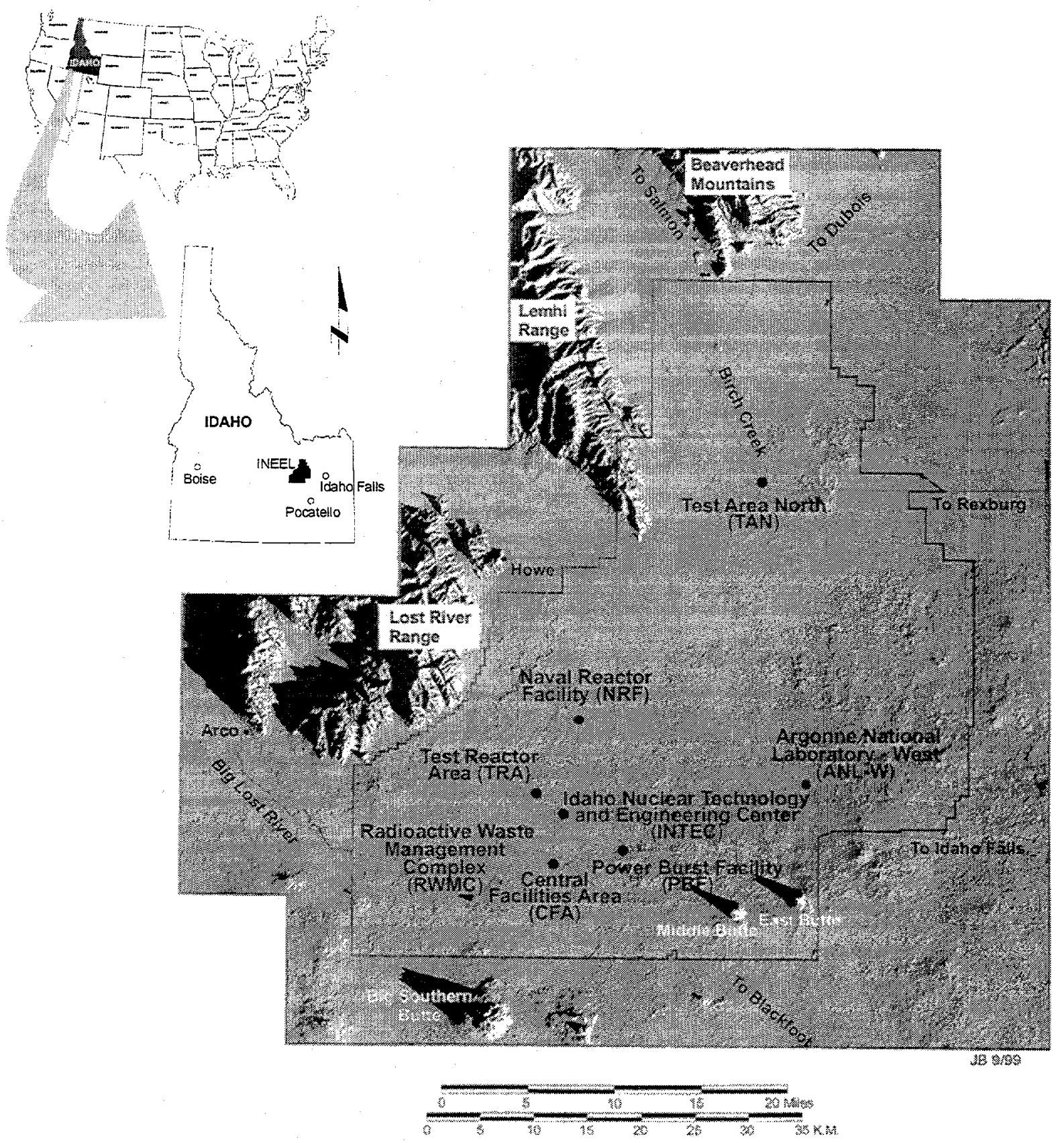

Figure 1. Map showing the locations of facility areas at INEEL relative to the mountain ranges located closest to INEEL within the northern Basin and Range Province. 


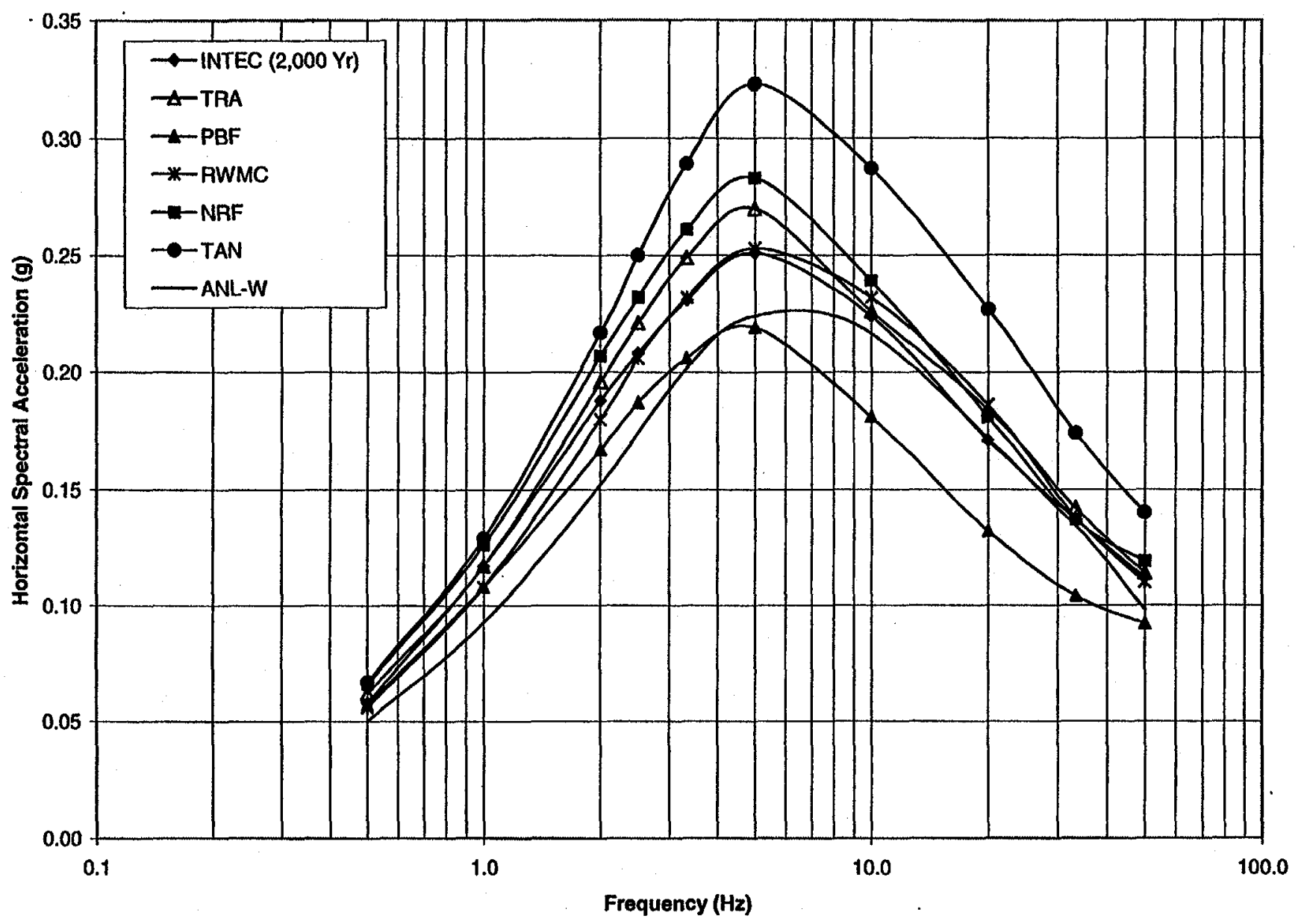

Figure 2. Comparison of the INTEC, TRA, PBF, RWMC, NRF, TAN, and ANL-W rock mean 5\% damped UHS at the 2,000year return period (WCFS, 1998; URSG-WCFS, 1999a; 1999b). 


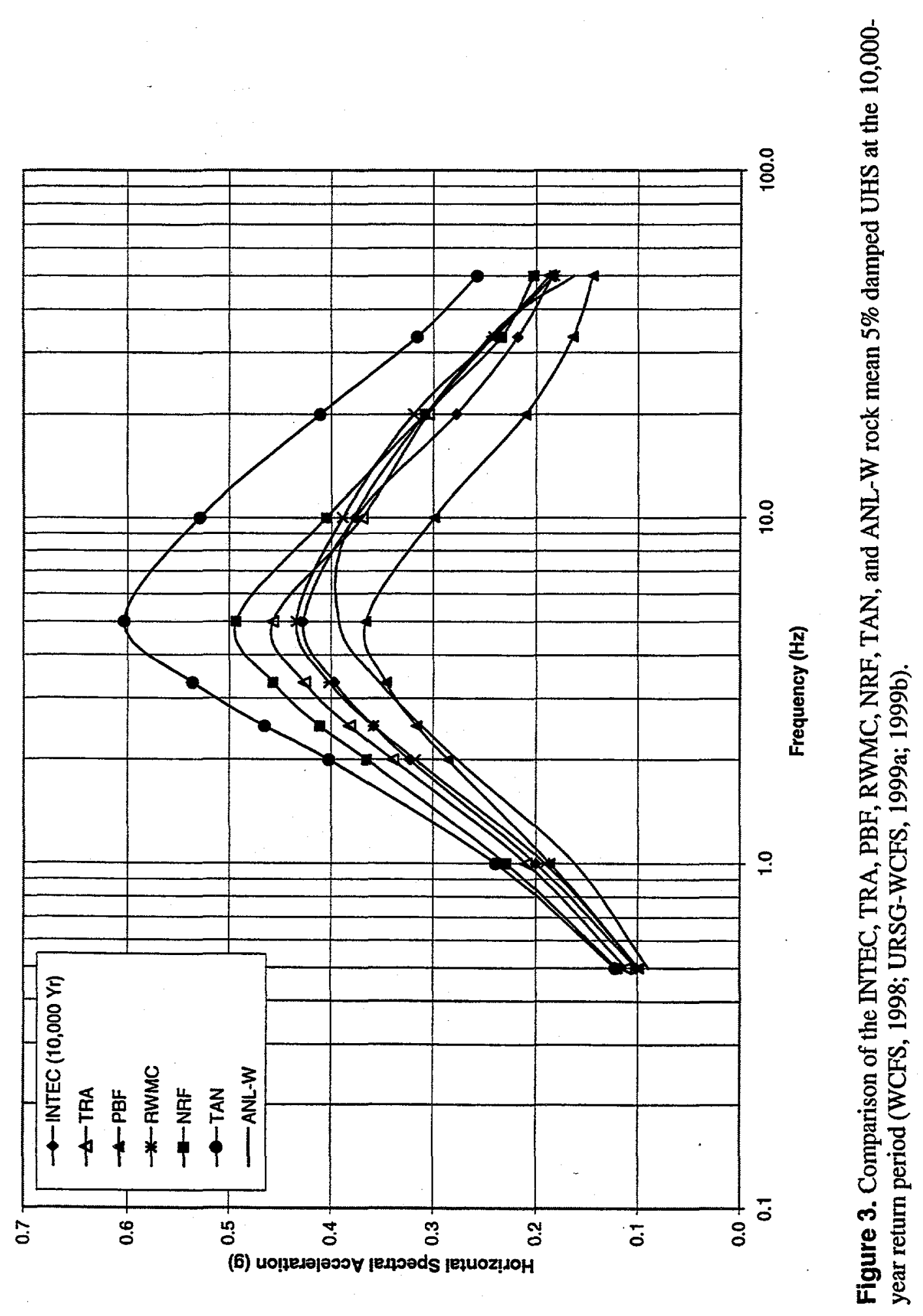




\section{DESIGN BASIS EARTHQUAKE FOR ROCK CONDITIONS AT INTEC, TRA, RWMC, AND PBF}

\subsection{Selection of Horizontal Rock UHS for PC 3 and PC 4}

The horizontal mean $5 \%$ damped UHS at 2,000 and 10,000 year return periods developed by URSG-WCFS (1999) for INTEC are used as the starting point for development of the rock DBE response spectra and peak accelerations for PC 3 and PC 4. INTEC was chosen because the URSG-WCFS (1999) evaluation (input data and methodologies) was thoroughly reviewed by the NRC and four nationally recognized experts as part of the licensing effort for the TMI-2 ISFSI. The INEEL NPHC and DOE approved the results (peak accelerations and UHS) of the TMI-2 ISFSI evaluation for use in development of DBE response spectra for INEEL facility areas.

For the TMI-2 ISFSI evaluation, the INTEC seismic hazard results at the 2,000-year and 10,000year return periods were deaggregated to determine the contributions of all earthquake sources in a selected earthquake magnitude and distance range. The dominant earthquakes at low (1 to $2.5 \mathrm{~Hz})$ and intermediate $(5$ to $10 \mathrm{~Hz}$ ) frequencies were used to supplement the response of the UHS. There were only minor increases in ground motions resulting, in part, from including more spectral frequencies in the spectral shapes than were used to compute the initial UHS, providing better interpolation and smoother spectral shapes (URSG-WCFS, 1999).

As part of the TMI-2 ISFSI evaluation, the probabilistic seismic hazard for INTEC was recomputed using ground motion attenuation relationships more appropriate for extensional tectonic regimes (URSGWCFS, 1999). URSG-WCFS (2000a) recomputed the UHS for TRA, RWMC, and PBF at return periods of 2,000 and 10,000 years to be consistent with the computations used to develop the UHS for INTEC (Figures 2 and 3). Table 1 lists the revised peak horizontal accelerations (PGA) for these facility areas based on the revised UHS. The PGA's and UHS produced using the revised attenuation relationships for extensional tectonic regimes result in 15 to $20 \%$ lower ground motions when compared to the results of the 1996 INEEL site-wide evaluation (WCFS, 1996). Observational seismologic evidence indicates that the state of stress in extensional or compressional regimes affects the amplitude of ground motions from earthquakes. Normal faulting earthquakes within extensional regimes have lower motions than strike-slip and thrust faulting earthquakes within compressional regimes. Also, differences occur in wave propagation characteristics between extensional and compressional tectonic regimes (Spudich et al., 1997; 1999).

\subsection{Adjustments for Multiple Facility Areas}

To develop rock UHS that would be applicable to a large region of INEEL, the PC 3 and PC 4 INTEC rock UHS were adjusted to account for higher spectral accelerations in the TRA and RWMC UHS. TRA has higher spectral accelerations than INTEC and PBF for most frequencies except from about 8 to $25 \mathrm{~Hz}$ where RWMC has slightly higher spectral accelerations (Figures 2 and 3). From 3 to 50 $\mathrm{Hz}$, the UHS for PBF has an average of $20 \%$ lower spectral accelerations than the peak spectral accelerations for the TRA and RWMC UHS. PBF has lower spectral accelerations because it is at a greater distance from earthquake sources and has slightly greater near-surface attenuation effects than the other sites. PBF was grouped with INTEC, TRA, and RWMC even though the resulting PC 3 and PC 4 DBE response spectra in this report will be conservative for that site.

The INTEC UHS at the 2,000-year return period was adjusted by the spectral ratios shown in Figure 4. The values for the TRA to INTEC spectral ratio from 0.5 to $8 \mathrm{~Hz}$ and from 25 to $50 \mathrm{~Hz}$ exceed the values for the other spectral ratios. The RWMC to INTEC spectral ratio has higher values from 8 to 
$25 \mathrm{~Hz}$. The adjusted rock UHS was determined by multiplying the INTEC UHS spectral accelerations by the highest spectral ratio values for TRA/INTEC and RWMC/INTEC. The spectra ratio values used to adjust the INTEC UHS are listed in Appendix A (Table A-1).

The spectral ratios of the 10,000-year return period UHS for TRA, RWMC, and PBF to INTEC are shown in Figure 5. The values for the TRA to INTEC spectral ratio exceed the values for the other spectral ratios from 0.5 to $5 \mathrm{~Hz}$ and from 33 to $50 \mathrm{~Hz}$. The RWMC to INTEC spectral ratio has higher values from 5 to $33 \mathrm{~Hz}$. The adjusted rock PC 4 UHS was determined by multiplying the INTEC PC 4 UHS by the highest spectral ratio values for TRA/INTEC and RWMC/NTEC. The spectral ratios used to adjust the INTEC UHS are also listed in Appendix A (Table A-1).

\subsection{Adjustment to 2,500 Year Return Period for PC 3}

The INTEC 2,000-year return period rock UHS was adjusted by an appropriate factor to account for anticipated changes in DOE regulations that will require a 2,500-year return period for PC 3 type facilities. The American Society of Civil Engineers (ASCE) standard currently under development from DOE-STD-1020-94 will revise the PC 3 DBE to be based on a 2,500-year return period instead of a 2,000-years. This change reflects the requirements of NEHRP97, the provisions being used to develop the 2000 edition of the International Building Code.

A review of the seismic hazard curves for INTEC shows that the $1 \mathrm{~Hz}$ spectral acceleration curve produces the largest factor of 1.08 for the ratio of the 2,500-year to 2,000-year return periods. Thus, the spectral accelerations for the INTEC rock UHS were increased by $8 \%$ (see Appendix A for analyses and adjustment factors). The adjusted PC 3 rock UHS accounting for the higher spectral accelerations at the other sites and the 2,500-year return period is shown in Figure 6 compared to the site-specific 2,000 year return period UHS developed by URSG-WCFS (2000a) for INTEC, TRA, RWMC, and PBF. The adjusted PC 3 rock UHS spectral accelerations are 15 to 35\% higher than the site-specific rock UHS for PBF.

The TAN UHS, supplemented for the dominant earthquake contributors, was developed at the 2,500 year return period (URSG-WCFS, 2000a). Development of the TAN DBE response spectra was added to this report to address a review comment on the draft report Revision 0 . Since the development of the INTEC UHS supplemented for dominant earthquake contributors was already completed for a 2,000 year return period prior to the decision to increase the return period to 2,500 years for PC 3 , the INTEC UHS was adjusted as discussed above. DOE Naval Reactors requested that the NRF UHS, supplemented for the dominant earthquake contributors, be developed at the 2,000 year return period (URSG-WCFS, 2000 a) to be consistent with current DOE Standards. No other adjustments were made to the NRF UHS. 
Table 1. Rock peak horizontal accelerations for INEEL facility areas.

\begin{tabular}{|c|c|c|c|c|}
\hline \multirow[b]{2}{*}{ Facility Area } & \multicolumn{2}{|c|}{ Probabilistic $\mathrm{PGA}^{\mathrm{a}}(\mathrm{g})$} & \multicolumn{2}{|c|}{ Deterministic PGA ${ }^{\mathrm{b}}(\mathrm{g})$} \\
\hline & (2,000 year) & $(10,000$ year $)$ & PC 3 & $\mathrm{PC} 4$ \\
\hline INTEC & 0.11 & 0.18 & 0.18 & 0.24 \\
\hline PBF & 0.09 & 0.14 & 0.17 & 0.22 \\
\hline RWMC & 0.11 & 0.18 & 0.16 & 0.21 \\
\hline TAN & 0.14 & 0.26 & 0.26 & 0.35 \\
\hline TRA & 0.11 & 0.18 & 0.18 & 0.24 \\
\hline a. URSG-WCFS & & & & \\
\hline b. DOE-ID Arch & eering Standard & & & \\
\hline
\end{tabular}




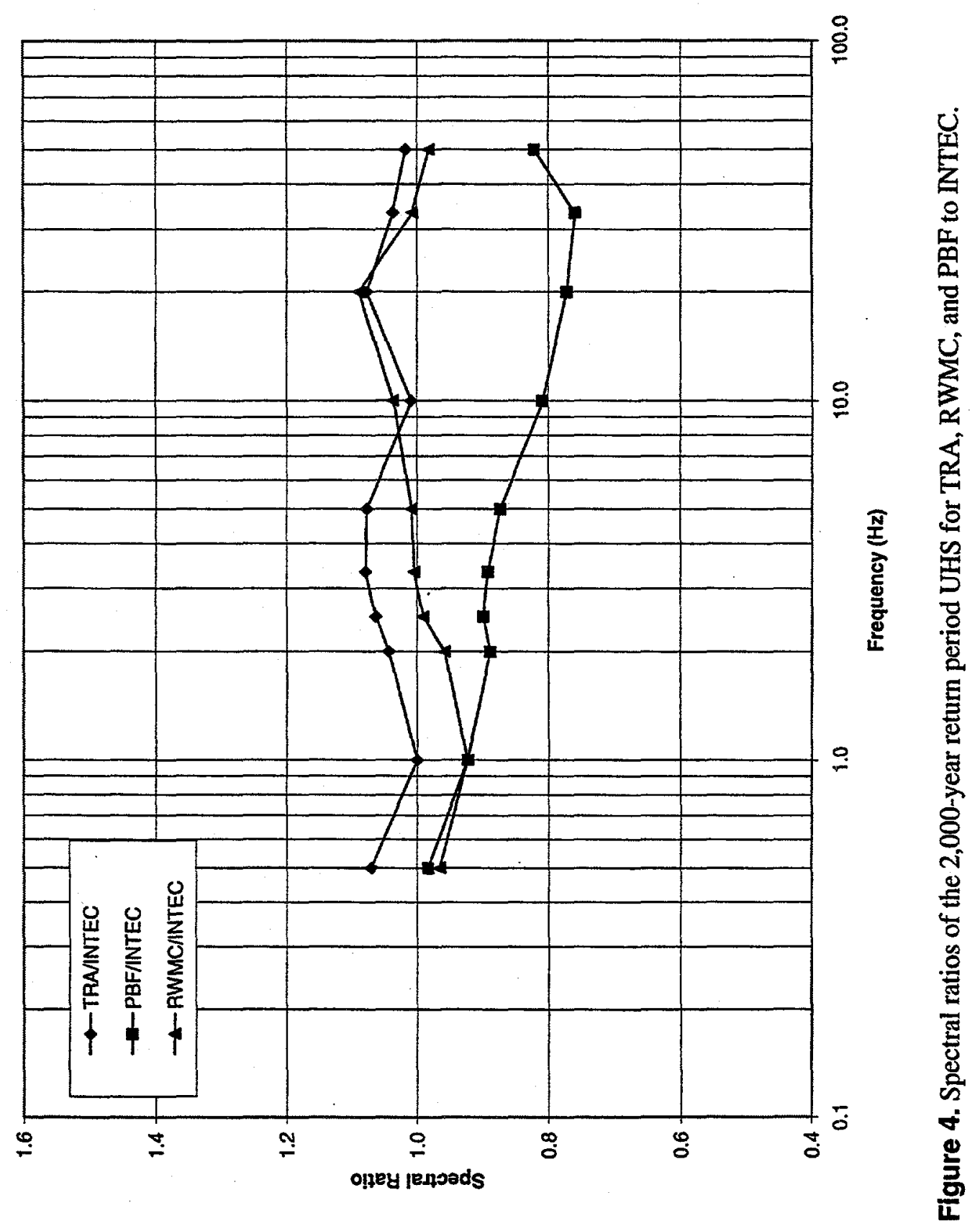




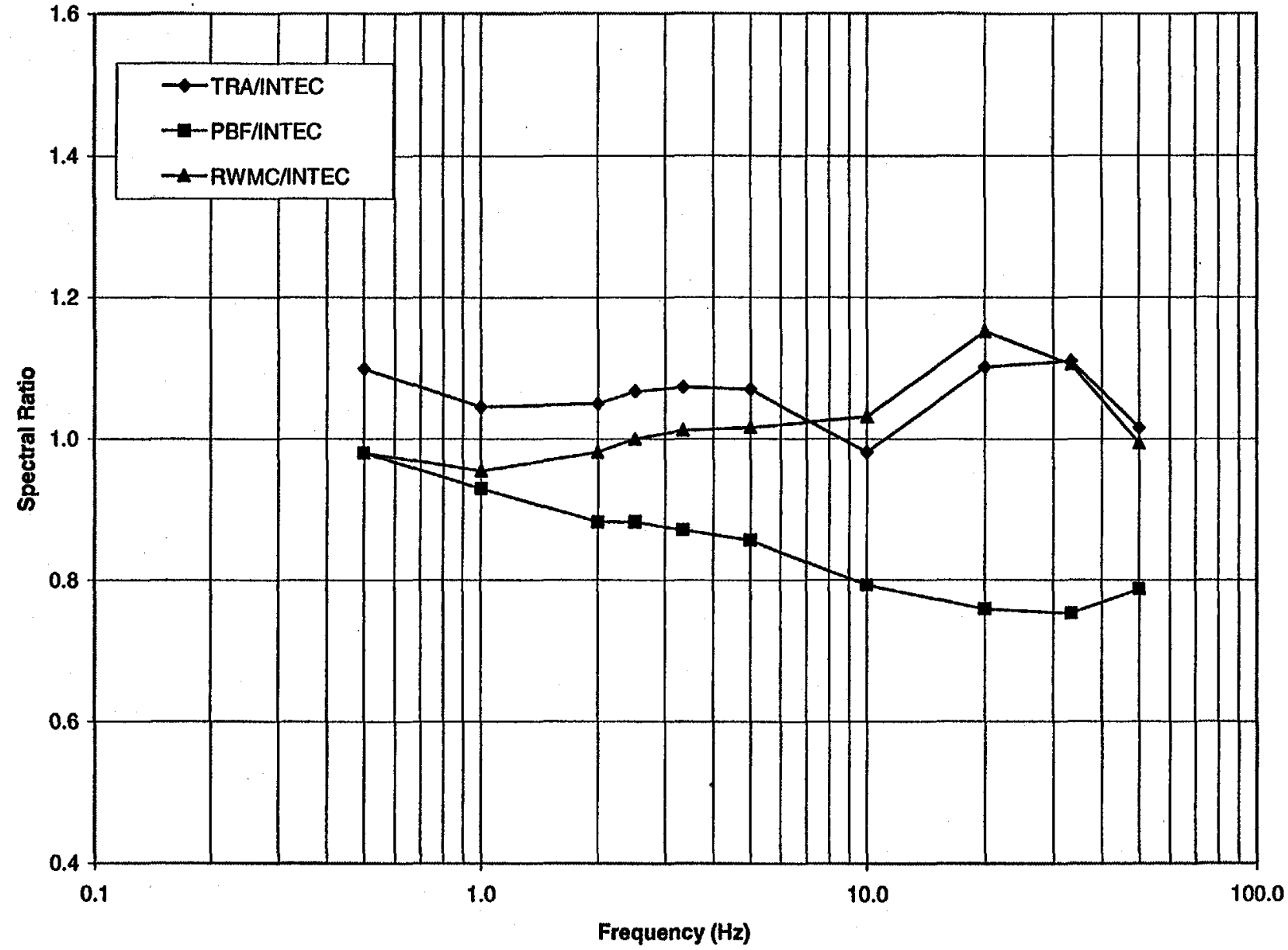

$\stackrel{700}{\stackrel{2}{2}}$

Figure 5. Spectral ratios of the 10,000-year return period UHS for TRA, RWMC, and PBF to INTEC. 


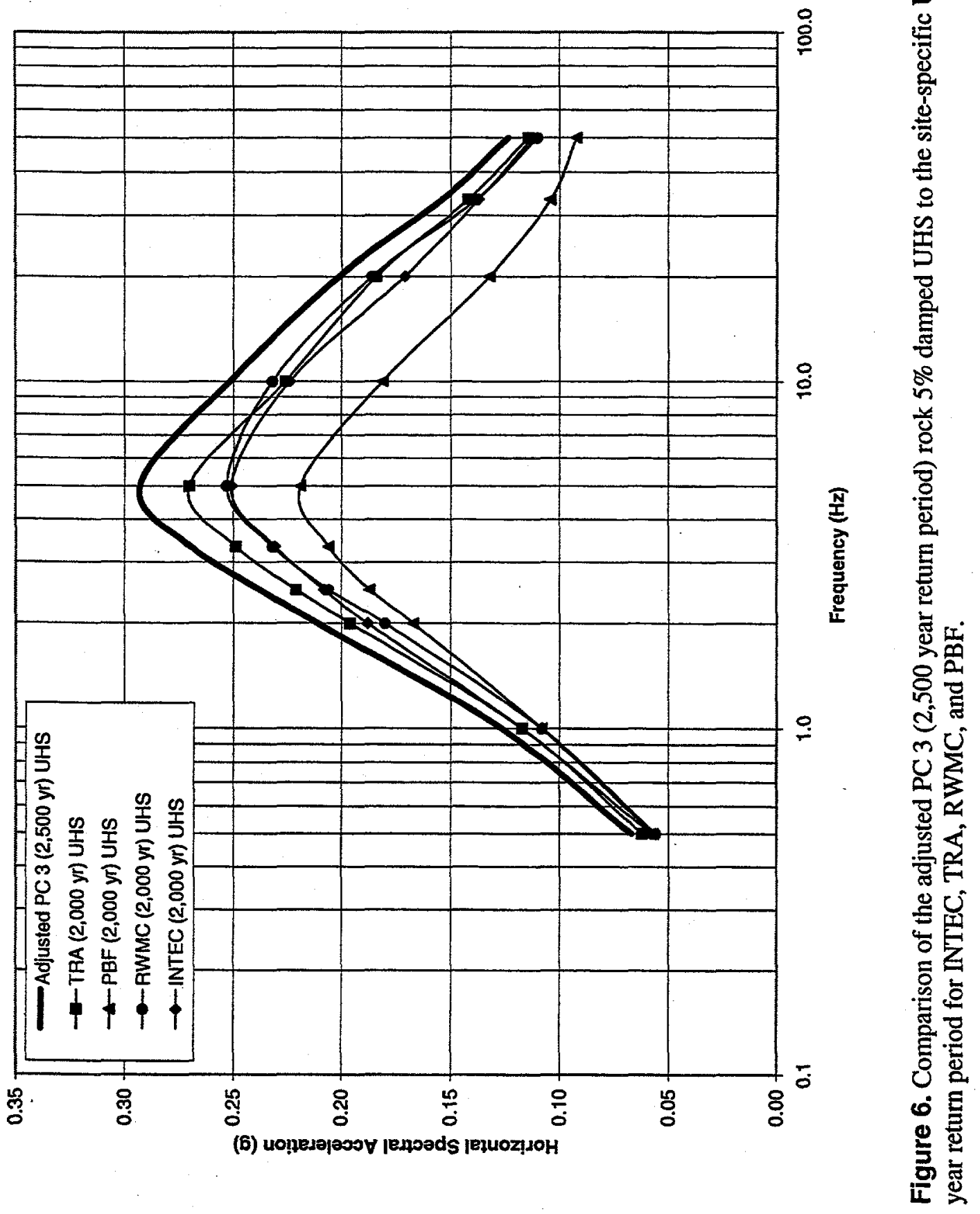




\subsection{Development of the PC 3 and PC 4 Horizontal Rock DBE}

The PC 3 and PC 4 horizontal rock DBE response spectra were derived from the adjusted PC 3 and PC 4 rock UHS (Tables 2 and 3, respectively). The rock DBE response spectra were developed by incorporating smoothed broadened regions of the peak accelerations, velocities, and displacements defined by the site-specific UHS. Portions of the rock DBE response spectra were adjusted to ensure conservatism for the structural design process.

The PC 3 (2,500 years) rock DBE response spectral shape was developed with the PGA (0.123 g), an increasing acceleration (by selecting $0.154 \mathrm{~g}$ at $33 \mathrm{~Hz}$ ), peak spectral acceleration $(0.293 \mathrm{~g}$ ), and constant velocity defined by the adjusted PC 3 (2,500 years) UHS (Table 2). The peak spectral displacement was selected to be 4 inches or $10.16 \mathrm{~cm}$ based on experience, professional judgement, and discussions with the Defense Nuclear Facilities Safety Board (DNFSB) on seismic design issues at other DOE sites (Per. Comm. J. Kimball, 1999) (see Appendix A for further discussion). Figure 7 shows the envelops of the response spectra to portions of the adjusted PC 3 UHS used to develop the PC 3 DBE response spectral shape for INTEC, TRA, RWMC, and PBF.

The PC $4(10,000$ years) rock DBE response spectral shape was developed in a similar manner as the PC 3 rock DBE. The PC 4 rock DBE response spectral shape was developed with the PGA (0.187 g), an increasing acceleration (by selecting $0.241 \mathrm{~g}$ at $33 \mathrm{~Hz}$ ), peak spectral acceleration $(0.457 \mathrm{~g}$ ), and constant velocity defined by the adjusted PC 4 (10,000 years) UHS (Table 3 ). The peak spectral displacement was selected to be 6 inches or $15.24 \mathrm{~cm}$ based on experience, professional judgement, and discussions with the DNFSB on seismic design issues at other DOE sites (Per. Comm. J. Kimball, 1999). Appendix A shows the envelops of the response spectra to portions of the adjusted PC 4 UHS used to develop the PC 4 DBE response spectral shape.

The PC 3 and PC 4 rock DBE response spectra have similar characteristics to a standard response spectrum of Newmark and Hall (1978), but not as much amplification. Since the rock DBE response spectral shapes were derived from the site-specific UHS, median amplification values from Newmark and Hall (1978) and current work of the Nuclear Regulatory Commission were used to check the adequacy of the resulting DBE response spectra. These median amplification values were not used to develop the rock DBE response spectra. The DBE response spectra have an adequate frequency range to accommodate the possible range of ground motions consistent with the approach developed by Newmark and Hall (1978) (see Appendix A for further discussion).

Figure 8 (a) and (b) show the PC 3 and PC 4 DBE 5\% damped response spectra to be used for design on rock compared to the adjusted PC 3 and PC 4 rock UHS, respectively. The PC 3 and PC 4 rock DBE response spectra have slightly higher spectral accelerations near $15 \mathrm{~Hz}$ than the adjusted PC 3 and PC 4 rock UHS. This occurs in part from the effect of semi-log versus log scale plotting. However, a slight exceedance of the UHS at this frequency range is unimportant (Per. Comm. C. Costantino, 1999).

Figure 9 shows the current design criteria in the DOE-ID AE Standards for INTEC and TRA compared to the PC 3 and PC 4 DBE response spectra for rock conditions at these sites. The PC 3 and PC 4 rock DBE response spectra have much lower ground motions than the RG 1.60 response spectrum tied to the PGA listed in Table 1 for INTEC and TRA (DOE-ID, 1998). The PC 3 and PC 4 rock DBE response spectra greatly reduces the design spectral accelerations between 1 and $10 \mathrm{~Hz}$, the primary range for most structure, system or component (SSC) evaluations for facilities at INTEC and TRA. Comparison of the current design criteria in the DOE-ID AE Standards (DOE-ID, 1998) for RWMC and PBF to the PC 3 and PC 4 rock DBE response spectra are shown in Appendix A. The comparisons show a significant reduction in design spectral accelerations for PC 3 at RWMC and PBF. For PC 4, the DBE response spectra exceed the current design criteria for RWMC and PBF at frequencies of 10 to $40 \mathrm{~Hz}$. 
Table 2. Spectral accelerations for the adjusted PC 3 (2,500 years) horizontal rock 5\% damped UHS at INTEC, TRA, RWMC, and PBF.

\begin{tabular}{cc}
$\begin{array}{c}\text { Frequency } \\
(\mathrm{Hz})\end{array}$ & $\begin{array}{c}\text { Horizontal Spectral } \\
\text { Acceleration } \\
(\mathrm{g})\end{array}$ \\
\hline 50.00 & 0.123 \\
33.33 & 0.154 \\
20.00 & 0.201 \\
10.00 & 0.252 \\
5.00 & 0.293 \\
3.33 & 0.269 \\
2.50 & 0.238 \\
2.00 & 0.211 \\
1.00 & 0.126 \\
0.50 & 0.067 \\
\hline
\end{tabular}

Table 3. Spectral accelerations for the adjusted PC 4 (10,000 years) horizontal rock $5 \%$ damped UHS at INTEC, TRA, RWMC, and PBF.

\begin{tabular}{cc}
\hline $\begin{array}{c}\text { Frequency } \\
(\mathrm{Hz})\end{array}$ & $\begin{array}{c}\text { Horizontal } \\
\text { Spectral Acceleration } \\
(\mathrm{g})\end{array}$ \\
\hline 50.00 & 0.187 \\
33.33 & 0.242 \\
20.00 & 0.319 \\
10.00 & 0.388 \\
5.00 & 0.457 \\
3.33 & 0.425 \\
2.50 & 0.383 \\
2.00 & 0.339 \\
1.00 & 0.210 \\
0.50 & 0.111 \\
\hline
\end{tabular}


(a)

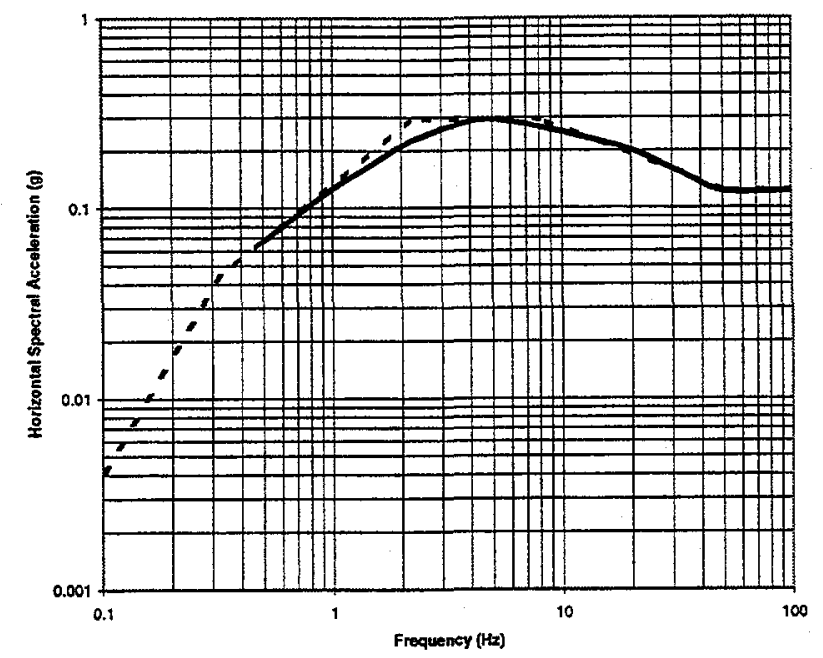

(b)

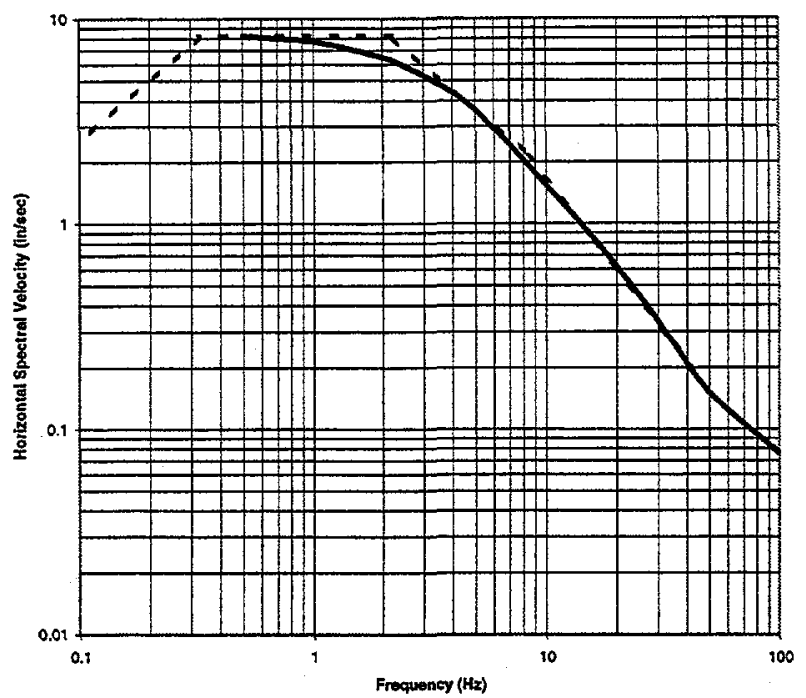

(c)

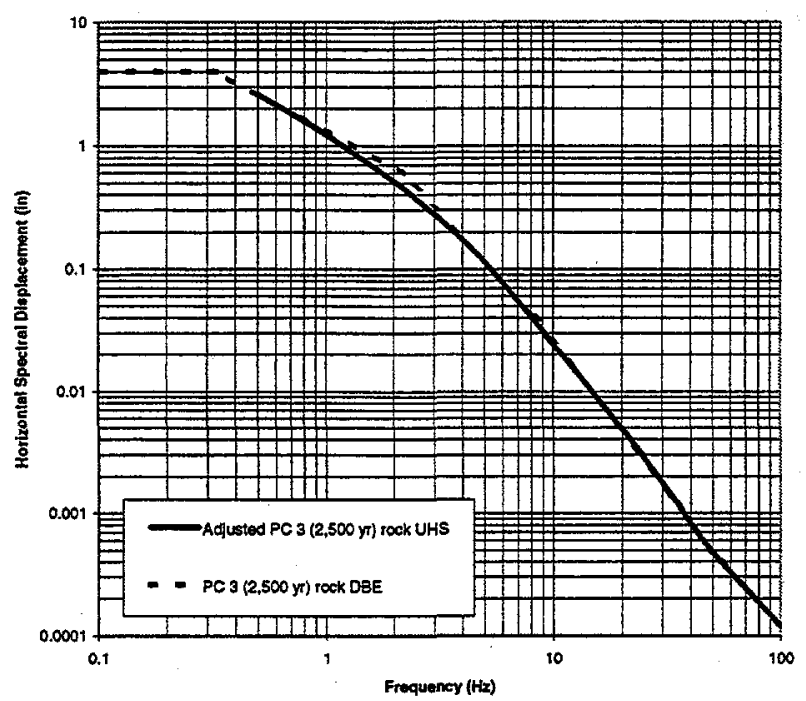

Figure 7. Envelopes of the horizontal response spectra, (a) acceleration, (b) velocity, and (c) displacement, to portions of the adjusted PC 3 UHS used to develop the PC 3 (2,500 years) horizontal rock DBE response spectral shape for INTEC, TRA, RWMC, and PBF. 
(a)

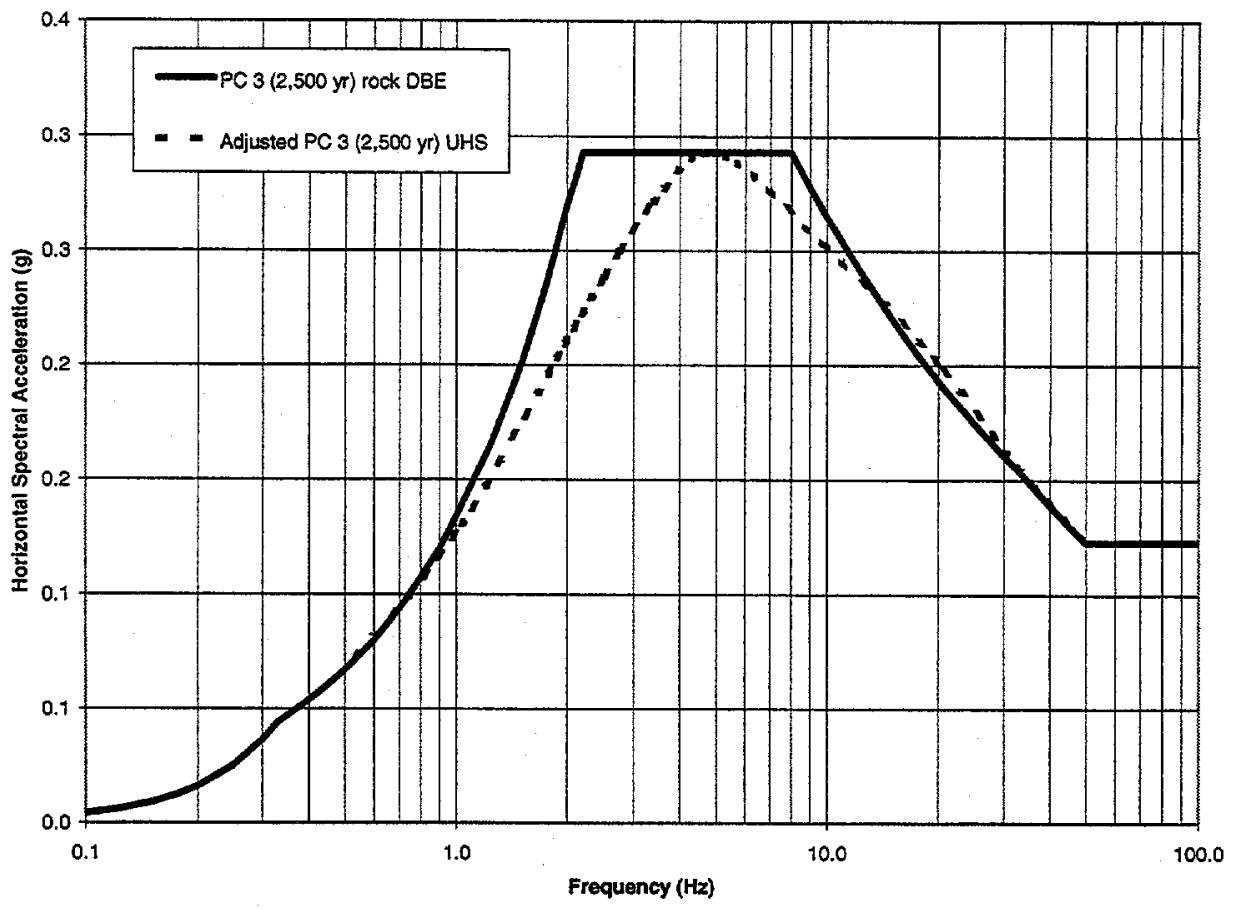

(b)

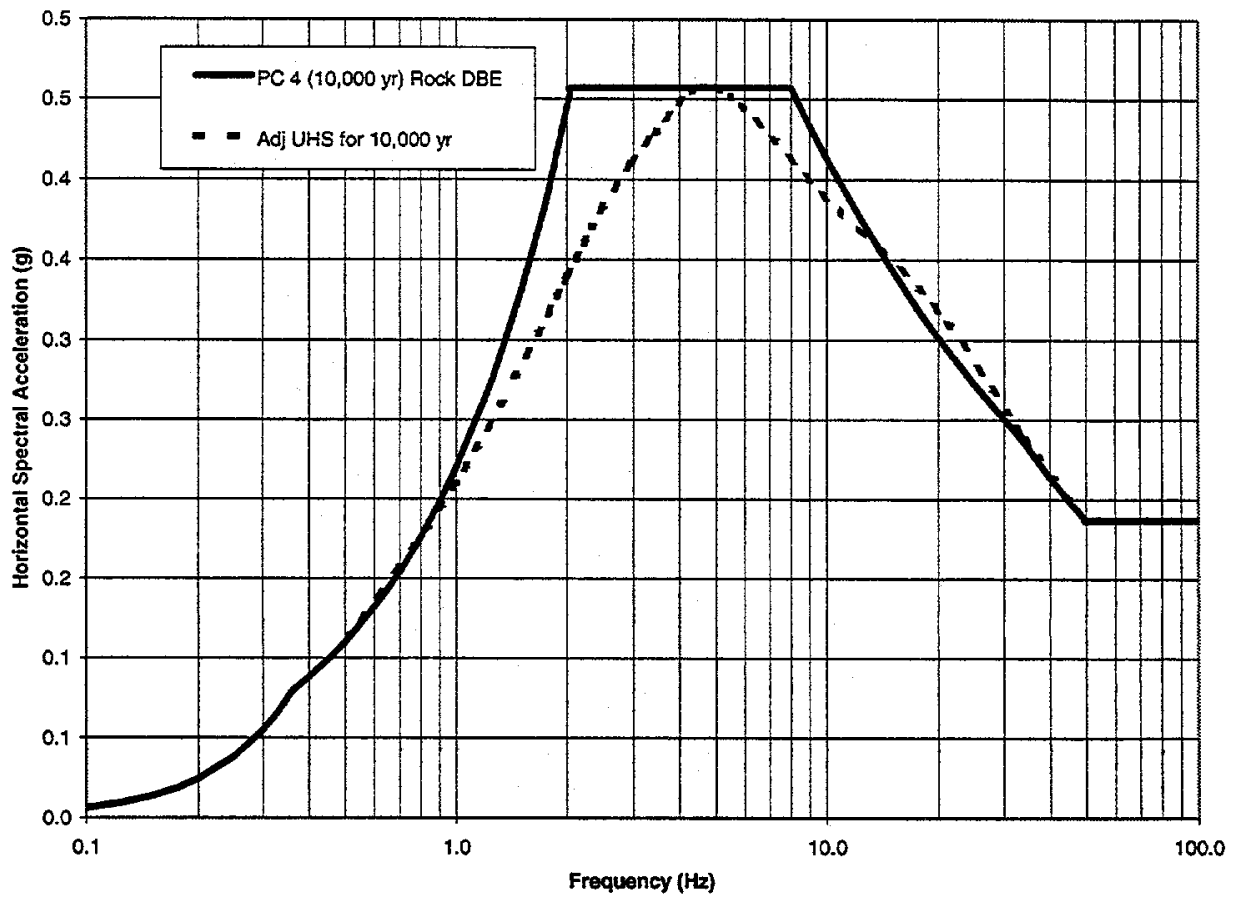

Figure 8. Comparison of the PC 3 (2,500 years) and PC 4 (10,000 years) horizontal rock DBE 5\% damped response spectra with the adjusted rock UHS for INTEC, TRA, RWMC, and PBF. 
(a)

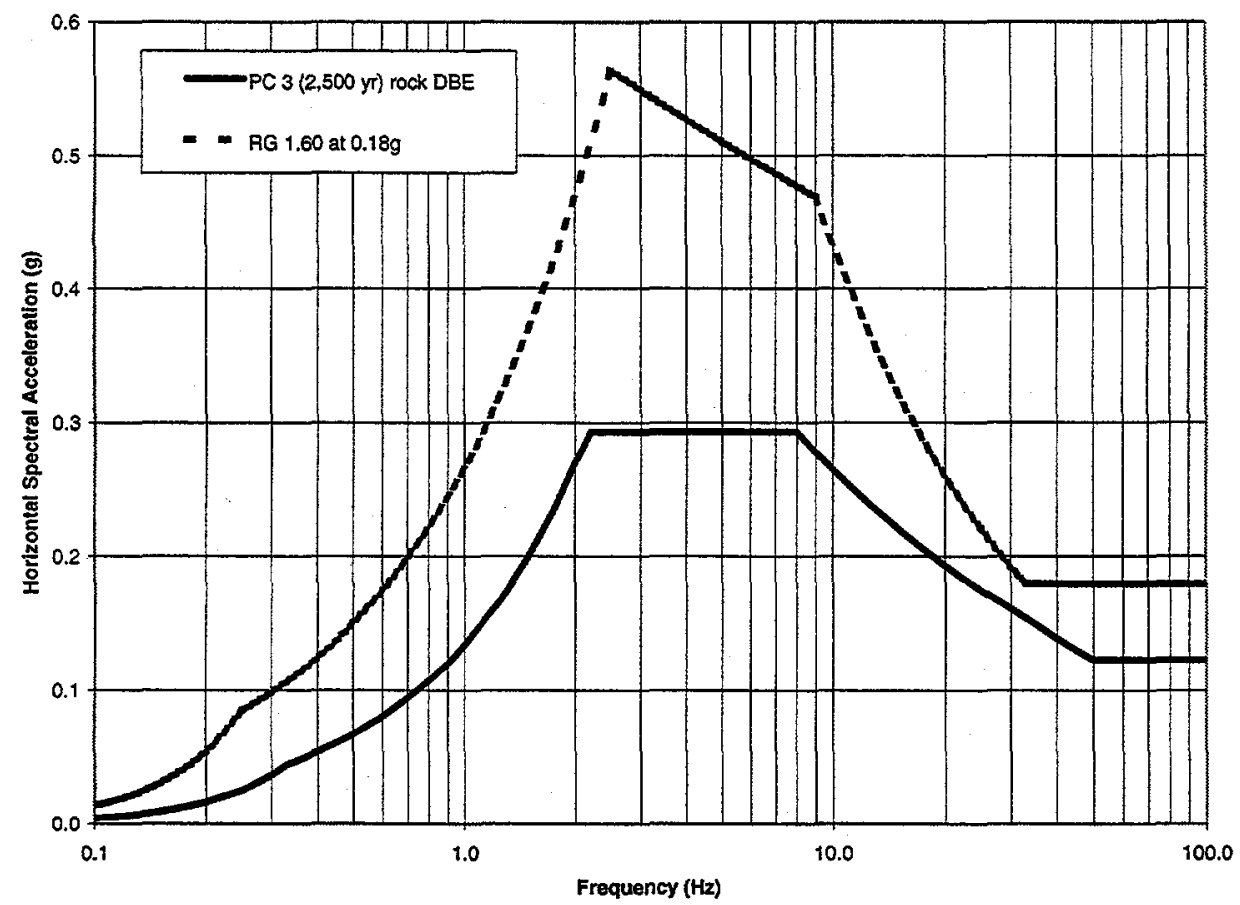

(b)

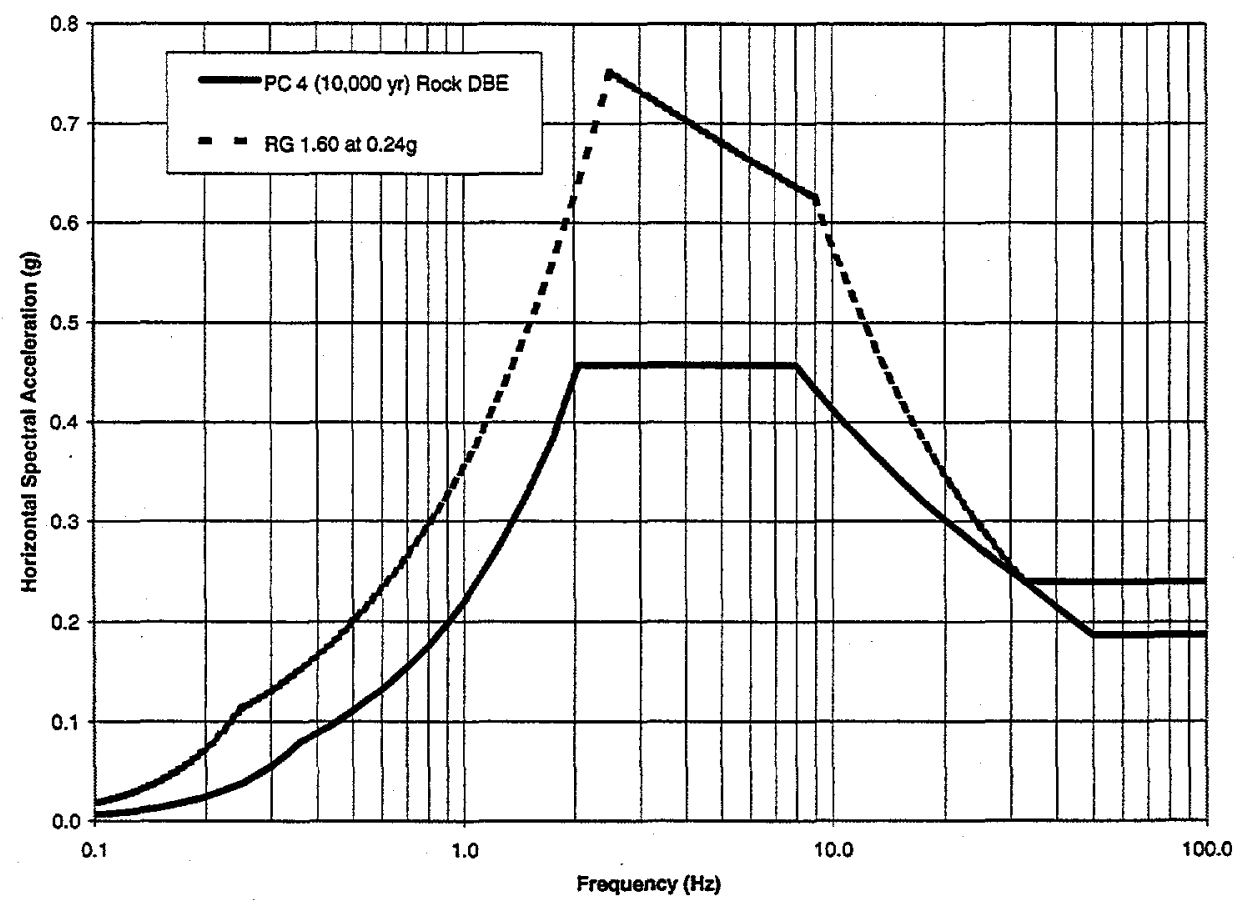

Figure 9. Comparison of the PC 3 (2,500 years) and PC 4 (10,000 years) horizontal rock DBE response spectra for INTEC, TRA, RWMC, and PBF with the current horizontal design criteria in the DOE-ID AE Standards for INTEC and TRA (DOE-ID, 1998). 


\subsection{Development of the PC 3 and PC 4 Vertical Rock DBE}

The PC 3 and PC 4 adjusted horizontal rock 5\% damped UHS (Tables 2 and 3) were used to develop the vertical rock DBE response spectra for PC 3 and PC 4, respectively. The PC 3 rock DBE was adjusted for a 2,500-year return period. Both the PC 3 and PC 4 rock UHS were adjusted for higher motions at other facility sites so that the vertical DBE will be applicable to multiple facility areas and a large region of the INEEL (Sections 2.2 and 2.3).

URSG-WCFS (1999) developed a ratio for the vertical to horizontal (V/H) ground motions applicable to INEEL (see Appendix B for discussion of development method). Figure 10 shows that the $\mathrm{V} / \mathrm{H}$ spectral ratio is a value of $2 / 3$ from 0.1 to $6 \mathrm{~Hz}$. From 6 to $50 \mathrm{~Hz}$ the spectral ratio increases to greater than 1 then decreases to 0.77 at $50 \mathrm{~Hz}$ where it is constant to $100 \mathrm{~Hz}$.

To derive the PC 3 and PC 4 vertical rock DBE response spectra, the horizontal rock UHS spectral accelerations shown in Tables 2 and 3 were multiplied by the $V / H$ spectral ratio (Figure 10) to produce vertical UHS. The constant acceleration, velocity, and displacement portions of the vertical DBE response spectra were determined by enveloping the vertical UHS. Figure 11 shows the envelopes of the vertical response spectra for the PC 3 (2,500 year) vertical rock DBE response spectrum (envelopes for PC 4 are show in Appendix A). For example, the constant peak acceleration portion of the vertical DBE spectrum was extends to $20 \mathrm{~Hz}$ to account for the portion of the $\mathrm{V} / \mathrm{H}$ ratio where it exceeds 1.00 (Figure $11 \mathrm{a}$ ).

The PC 3 and PC 4 vertical rock DBE response spectra are compared to the vertical design spectra defined in the DOE-ID AE Standards. In Figure 12 (a), the RG 1.60 response spectrum is tied to $0.12 \mathrm{~g}$ (Table 7), the peak vertical acceleration for PC 3 at INTEC and TRA in the DOE-ID AE Standards (DOE, 1998). In Figure 12 (b), the RG 1.60 response spectrum is tied to $0.18 \mathrm{~g}$ (Table 7), the peak vertical acceleration for PC 4 at INTEC and TRA in the DOE-ID AE Standards. The spectral accelerations for the PC 3 and $P C 4$ vertical rock DBE response spectra are much lower at frequencies less than $13 \mathrm{~Hz}$, but exceed the spectral accelerations from 13 to $40 \mathrm{~Hz}$ for the vertical design spectra in the DOE-ID AE Standards (DOE, 1998). Comparisons of current vertical design for RWMC and PBF are show in Appendix A. The vertical PC $3 \mathrm{DBE}$ response spectra exceed the current vertical design criteria for RWMC and PBF at frequencies between 12.5 and $43 \mathrm{~Hz}$. The vertical PC $4 \mathrm{DBE}$ response spectrum exceeds the current vertical design criteria for PBF at frequencies of 10 to $45 \mathrm{~Hz}$. The vertical PC $4 \mathrm{DBE}$ response spectrum and the current vertical design criteria for RWMC have the same PGA, and thus, the $\mathrm{PC} 4 \mathrm{DBE}$ response spectrum exceeds the current vertical design criteria from 10 to $50 \mathrm{~Hz}$. 


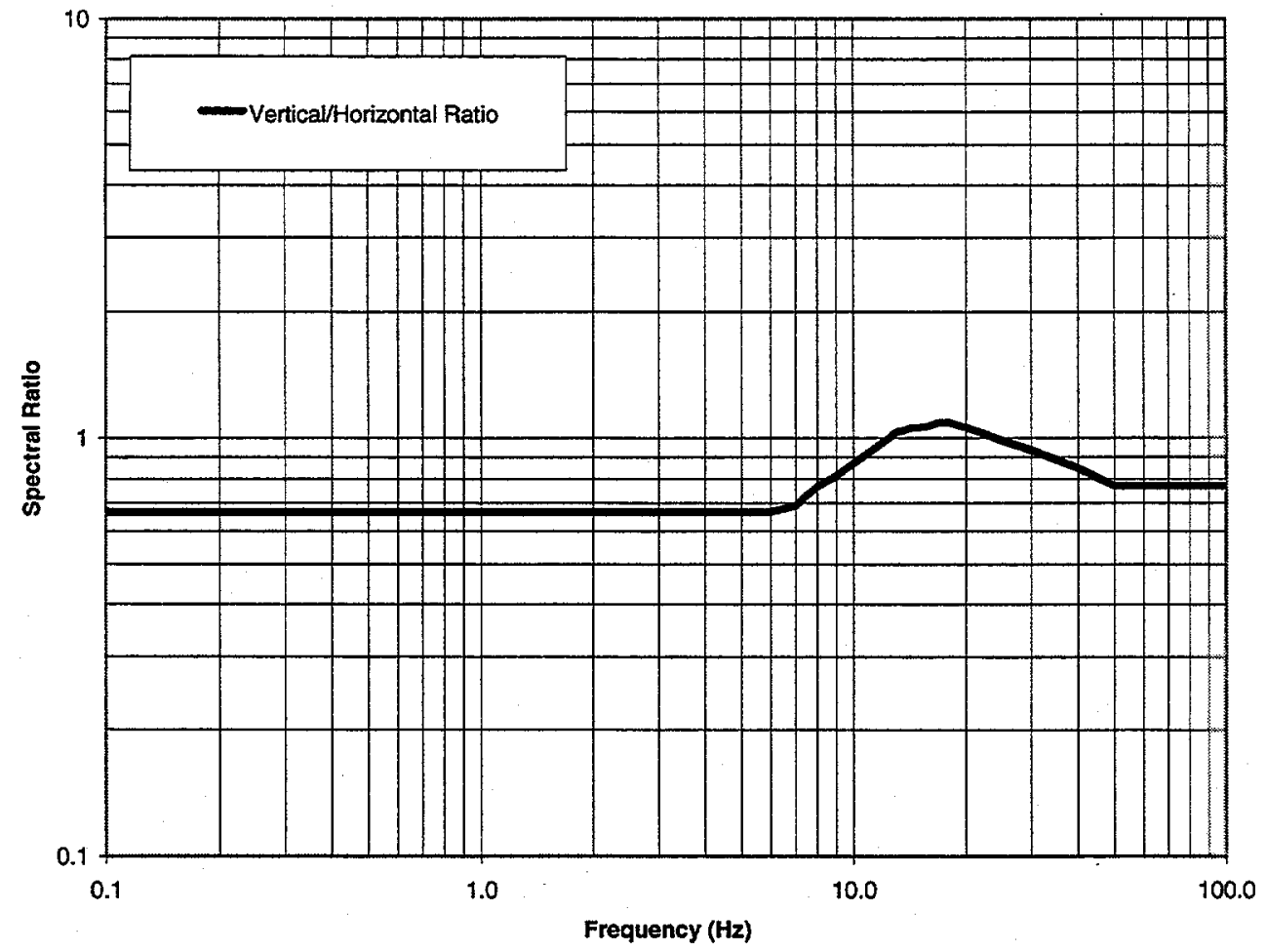

Figure 10. Vertical to horizontal spectral ratios developed for INEEL by URSG-WCFS (1999). 
(a)

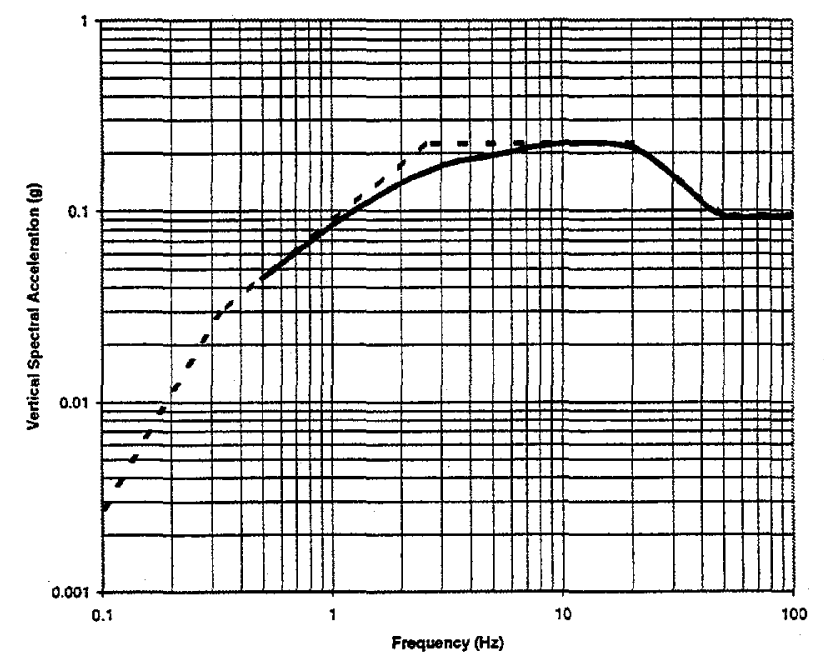

(b)

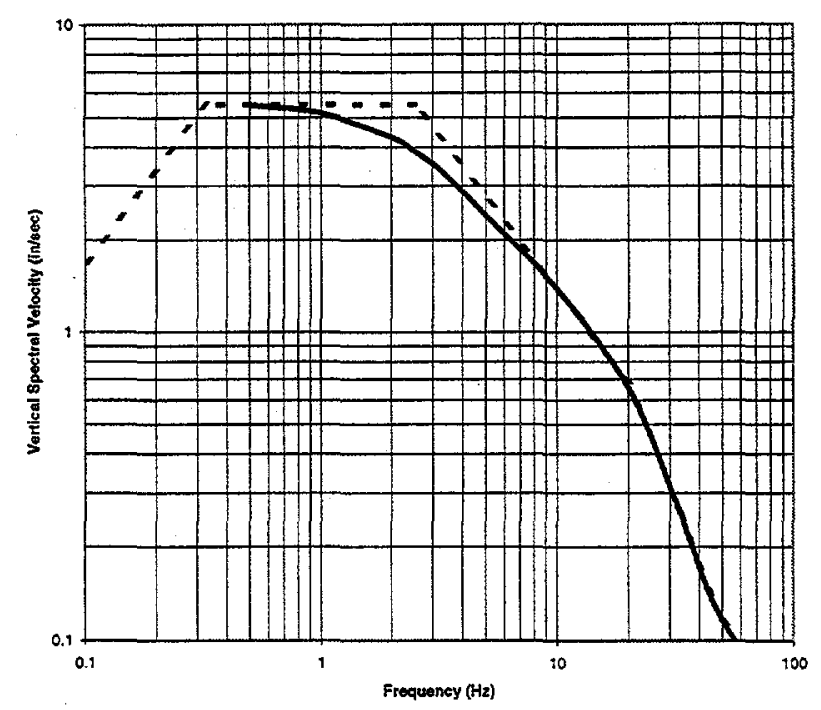

(c)

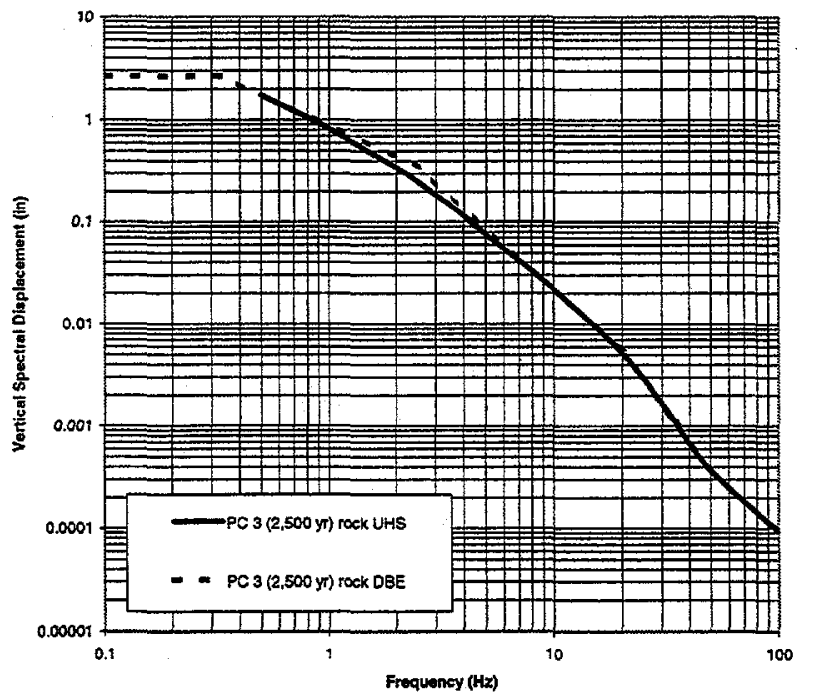

Figure 11. Envelopes of the vertical response spectra, (a) acceleration, (b) velocity, and (c) displacement, to portions of the vertical rock PC 3 UHS used to develop the PC 3 (2,500 years) vertical rock DBE response spectral shape for INTEC, TRA, RWMC, and PBF. 
(a)

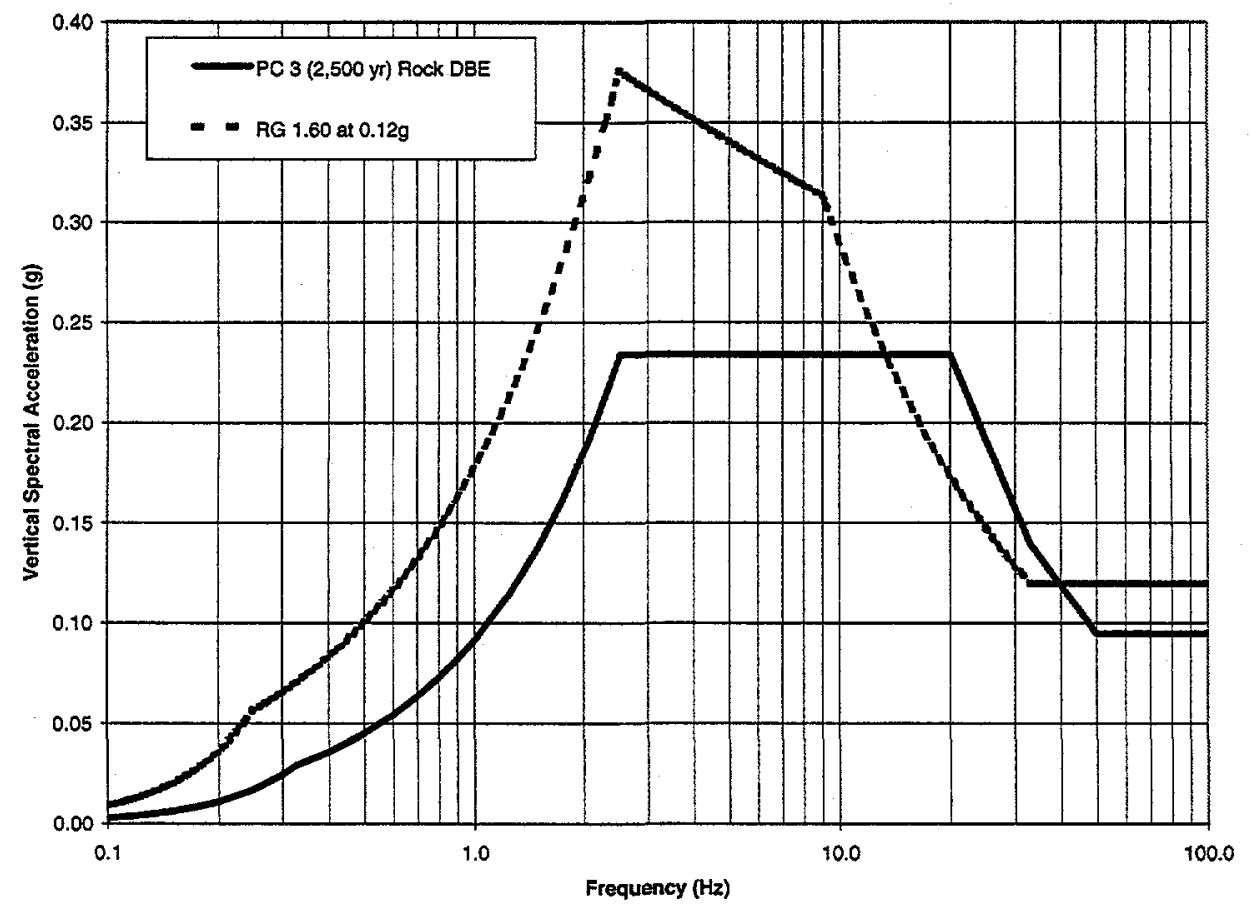

(b)

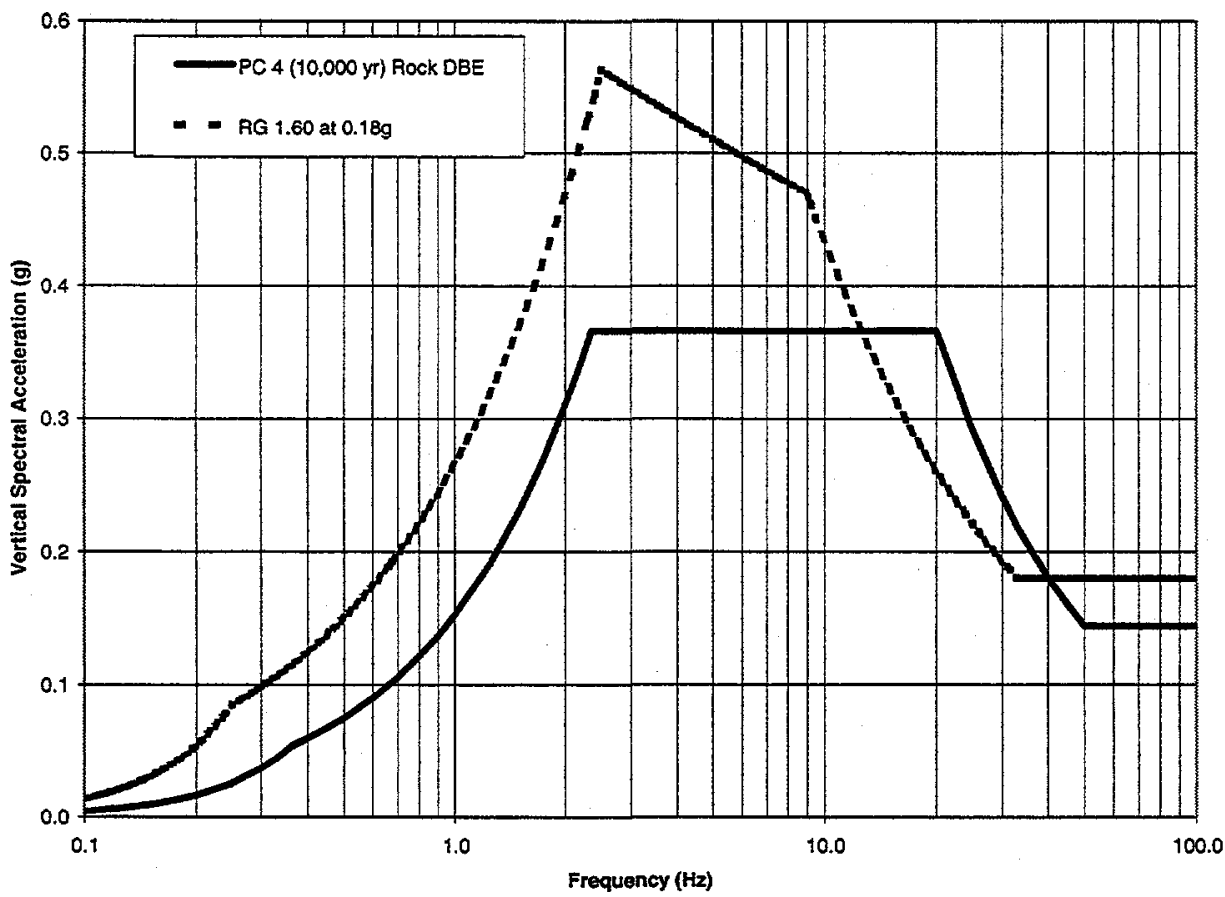

Figure 12. Comparison of the PC 3 (2,500 years) and $\mathrm{PC} 4$ (10,000 years) vertical rock DBE response spectra for INTEC, TRA, RWMC, and PBF with current vertical design criteria in the DOE-ID AE Standards for INTEC and TRA (DOE-ID, 1998). 


\subsection{Use of the PC 3 and PC 4 Rock DBE}

The PC 3 and PC 4 horizontal and vertical rock DBE 5\% damped response spectra for INTEC, TRA, RWMC, and PBF are shown in Figures 13 and 14, respectively. In both figures, the vertical DBE spectra have higher accelerations from 12.5 to $30 \mathrm{~Hz}$ because of the higher spectral ratios over this frequency range where the $\mathrm{V} / \mathrm{H}$ ratio exceeds 1.00 . The $\mathrm{PC} 3$ and $\mathrm{PC} 4$ horizontal and vertical rock $\mathrm{DBE}$ response spectra will be adopted into the DOE-ID AE Standards under Section 0111 Structural Design. Corresponding DBE horizontal and vertical spectral accelerations for 5\% damping are listed in Tables 4 and 5. The spectral accelerations for damping values of 2,3,7, and 10\% are listed in Appendix C. The PC 3 and PC 4 DBE are also plotted on tripartite graphs in Figures 15 and 16 (spectral velocities are listed in Appendix C). The horizontal and vertical peak accelerations (or zero period accelerations - ZPA) are listed in Tables 6 and 7. These revisions to the DOE-ID AE Standards include PC 3 rock DBE response spectra adjusted for a 2,500-year return period even though the current DOE Standards require a 2,000year return period. An $8 \%$ adjustment for a 2,500-year event is small compared to the large reduction in spectral accelerations from the past design criteria requiring a RG 1.60 response spectra tied to higher PGAs for INTEC, TRA, RWMC, and PBF (e.g., Figures 9 and 12).

The DOE-ID AE Standards will specify the PC 3 and PC 4 rock DBE response spectra (Figures 15 and 16) with the PGAs defined in Tables 6 and 7 will be applicable to INTEC, TRA, RWMC, and PBF facility areas. The PC 3 and PC 4 rock DBE can be used for design and seismic evaluation for facilities at rock outcrop surface. The PC 3 and PC 4 rock DBE will also be applicable to the region around these facility areas to the east and south of the boundary shown in Figure 17. The boundary in Figure 17 has a distance of $4 \mathrm{~km}$ to the north and west of TRA and a distance of $1.6 \mathrm{~km}$ west of RWMC (see Appendix D for discussion of applicable region).

Two statistically independent horizontal and one vertical time histories have been developed from the PC 3 and PC 4 rock DBE response spectra, resulting in six time histories total; three time histories per each PC which has one vertical and two horizontal components (URSG-WCFS, 2000b). These time histories have been developed for the PC 3 and PC 4 DBE response spectra at rock outcrop surface and are to be used for seismic design and evaluations for these conditions at INTEC, TRA, RWMC, and PBF (Figures 18 through 23). See Section 2.7 for time histories for bedrock outcrop conditions. The time histories will be available at a web site specified in the DOE-ID AE Standards under Section 0111 Structural Design. The time histories have been developed in accordance with the requirements of ASCE-4 (1986; draft 1998). The enveloping criteria used to match the time histories to the DBE response spectra also satisfy requirements of Standard Review Plan 3.7.1 (NUREG-0800, 1981). 
Table 4. Spectral accelerations for the PC 3 (2,500 year) and PC 4 (10,000 year) horizontal rock DBE 5 $\%$ damping response spectra at INTEC, TRA, RWMC, and PBF.

\begin{tabular}{|c|c|c|}
\hline \multirow{2}{*}{$\begin{array}{c}\text { Frequency } \\
(\mathrm{Hz})\end{array}$} & \multicolumn{2}{|c|}{ Horizontal Spectral Acceleration (g) } \\
\hline & 2,500 Year & 10,000 Year \\
\hline 100.00 & 0.123 & 0.187 \\
\hline 50.00 & 0.123 & 0.187 \\
\hline 45.00 & 0.130 & 0.199 \\
\hline 40.00 & 0.139 & 0.214 \\
\hline 33.33 & 0.154 & 0.240 \\
\hline 30.00 & 0.161 & 0.251 \\
\hline 25.00 & 0.175 & 0.272 \\
\hline 20.00 & 0.193 & 0.301 \\
\hline 17.50 & 0.205 & 0.320 \\
\hline 15.00 & 0.220 & 0.343 \\
\hline 12.50 & 0.239 & 0.373 \\
\hline 10.00 & 0.265 & 0.413 \\
\hline 9.00 & 0.278 & 0.433 \\
\hline 8.00 & 0.293 & 0.457 \\
\hline 7.00 & 0.293 & 0.457 \\
\hline 6.00 & 0.293 & 0.457 \\
\hline 5.00 & 0.293 & 0.457 \\
\hline 4.50 & 0.293 & 0.457 \\
\hline 4.00 & 0.293 & 0.457 \\
\hline 3.50 & 0.293 & 0.457 \\
\hline 3.00 & 0.293 & 0.457 \\
\hline 2.50 & 0.293 & 0.457 \\
\hline 2.20 & 0.293 & 0.457 \\
\hline 2.08 & 0.279 & 0.457 \\
\hline 2.05 & 0.276 & 0.457 \\
\hline 2.00 & 0.270 & 0.445 \\
\hline 1.75 & 0.235 & 0.385 \\
\hline 1.50 & 0.200 & 0.330 \\
\hline 1.25 & 0.167 & 0.275 \\
\hline 1.00 & 0.134 & 0.220 \\
\hline 0.90 & 0.120 & 0.198 \\
\hline
\end{tabular}


Table 4. (continued).

\begin{tabular}{ccc}
\hline $\begin{array}{c}\text { Frequency } \\
(\mathrm{Hz})\end{array}$ & \multicolumn{2}{c}{ Horizontal Spectral Acceleration $(\mathrm{g})$} \\
\cline { 2 - 3 } 2,500 Year & 10,000 Year \\
\hline 0.80 & 0.107 & 0.176 \\
0.70 & 0.094 & 0.154 \\
0.60 & 0.080 & 0.132 \\
0.50 & 0.067 & 0.110 \\
0.45 & 0.060 & 0.099 \\
0.40 & 0.054 & 0.088 \\
0.36 & 0.048 & 0.079 \\
0.33 & 0.044 & 0.066 \\
0.30 & 0.036 & 0.055 \\
0.25 & 0.025 & 0.038 \\
0.20 & 0.016 & 0.024 \\
0.175 & 0.012 & 0.018 \\
0.15 & 0.009 & 0.014 \\
0.125 & 0.006 & 0.009 \\
0.10 & 0.004 & 0.006 \\
\hline
\end{tabular}


Table 5. Spectral accelerations for the PC 3 (2,500 year) and PC 4 (10,000 year) vertical rock DBE 5\% damped response spectra for INTEC, TRA, RWMC, and PBF.

\begin{tabular}{|c|c|c|c|}
\hline \multicolumn{2}{|c|}{ PC 3 (2,500 Year) DBE } & \multicolumn{2}{|c|}{ PC $4(10,000$ Year $)$ DBE } \\
\hline $\begin{array}{c}\text { Frequency } \\
(\mathrm{Hz})\end{array}$ & $\begin{array}{c}\text { Vertical Spectral } \\
\text { Acceleration } \\
\text { (g) }\end{array}$ & $\begin{array}{c}\text { Frequency } \\
(\mathrm{Hz})\end{array}$ & $\begin{array}{c}\text { Vertical Spectral } \\
\text { Acceleration } \\
(\mathrm{g})\end{array}$ \\
\hline 100.00 & 0.095 & 100.00 & 0.144 \\
\hline 50.00 & 0.095 & 50.00 & 0.144 \\
\hline 45.00 & 0.106 & 45.00 & 0.160 \\
\hline 40.00 & 0.119 & 40.00 & 0.180 \\
\hline 33.33 & 0.139 & 33.33 & 0.219 \\
\hline 30.00 & 0.157 & 30.00 & 0.242 \\
\hline 25.00 & 0.192 & 25.00 & 0.291 \\
\hline 20.00 & 0.234 & 20.00 & 0.366 \\
\hline 17.50 & 0.234 & 17.50 & 0.366 \\
\hline 15.00 & 0.234 & 15.00 & 0.366 \\
\hline 12.50 & 0.234 & 12.50 & 0.366 \\
\hline 10.00 & 0.234 & 10.00 & 0.366 \\
\hline 9.00 & 0.234 & 9.00 & 0.366 \\
\hline 8.00 & 0.234 & 8.00 & 0.366 \\
\hline 7.00 & 0.234 & 7.00 & 0.366 \\
\hline 6.00 & 0.234 & 6.00 & 0.366 \\
\hline 5.00 & 0.234 & 5.00 & 0.366 \\
\hline 4.50 & 0.234 & 4.50 & 0.366 \\
\hline 4.00 & 0.234 & 4.00 & 0.366 \\
\hline 3.50 & 0.234 & 3.50 & 0.366 \\
\hline 3.00 & 0.234 & 3.00 & 0.366 \\
\hline 2.517 & 0.234 & 2.50 & 0.366 \\
\hline 2.50 & 0.232 & 2.349 & 0.366 \\
\hline 2.20 & 0.204 & 2.20 & 0.342 \\
\hline 2.08 & 0.192 & 2.08 & 0.323 \\
\hline 2.05 & 0.189 & 2.058 & 0.320 \\
\hline 2.00 & 0.185 & 2.00 & 0.310 \\
\hline 1.75 & 0.161 & 1.75 & 0.270 \\
\hline 1.50 & 0.138 & 1.50 & 0.231 \\
\hline
\end{tabular}


Table 5. (continued).

\begin{tabular}{lccc}
\hline & PC 3 (2,500 Year) DBE & \multicolumn{2}{c}{ PC 4 (10,000 Year) DBE } \\
\cline { 2 - 4 } $\begin{array}{c}\text { Frequency } \\
\text { (Hz) }\end{array}$ & $\begin{array}{c}\text { Vertical Spectral } \\
\text { Acceleration } \\
(\mathrm{g})\end{array}$ & $\begin{array}{c}\text { Frequency } \\
(\mathrm{Hz})\end{array}$ & $\begin{array}{c}\text { Vertical Spectral } \\
\text { Acceleration } \\
(\mathrm{g})\end{array}$ \\
\hline 1.25 & 0.114 & 1.25 & 0.191 \\
1.00 & 0.091 & 1.00 & 0.152 \\
0.90 & 0.082 & 0.90 & 0.137 \\
0.80 & 0.073 & 0.80 & 0.121 \\
0.70 & 0.063 & 0.70 & 0.105 \\
0.60 & 0.054 & 0.60 & 0.090 \\
0.50 & 0.045 & 0.50 & 0.075 \\
0.45 & 0.040 & 0.45 & 0.067 \\
0.40 & 0.036 & 0.40 & 0.059 \\
0.36 & 0.032 & 0.362 & 0.054 \\
0.33 & 0.029 & 0.33 & 0.044 \\
0.30 & 0.024 & 0.30 & 0.037 \\
0.25 & 0.017 & 0.25 & 0.025 \\
0.20 & 0.011 & 0.20 & 0.016 \\
0.175 & 0.008 & 0.175 & 0.012 \\
0.15 & 0.006 & 0.15 & 0.009 \\
0.125 & 0.004 & 0.125 & 0.006 \\
0.10 & 0.003 & & 0.004 \\
\hline
\end{tabular}


Table 6. Rock DBE compared to previous peak horizontal accelerations for INEEL facilities

\begin{tabular}{|c|c|c|c|c|}
\hline \multirow[b]{2}{*}{ Facility Area } & \multicolumn{2}{|c|}{$\begin{array}{c}\text { DBE PGA }{ }^{\mathrm{a}} \\
(\mathrm{g})\end{array}$} & \multicolumn{2}{|c|}{$\begin{array}{c}\text { Deterministic PGA } \\
(\mathrm{g})\end{array}$} \\
\hline & $\begin{array}{c}\text { PC } 3 \\
(2,500 \text { year }) \\
\end{array}$ & $\begin{array}{c}\text { PC } 4 \\
(10,000 \text { year }) \\
\end{array}$ & PC 3 & $\mathrm{PC} 4$ \\
\hline INTEC & 0.12 & 0.19 & 0.18 & 0.24 \\
\hline PBF & 0.12 & 0.19 & 0.17 & 0.22 \\
\hline RWMC & 0.12 & 0.19 & 0.16 & 0.21 \\
\hline TRA & 0.12 & 0.19 & 0.18 & 0.24 \\
\hline TAN & 0.16 & 0.27 & 0.26 & 0.35 \\
\hline \multicolumn{5}{|c|}{ a. Revisions for DOE-ID AE Standards. } \\
\hline
\end{tabular}

Table 7. Peak vertical accelerations.

\begin{tabular}{|c|c|c|c|c|}
\hline \multirow[b]{2}{*}{$\begin{array}{l}\text { Facility } \\
\text { Area }\end{array}$} & \multicolumn{2}{|c|}{$\begin{array}{c}\text { DBE Peak Acceleration }^{\mathrm{a}} \\
(\mathrm{g})\end{array}$} & \multicolumn{2}{|c|}{$\begin{array}{c}\text { Deterministic Peak } \\
\text { Acceleration } \\
(\mathrm{b}) \\
\end{array}$} \\
\hline & $\begin{array}{c}\text { PC } 3 \\
(2,500 \text { year }) \\
\end{array}$ & $\begin{array}{c}\text { PC } 4 \\
(10,000 \text { year }) \\
\end{array}$ & PC 3 & $\mathrm{PC} 4$ \\
\hline INTEC & 0.09 & 0.14 & 0.12 & 0.16 \\
\hline PBF & 0.09 & 0.14 & 0.11 & 0.15 \\
\hline RWMC & 0.09 & 0.14 & 0.11 & 0.14 \\
\hline TRA & 0.09 & 0.14 & 0.12 & 0.16 \\
\hline TAN & 0.12 & 0.21 & 0.17 & 0.23 \\
\hline
\end{tabular}




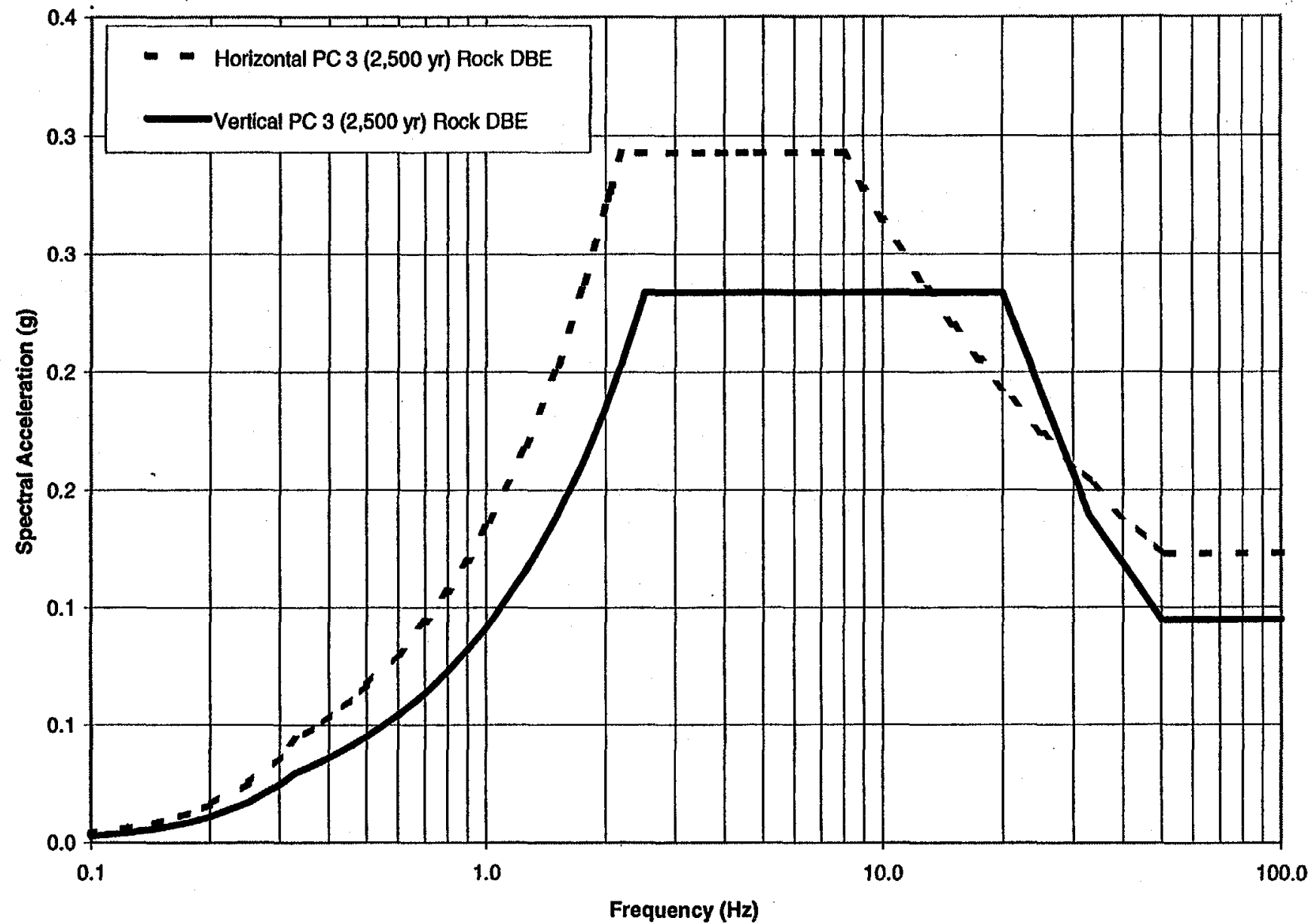

Figure 13. The horizontal and vertical rock DBE 5\% damped response spectra for PC 3 (2,500 years) to be used for seismic design and evaluations at INTEC, TRA, RWMC and PBF. 


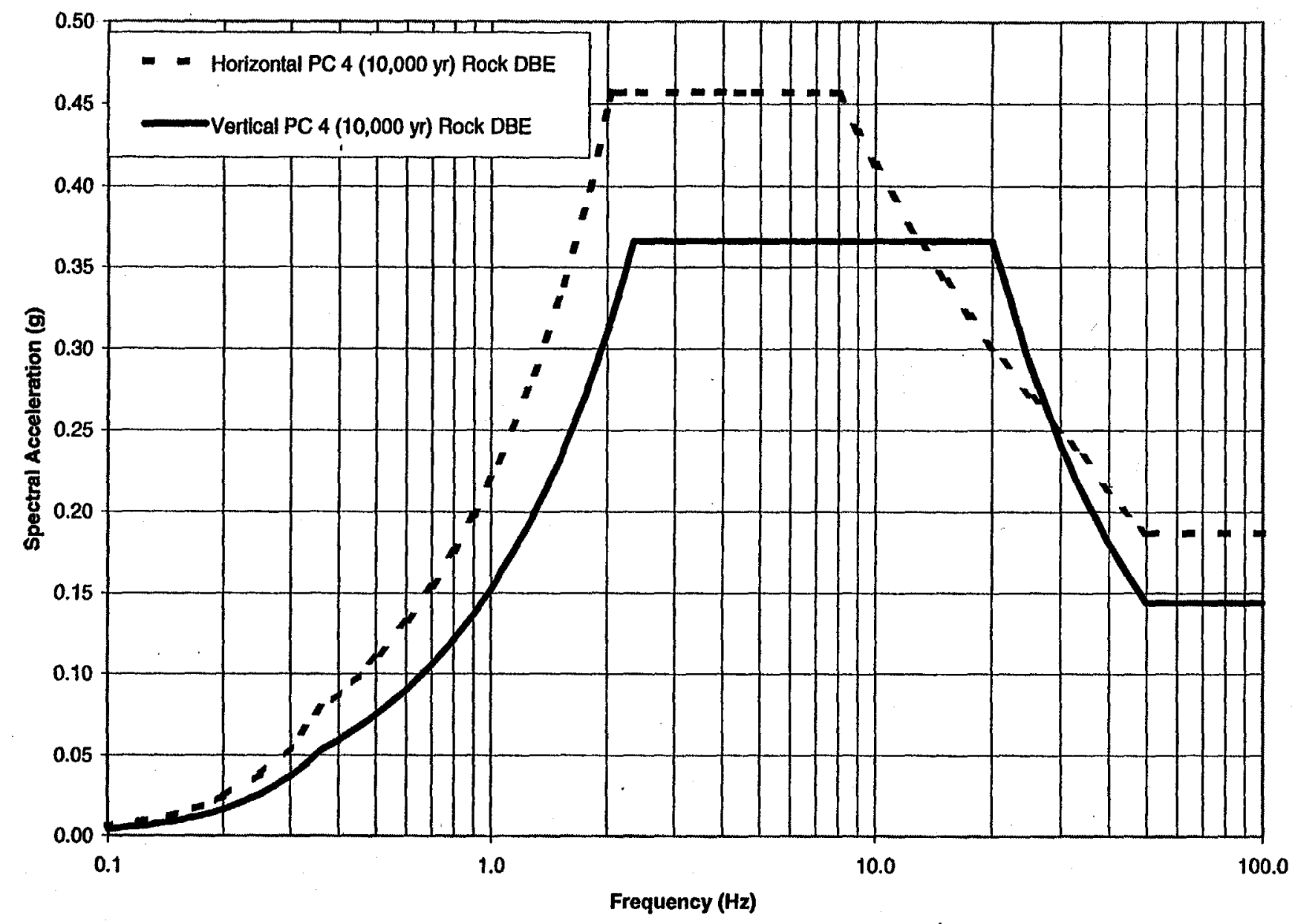

$\stackrel{\dddot{9}}{\longleftarrow}$

Figure 14. The horizontal and vertical rock DBE 5\% damped response spectra for PC 4 (10,000 years) to be used for seismic design and evaluations at INTEC, TRA, RWMC, and PBF. 


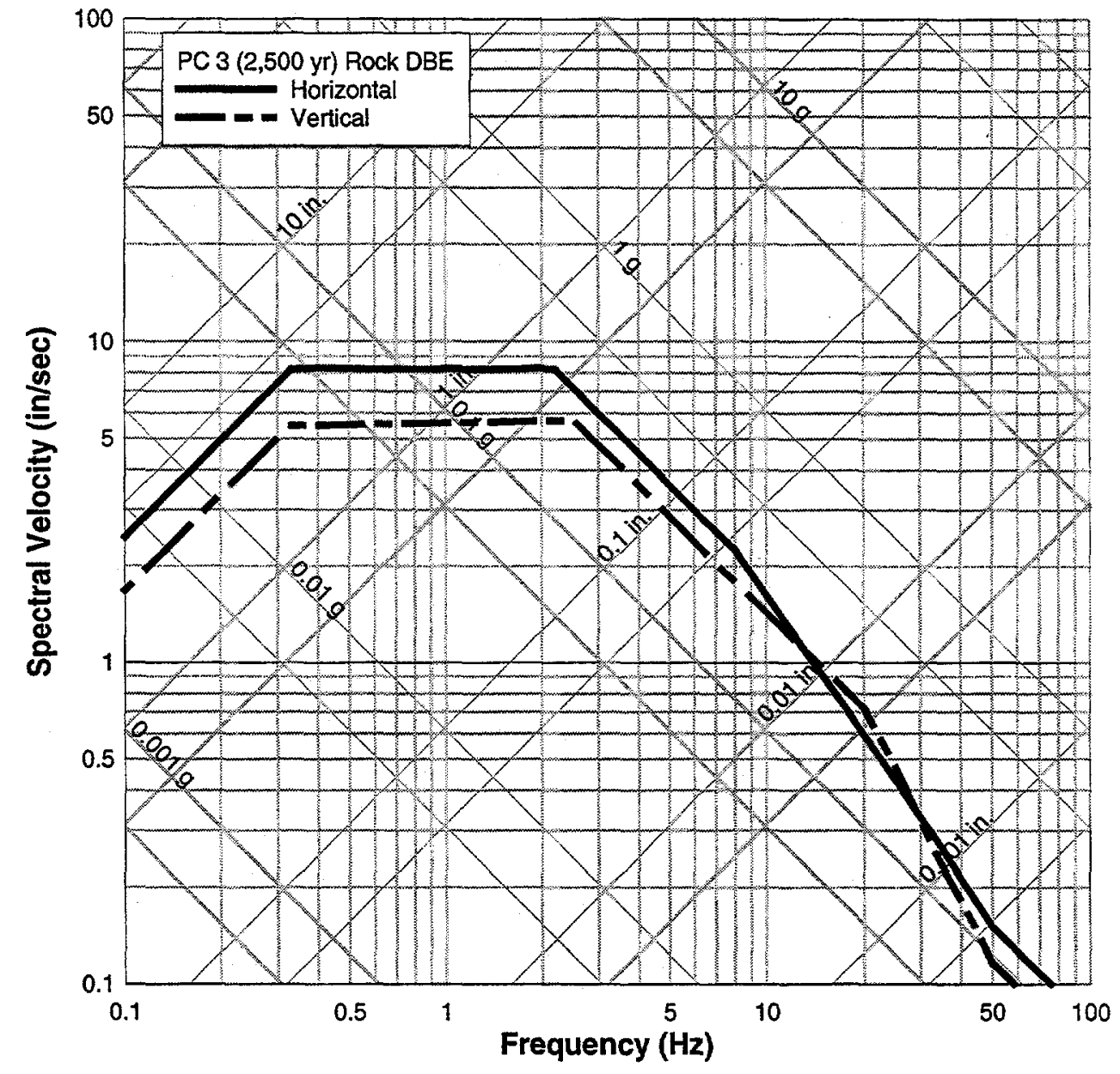

Figure 15. Tripartite graph of the horizontal and vertical PC 3 (2,500 years) rock DBE 5\% damped response spectra to be used for seismic design and evaluations at INTEC, TRA, RWMC, and PBF (see Appendix C, Tables C-5 and C-6 for spectral velocities). 


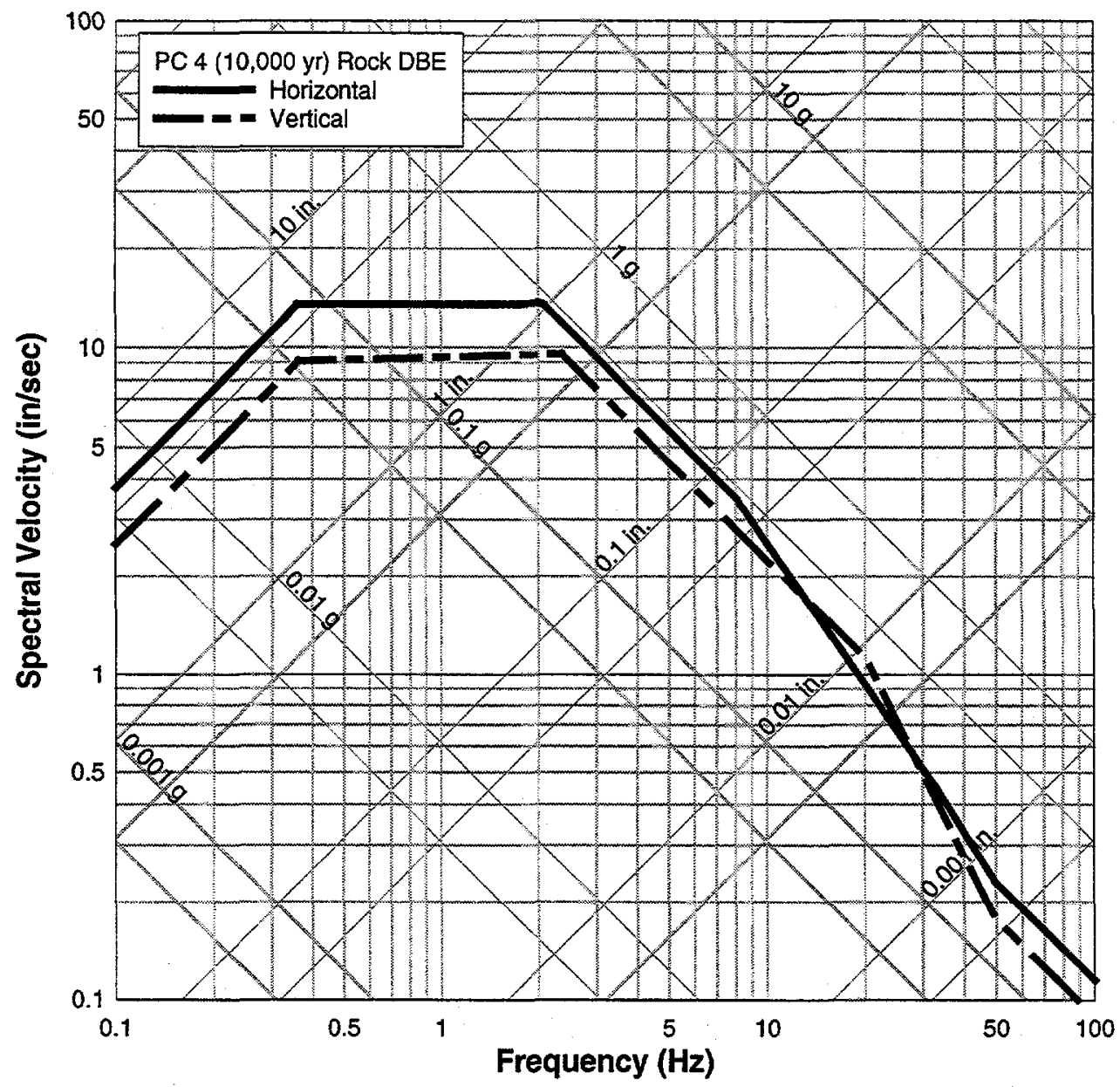

Figure 16. Tripartite graph of the horizontal and vertical PC $4(10,000$ years) rock DBE $5 \%$ damped response spectra to be used for seismic design and evaluations at INTEC, TRA, RWMC, and PBF (see Appendix C, Tables C-5 and C-6 for spectral velocities). 


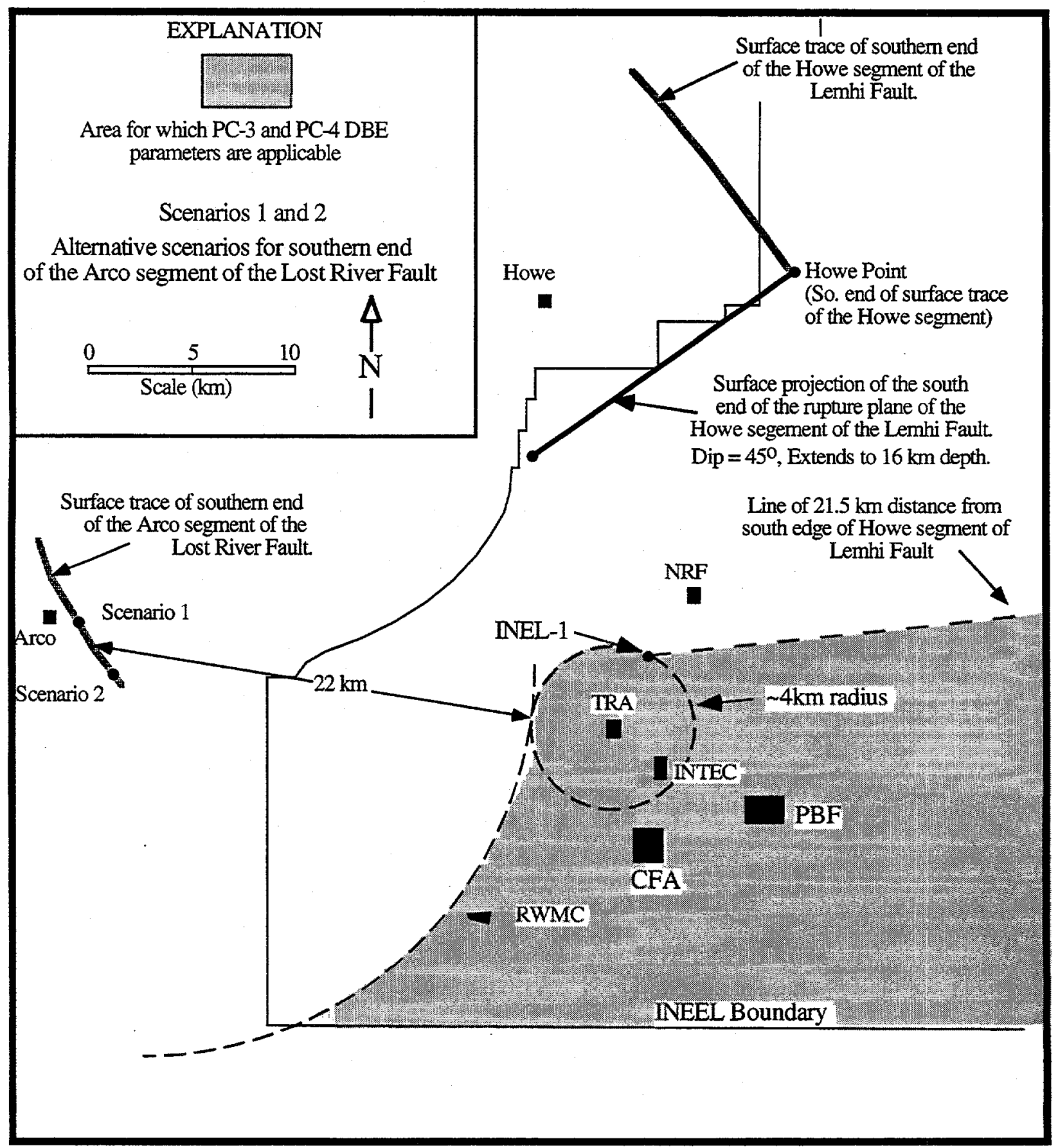

Figure 17. Map showing the western boundary for the INEEL region and facility areas (shaded portion) that the PC 3 (2,500 years) and PC 4 (10,000 years) rock DBE response spectra for INTEC, TRA, RWMC, and PBF can be used for seismic design and evaluations. The boundary line is $1.6 \mathrm{~km}$ west of RWMC and $4 \mathrm{~km}$ west and north of TRA. 

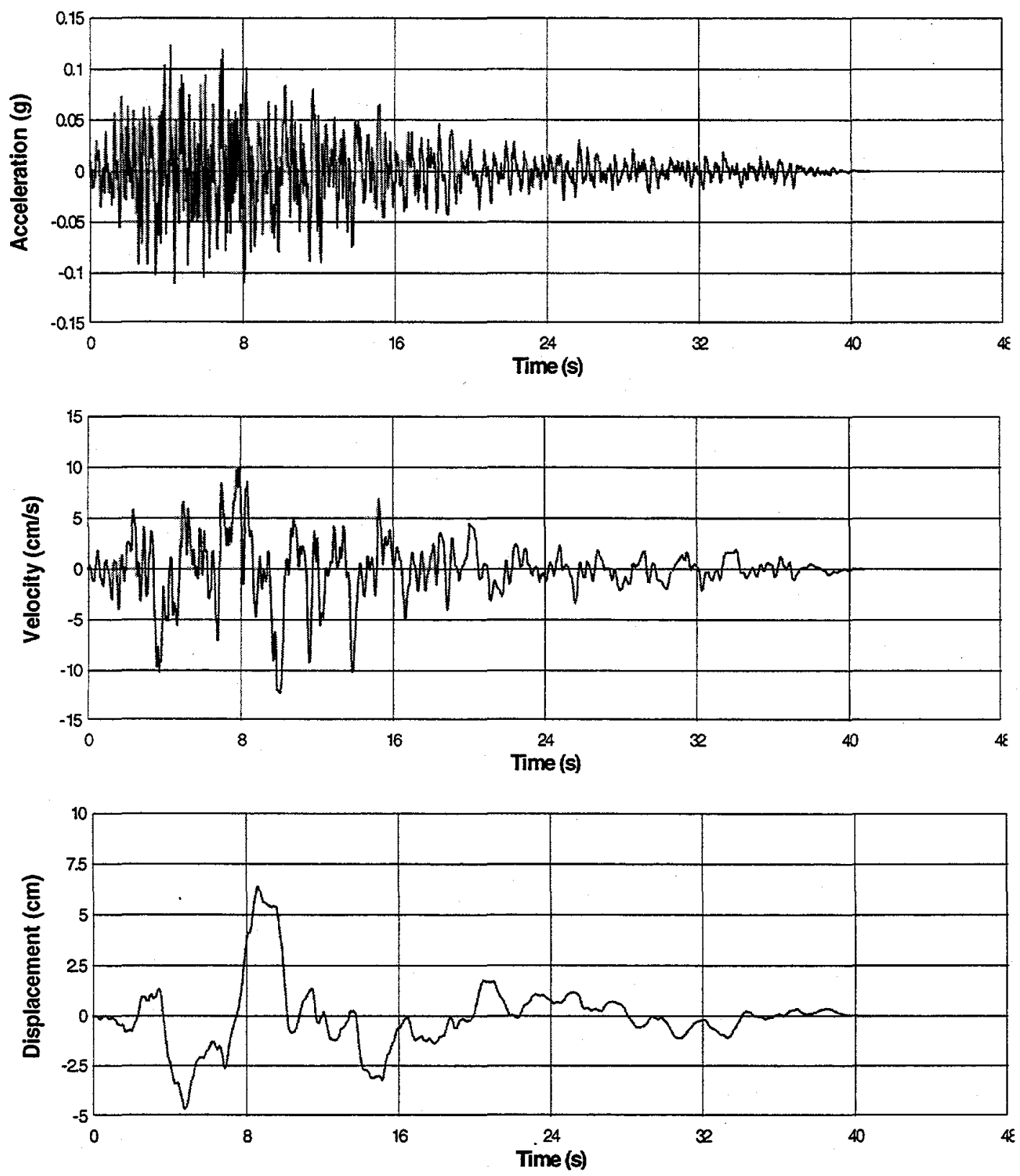

Figure 18. Plots of the acceleration, velocity, and displacement time histories for one horizontal component of the PC 3 (2,500 years) rock DBE response spectrum at INTEC, TRA, RWMC, and PBF (URSG-WCFS, 2000b). The time histories can be used for rock surface outcrop conditions and as bedrock outcrop motions for input to soil response and soil structure interaction analyses. 

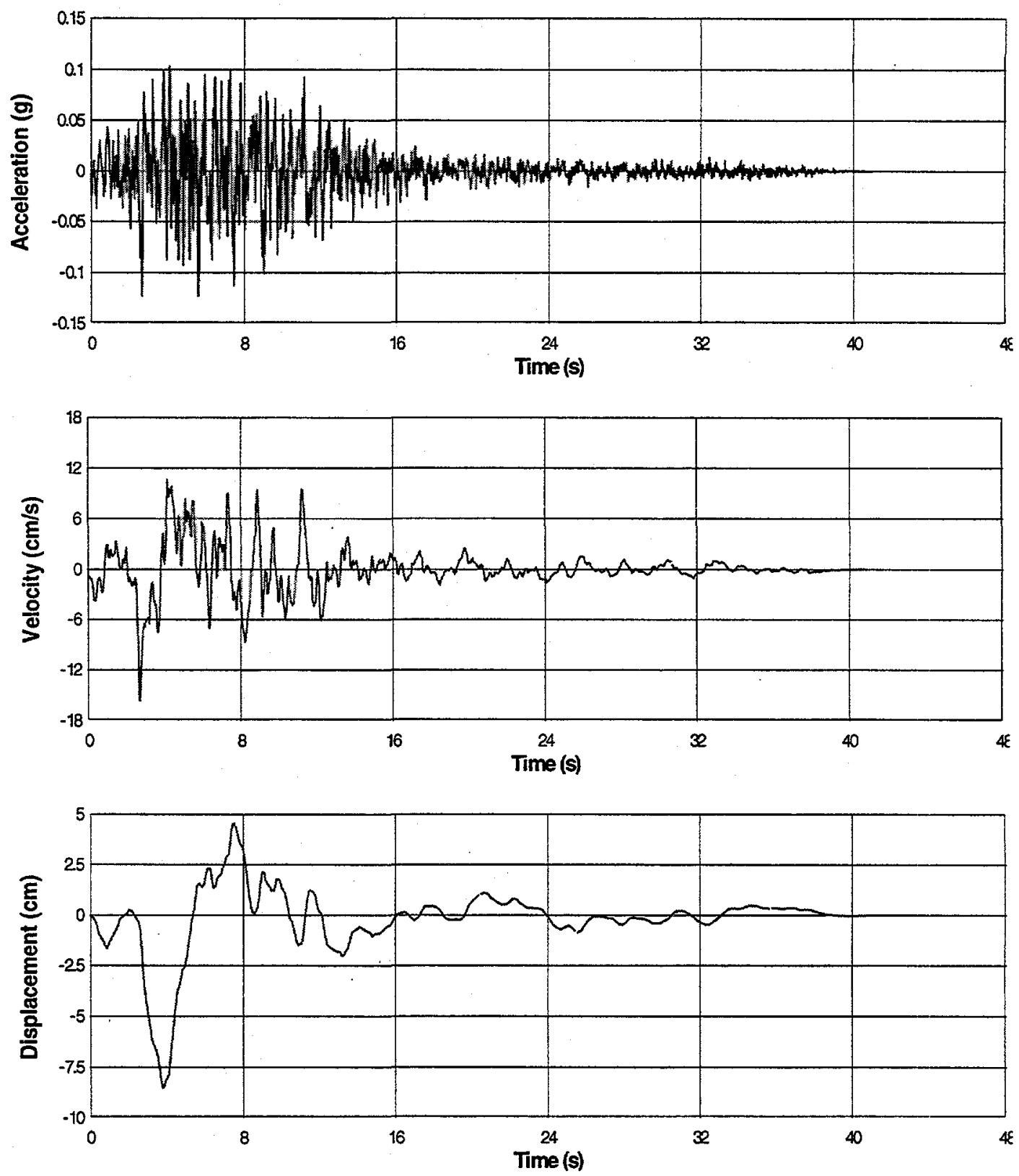

Figure 19. Plots of the acceleration, velocity, and displacement time histories for the second horizontal component of the PC 3 (2,500 years) rock DBE response spectrum at INTEC, TRA, RWMC, and PBF (URSG-WCFS, 2000b). The time histories can be used for rock surface outcrop conditions and as bedrock outcrop motions for input to soil response and soil structure interaction analyses. 

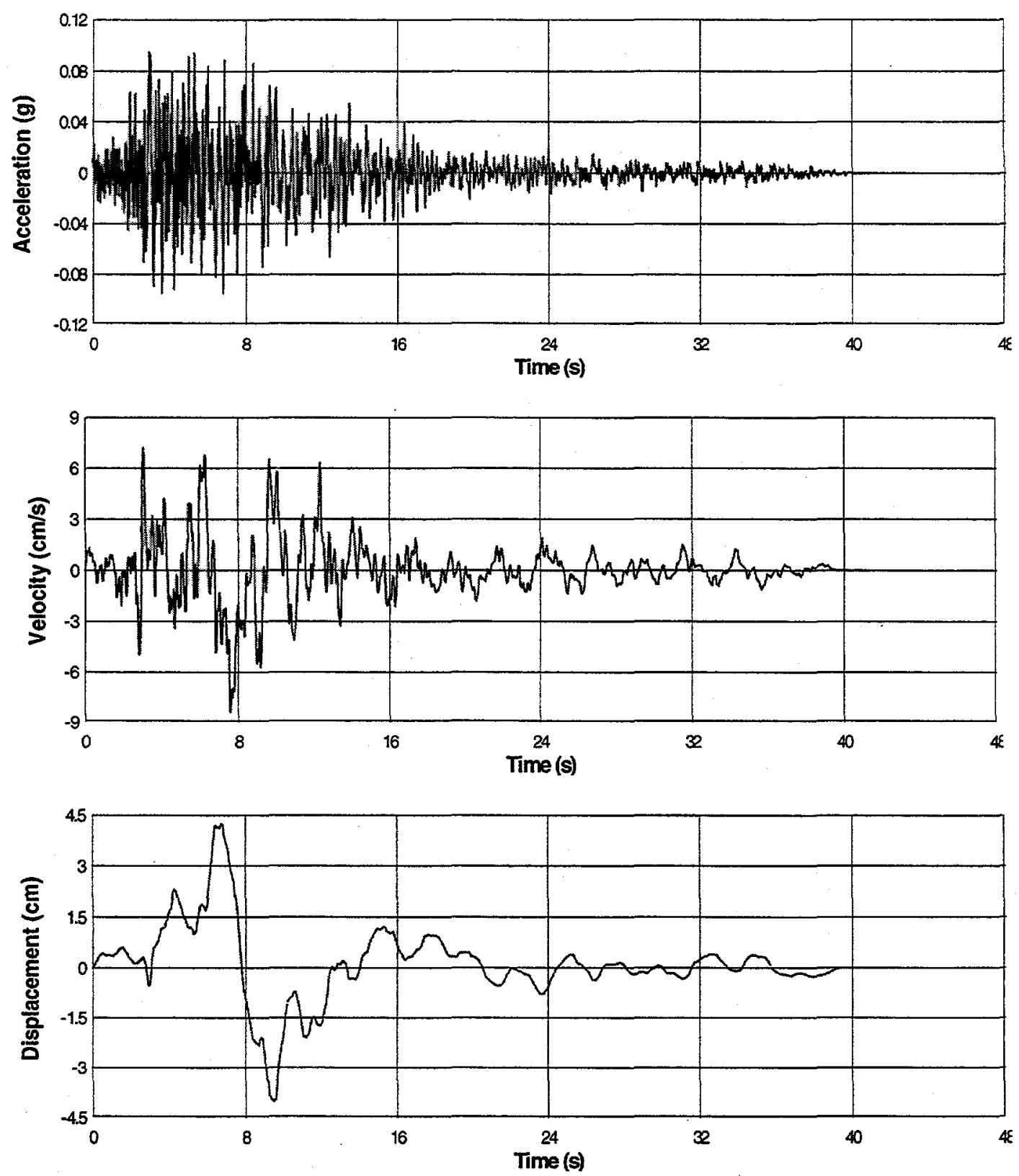

Figure 20. Plots of the acceleration, velocity, and displacement time histories for the vertical component of the PC 3 (2,500 years) rock DBE response spectrum at INTEC, TRA, RWMC, and PBF (URSG-WCFS, 2000b). The time histories can be used for structural analyses at rock surface outcrop conditions. See Section 2.7 for details about the vertical component for bedrock outcrop conditions as input to soil response and SSI analyses. 

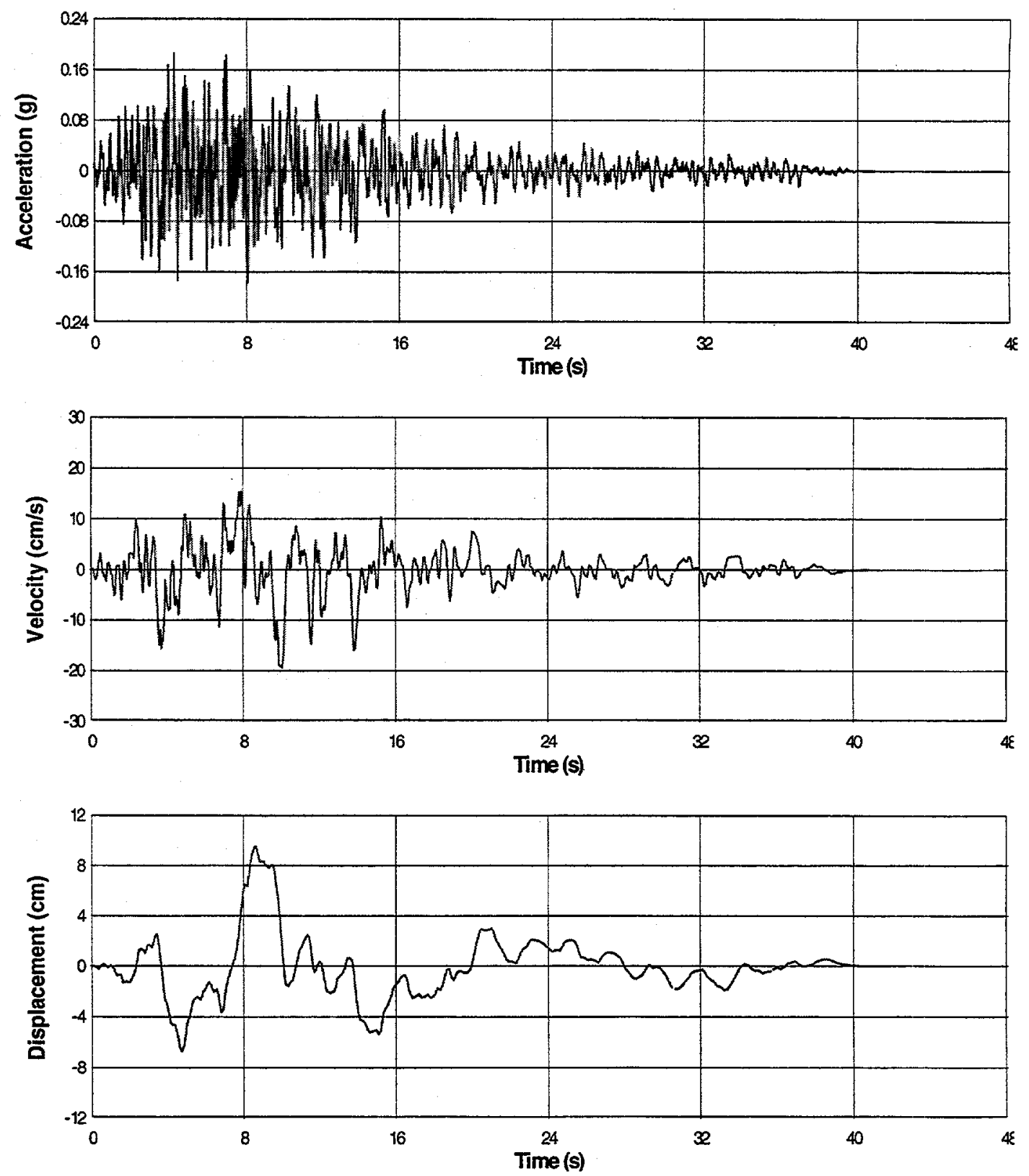

Figure 21. Plots of the acceleration, velocity, and displacement time histories for one horizontal component of the PC 4 (10,000 years) rock DBE response spectrum at INTEC, TRA, RWMC, and PBF (URSG-WCFS, 2000b). The time histories can be used for rock surface outcrop conditions and as bedrock outcrop motions for input to soil response and soil structure interaction analyses. 

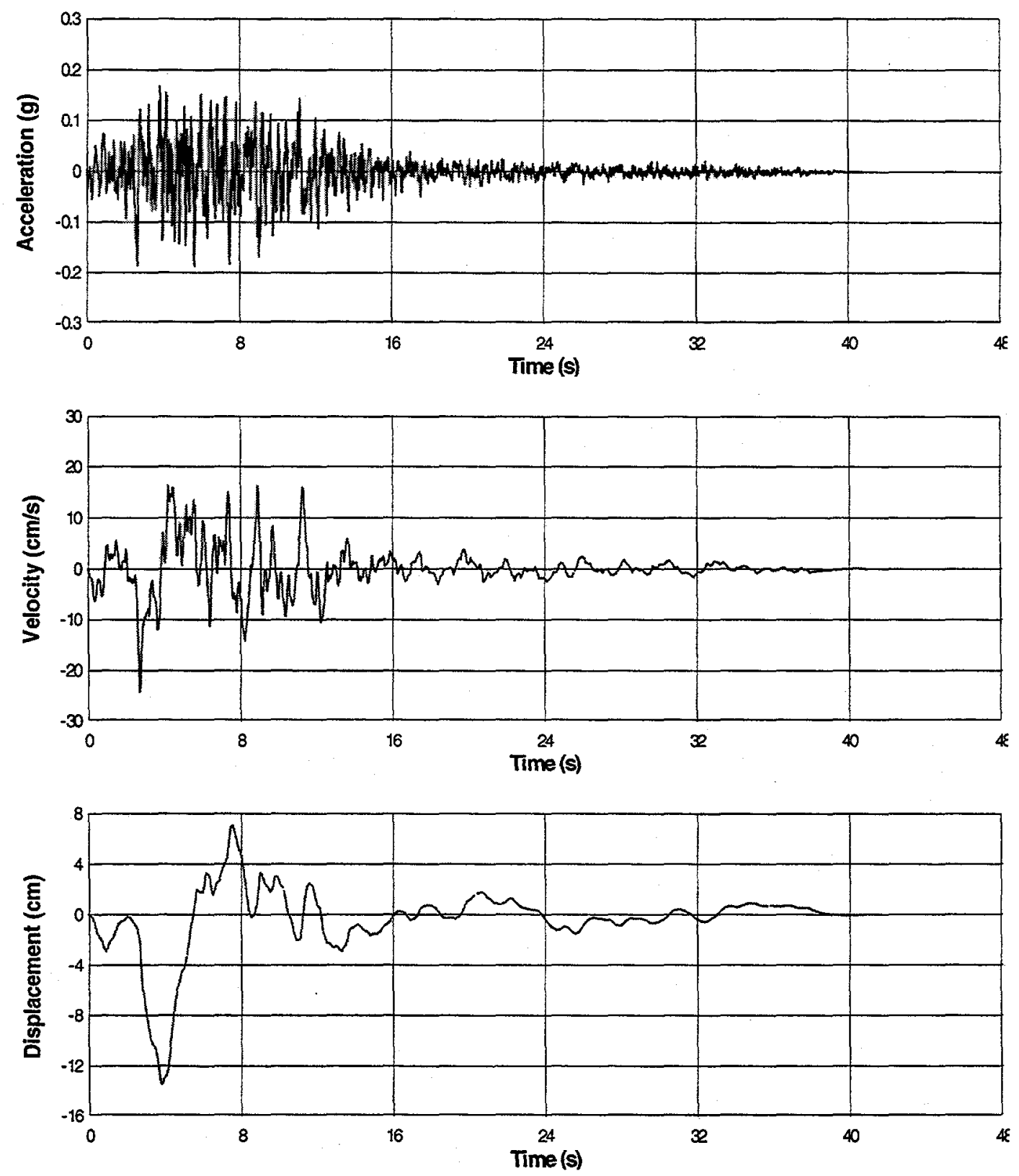

Figure 22. Plots of the acceleration, velocity, and displacement time histories for the second horizontal component of the PC $4(10,000$ years) rock DBE response spectrum at INTEC, TRA, RWMC, and PBF (URSG-WCFS, 2000b). The time histories can be used for rock surface outcrop conditions and as bedrock outcrop motions for input to soil response and soil structure interaction analyses. 

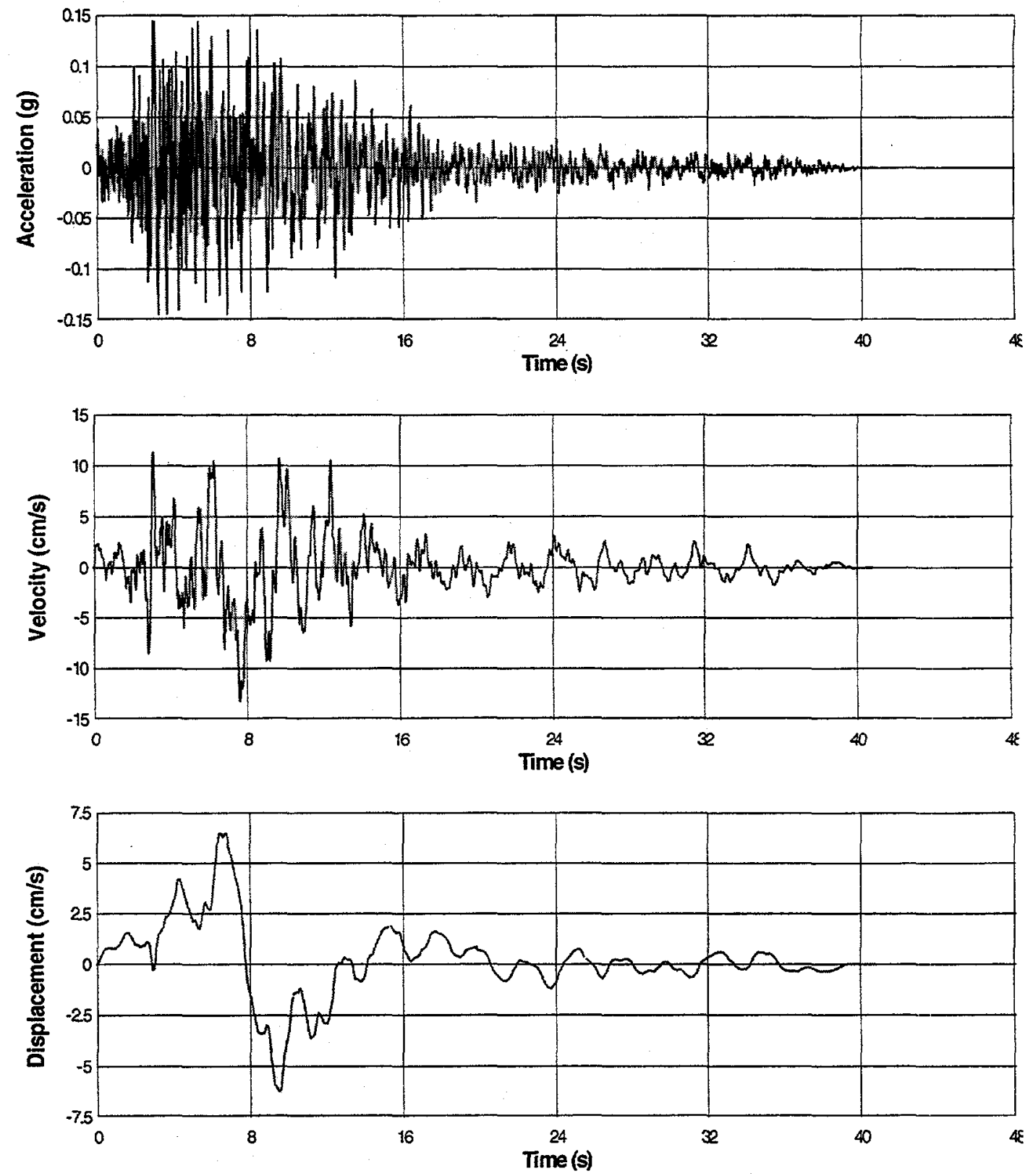

Figure 23. Plots of the acceleration, velocity, and displacement time histories for the vertical component of the PC 4 (10,000 years) rock DBE response spectrum at INTEC, TRA, RWMC, and PBF (URSG-WCFS, 2000b). The time histories can be used for structural analyses at rock surface outcrop conditions. See Section 2.7 for details about the vertical component for bedrock outcrop conditions as input to soil response and SSI analyses. 


\subsection{Rock DBE for Input to Soil Response and Soil Structure Interaction Analyses}

The horizontal and vertical PC 3 (2,500 years) rock DBE response spectra (Figure 15) and PC 4 (10,000 years) rock DBE response spectra (Figure 16) were used to develop time histories that can be used as input to soil response and SSI (URSG-WCFS, 2000b). The motion at the top of the bedrock without the soil deposit present is referred to as the bedrock outcropping motion. The PC 3 and PC $4 \mathrm{DBE}$ time histories (Figures 18 through 23) also serve as bedrock outcrop motions. URSG-WCFS (2000b) determined that the difference in seismic velocities at the surface outcrop and at bedrock outcrop have been accounted for in their development of the site-specific UHS for INTEC, TRA, RWMC, and PBF. Thus, one set of time histories can be used for rock surface and bedrock outcrop conditions.

The DOE-ID AE Standards will specify that the horizontal and vertical components of the PC 3 and PC $4 \mathrm{DBE}$ time histories will be applicable for structural analyses at rock surface conditions. However, the DOE-ID AE Standards will specify that only the horizontal components of the PC 3 and PC 4 DBE time histories will be applicable for soil response and SSI analyses as bedrock outcrop motions. The vertical component of the PC 3 and PC 4 DBE time histories should not be used for soil response and SSI analyses for primarily two reasons:

1. The current state of the knowledge for seismology is in debate about whether the vertical component of earthquake motions can be modeled solely from vertically propagating compressional $(\mathrm{P})$ waves.

2. The $\mathrm{PC} 3$ and $\mathrm{PC} 4$ vertical $\mathrm{DBE}$ response spectra were developed from the $\mathrm{V} / \mathrm{H}$ ratio which includes higher motions at frequencies between 10 and $30 \mathrm{~Hz}$ based on empirical data. The empirical data account for the content of the seismic waves generating the vertical motions. Thus, propagating the vertical component of the DBE time histories through a soil column may result in unnecessary conservatism.

The DOE-ID AE Standards will suggest the following steps be taken to develop the vertical soil surface response for input to a structural analysis:

1. Perform a standard analysis to determine the horizontal soil response using the PC 3 or PC 4 rock DBE time histories. Randomization of 30 soil horizontal analyses using a program like SHAKE (an equivalent linear seismic response analysis of horizontally layered soil deposits) is recommended to determine the best horizontal free surface soil response.

2. Multiply the horizontal soil response by the $\mathrm{V} / \mathrm{H}$ ratio (Figure 10 ) to determine the vertical soil response. The $\mathrm{V} / \mathrm{H}$ ratio was developed using empirical data for rock and shallow soil sites of less than about $100 \mathrm{ft}$ (Per. Comm. W. Silva, 2000).

3. Use the horizontal and vertical free surface soil response to generate time histories that can be input to the structural analysis.

The DOE-ID AE Standards will also suggest the following steps be taken to develop the vertical soil response for input to a SSI analysis:

1. Perform a standard analysis to determine the horizontal soil response using the PC 3 or PC 4 rock DBE time histories. Randomization of 30 soil horizontal analyses using a program like SHAKE is recommended to select the best mean representing the best soil column and soil response. 
2. Multiply the best, mean horizontal soil response by the $\mathrm{V} / \mathrm{H}$ ratio (Figure 10) to determine the best, mean vertical response. The $\mathrm{V} / \mathrm{H}$ ratio was developed using empirical data for rock and shallow soil sites of less than about $100 \mathrm{ft}$ (Per. Comm. W. Silva, 2000).

3. Use the low-strain shear wave velocity (Vs) used in the horizontal soil response analyses and Poisson's ratio to determine the low-strain compressional wave velocity (Vp). See Appendix E for a discussion of Poisson's ratio. Use the iterated low-strain S-wave damping used in the horizontal soil analyses as the P-wave damping.

4. The P-wave velocity and damping should not be iterated further in either the soil response or SSI analysis.

5. Generate time histories for horizontal and vertical response using the information determined in steps 2,3 , and 4 that can be input to the SSI analysis. 


\section{DESIGN BASIS EARTHQUAKE FOR SOIL SURFACE CONDITIONS AT INTEC}

\subsection{Selection of Horizontal Soil UHS for PC 3 and PC 4}

For the TMI-2 ISFSI, URSG-WCFS performed a soil response analysis for soil thicknesses and properties measured at the TMI-2 ISFSI site and characteristic of other locations at INTEC. The soils are predominantly sands, silt, and gravel. The soil thicknesses ranged from 20 to $65 \mathrm{ft}$ ( 6 to $20 \mathrm{~m}$ ) with an average thickness of $42.5 \mathrm{ft}(13 \mathrm{~m})$. For the soil response analysis, URSG-WCFS (1999) calculated power spectra derived by spectrally matching their horizontal rock UHS and propagating them through the one-dimensional soil and shallow rock profile developed for INTEC using a frequency-domain equivalent linear formulation similar to the program SHAKE (for details, see URSG-WCFS, 1999). Thirty runs were made to incorporate the ranges and uncertainties in the seismic velocities and thicknesses of the soil. The soil properties used in the URSG-WCFS (1999) analysis are listed in Appendix E.

As an example, Figure 24 shows the ranges in acceleration responses as a function of frequency from the thirty runs for the 2,000-year return period. The spectral ground motions are sensitive to soil thickness and seismic velocities. The shallow soil conditions at INTEC amplify the acceleration portion of the spectrum. Spectral peaks can occur anywhere between 3 and $12 \mathrm{~Hz}$. The mean unsmoothed peak soil response shown in Figure 24 is less than many of the peak responses for various soil thicknesses and properties. Thus, URSG-WCFS (1999) intentionally raised the peak spectral accelerations (between 3 to $12 \mathrm{~Hz}$ ) to develop a broad smoothed UHS that accounts for the wide range of soil thickness and associated response as indicated by the large variability in peak spectral responses. Figure 24 shows that the broad smoothed UHS developed by URSG-WCFS (1999) is well above the spectral peaks of the unsmoothed mean UHS.

The spectral ratio of the smoothed soil UHS to the rock UHS for the 2,000- and 10,000-year return periods at INTEC are shown in Figure 25 (a) and (b), respectively. At both return periods, the shallow soil conditions (thickness 20 to $65 \mathrm{ft}$ ) at INTEC amplify ground motions by factors of 1.5 to 3 for frequencies greater than $2 \mathrm{~Hz}$. Also shown in Figure 25 (a) and (b) for comparison are the spectral ratio of the soil UHS to the rock UHS for the 2,000- and 10,000-year return periods at ANL-W, respectively. In both figures, the soil response at ANL-W shows amplification factors of 1.5 to 2.2 for frequencies greater than $4 \mathrm{~Hz}$. At the 2,000- and 10,000-year return periods, both spectral ratios for INTEC and ANL-W have peaks at about 9 to $10 \mathrm{~Hz}$. The ANL-W soil responses were computed for soil conditions having a thickness of 5 to $25 \mathrm{ft}$ ( 1.5 to $7.6 \mathrm{~m}$ ) and composed of sands and silts (WCFS, 1998).

The INTEC 2,000-year return period smoothed soil UHS (Figure 26) was adjusted to account for a 2,500-year return period. The adjustment was made because URSG-WCFS was not requested to develop a response at 2,500 years. The URSG-WCFS (1999) study had already been completed when the INEEL NPHC decided to use a 2,500-year return period for PC 3 in anticipation of changes in DOE regulations. Thus, the spectra for the INTEC soil UHS were increased by $8 \%$ as per the discussion in Appendix A. Also shown in Figure 26 is the INTEC 10,000-year return period smoothed soil UHS developed by URSG-WCSF (1999). No adjustments were made to the 10,000-year soil UHS. 


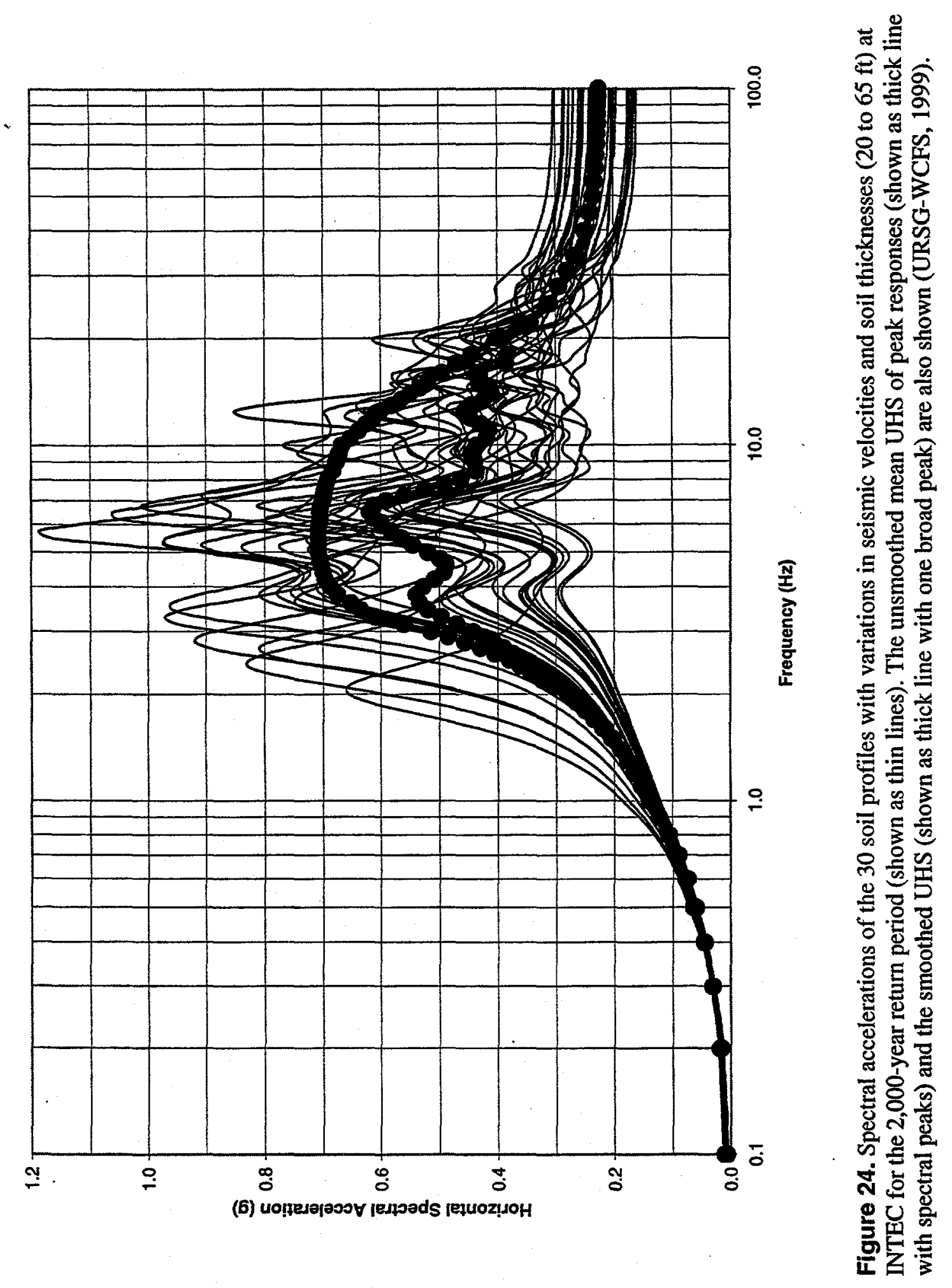


(a)

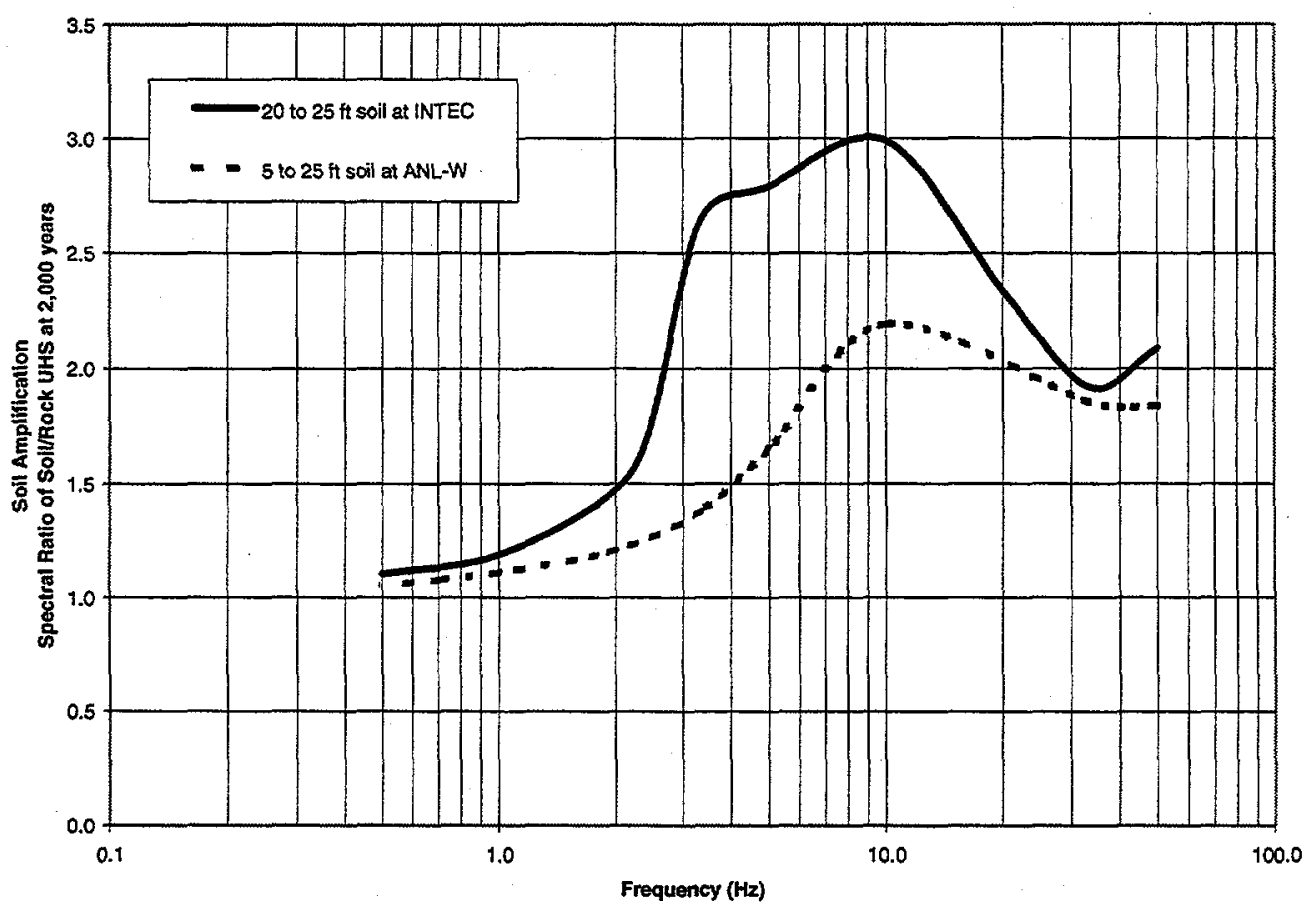

(b)

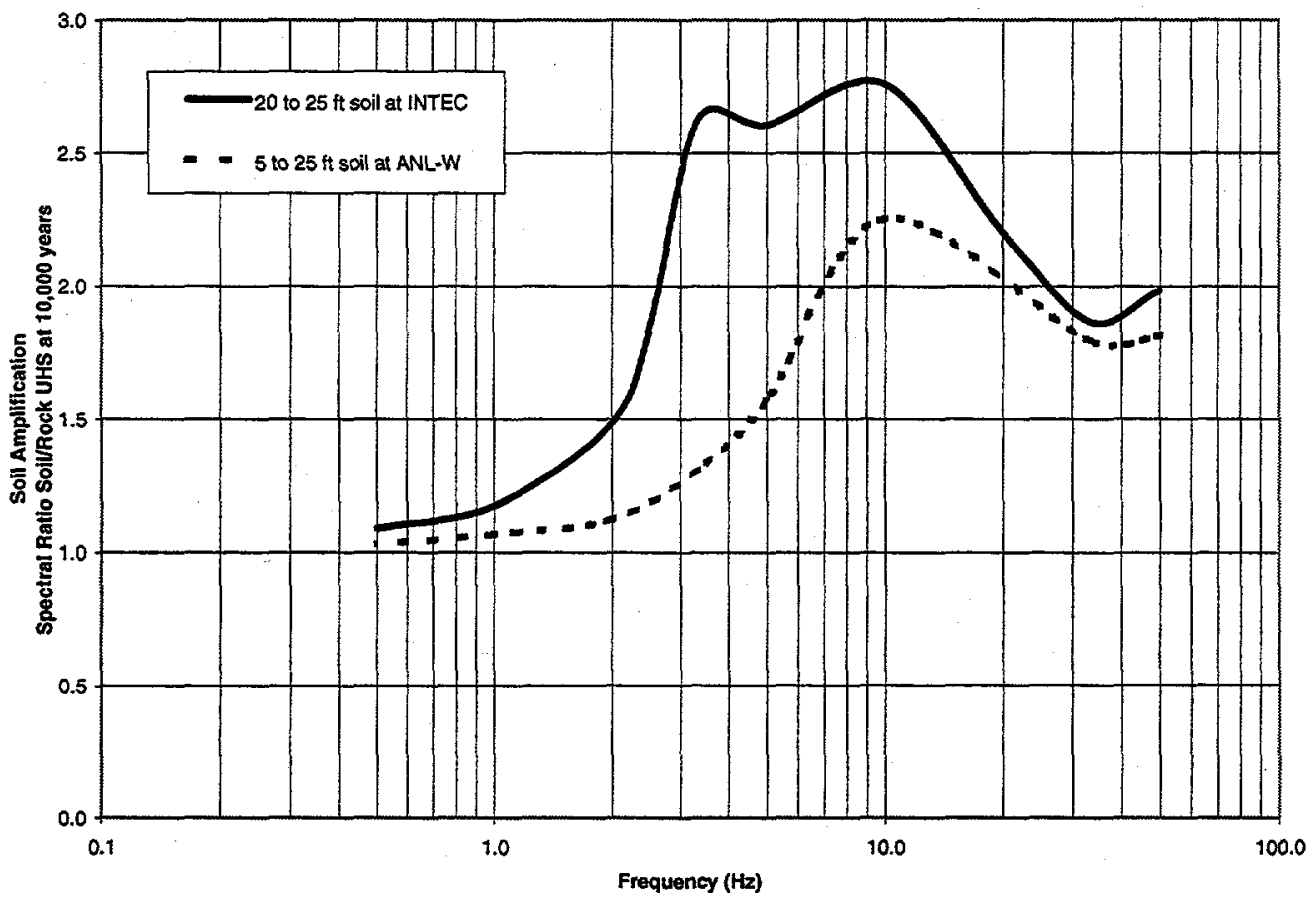

Figure 25. Soil amplification factors for the spectral ratios of soil to rock UHS for 20 to $65 \mathrm{ft}$ soil thickness at INTEC (URSG-WCFS, 1999) and for 5 to 25 soil thickness at ANL-W (WCFS, 1998) at (a) 2,000 years and (b) 10,000 years. 
(a)

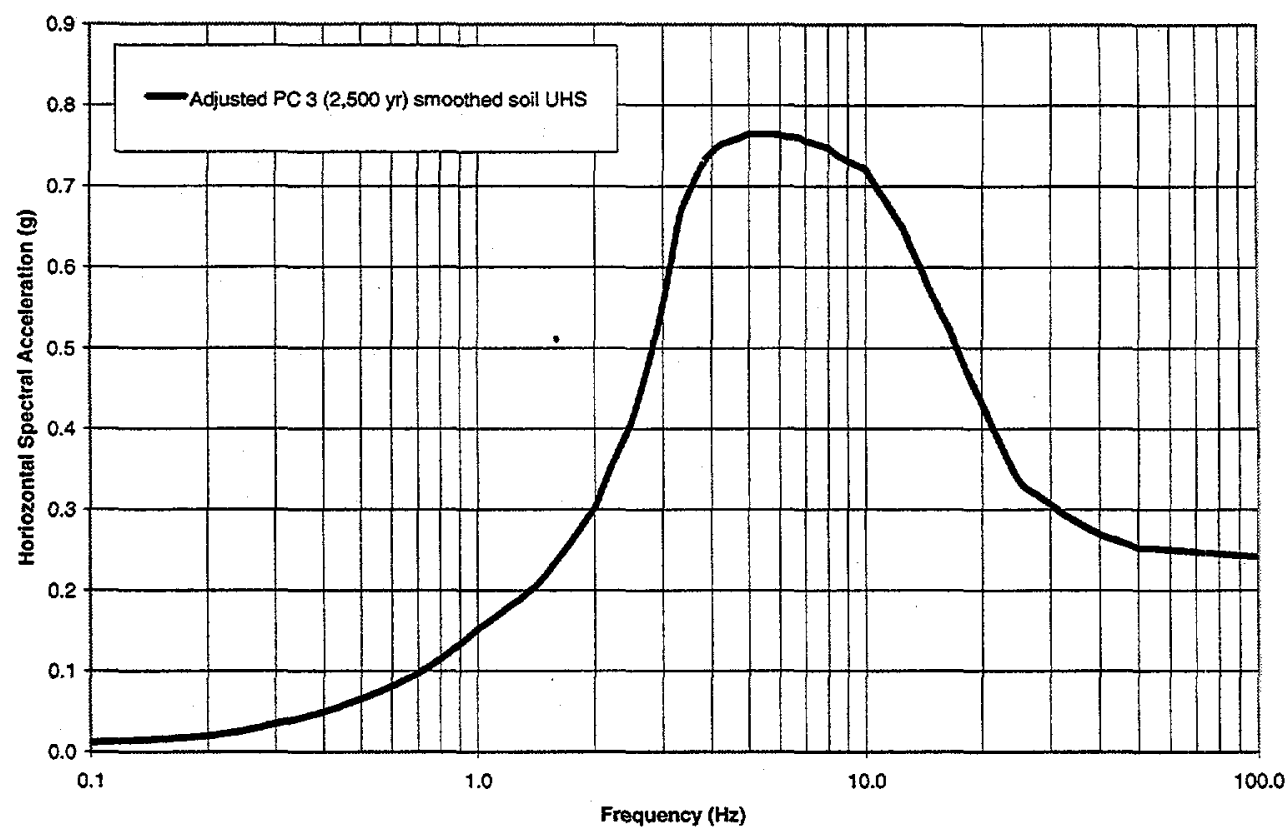

(b)

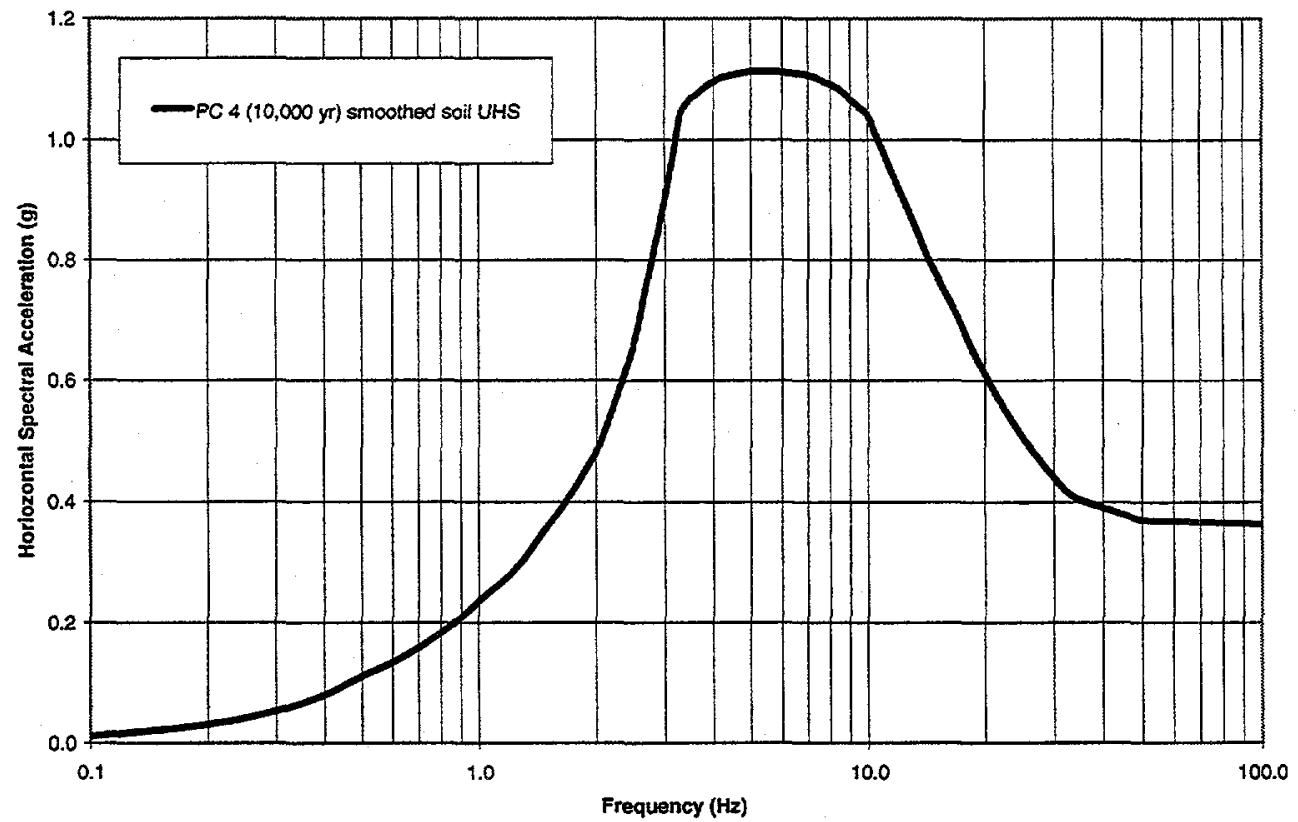

Figure 26. (a) The adjusted smoothed PC 3 (2,500 years) soil 5\% damped UHS. (b) The smoothed PC 4 (10,000 years) soil 5\% damped UHS from URSG-WCFS (1999). 


\subsection{Development of the PC 3 and PC 4 Horizontal Soil DBE}

The PC 3 and PC 4 horizontal soil DBE response spectra were derived from the adjusted PC 3 and PC 4 smoothed horizontal soil UHS (Tables 8 and 9, respectively). The horizontal soil DBE response spectra were developed by incorporating smoothed broadened regions of the peak accelerations, velocities, and displacements defined by the site-specific UHS. Portions of the horizontal soil DBE response spectra were adjusted to ensure conservatism for the structural design process.

The PC 3 (2,500 years) soil DBE response spectral shape was developed with the PGA $(0.254 \mathrm{~g})$, an increasing acceleration (by selecting $0.288 \mathrm{~g}$ at $33 \mathrm{~Hz}$ ), peak spectral acceleration $(0.765 \mathrm{~g}$ ), and constant velocity defined by the adjusted smoothed PC 3 (2,500 years) soil UHS (Table 8). The peak spectral displacement was selected to be 10 inches or $25.40 \mathrm{~cm}$ based on experience, professional judgement, and discussions with the DNFSB (see Appendix A for further discussion). Appendix A also shows the envelops of the response spectra to portions of the adjusted smoothed PC 3 soil UHS used to develop the PC 3 soil DBE response spectral shape for INTEC.

The PC 4 (10,000 years) soil DBE response spectral shape was developed in a similar manner as the PC 3 soil DBE response spectra. The PC 4 soil DBE response spectral shape was developed with the PGA $(0.363 \mathrm{~g}$ ), an increasing acceleration (by selecting $0.407 \mathrm{~g}$ at $33 \mathrm{~Hz}$ ), peak spectral acceleration $(1.113 \mathrm{~g})$, and constant velocity defined by the smoothed PC 4 (10,000 years) soil UHS (Table 9). The peak spectral displacement was selected to be 12 inches or $30.48 \mathrm{~cm}$ (see Appendix $A$ for further discussion). Appendix A shows the envelops of the response spectra to portions of the smoothed PC 4 soil UHS used to develop the PC 4 soil DBE response spectral shape for INTEC.

The PC 3 and PC 4 soil DBE response spectra have similar characteristics to a standard response spectrum of Newmark and Hall (1978). Since the soil DBE response spectral shapes were derived from the site-specific UHS, median amplification values from Newmark and Hall (1978) and current work of the Nuclear Regulatory Commission were used to check the adequacy of the DBE response spectra. These median amplification values were not used to develop the soil DBE response spectra. The soil DBE response spectra have an adequate frequency range to accommodate the possible range of ground motions consistent with the approach developed by Newmark and Hall (1978) (see Appendix A for further discussion).

Figure 27 (a) and (b) show the PC 3 and PC 4 horizontal soil DBE 5\% damped response spectra to be used for design at INTEC compared to the PC 3 and PC 4 soil UHS, respectively. The PC 3 and PC 4. soil DBE response spectra envelop the PC 3 and PC 4 soil UHS. Figure 28 (a) and (b) show the PC 3 and PC 4 soil DBE response spectra compared to the current design for soil thickness greater than $20 \mathrm{ft}$ at INTEC in the DOE-ID AE Standards (DOE-ID, 1998). Figure 28 (a) shows that the PC 3 (2,500 years) soil DBE response spectrum exceeds the RG 1.60 response spectrum tied to $0.27 \mathrm{~g}$ at frequencies between 5 and $40 \mathrm{~Hz}$. The PC 3 soil DBE has lower spectral accelerations at frequencies less than $5 \mathrm{~Hz}$. Figure 28 (b) shows that the PC 4 soil DBE response spectrum exceeds the RG 1.60 response spectrum tied to 0.36 $\mathrm{g}$ for frequencies between 3.5 to $45 \mathrm{~Hz}$. The PC 4 soil DBE has lower accelerations at frequencies less than $3.5 \mathrm{~Hz}$. The higher accelerations shown in Figure 28 (a) and (b) for the PC 3 and PC 4 soil DBE response spectra are due to amplification of the accelerations in this part of the spectra by the shallow soil conditions at INTEC (see Figure $25 \mathrm{a}$ and $\mathrm{b}$ ). 
Table 8. Spectral accelerations for the adjusted PC 3 (2,500 years) horizontal soil $5 \%$ damped UHS at INTEC.

\begin{tabular}{cc}
\hline $\begin{array}{c}\text { Frequency } \\
(\mathrm{Hz})\end{array}$ & $\begin{array}{c}\text { Horizontal } \\
\text { Spectral Acceleration } \\
(\mathrm{g})\end{array}$ \\
\hline 50.00 & 0.254 \\
34.00 & 0.288 \\
20.00 & 0.432 \\
10.00 & 0.720 \\
5.00 & 0.765 \\
3.33 & 0.659 \\
3.00 & 0.600 \\
2.50 & 0.410 \\
2.00 & 0.302 \\
1.00 & 0.151 \\
0.50 & 0.065 \\
\hline
\end{tabular}

Table 9. Spectral accelerations for the PC 4 (10,000 years) horizontal soil 5\% damped UHS at INTEC.

\begin{tabular}{ccc} 
& $\begin{array}{c}\text { Frequency } \\
(\mathrm{Hz})\end{array}$ & $\begin{array}{c}\text { Horizontal } \\
\text { Spectral Acceleration } \\
(\mathrm{g})\end{array}$ \\
\hline 50.00 & 0.363 \\
34.00 & 0.407 \\
20.00 & 0.610 \\
10.00 & 1.040 \\
5.00 & 1.113 \\
3.33 & 1.042 \\
3.00 & 0.900 \\
2.50 & 0.660 \\
2.00 & 0.480 \\
1.00 & 0.235 \\
\hline 0.50 & 0.110 \\
\hline
\end{tabular}




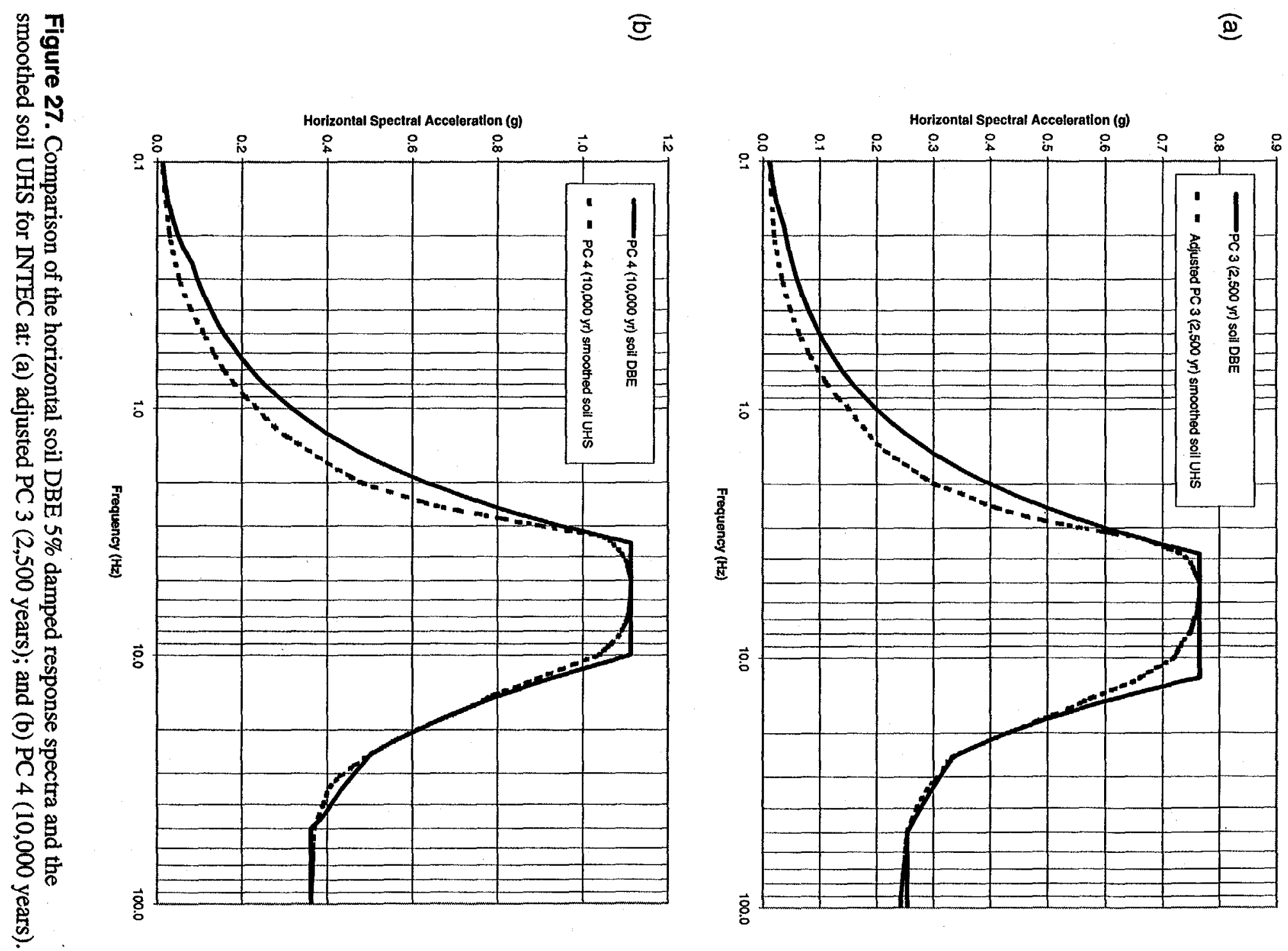


(a)

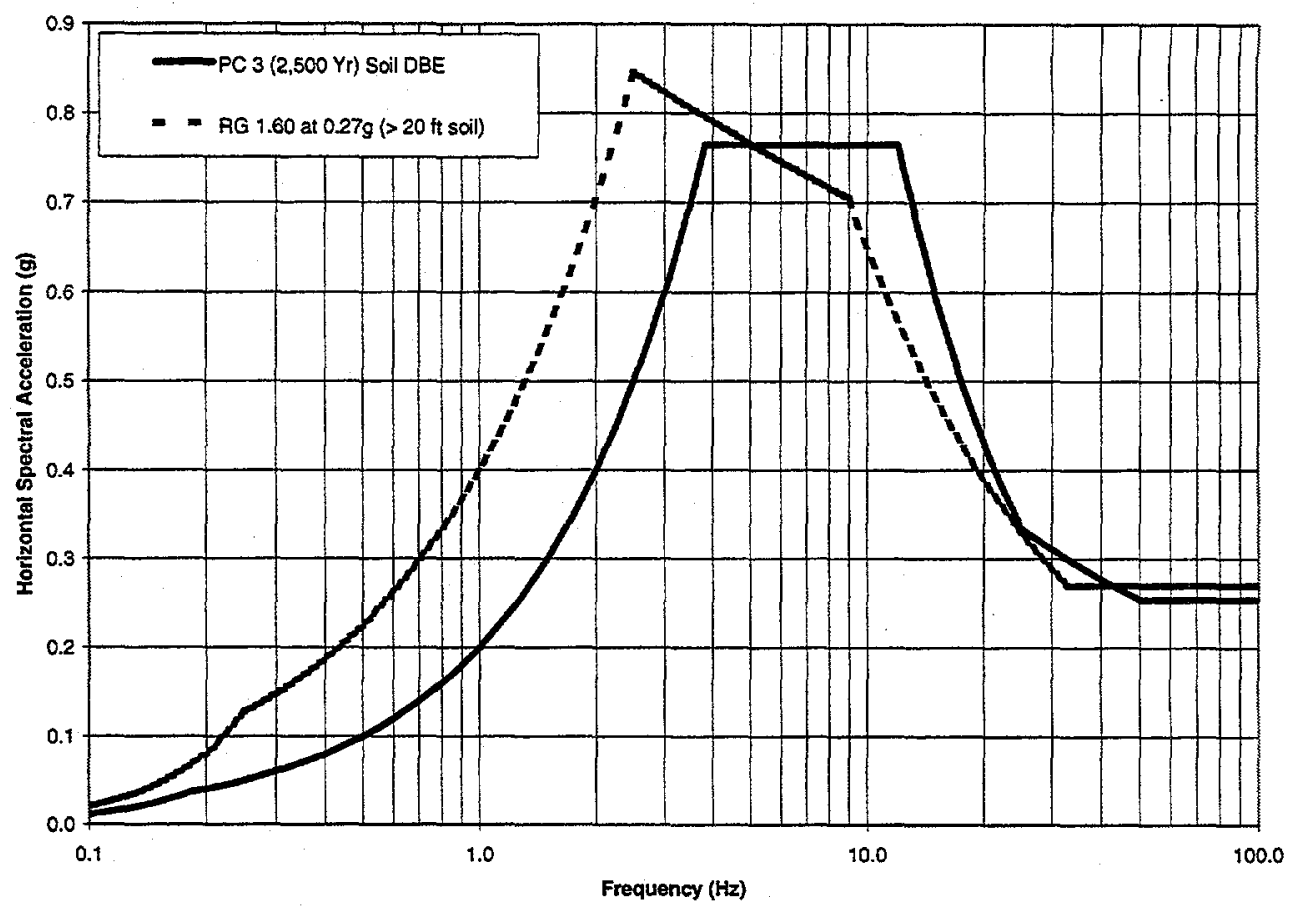

(b)

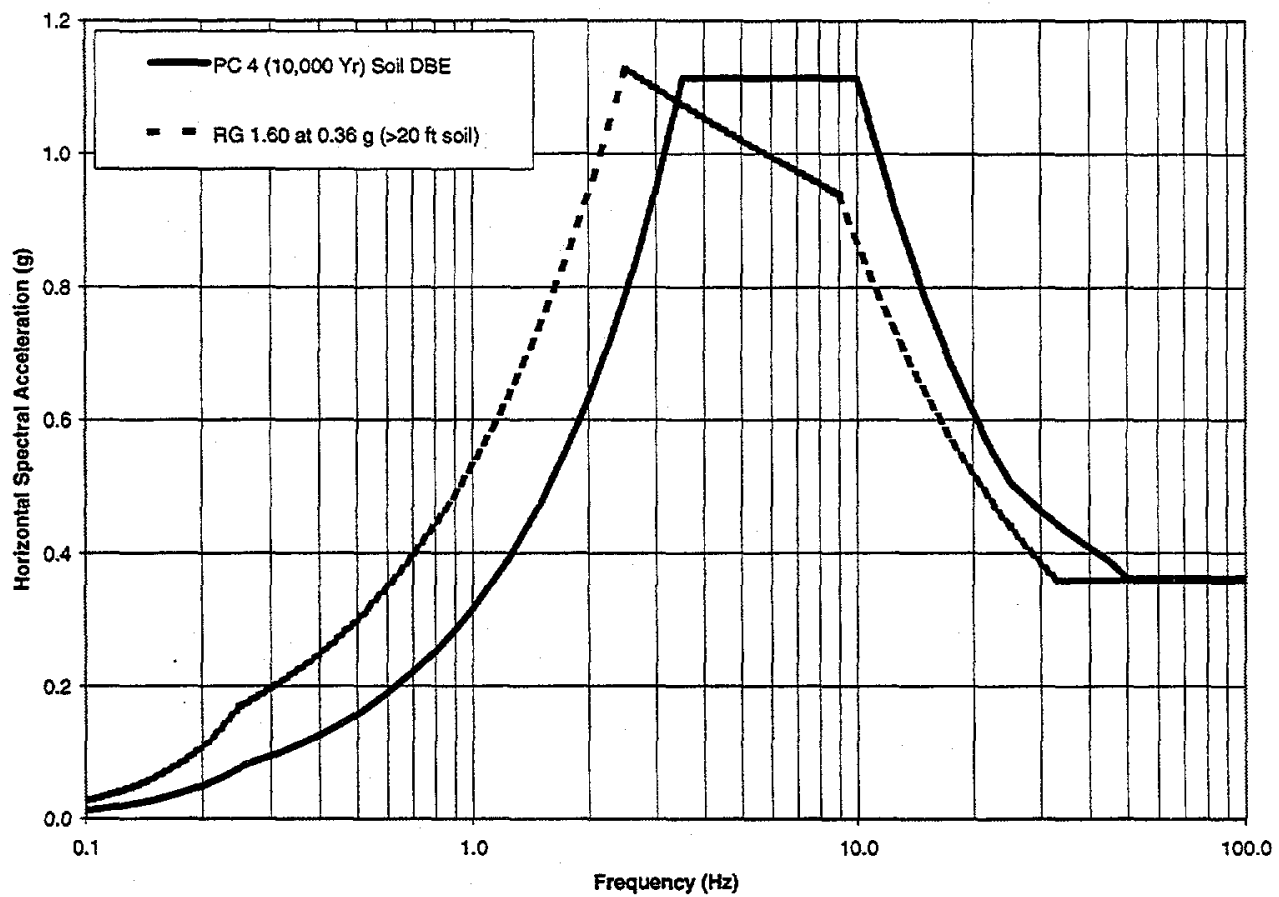

Figure 28. Comparison of the PC 3 (2,500 years) and PC 4 (10,000 years) horizontal soil DBE $5 \%$ damped response spectra with the current design criteria for a soil thickness greater than $20 \mathrm{ft}$ at INTEC as defined by DOE-ID AE Standards (DOE-ID, 1998). 


\subsection{Development of the PC 3 and PC 4 Vertical Soil DBE}

The PC 3 and PC 4 horizontal soil 5\% damped UHS were used to develop the vertical soil DBE response spectra for PC 3 and PC 4 at INTEC, respectively. The PC 3 soil UHS was adjusted for a 2,500year return period. URSG-WCFS (1999) developed a ratio for the vertical to horizontal (V/H) ground motions applicable to INEEL (see Appendix B). To derive the PC 3 and PC 4 vertical soil DBE response spectra, the horizontal soil UHS spectral accelerations shown in Tables 8 and 9 were multiplied by the V/H spectral ratio (Figure 10) to produce vertical UHS. The constant acceleration, velocity, and displacement portions of the vertical DBE response spectra were determined by enveloping the vertical UHS. The envelopes of the vertical response spectra used to develop the PC 3 (2,500 years) and PC 4 (10,000 years) vertical soil DBE response spectra are show in Appendix A.

The PC 3 and PC 4 vertical soil DBE response spectra are compared to the vertical design spectra defined in the DOE-ID AE Standards. In Figure 29 (a), the RG 1.60 response spectrum is tied to $0.18 \mathrm{~g}$, the peak vertical acceleration for PC 3 at INTEC for soil thickness greater than $20 \mathrm{ft}$ as defined in the DOE-ID AE Standards (DOE, 1998). In Figure 29 (b), the RG 1.60 response spectrum is tied to $0.24 \mathrm{~g}$, the peak vertical acceleration for PC 4 at INTEC for soil thickness greater than $20 \mathrm{ft}$ as defined in the DOE-ID AE Standards. From 4 to $100 \mathrm{~Hz}$, the vertical PC 3 soil DBE response spectrum exceed the vertical RG 1.60 response spectrum defined in the DOE-ID AE Standards for INTEC (Figure 29 a). From 3.5 to $100 \mathrm{~Hz}$, the vertical PC 4 soil DBE response spectrum also exceeds the PC 4 DBE response spectrum defined in the DOE-ID AE Standards for INTEC (Figure $29 \mathrm{~b}$ ). The PC 3 and PC 4 soil DBE response spectra exceed the RG 1.60 response spectra because of the soil amplification in this frequency range and use of the $\mathrm{V} / \mathrm{H}$ ratio which exceed 1.00 in this same frequency range. 
(a)

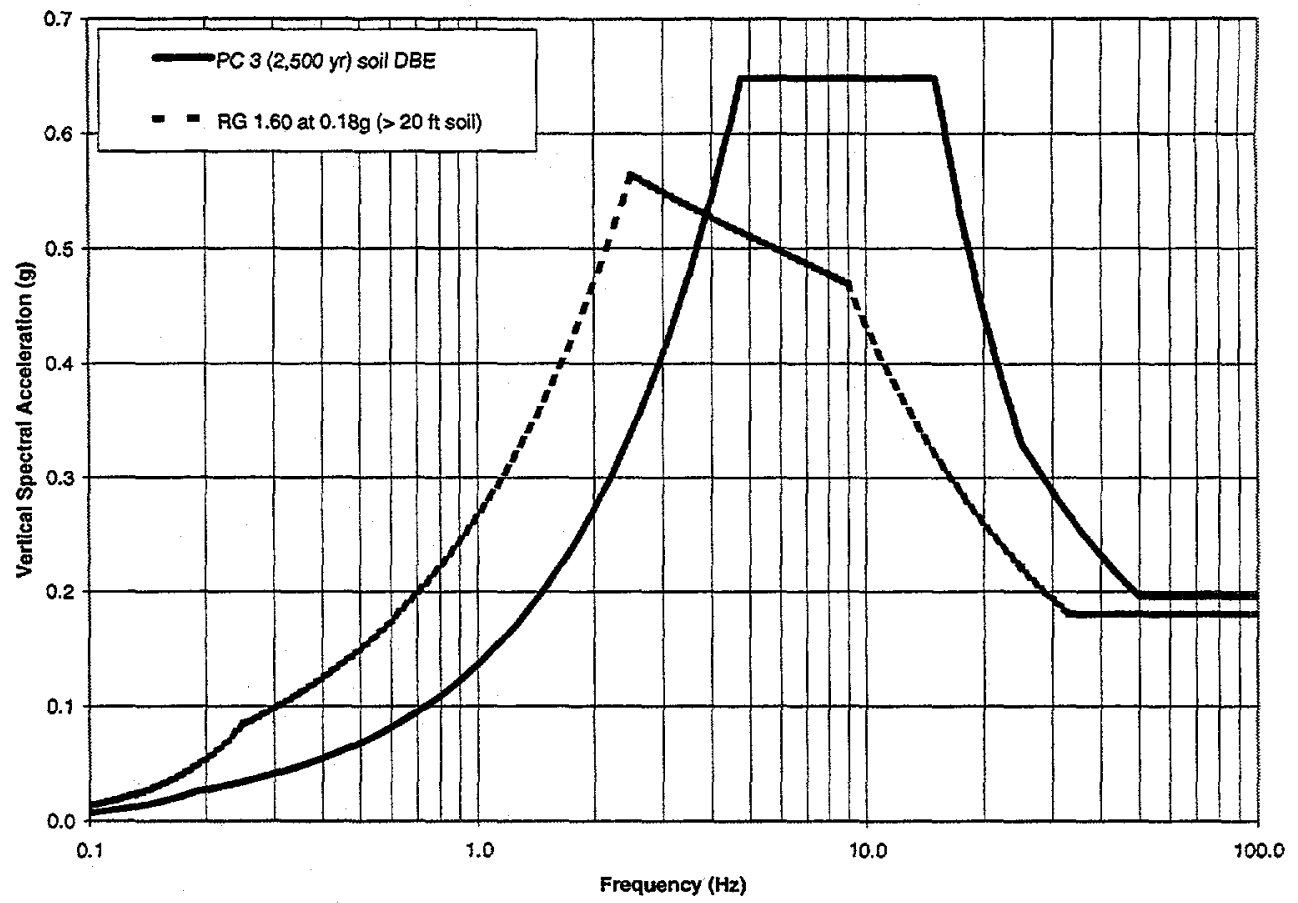

(b)

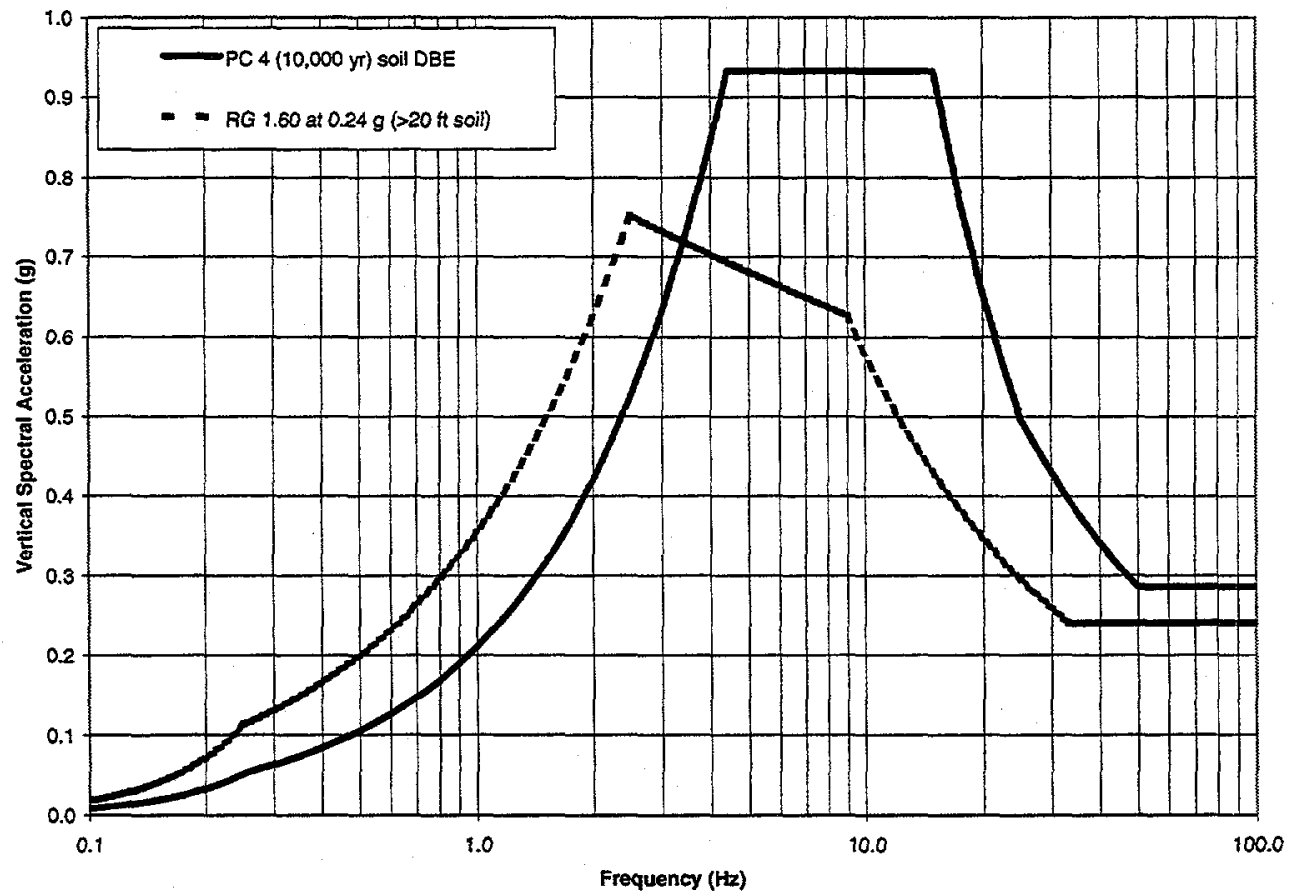

Figure 29. Comparison of the PC 3 (2,500 years) and PC 4 (10,000 years) vertical soil DBE response spectra for INTEC with the current vertical design criteria for a soil thickness greater than $20 \mathrm{ft}$ at INTEC as defined by DOE-ID AE Standards (DOE-ID, 1998). 


\subsection{Use of the PC 3 and PC 4 Soil DBE}

The horizontal and vertical PC 3 and PC 4 soil DBE 5\% damped response spectra shown in Figures 30 and 31 will be adopted into the DOE-ID AE Standards for INTEC. The horizontal and vertical spectral accelerations for the PC 3 soil DBE 5\% damped response spectra are listed in Tables 10 and 11. The spectral velocities for the tripartite graphs shown in Figures 32 through 33 are listed in Appendix C. The horizontal and vertical peak accelerations are listed in Table 12. The vertical PC 3 and PC 4 soil DBE response spectra have higher accelerations from 12.5 to $25 \mathrm{~Hz}$ than the horizontal spectra because of the higher $\mathrm{V} / \mathrm{H}$ spectral ratio over this frequency range. The PC 3 soil DBE response spectrum was adjusted for a 2,500-year return period.

The DOE-ID AE Standards will specify the horizontal and vertical PC 3 and PC 4 soil DBE response spectra (Figures 32 and 33) and peak accelerations listed in Table 12 are applicable at INTEC where the soil conditions have an average thickness of $40 \mathrm{ft}(12.2 \mathrm{~m})$ over a thickness range between 30 to $50 \mathrm{ft}(9.1$ to $15.2 \mathrm{~m})$. These restrictions are necessary to be within the peak acceleration response of the smoothed PC 3 and PC 4 soil UHS used to develop the DBE response spectra. The PC 3 and PC 4 soil DBE response spectra may be applicable to other facility areas where the soil conditions are within the thickness range and have similar soil properties used to develop the PC 3 and PC 4 soil DBE (see Appendix E).

The DOE-ID AE Standards will provide interim guidance that specifies for existing and new PC 3 and PC 4 facilities on soil sites shallower than $30 \mathrm{ft}(9.1 \mathrm{~m})$ and deeper than $50 \mathrm{ft}(15.2 \mathrm{~m})$ that a soil response analysis must be performed using the time histories applicable for the PC 3 or PC 4 rock DBE response spectra (see Section 2.7). This specification will also apply to soil sites that are within the thickness range of the PC 3 and PC 4 soil DBE response spectra, but have vastly different soil properties. Preliminary review of the spectral ratios of the soil UHS to rock UHS at the 2,000-and 10,000-year return period for INTEC and ANL-W show that soil conditions at INEEL (varied compositions of sand, silt, and gravel and thicknesses of 5 to $65 \mathrm{ft}$ ) amplify ground motions up to a factor of three for frequencies greater than $2 \mathrm{~Hz}$ (Figure $25 \mathrm{a}$ and $\mathrm{b}$ ). The interim guidance will be replaced at a later date with soil DBE response spectra that are applicable to a range of soil thicknesses and properties for multiple facility areas. To develop generic soil DBE response spectra, a more thorough analysis is required beyond that performed by URSG-WCFS (1999) for the TMI-2 ISFSI. Because additional soil response analyses are needed, time histories and additional damping values for the PC 3 and PC 4 soil DBE response spectra will be developed at a later date. 
Table 10. Spectral accelerations for the PC 3 (2,500 year) and PC 4 (10,000 year) horizontal soil DBE response spectra for $5 \%$ damping at INTEC.

\begin{tabular}{|c|c|c|c|}
\hline $\begin{array}{c}\text { Frequency } \\
(\mathrm{Hz})\end{array}$ & $\begin{array}{l}\text { Horizontal Spectral } \\
\text { Acceleration (g) } \\
\text { PC } 3(2,500 \mathrm{Yr})\end{array}$ & $\begin{array}{c}\text { Frequency } \\
(\mathrm{Hz})\end{array}$ & $\begin{array}{l}\text { Horizontal Spectral } \\
\text { Acceleration (g) } \\
\text { PC } 4(10,000 \mathrm{Yr})^{\mathrm{a}}\end{array}$ \\
\hline 100.00 & 0.254 & 100.00 & 0.363 \\
\hline 90.00 & 0.254 & 90.00 & 0.363 \\
\hline 80.00 & 0.254 & 80.00 & 0.363 \\
\hline 70.00 & 0.254 & 70.00 & 0.363 \\
\hline 60.00 & 0.254 & 60.00 & 0.363 \\
\hline 55.00 & 0.254 & 55.00 & 0.363 \\
\hline 50.00 & 0.254 & 50.00 & 0.363 \\
\hline 45.00 & 0.265 & 45.00 & 0.388 \\
\hline 40.00 & 0.277 & 40.00 & 0.409 \\
\hline 35.00 & 0.293 & 35.00 & 0.434 \\
\hline 30.00 & 0.311 & 30.00 & 0.465 \\
\hline 27.50 & 0.322 & 27.50 & 0.484 \\
\hline 25.00 & 0.335 & 25.00 & 0.505 \\
\hline 22.50 & 0.377 & 22.50 & 0.553 \\
\hline 20.00 & 0.430 & 20.00 & 0.612 \\
\hline 17.50 & 0.500 & 17.50 & 0.687 \\
\hline 15.00 & 0.595 & 15.00 & 0.785 \\
\hline 12.50 & 0.730 & 12.50 & 0.918 \\
\hline 12.00 & 0.765 & 10.00 & 1.113 \\
\hline 10.00 & 0.765 & 9.00 & 1.113 \\
\hline 9.00 & 0.765 & 8.00 & 1.113 \\
\hline 8.00 & 0.765 & 7.00 & 1.113 \\
\hline 7.00 & 0.765 & 6.00 & 1.113 \\
\hline 6.00 & 0.765 & 5.50 & 1.113 \\
\hline 5.50 & 0.765 & 5.00 & 1.113 \\
\hline 5.00 & 0.765 & 4.50 & 1.113 \\
\hline 4.50 & 0.765 & 4.00 & 1.113 \\
\hline 4.00 & 0.765 & 3.523 & 1.113 \\
\hline 3.829 & 0.765 & 3.50 & 1.106 \\
\hline 3.50 & 0.699 & 3.00 & 0.948 \\
\hline
\end{tabular}


Table 10. (continued).

\begin{tabular}{|c|c|c|c|}
\hline $\begin{array}{c}\text { Frequency } \\
(\mathrm{Hz})\end{array}$ & $\begin{array}{l}\text { Horizontal Spectral } \\
\text { Acceleration }(\mathrm{g}) \\
\text { PC } 3(2,500 \mathrm{Yr}) \\
\end{array}$ & $\begin{array}{c}\text { Frequency } \\
(\mathrm{Hz})\end{array}$ & $\begin{array}{l}\text { Horizontal Spectral } \\
\text { Acceleration }(\mathrm{g}) \\
\text { PC } 4(10,000 \mathrm{Yr})^{\mathrm{a}}\end{array}$ \\
\hline 3.00 & 0.599 & 2.75 & 0.869 \\
\hline 2.75 & 0.549 & 2.50 & 0.790 \\
\hline 2.50 & 0.499 & 2.25 & 0.711 \\
\hline 2.25 & 0.449 & 2.00 & 0.632 \\
\hline 2.00 & 0.399 & 1.75 & 0.553 \\
\hline 1.75 & 0.349 & 1.50 & 0.474 \\
\hline 1.50 & 0.300 & 1.25 & 0.395 \\
\hline 1.25 & 0.250 & 1.00 & 0.316 \\
\hline 1.00 & 0.200 & 0.90 & 0.284 \\
\hline 0.90 & 0.180 & 0.80 & 0.253 \\
\hline 0.80 & 0.160 & 0.70 & 0.221 \\
\hline 0.70 & 0.140 & 0.60 & 0.190 \\
\hline 0.60 & 0.120 & 0.55 & 0.174 \\
\hline 0.55 & 0.110 & 0.50 & 0.158 \\
\hline 0.50 & 0.100 & 0.45 & 0.142 \\
\hline 0.45 & 0.090 & 0.40 & 0.126 \\
\hline 0.40 & 0.080 & 0.35 & 0.111 \\
\hline 0.35 & 0.070 & 0.30 & 0.095 \\
\hline 0.30 & 0.060 & 0.275 & 0.087 \\
\hline 0.275 & 0.055 & 0.2577 & 0.081 \\
\hline 0.25 & 0.050 & 0.25 & 0.077 \\
\hline 0.225 & 0.045 & 0.225 & 0.062 \\
\hline 0.20 & 0.040 & 0.20 & 0.049 \\
\hline 0.1815 & 0.036 & 0.175 & 0.038 \\
\hline 0.175 & 0.034 & 0.15 & 0.028 \\
\hline 0.15 & 0.025 & 0.125 & 0.019 \\
\hline 0.125 & 0.017 & 0.10 & 0.012 \\
\hline 0.10 & 0.011 & & \\
\hline
\end{tabular}


Table 11. Spectral accelerations for the PC 3 (2,500 year) and PC 4 (10,000 year) vertical soil DBE response spectra for $5 \%$ damping at INTEC.

\begin{tabular}{|c|c|c|c|}
\hline $\begin{array}{c}\text { Frequency } \\
(\mathrm{Hz})\end{array}$ & $\begin{array}{l}\text { Vertical Spectral } \\
\text { Acceleration }(\mathrm{g}) \\
\text { PC } 3(2,500 \mathrm{Yr}) \\
\end{array}$ & $\begin{array}{c}\text { Frequency } \\
(\mathrm{Hz})\end{array}$ & $\begin{array}{l}\text { Vertical Spectral } \\
\text { Acceleration (g) } \\
\text { PC } 4(10,000 \text { Yr) }\end{array}$ \\
\hline 100.00 & 0.195 & 100.00 & 0.285 \\
\hline 90.00 & 0.195 & 90.00 & 0.285 \\
\hline 80.00 & 0.195 & 80.00 & 0.285 \\
\hline 70.00 & 0.195 & 70.00 & 0.285 \\
\hline 60.00 & 0.195 & 60.00 & 0.285 \\
\hline 55.00 & 0.195 & 55.00 & 0.285 \\
\hline 50.00 & 0.195 & 50.00 & 0.285 \\
\hline 45.00 & 0.212 & 45.00 & 0.424 \\
\hline 40.00 & 0.231 & 40.00 & 0.341 \\
\hline 35.00 & 0.256 & 35.00 & 0.380 \\
\hline 30.00 & 0.287 & 30.00 & 0.430 \\
\hline 27.50 & 0.307 & 27.50 & 0.461 \\
\hline 25.00 & 0.330 & 25.00 & 0.497 \\
\hline 22.50 & 0.379 & 22.50 & 0.566 \\
\hline 20.00 & 0.443 & 20.00 & 0.654 \\
\hline 17.50 & 0.529 & 17.50 & 0.771 \\
\hline 15.00 & 0.648 & 15.00 & 0.932 \\
\hline 12.50 & 0.648 & 12.50 & 0.932 \\
\hline 10.00 & 0.648 & 10.00 & 0.932 \\
\hline 9.00 & 0.648 & 9.00 & 0.932 \\
\hline 8.00 & 0.648 & 8.00 & 0.932 \\
\hline 7.00 & 0.648 & 7.00 & 0.932 \\
\hline 6.00 & 0.648 & 6.00 & 0.932 \\
\hline 5.50 & 0.648 & 5.50 & 0.932 \\
\hline 5.00 & 0.648 & 5.00 & 0.932 \\
\hline 4.76 & 0.648 & 4.50 & 0.932 \\
\hline 4.50 & 0.613 & 4.425 & 0.932 \\
\hline 4.00 & 0.544 & 4.00 & 0.843 \\
\hline 3.50 & 0.476 & 3.50 & 0.737 \\
\hline 3.00 & 0.408 & 3.00 & 0.632 \\
\hline
\end{tabular}


Table 11. (continued).

\begin{tabular}{|c|c|c|c|}
\hline $\begin{array}{l}\text { Frequency } \\
(\mathrm{Hz})\end{array}$ & $\begin{array}{l}\text { Vertical Spectral } \\
\text { Acceleration }(\mathrm{g}) \\
\text { PC } 3(2,500 \mathrm{Yr})\end{array}$ & $\begin{array}{c}\text { Frequency } \\
(\mathrm{Hz})\end{array}$ & $\begin{array}{l}\text { Vertical Spectral } \\
\text { Acceleration (g) } \\
\text { PC } 4(10,000 \mathrm{Yr})\end{array}$ \\
\hline 2.75 & 0.374 & 2.75 & 0.579 \\
\hline 2.50 & 0.340 & 2.50 & 0.527 \\
\hline 2.25 & 0.306 & 2.25 & 0.474 \\
\hline 2.00 & 0.272 & 2.00 & 0.421 \\
\hline 1.75 & 0.238 & 1.75 & 0.369 \\
\hline 1.50 & 0.204 & 1.50 & 0.316 \\
\hline 1.25 & 0.170 & 1.25 & 0.263 \\
\hline 1.00 & 0.136 & 1.00 & 0.211 \\
\hline 0.90 & 0.123 & 0.90 & 0.190 \\
\hline 0.80 & 0.109 & 0.80 & 0.169 \\
\hline 0.70 & 0.095 & 0.70 & 0.147 \\
\hline 0.60 & 0.082 & 0.60 & 0.126 \\
\hline 0.55 & 0.075 & 0.55 & 0.116 \\
\hline 0.50 & 0.068 & 0.50 & 0.105 \\
\hline 0.45 & 0.061 & 0.45 & 0.095 \\
\hline 0.40 & 0.054 & 0.40 & 0.084 \\
\hline 0.35 & 0.048 & 0.35 & 0.074 \\
\hline 0.30 & 0.041 & 0.30 & 0.063 \\
\hline 0.275 & 0.037 & 0.275 & 0.058 \\
\hline 0.25 & 0.034 & 0.257 & 0.054 \\
\hline 0.225 & 0.031 & 0.25 & 0.051 \\
\hline 0.20 & 0.027 & 0.225 & 0.041 \\
\hline 0.189 & 0.026 & 0.20 & 0.033 \\
\hline 0.175 & 0.022 & 0.175 & 0.025 \\
\hline 0.15 & 0.016 & 0.15 & 0.018 \\
\hline 0.125 & 0.011 & 0.125 & 0.013 \\
\hline 0.10 & 0.007 & 0.10 & 0.008 \\
\hline
\end{tabular}


Table 12. Peak horizontal and vertical accelerations for soil conditions at INTEC.

\begin{tabular}{|c|c|c|c|c|c|}
\hline \multirow[b]{2}{*}{ Component } & \multirow[b]{2}{*}{$\begin{array}{l}\text { Performance } \\
\text { Category }\end{array}$} & \multicolumn{4}{|c|}{$\begin{array}{c}\text { Peak Acceleration } \\
(\mathrm{g})\end{array}$} \\
\hline & & $\begin{array}{l}\text { Current DBE } \\
\text { Soil Thickness } \\
<20 \mathrm{ft} \\
\end{array}$ & $\begin{array}{c}\text { Current DBE } \\
\text { Soil Thickness } \\
>20 \mathrm{ft} \\
\end{array}$ & $\begin{array}{c}\text { Smoothed UHS } \\
\text { Soil Thickness } \\
30 \text { to } 50 \mathrm{ft} \\
\end{array}$ & $\begin{array}{c}\text { Revised DBE } \\
\text { Soil Thickness } \\
30 \text { to } 50 \mathrm{ft} \\
\end{array}$ \\
\hline \multirow[t]{2}{*}{ Horizontal } & 3 & 0.22 & 0.27 & 0.22 & $0.25^{\mathrm{d}}$ \\
\hline & 4 & 0.29 & 0.36 & 0.36 & $0.36^{\mathrm{d}}$ \\
\hline \multirow[t]{2}{*}{ Vertical } & 3 & 0.15 & 0.18 & 0.17 & $0.19^{d}$ \\
\hline & 4 & 0.19 & 0.24 & 0.28 & $0.28^{\mathrm{d}}$ \\
\hline \multicolumn{6}{|c|}{ a. DOE-ID AE Standards (DOE-ID, 1998). } \\
\hline \multicolumn{6}{|c|}{ b. URSG-WCFS (1999) where PC 3 is defined at the 2,000-year retum period and PC 4 is at 10,000-year return period. } \\
\hline
\end{tabular}




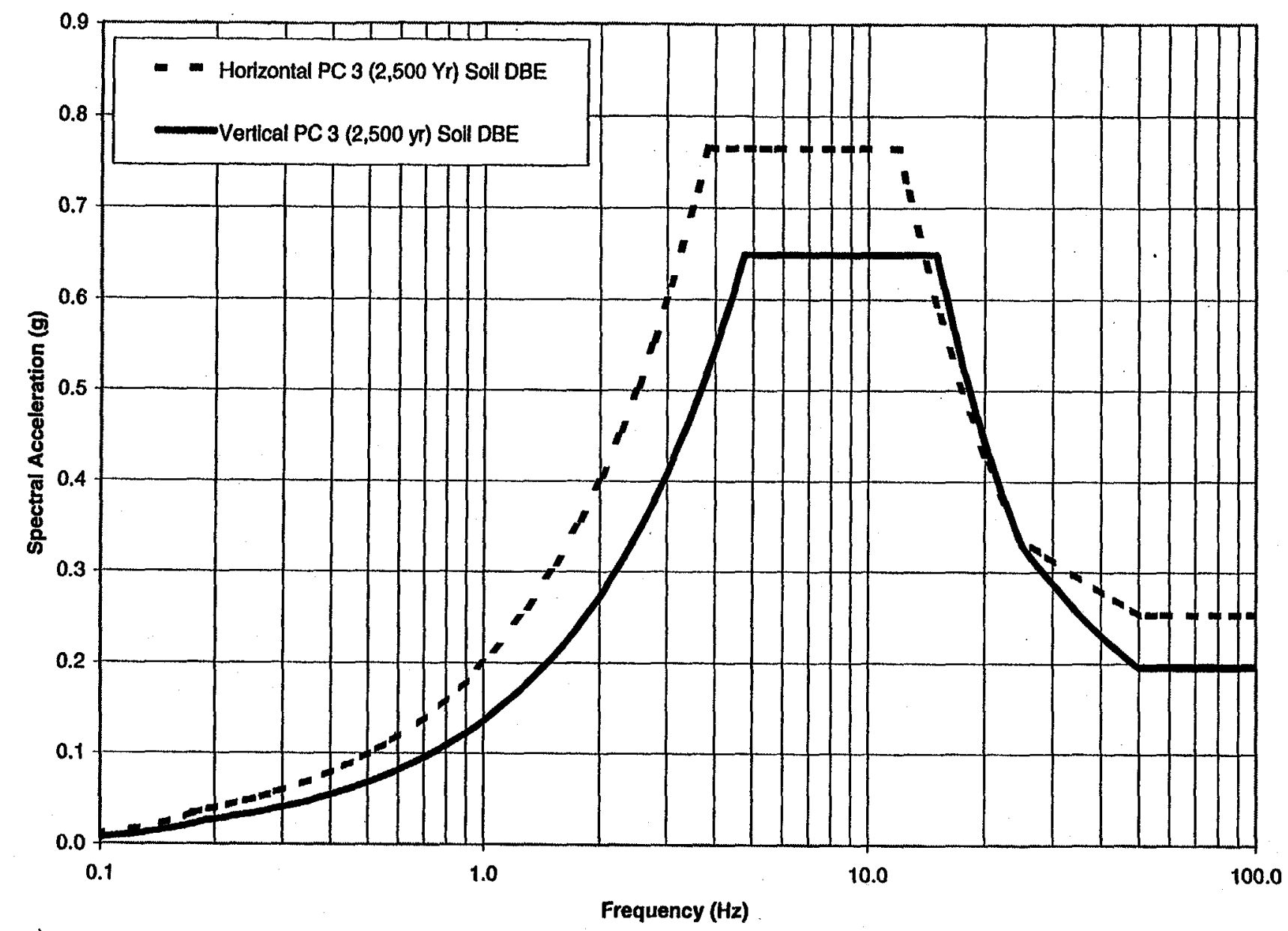

Figure 30. The horizontal and vertical PC 3 (2,500 years) soil DBE $5 \%$ damped response spectra for INTEC soil thickness between 30 to $50 \mathrm{ft}$. 


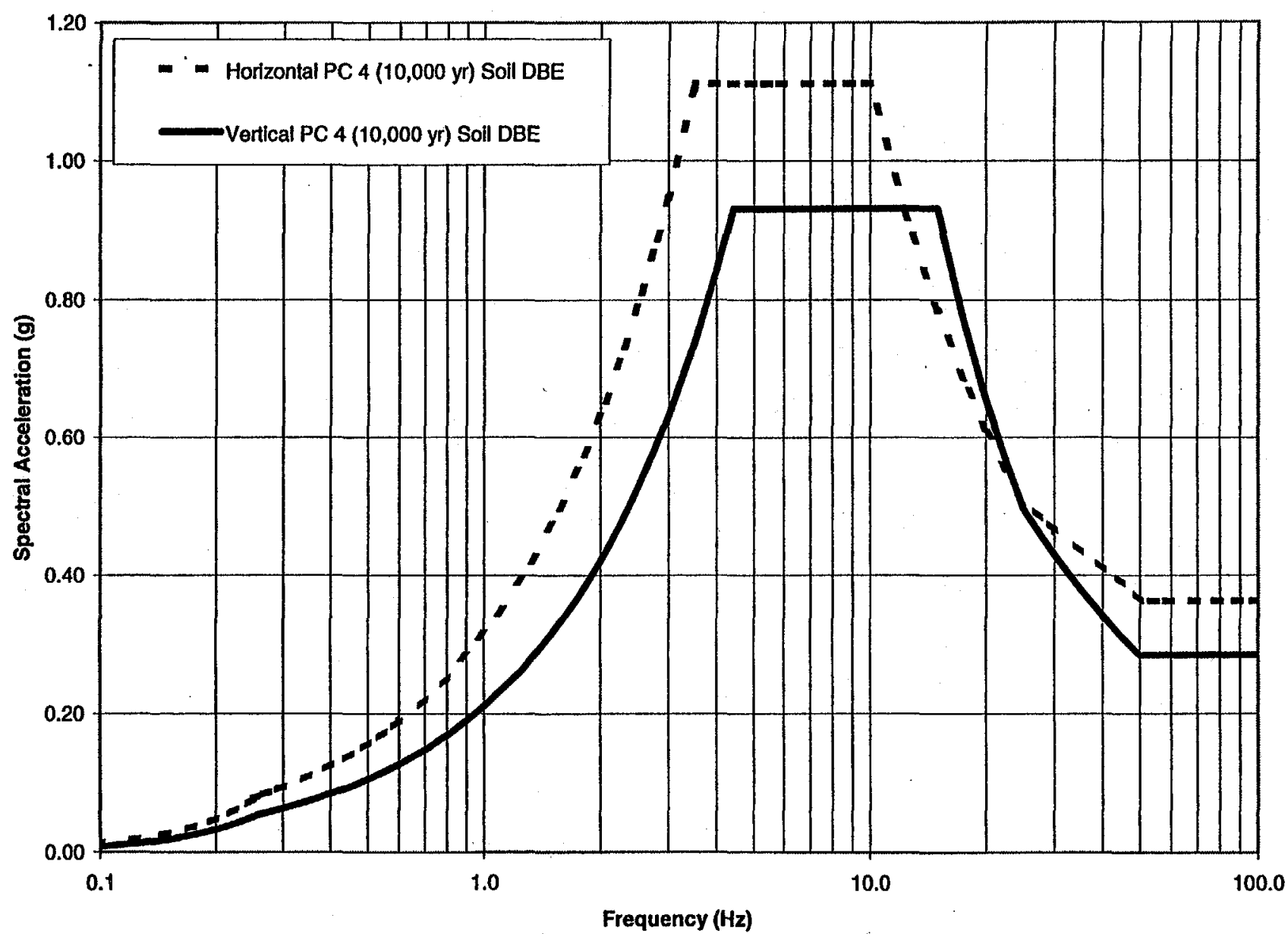

Figure 31. The horizontal and vertical PC 4 (10,000 years) soil DBE 5\% damped response spectra for INTEC soil thickness between 30 to $50 \mathrm{ft}$. 


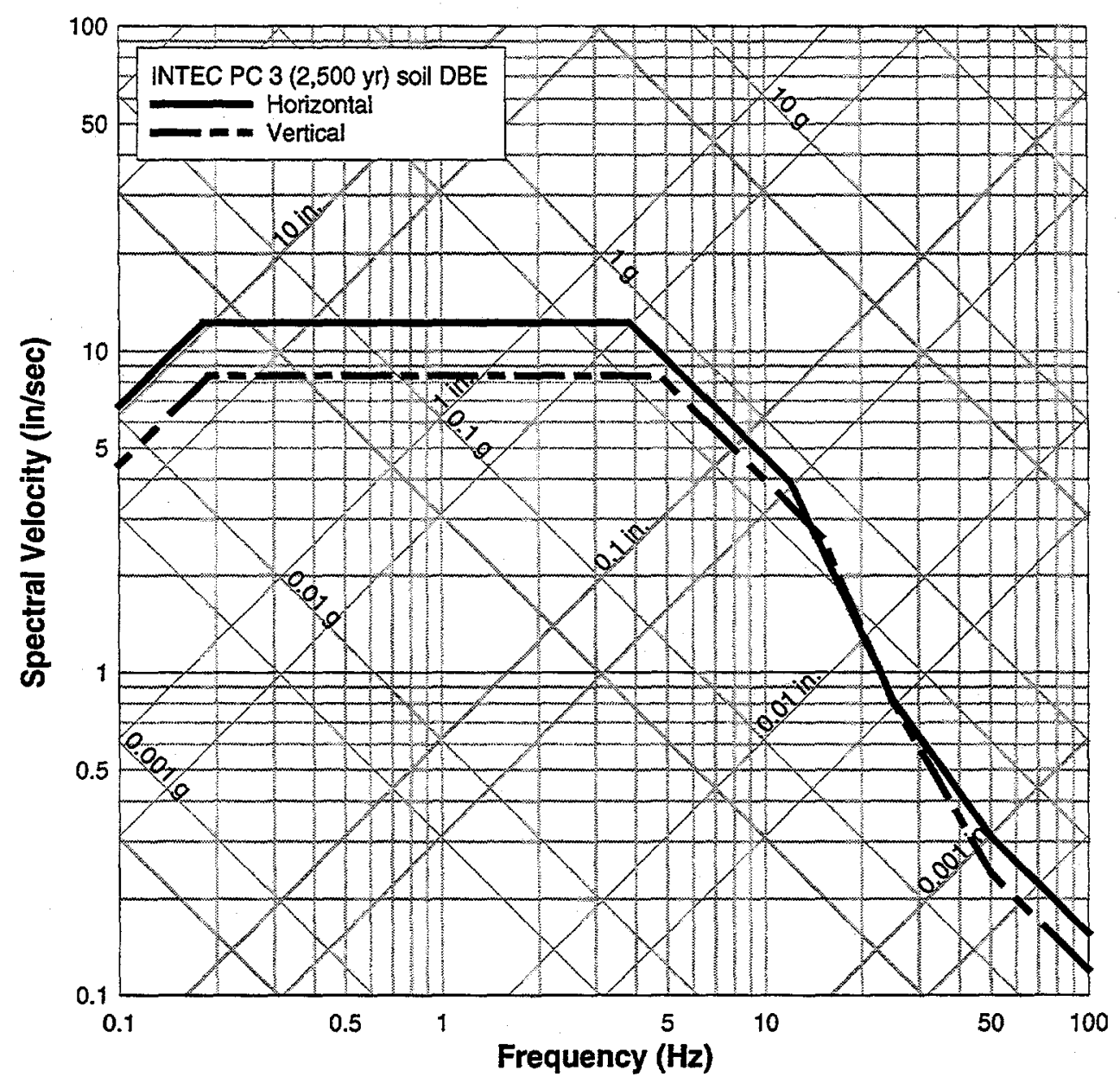

Figure 32. Tripartite graph of the horizontal and vertical PC 3 (2,500 years) soil DBE 5\% damped response spectra for INTEC soil thickness between 30 to $50 \mathrm{ft}$ (see Appendix C, Tables C-7 and C-8 for spectral velocities). 


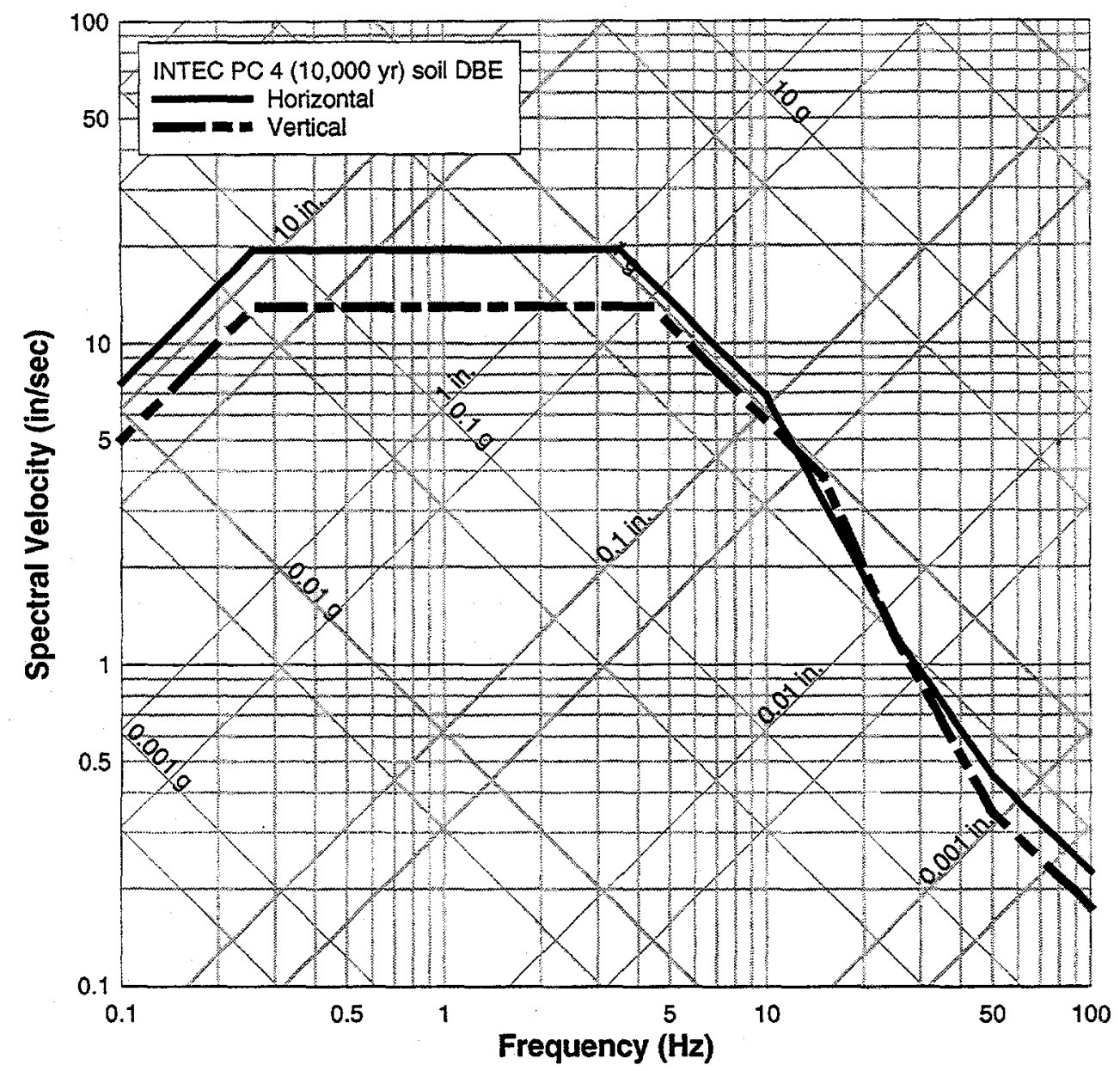

Figure 33. Tripartite graph of the horizontal and vertical PC 4 (10,000 years) soil DBE 5\% damped response spectra for INTEC soil thickness between 30 to $50 \mathrm{ft}$ (see Appendix C, Tables C-7 and C-8 for spectral velocities). 


\section{DESIGN BASIS EARTHQUAKE FOR ROCK CONDITIONS AT TAN}

\subsection{Selection of the Rock UHS for PC 3 and PC 4}

The horizontal mean $5 \%$ damped UHS at 2,500 year and 10,000 year return periods developed by URSG-WCFS (2000a) for TAN are used as the basis for development of the rock DBE response spectra and peak accelerations for PC 3 and PC 4. URSG-WCFS (2000a) recomputed the seismic hazard for TAN to be consistent with the URSG-WCFS (1999) evaluation that developed site-specific UHS for the NRC licensing effort of the TMI-2 ISFSI. As part of the licensing effort for the TMI-2 ISFSI, the URSGWCFS (1999) seismic hazard evaluation (input data, methodologies, and results) was thoroughly reviewed by the NRC and four nationally recognized experts. The INEEL NPHC and DOE approved the results of the TMI-2 ISFSI evaluation (URSG-WCFS, 1999) and the recent evaluation that recomputed the seismic hazard of other INEEL facilities (URSG-WCFS, 2000a) for use in development of DBE response spectra for INEEL facility areas.

For this report, URSG-WCFS (2000a) was requested to develop site-specific UHS at the 2,500year return period for TAN. URSG-WCFS (2000a) deaggregated the seismic hazard results at the 2,500year and 10,000-year return period to determine the contributions of all earthquake sources in a selected earthquake magnitude and distance range. The dominant earthquakes at low $(1$ to $2.5 \mathrm{~Hz})$ and intermediate frequencies $(5$ to $10 \mathrm{~Hz}$ ) were used to supplement the response of the TAN UHS spectral shape. For the TAN UHS, there were only slight increases in ground motions at high frequencies (URSG-WCFS, 2000a). Figure 34 shows the PC $3(2,500$ years) and PC $4(10,000)$ rock UHS for TAN developed by URSG-WCFS (2000a). 
(a)

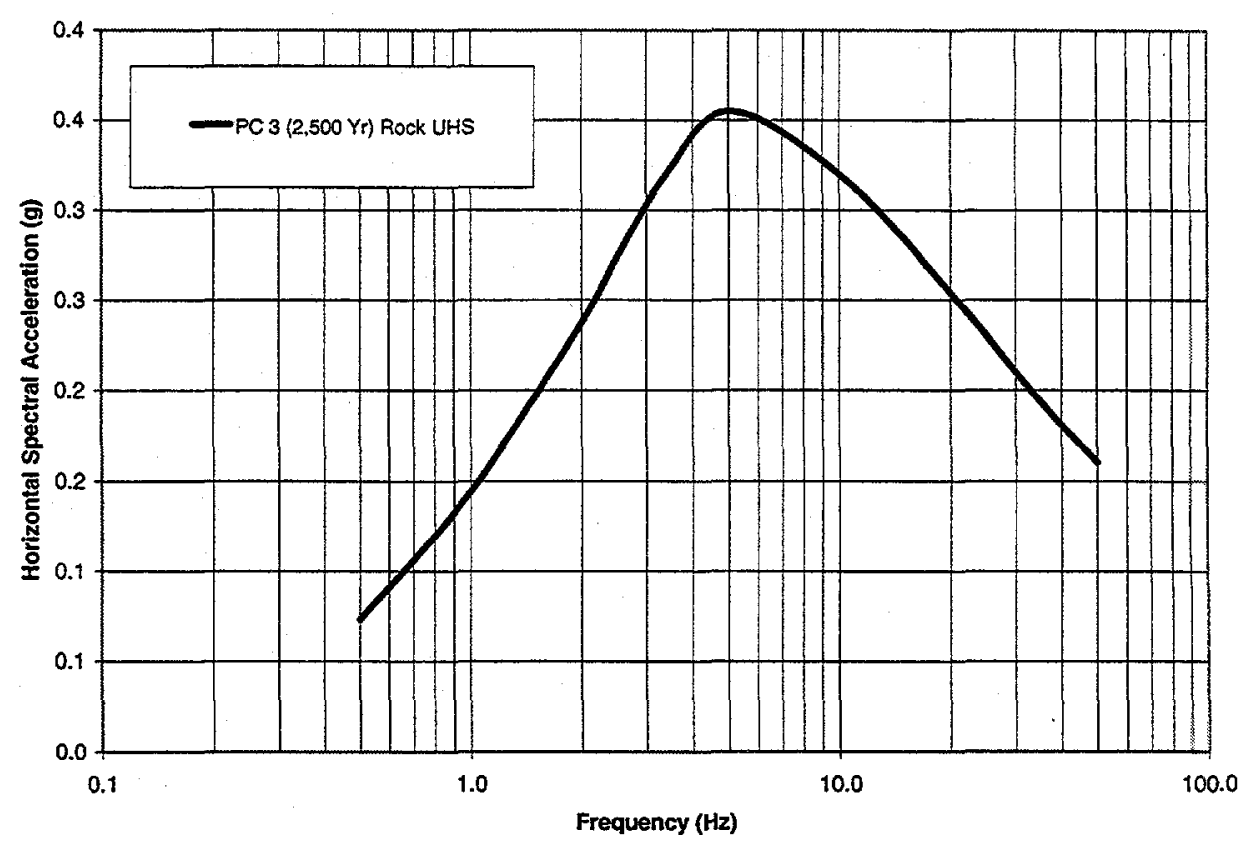

(b)

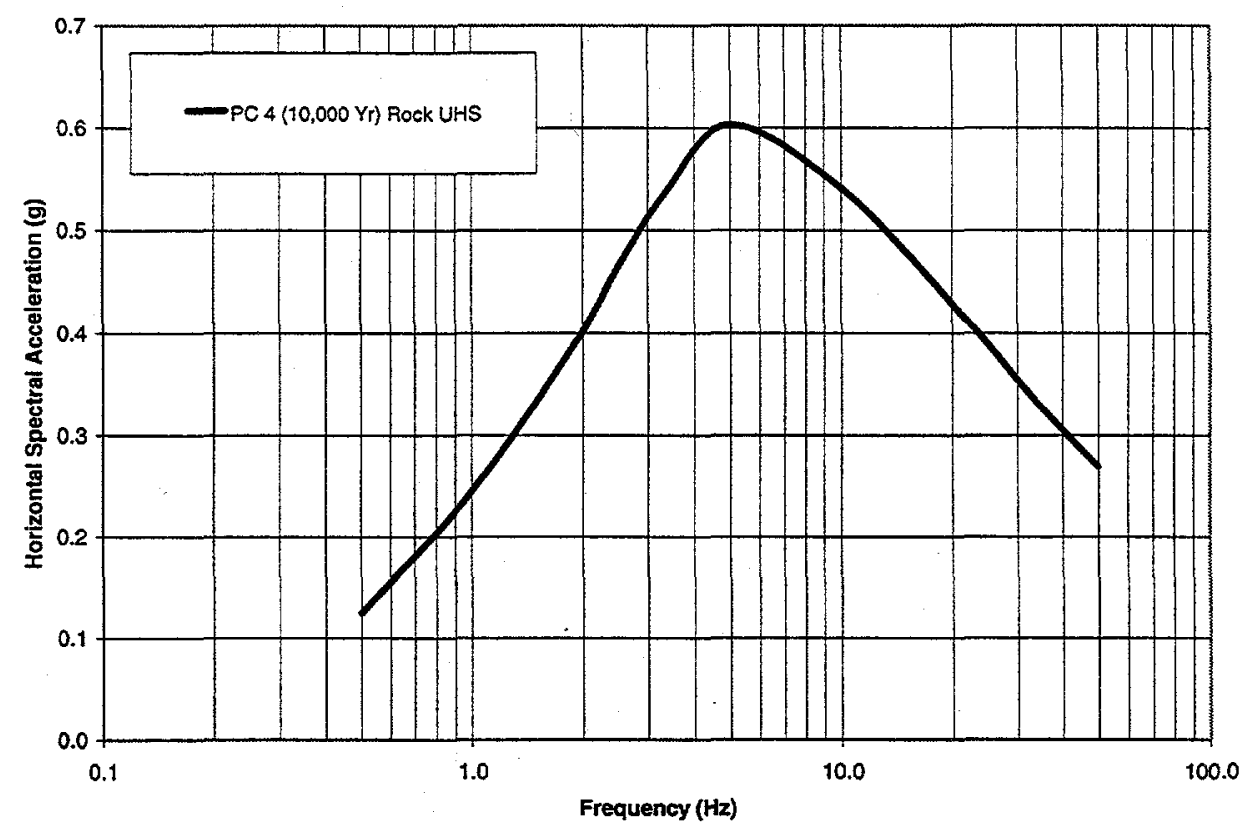

Figure 34. Site-specific rock UHS for TAN at the (a) 2,500 year return period and (b) 10,000 year return period (URSG-WCFS, 2000a). 


\subsection{Development of the PC 3 and PC 4 Horizontal Rock DBE}

The PC 3 and PC 4 horizontal rock DBE response spectra for TAN were derived from the PC 3 and PC 4 rock UHS (Tables 13 and 14, respectively). The rock DBE response spectra were developed by incorporating smoothed broadened regions of the peak accelerations, velocities, and displacements defined by the site-specific UHS. Portions of the rock DBE response spectra were adjusted to ensure conservatism for the structural design process.

The PC 3 (2,500 years) rock DBE response spectral shape was developed with the PGA $(0.160 \mathrm{~g})$, an increasing acceleration (by selecting $0.199 \mathrm{~g}$ at $33 \mathrm{~Hz}$ ), peak spectral acceleration $(0.355 \mathrm{~g}$ ), and constant velocity defined by the PC 3 (2,500 years) UHS (Table 13). The peak spectral displacement was selected to be 4 inches or $10.16 \mathrm{~cm}$ (see Appendix A for further discussion). The envelops of the response spectra to portions of the PC 3 UHS used to develop the PC 3 DBE response spectral shape for TAN are shown in Appendix A.

The PC $4(10,000$ years) rock DBE response spectral shape was developed in a similar manner as the PC 3 rock DBE. The PC 4 rock DBE response spectral shape was developed with the PGA $(0.269 \mathrm{~g})$, an increasing acceleration (by selecting $0.336 \mathrm{~g}$ at $33 \mathrm{~Hz}$ ), peak spectral acceleration $(0.603 \mathrm{~g}$ ), and constant velocity defined by the adjusted PC 4 (10,000 years) UHS (Table 14). The peak spectral displacement was selected to be 6 inches or $15.24 \mathrm{~cm}$ (Appendix A). The envelops of the response spectra to portions of the PC 4 UHS used to develop the PC 4 DBE response spectral shape for TAN are also shown in Appendix A.

The PC 3 and PC 4 rock DBE response spectra have similar characteristics to a standard response spectrum of Newmark and Hall (1978), but not as much amplification. Since the rock DBE response spectral shapes were derived from the site-specific UHS, median amplification values from Newmark and Hall (1978) and current work of the Nuclear Regulatory Commission were used to check the adequacy of the DBE response spectra. These median amplification values were not used to develop the rock DBE response spectra. The DBE response spectra have an adequate frequency range to accommodate the possible range of ground motions consistent with the approach developed by Newmark and Hall (1978) (see Appendix A for further discussion).

Figure 35 (a) and (b) show the PC 3 and PC 4 rock DBE 5\% damped response spectra to be used for design at TAN compared to the PC 3 and $\mathrm{PC} 4$ rock UHS, respectively. The PC 3 and PC 4 rock DBE response spectra have slightly higher spectral accelerations near $15 \mathrm{~Hz}$ than the adjusted PC 3 and PC 4 rock UHS. This occurs in part from the effect of semi-log versus log scale plotting. However, the slight exceedance of the UHS is unimportant at this frequency range (Per. Comm. C. Costantino, 1999).

Figure 36 (a) and (b) show the current design criteria in the DOE-ID AE Standards (DOE-ID, 1998) for TAN compared to the PC 3 and PC 4 rock DBE response spectra. The PC 3 and PC 4 rock DBE response spectra have much lower ground motions than the RG 1.60 response spectra tied to the PGA listed in Table 1 for TAN. The PC 3 and PC 4 rock DBE response spectra greatly reduces the design spectral accelerations between 1 and $10 \mathrm{~Hz}$, the primary range for most structure, system or component (SSC) evaluations for facilities at TAN. 
Table 13. Spectral accelerations for the horizontal PC 3 (2,500 years) rock 5\% damped UHS at TAN ${ }^{\mathrm{a}}$.

\begin{tabular}{cc} 
Frequency & $\begin{array}{c}\text { Horizontal Spectral } \\
\text { Acceleration } \\
(\mathrm{Hz})\end{array}$ \\
\hline 50.00 & 0.160 \\
33.33 & 0.199 \\
20.00 & 0.254 \\
10.00 & 0.320 \\
5.00 & 0.355 \\
3.33 & 0.317 \\
2.50 & 0.274 \\
2.00 & 0.237 \\
1.00 & 0.144 \\
0.50 & 0.073 \\
\hline a. URSG-WCFS (2000a). & \\
\hline
\end{tabular}

Table 14. Spectral accelerations for the horizontal PC 4 (10,000 years) rock 5\% damped UHS at TANa.

\begin{tabular}{|c|c|}
\hline $\begin{array}{c}\text { Frequency } \\
(\mathrm{Hz})\end{array}$ & $\begin{array}{c}\text { Horizontal } \\
\text { Spectral Acceleration } \\
(\mathrm{g})\end{array}$ \\
\hline 50.00 & 0.269 \\
\hline 33.33 & 0.336 \\
\hline 20.00 & 0.429 \\
\hline 10.00 & 0.541 \\
\hline 5.00 & 0.603 \\
\hline 3.33 & 0.536 \\
\hline 2.50 & 0.465 \\
\hline 2.00 & 0.402 \\
\hline 1.00 & 0.245 \\
\hline 0.50 & 0.125 \\
\hline
\end{tabular}


(a)

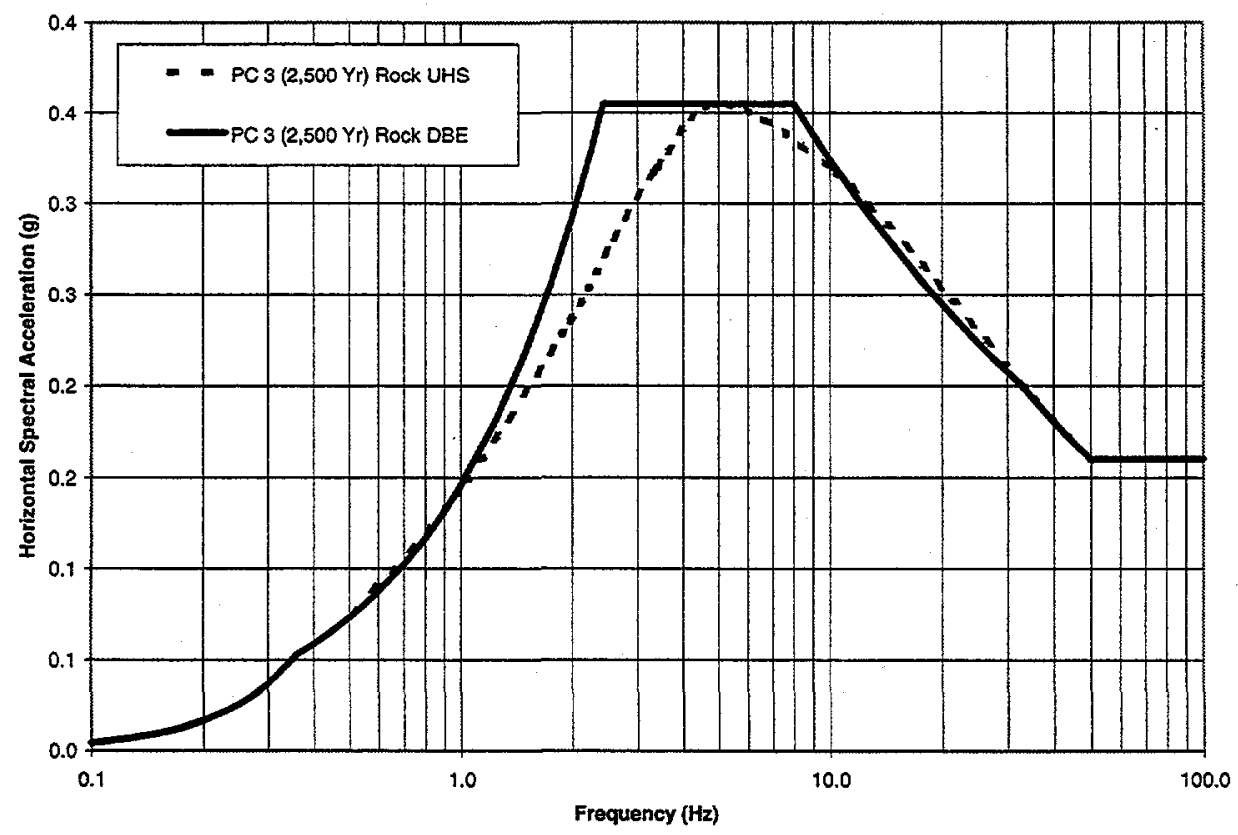

(b)

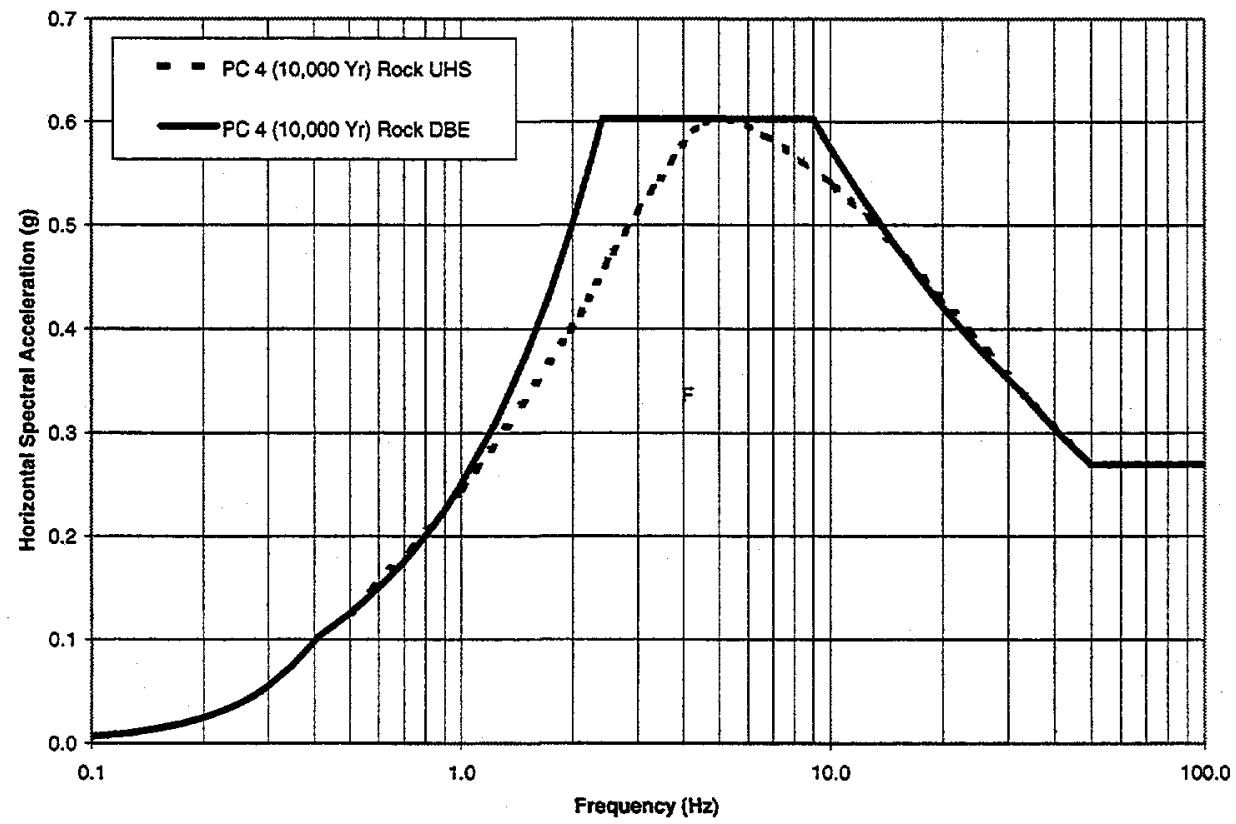

Figure 35. Comparison of the PC 3 (2,500 years) and PC 4 (10,000 years) horizontal rock DBE 5\% damped response spectra with the adjusted PC 4 rock UHS at TAN. 
(a)

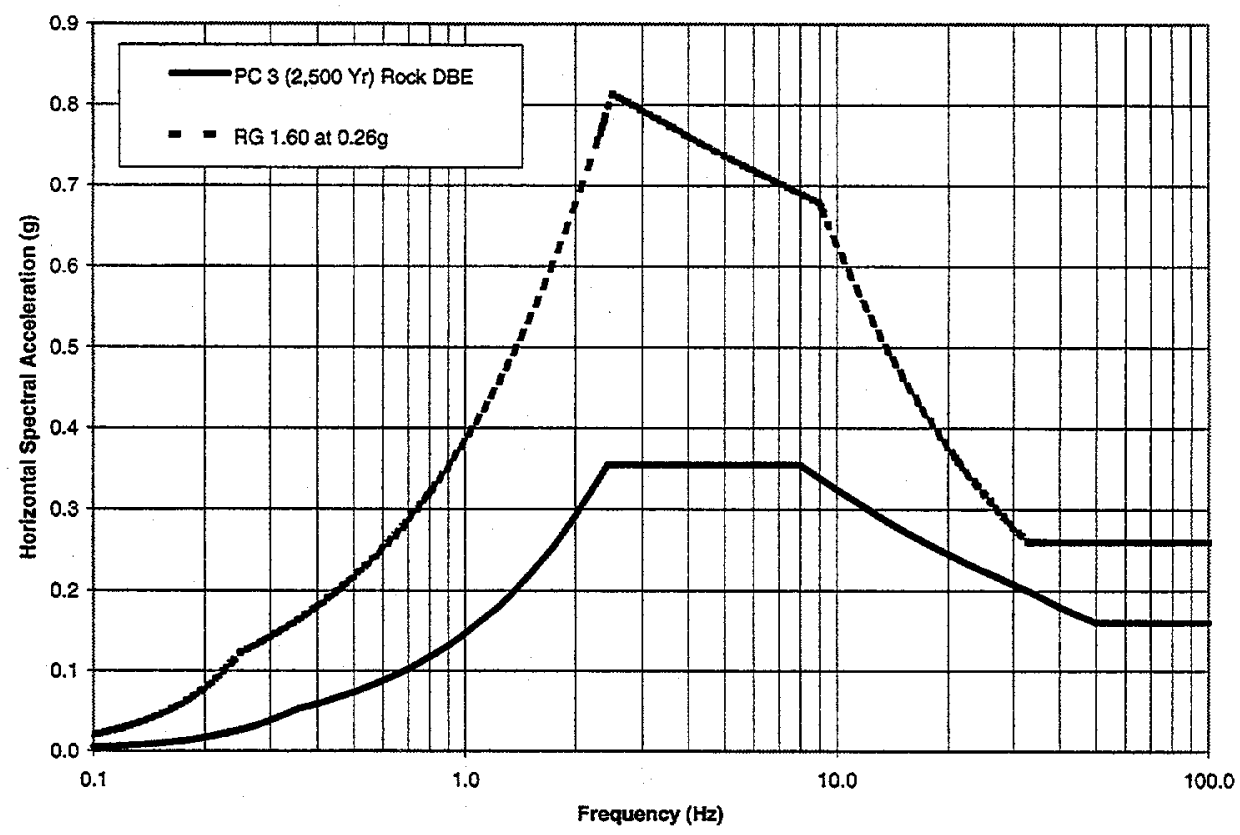

(b)

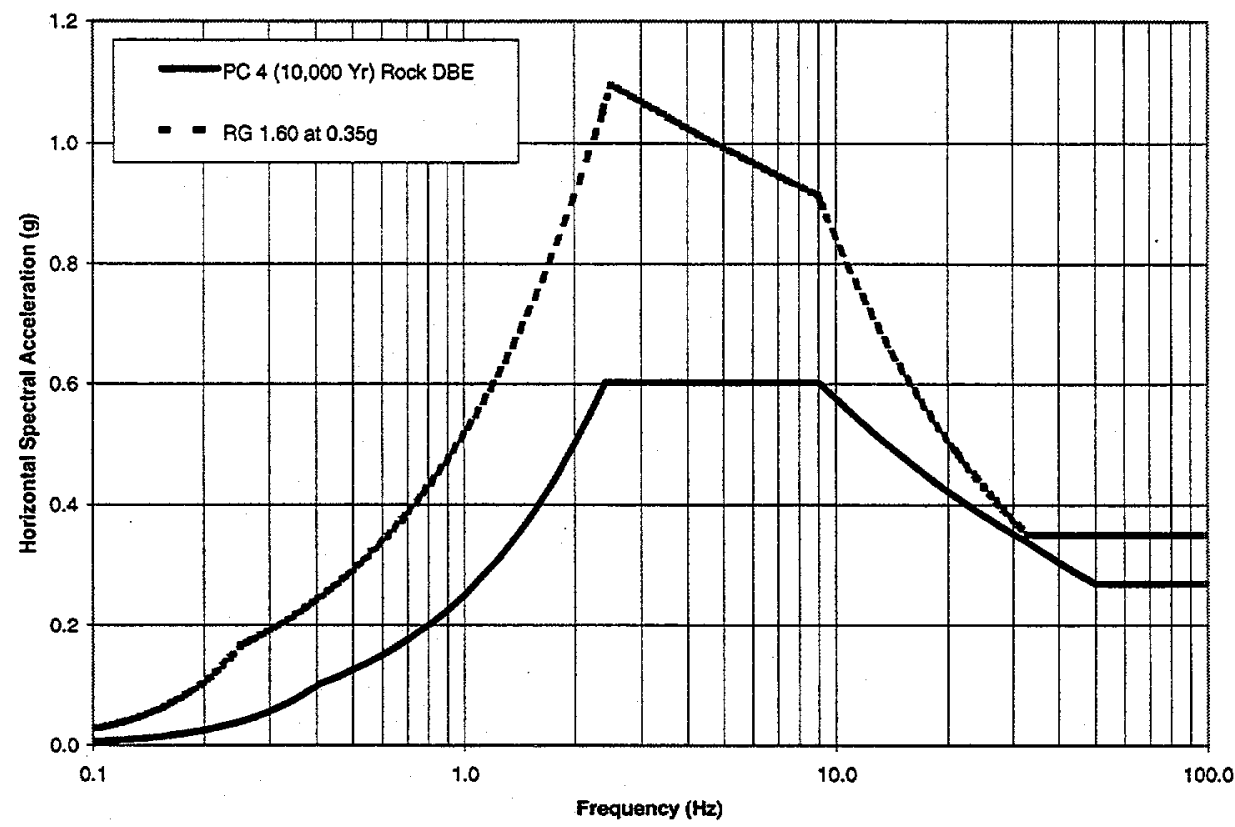

Figure 36. Comparison of the TAN PC 3 (2,500 years) and PC 4 (10,000 years) horizontal rock DBE $5 \%$ damped response spectra with the current design criteria in the DOE-ID AE Standards for TAN (DOE-ID, 1998). 


\subsection{Development of the PC 3 and PC 4 Vertical Rock DBE}

The PC 3 and PC 4 horizontal rock 5\% damped UHS were used to develop the vertical rock DBE response spectra for PC 3 and PC 4 at TAN, respectively. The PC 3 horizontal rock UHS is for a 2,500year return period. URSG-WCFS (1999) developed a ratio for the vertical to horizontal (V/H) ground motions applicable to INEEL (see Appendix B for discussion of development method). To derive the PC 3 and PC 4 vertical rock DBE response spectra, the horizontal rock UHS spectral accelerations shown in Tables 13 and 14 were multiplied by the $V / H$ spectral ratio (Figure 10) to produce vertical UHS. The constant acceleration, velocity, and displacement portions of the vertical DBE response spectra were determined by enveloping the vertical UHS. The envelopes of the vertical response spectra for the PC 3 and PC 4 vertical rock DBE response spectra are shown in Appendix A.

The PC 3 and PC 4 vertical rock DBE response spectra are compared to the vertical design spectra defined in the DOE-ID AE Standards. In Figure 37 (a), the RG 1.60 response spectrum is tied to $0.17 \mathrm{~g}$, the peak vertical acceleration for PC 3 at TAN in the DOE-ID AE Standards (DOE, 1998). In Figure 37

(b), the RG 1.60 response spectrum is tied to $0.23 \mathrm{~g}$, the peak vertical acceleration for PC 4 at TAN in the DOE-ID AE Standards. The spectral accelerations for the $\mathrm{PC} 3$ vertical rock $\mathrm{DBE}$ response spectrum are much lower at frequencies less than about $11 \mathrm{~Hz}$, but exceed the spectral accelerations from 11 to $35 \mathrm{~Hz}$ for the vertical design spectrum in the DOE-ID AE Standards (DOE, 1998). The spectral accelerations for the PC 4 vertical rock DBE response spectrum are much lower at frequencies less than $15 \mathrm{~Hz}$, but exceed the spectral accelerations from 15 to $45 \mathrm{~Hz}$ for the vertical design spectrum in the DOE-ID AE Standards (DOE, 1998). 
(a)

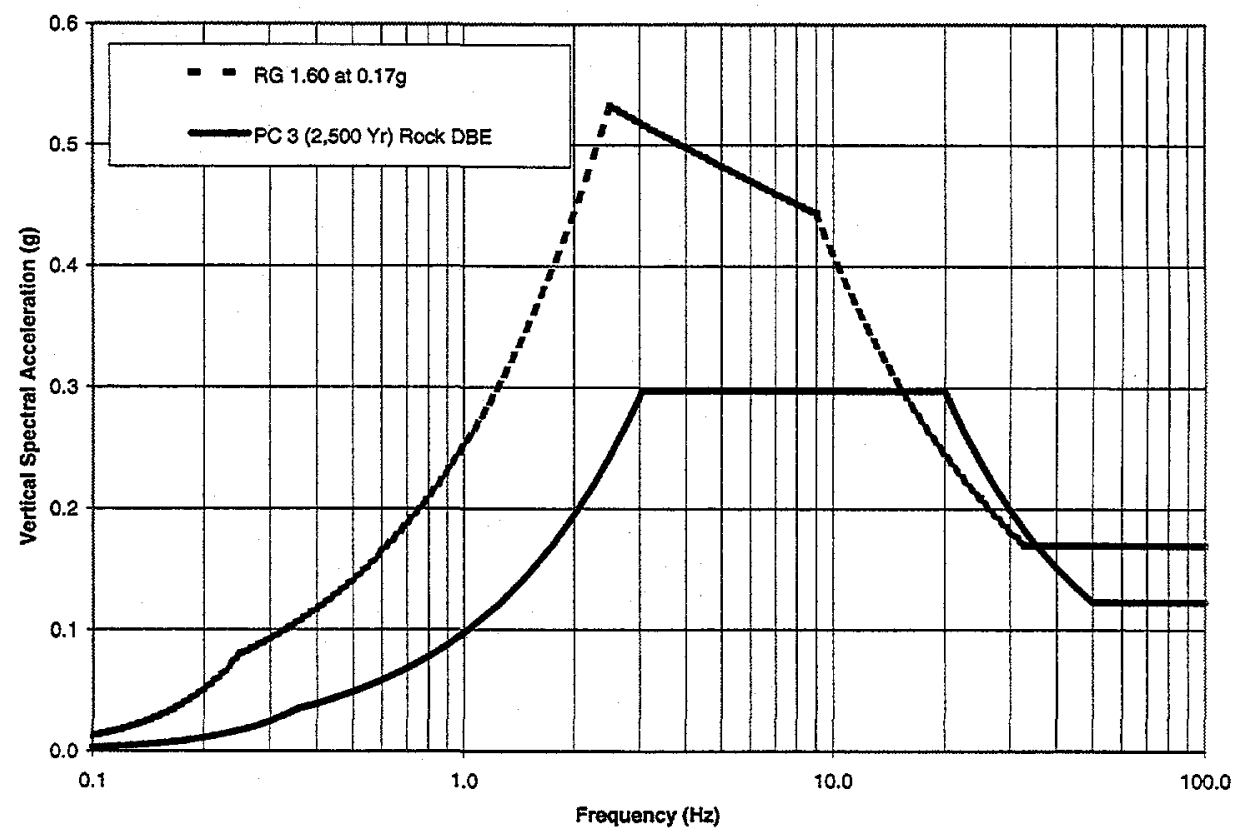

(b)

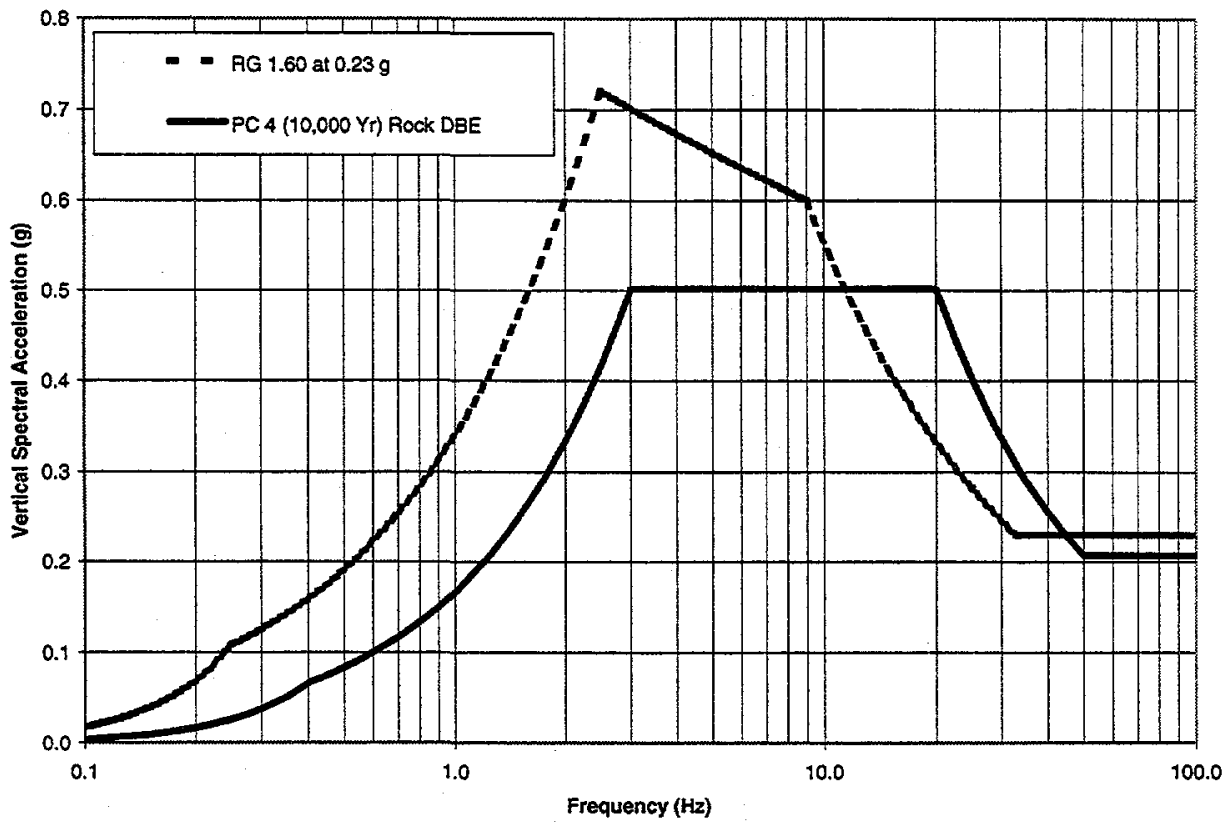

Figure 37. Comparison of the TAN PC 3 (2,500 years) and PC 4 (10,000 years) vertical rock DBE 5\% damped response spectra with the current vertical design criteria in the DOE-ID AE Standards for TAN (DOE-ID, 1998). 


\subsection{Use of the PC 3 and PC 4 Rock DBE}

The PC 3 and PC 4 horizontal and vertical rock DBE 5\% damped response spectra for TAN are shown in Figures 38 and 39, respectively. In both figures, the vertical DBE spectra have higher accelerations from 12.5 to $30 \mathrm{~Hz}$ because of the higher spectral ratios over this frequency range where the $\mathrm{V} / \mathrm{H}$ ratio exceeds 1.00. The PC 3 and PC 4 horizontal and vertical rock DBE response spectra will be adopted into the DOE-ID AE Standards under Section 0111 Structural Design. Corresponding DBE horizontal and vertical spectral accelerations for 5\% damping are listed in Tables 15 and 16. The PC 3 and PC $4 \mathrm{DBE}$ are also plotted on tripartite graphs in Figures 40 and 41 (spectral velocities are listed in Appendix C). The horizontal and vertical peak accelerations (or ZPA) are listed in Tables 6 and 7. These revisions to the DOE-ID AE Standards include a PC 3 DBE response spectra adjusted for a 2,500-year return period even though the current DOE Standards require a 2,000-year return period. Selection of a 2,500-year return period is small compared to the large reduction in spectral accelerations from the past design criteria requiring a RG 1.60 response spectra tied to higher PGAs for TAN (e.g., Figure 35).

The DOE-ID AE Standards will specify the PC 3 and PC 4 rock DBE response spectra (Figures 40 and 41) with the PGAs defined in Tables 6 and 7 will be applicable to TAN. The PC 3 and PC 4 rock $\mathrm{DBE}$ can be used for design and seismic evaluation for facilities at rock outcrop surface. Two statistically independent horizontal and one vertical time histories have not been developed from the PC 3 and PC 4 rock $\mathrm{DBE}$ response spectra for TAN. The time histories and DBE spectra at other damping values will be developed at a later date in support of a seismic requalification evaluation. 
Table 15. Spectral accelerations for the PC 3 (2,500 year) and PC 4 (10,000 year) horizontal rock DBE response spectra for $5 \%$ damping at TAN.

\begin{tabular}{|c|c|c|c|}
\hline $\begin{array}{c}\text { Frequency } \\
(\mathrm{Hz})\end{array}$ & $\begin{array}{l}\text { Horizontal Spectral } \\
\text { Acceleration (g) } \\
\text { PC } 3(2,500 \text { Yr }) \\
\end{array}$ & $\begin{array}{c}\text { Frequency } \\
(\mathrm{Hz})\end{array}$ & $\begin{array}{l}\text { Horizontal Spectral } \\
\text { Acceleration (g) } \\
\text { PC } 4(10,000 \mathrm{Yr})^{\mathrm{a}} \\
\end{array}$ \\
\hline 100.00 & 0.160 & 100.00 & 0.269 \\
\hline 90.00 & 0.160 & 90.00 & 0.269 \\
\hline 80.00 & 0.160 & 80.00 & 0.269 \\
\hline 70.00 & 0.160 & 70.00 & 0.269 \\
\hline 60.00 & 0.160 & 60.00 & 0.269 \\
\hline 55.00 & 0.160 & 55.00 & 0.269 \\
\hline 50.00 & 0.160 & 50.00 & 0.269 \\
\hline 45.00 & 0.169 & 45.00 & 0.285 \\
\hline 40.00 & 0.180 & 40.00 & 0.304 \\
\hline 35.00 & 0.194 & 35.00 & 0.327 \\
\hline 33.33 & 0.199 & 33.33 & 0.336 \\
\hline 30.00 & 0.208 & 30.00 & 0.352 \\
\hline 27.50 & 0.215 & 27.50 & 0.366 \\
\hline 25.00 & 0.224 & 25.00 & 0.382 \\
\hline 22.50 & 0.233 & 22.50 & 0.400 \\
\hline 20.00 & 0.245 & 20.00 & 0.422 \\
\hline 17.50 & 0.258 & 17.50 & 0.448 \\
\hline 15.00 & 0.275 & 15.00 & 0.480 \\
\hline 12.50 & 0.296 & 12.50 & 0.521 \\
\hline 10.00 & 0.324 & 10.00 & 0.575 \\
\hline 9.00 & 0.338 & 9.00 & 0.603 \\
\hline 8.00 & 0.355 & 8.00 & 0.603 \\
\hline 7.00 & 0.355 & 7.00 & 0.603 \\
\hline 6.00 & 0.355 & 6.00 & 0.603 \\
\hline 5.50 & 0.355 & 5.50 & 0.603 \\
\hline 5.00 & 0.355 & 5.00 & 0.603 \\
\hline 4.50 & 0.355 & 4.50 & 0.603 \\
\hline 4.00 & 0.355 & 4.00 & 0.603 \\
\hline 3.50 & 0.355 & 3.50 & 0.603 \\
\hline 3.00 & 0.355 & 3.00 & 0.603 \\
\hline
\end{tabular}


Table 15. (continued).

\begin{tabular}{|c|c|c|c|}
\hline $\begin{array}{c}\text { Frequency } \\
(\mathrm{Hz})\end{array}$ & $\begin{array}{l}\text { Horizontal Spectral } \\
\text { Acceleration (g) } \\
\text { PC } 3(2,500 \mathrm{Yr})\end{array}$ & $\begin{array}{c}\text { Frequency } \\
(\mathrm{Hz})\end{array}$ & $\begin{array}{l}\text { Horizontal Spectral } \\
\text { Acceleration }(\mathrm{g}) \\
\text { PC } 4(10,000 \mathrm{Yr})^{\mathrm{a}}\end{array}$ \\
\hline 2.75 & 0.355 & 2.75 & 0.603 \\
\hline 2.50 & 0.355 & 2.50 & 0.603 \\
\hline 2.431 & 0.355 & 2.412 & 0.603 \\
\hline 2.25 & 0.329 & 2.25 & 0.563 \\
\hline 2.00 & 0.292 & 2.00 & 0.500 \\
\hline 1.75 & 0.256 & 1.75 & 0.438 \\
\hline 1.50 & 0.219 & 1.50 & 0.375 \\
\hline 1.25 & 0.183 & 1.25 & 0.313 \\
\hline 1.00 & 0.146 & 1.00 & 0.250 \\
\hline 0.90 & 0.131 & 0.90 & 0.225 \\
\hline 0.80 & 0.117 & 0.80 & 0.200 \\
\hline 0.70 & 0.102 & 0.70 & 0.175 \\
\hline 0.60 & 0.088 & 0.60 & 0.150 \\
\hline 0.55 & 0.080 & 0.55 & 0.138 \\
\hline 0.50 & 0.073 & 0.50 & 0.125 \\
\hline 0.45 & 0.066 & 0.45 & 0.113 \\
\hline 0.40 & 0.058 & 0.408 & 0.102 \\
\hline 0.357 & 0.052 & 0.40 & 0.098 \\
\hline 0.35 & 0.050 & 0.35 & 0.075 \\
\hline 0.30 & 0.037 & 0.30 & 0.055 \\
\hline 0.275 & 0.031 & 0.275 & 0.046 \\
\hline 0.25 & 0.026 & 0.25 & 0.038 \\
\hline 0.225 & 0.021 & 0.225 & 0.031 \\
\hline 0.20 & 0.016 & 0.20 & 0.025 \\
\hline 0.175 & 0.013 & 0.175 & 0.019 \\
\hline 0.15 & 0.009 & 0.15 & 0.014 \\
\hline 0.125 & 0.006 & 0.125 & 0.010 \\
\hline 0.10 & 0.004 & 0.10 & 0.006 \\
\hline
\end{tabular}


Table 16. Spectral accelerations for the PC 3 (2,500 year) and PC 4 (10,000 year) vertical rock DBE 5\% damped response spectra for TAN.

\begin{tabular}{|c|c|c|c|}
\hline $\begin{array}{c}\text { Frequency } \\
(\mathrm{Hz})\end{array}$ & $\begin{array}{l}\text { Vertical Spectral } \\
\text { Acceleration }(\mathrm{g}) \\
\text { PC } 3(2,500 \mathrm{Yr})\end{array}$ & $\begin{array}{c}\text { Frequency } \\
(\mathrm{Hz})\end{array}$ & $\begin{array}{l}\text { Vertical Spectral } \\
\text { Acceleration (g) } \\
\text { PC } 4(10,000 \text { Yr) }\end{array}$ \\
\hline 100.00 & 0.123 & 100.00 & 0.207 \\
\hline 90.00 & 0.123 & 90.00 & 0.207 \\
\hline 80.00 & 0.123 & 80.00 & 0.207 \\
\hline 70.00 & 0.123 & 70.00 & 0.207 \\
\hline 60.00 & 0.123 & 60.00 & 0.207 \\
\hline 55.00 & 0.123 & 55.00 & 0.207 \\
\hline 50.00 & 0.123 & 50.00 & 0.207 \\
\hline 45.00 & 0.136 & 45.00 & 0.229 \\
\hline 40.00 & 0.152 & 40.00 & 0.256 \\
\hline 35.00 & 0.172 & 35.00 & 0.290 \\
\hline 33.33 & 0.180 & 33.33 & 0.304 \\
\hline 30.00 & 0.200 & 30.00 & 0.337 \\
\hline 27.50 & 0.217 & 27.50 & 0.367 \\
\hline 25.00 & 0.239 & 25.00 & 0.403 \\
\hline 22.50 & 0.265 & 22.50 & 0.447 \\
\hline 20.00 & 0.297 & 20.00 & 0.502 \\
\hline 17.50 & 0.297 & 17.50 & 0.502 \\
\hline 15.00 & 0.297 & 15.00 & 0.502 \\
\hline 12.50 & 0.297 & 12.50 & 0.502 \\
\hline 10.00 & 0.297 & 10.00 & 0.502 \\
\hline 9.00 & 0.297 & 9.00 & 0.502 \\
\hline 8.00 & 0.297 & 8.00 & 0.502 \\
\hline 7.00 & 0.297 & 7.00 & 0.502 \\
\hline 6.00 & 0.297 & 6.00 & 0.502 \\
\hline 5.50 & 0.297 & 5.50 & 0.502 \\
\hline 5.00 & 0.297 & 5.00 & 0.502 \\
\hline 4.76 & 0.297 & 4.50 & 0.502 \\
\hline 4.50 & 0.297 & 4.00 & 0.502 \\
\hline 4.00 & 0.297 & 3.50 & 0.502 \\
\hline 3.50 & 0.297 & 3.011 & 0.502 \\
\hline
\end{tabular}


Table 16. (continued).

\begin{tabular}{|c|c|c|c|}
\hline $\begin{array}{c}\text { Frequency } \\
(\mathrm{Hz})\end{array}$ & $\begin{array}{l}\text { Vertical Spectral } \\
\text { Acceleration }(\mathrm{g}) \\
\text { PC } 3(2,500 \mathrm{Yr})\end{array}$ & $\begin{array}{c}\text { Frequency } \\
(\mathrm{Hz})\end{array}$ & $\begin{array}{l}\text { Vertical Spectral } \\
\text { Acceleration (g) } \\
\text { PC } 4(10,000 \text { Yr) }\end{array}$ \\
\hline 3.051 & 0.297 & 3.00 & 0.500 \\
\hline 3.00 & 0.292 & 2.75 & 0.459 \\
\hline 2.75 & 0.268 & 2.50 & 0.417 \\
\hline 2.50 & 0.243 & 2.25 & 0.375 \\
\hline 2.25 & 0.219 & 2.00 & 0.334 \\
\hline 2.00 & 0.195 & 1.75 & 0.292 \\
\hline 1.75 & 0.170 & 1.50 & 0.250 \\
\hline 1.50 & 0.146 & 1.25 & 0.208 \\
\hline 1.25 & 0.122 & 1.00 & 0.167 \\
\hline 1.00 & 0.097 & 0.90 & 0.150 \\
\hline 0.90 & 0.088 & 0.80 & 0.133 \\
\hline 0.80 & 0.078 & 0.70 & 0.117 \\
\hline 0.70 & 0.068 & 0.60 & 0.100 \\
\hline 0.60 & 0.058 & 0.55 & 0.092 \\
\hline 0.55 & 0.054 & 0.50 & 0.083 \\
\hline 0.50 & 0.049 & 0.45 & 0.075 \\
\hline 0.45 & 0.044 & 0.408 & 0.068 \\
\hline 0.40 & 0.039 & 0.40 & 0.065 \\
\hline 0.35 & 0.033 & 0.35 & 0.050 \\
\hline 0.30 & 0.025 & 0.30 & 0.037 \\
\hline 0.275 & 0.021 & 0.275 & 0.031 \\
\hline 0.25 & 0.017 & 0.25 & 0.026 \\
\hline 0.225 & 0.014 & 0.225 & 0.021 \\
\hline 0.20 & 0.011 & 0.20 & 0.016 \\
\hline 0.175 & 0.008 & 0.175 & 0.013 \\
\hline 0.15 & 0.006 & 0.15 & 0.009 \\
\hline 0.125 & 0.004 & 0.125 & 0.006 \\
\hline 0.10 & 0.003 & 0.10 & 0.004 \\
\hline
\end{tabular}




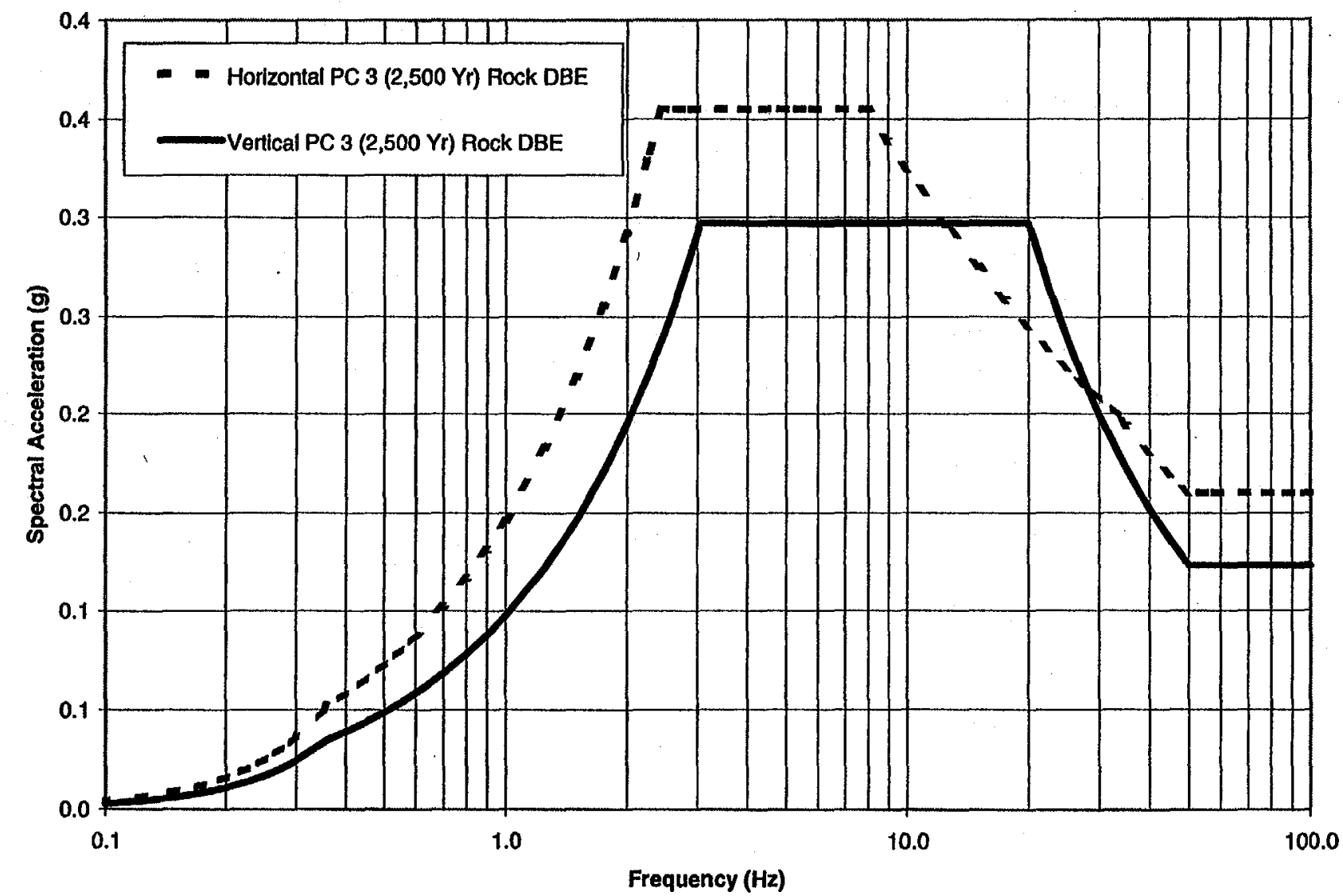

Figure 38. The horizontal and vertical rock DBE $5 \%$ damped response spectra for PC 3 (2,500 years) to be used for seismic design and evaluations at TAN. 


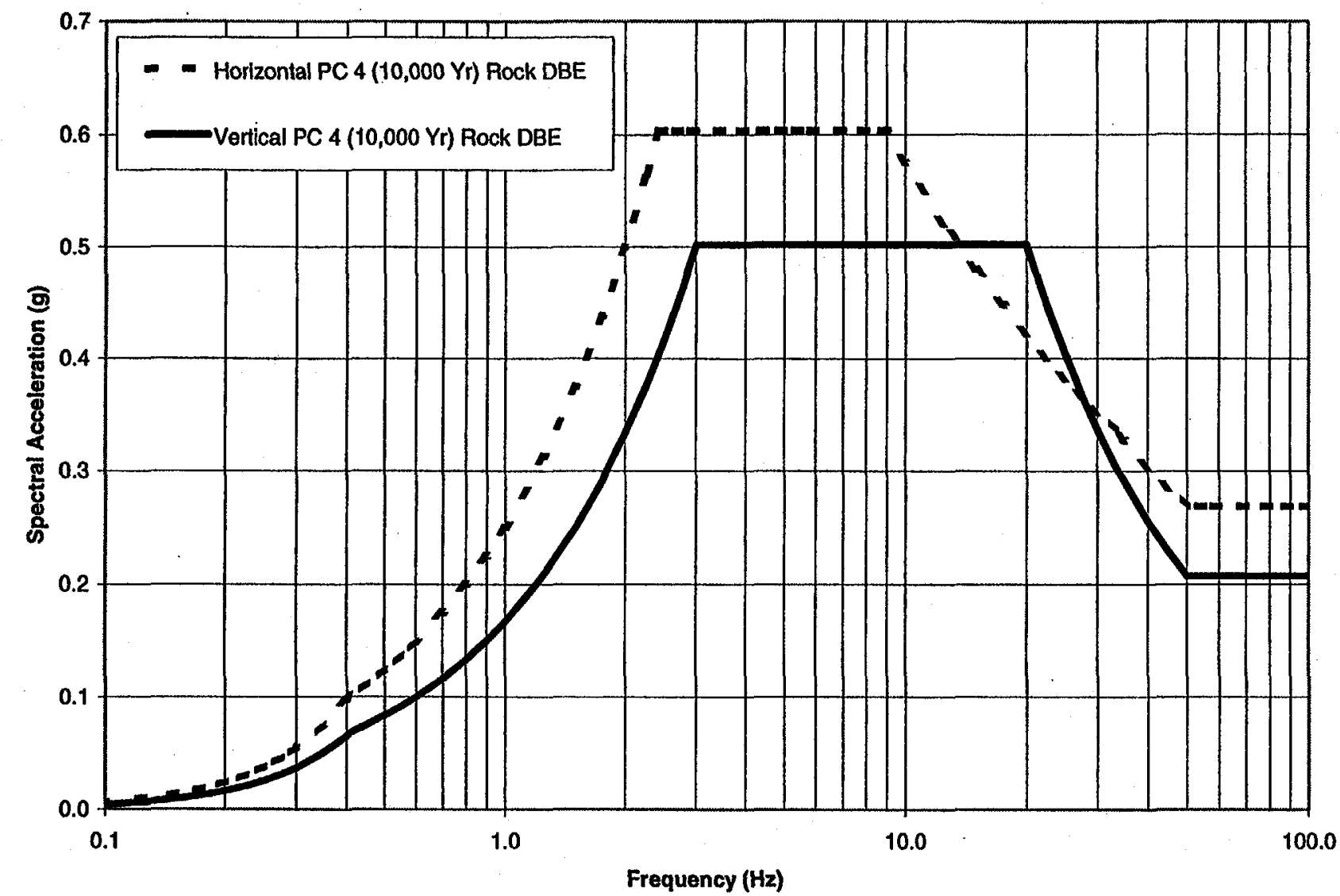

Figure 39. The horizontal and vertical rock DBE $5 \%$ damped response spectra for $\mathrm{PC} 4(10,000$ years) to be used for seismic design and evaluations at TAN. 


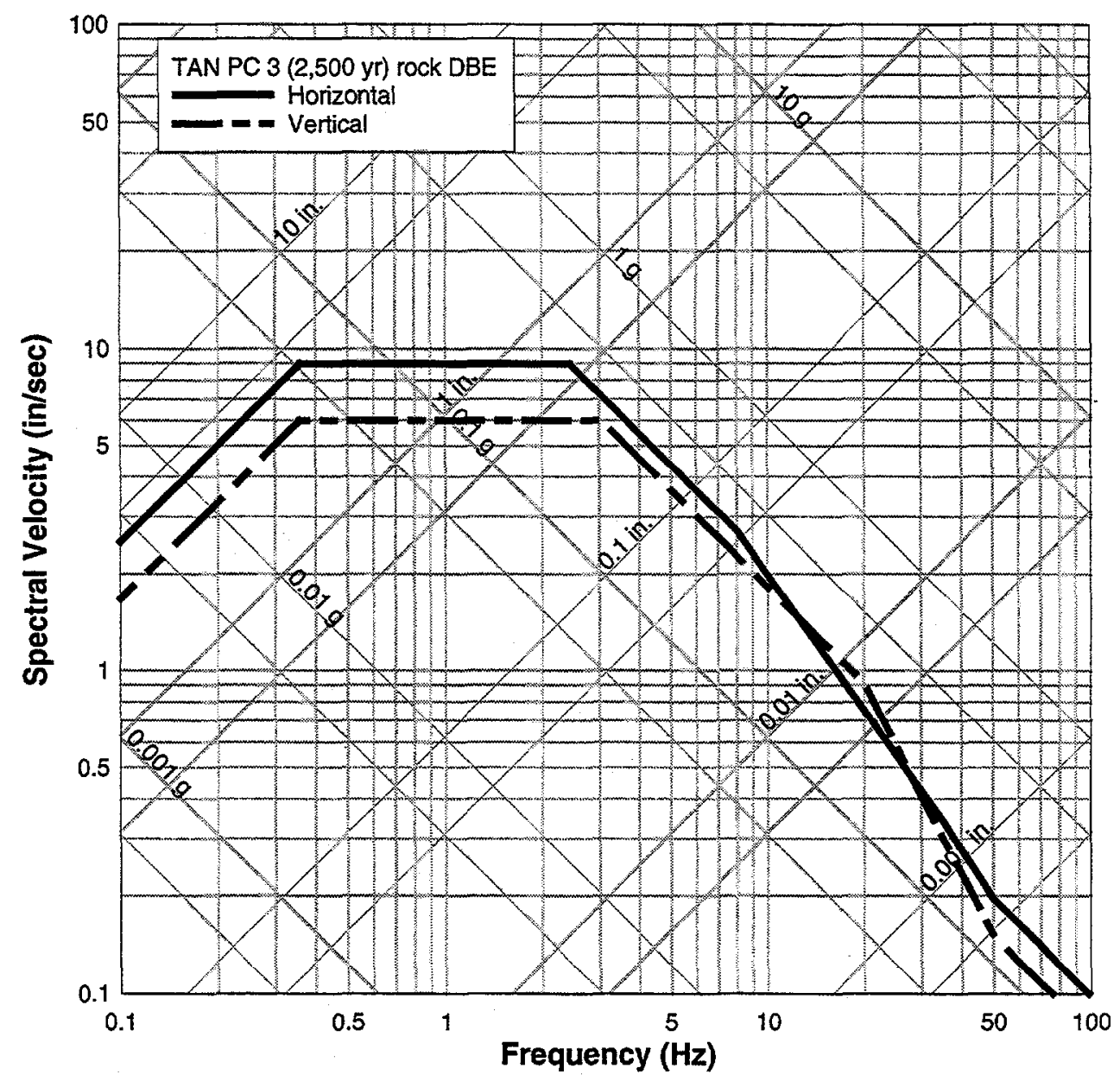

Figure 40. Tripartite graph of the horizontal and vertical PC 3 (2,500 years) rock DBE 5\% damped response spectra to be used for seismic design and evaluations at TAN (see Appendix C, Tables C-9 and C-10 for spectral velocities). 


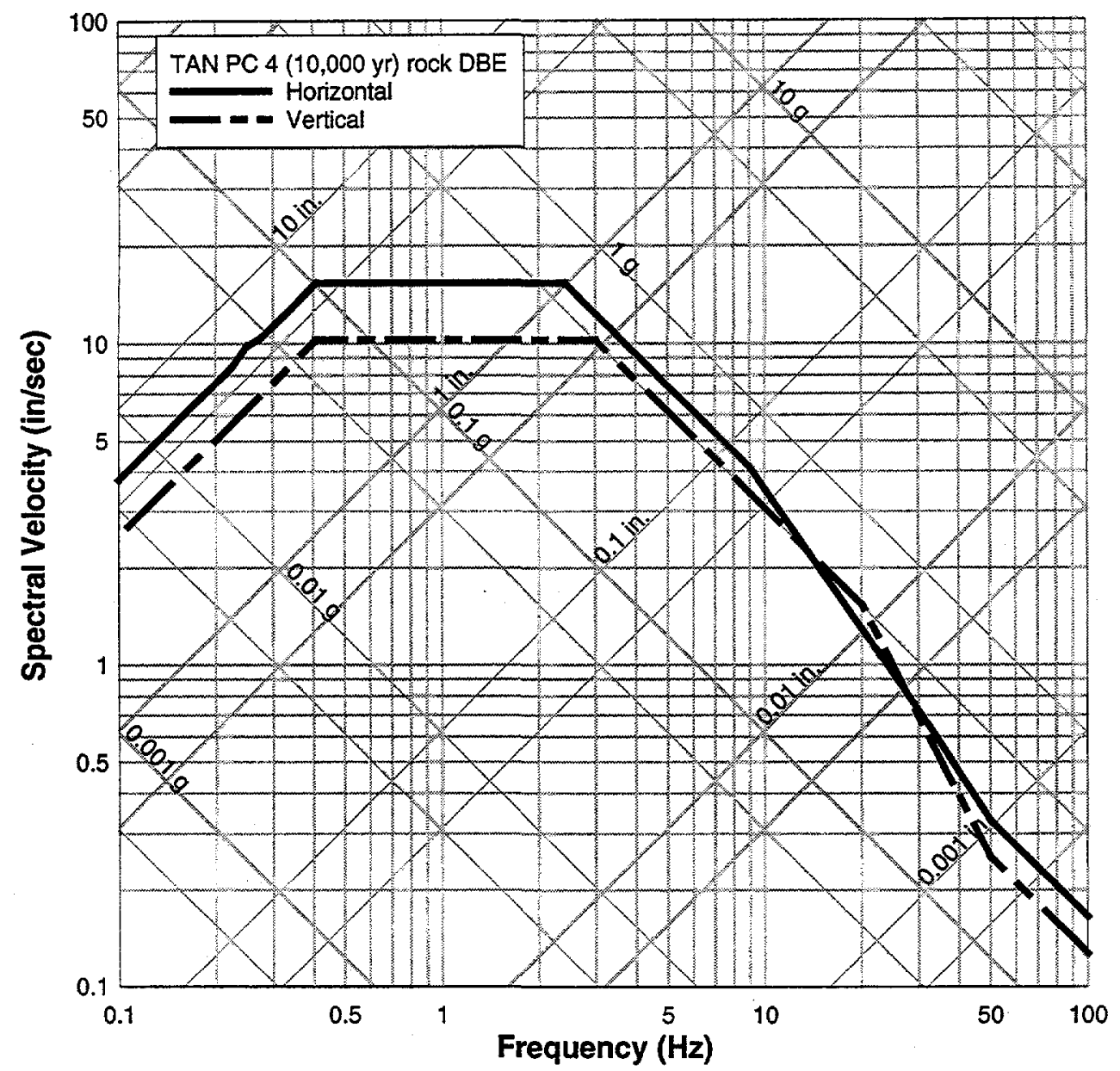

Figure 41. Tripartite graph of the horizontal and vertical PC 4 (10,000 years) rock DBE 5\% damped response spectra to be used for seismic design and evaluations at TAN (see Appendix C, Tables C-9 and C-10 for spectral velocities). 


\subsection{Rock DBE for Input to Soil Response and Soil Structure Interaction Analyses}

The horizontal and vertical PC 3 (2,500 years) rock DBE response spectra (Figure 41) and PC 4 (10,000 years) rock DBE response spectra (Figure 42) can be used in the evaluation to develop time histories for rock surface and bedrock outcrop conditions. As discussed in Section 2.7 only the horizontal components of the PC 3 and PC 4 rock DBE time histories will be applicable for soil response and SSI analyses at TAN. Additional steps need to be taken to use the vertical component in soil response and SSI analyses (see Section 2.7). The soil properties for a soil response and SSI analysis should be consistent with the properties used to develop the DBE response spectra and time histories. Limited information is available for soil properties at TAN (Kaiser Engineering, 1964; Smith et al., 1994), additional information is needed to select appropriate degradation (shear wave modulus and damping reduction) models for soil response or SSI analyses at TAN. 


\section{DESIGN BASIS EARTHQUAKE FOR ROCK CONDITIONS AT NRF}

\subsection{Selection of the Rock UHS for PC 3 and PC 4}

The horizontal mean 5\% damped UHS at 2,000 and 10,000 year return periods developed by URSG-WCFS (2000a) for NRF are used as the basis for development of the rock DBE response spectra and peak accelerations for PC 3 and PC 4. DOE Naval Reactors requested that the DBE be consistent with the current DOE Standards requiring a 2,000-year return period for PC 3.

URSG-WCFS (2000a) recomputed the seismic hazard for NRF to be consistent with the URSGWCFS (1999) evaluation that developed site-specific UHS for the NRC licensing effort of the TMI-2 ISFSI. As part of the licensing effort for the TMI-2 ISFSI, the URSG-WCFS (1999) seismic hazard evaluation (input data, methodologies, and results) was thoroughly reviewed by the NRC and four nationally recognized experts. The INEEL NPHC and DOE approved the results of the TMI-2 ISFSI evaluation (URSG-WCFS, 1999) and the recent evaluation that recomputed the seismic hazard of other INEEL facilities (URSG-WCFS, 2000a) for use in development of DBE parameters for INEEL facility areas.

When URSG-WCFS (2000a) recomputed the seismic hazard for NRF, they used revised attenuation relationships more appropriate for extensional tectonic regimes. URSG-WCFS (2000a) deaggregated the seismic hazard results at the 2,000-year and 10,000-year return period to determine the contributions of all earthquake sources in a selected earthquake magnitude and distance range. The dominant earthquakes at low $(1$ to $2.5 \mathrm{~Hz})$ and intermediate frequencies $(5$ to $10 \mathrm{~Hz})$ were used to supplement the response of the NRF UHS spectral shape. For the 2,000-year UHS, there were only minor increases in ground motions, less than $0.008 \mathrm{~g}$ at $33 \mathrm{~Hz}$. For the 10,000-year UHS, the increases were less than $0.015 \mathrm{~g}$ at $33 \mathrm{~Hz}$. The PGA was increased by $0.013 \mathrm{~g}$. The small increase for the 10,000 -year UHS resulted from enveloping the dominant earthquake contributors at this year return period (URSG-WCFS, 2000a).

The comparison of the NRF UHS computed by WCFS (1996) and the NRF UHS computed by URSG-WCFS (2000a) using the revised attenuation relationships and supplemented for the contributions from the dominant earthquakes for the 2,000- and 10,000-year return periods are shown in Figure 42 (a) and (b). The comparison shows that the revised attenuation relationships for extensional tectonic regimes results in a decrease in the ground motions for all frequencies. Peak spectral accelerations were reduced by as much as $23 \%$ and the PGA by $15 \%$. Observational seismologic evidence indicates that the state of stress in extensional and compressional tectonic regimes affects the amplitude of ground motions from earthquake. Normal faulting earthquakes in extensional regimes have lower motions than strike-slip and thrust faulting earthquakes in compressional regimes. Also, differences occur in wave propagation characteristics between extensional and compressional tectonic regimes (Spudich et al., 1997; 1999). 
(a)

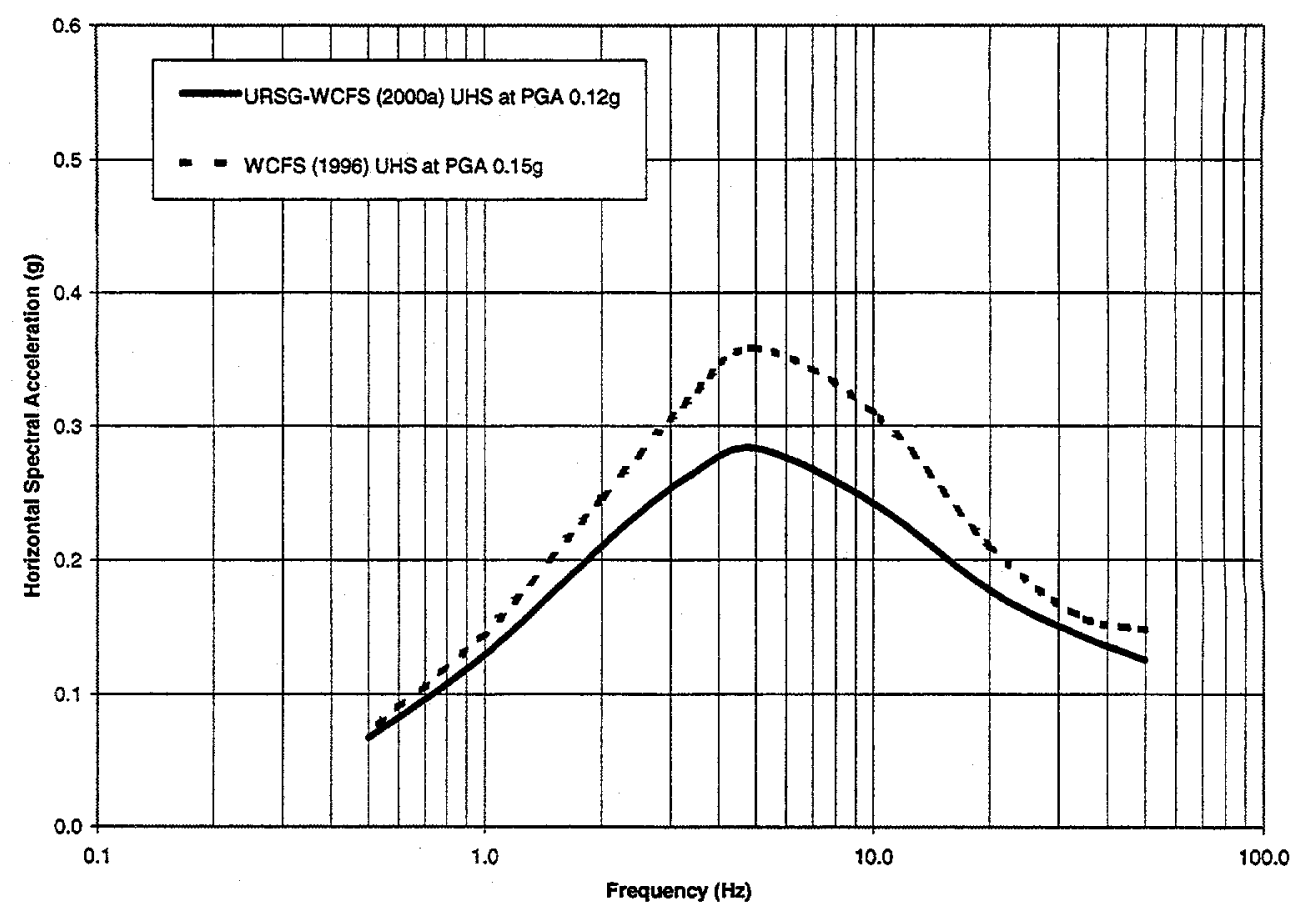

(b)

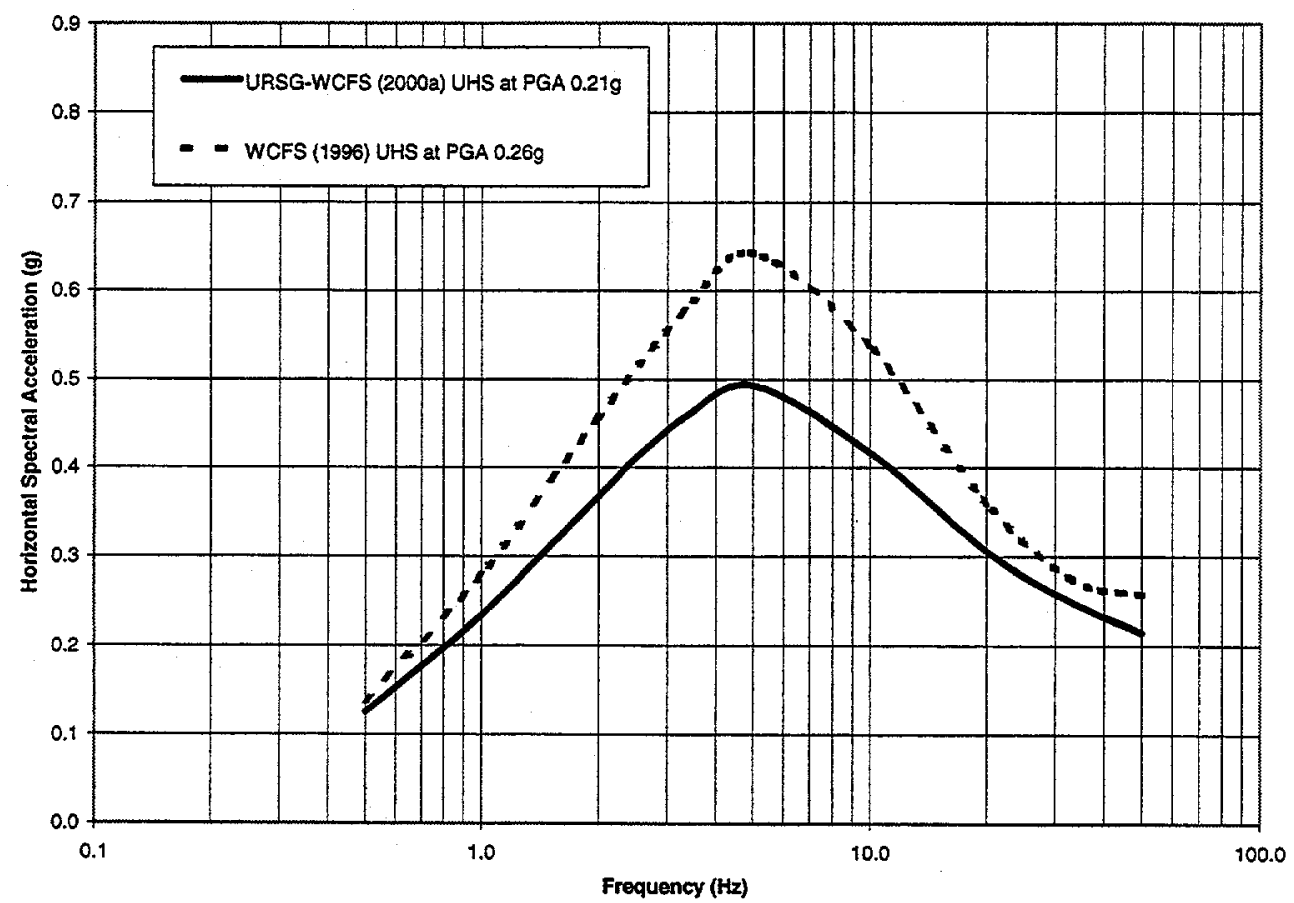

Figure 42. Comparison of the NRF rock 5\% damped UHS computed by WCFS (1996) using contributions from empirical California strong motion attenuation relationships and the NRF rock UHS computed by URSG-WCFS (2000a) using contributions from extensional tectonic attenuation relationships at (a) 2,000 years and (b) 10,000 years. 


\subsection{Development of the PC 3 and PC 4 Horizontal Rock DBE}

The PC 3 (2,000-year) and PC $4(10,000)$ rock DBE 5\% damped response spectra for NRF were developed using the URSG-WCFS (2000a) 2,000-year UHS (Table 17) and 10,000-year UHS (Table 18) for NRF. The rock DBE response spectra for NRF were developed by incorporating smoothed broadened regions of the peak accelerations, velocities, and displacements defined by the site-specific UHS at NRF. Portions of the rock DBE response spectra were adjusted to ensure conservatism for the structural design process. The PC 3 and PC 4 rock DBE response spectra for NRF have similar characteristics to a standard response spectrum of Newmark and Hall (1978), but not as much amplification. Since the rock DBE response spectral shapes were derived from the site-specific UHS, median amplification values from Newmark and Hall (1978) and current work of the Nuclear Regulatory Commission were used to check the adequacy of the DBE response spectra. These median amplification values were not used to develop the rock DBE response spectra. The DBE response spectra have an adequate frequency range to accommodate the possible range of ground motions consistent with the approach developed by Newmark and Hall (1978) (see Appendix A for further discussion).

The PC 3 (2,000 years) rock DBE response spectral shape was developed with the PGA $(0.125 \mathrm{~g})$, an increasing acceleration (by selecting $0.145 \mathrm{~g}$ at $33 \mathrm{~Hz}$ ), peak spectral acceleration $(0.283 \mathrm{~g}$ ), and constant velocity defined by the PC 3 (2,000 years) UHS (Table 17). The peak spectral displacement was selected to be 4 inches or $10.16 \mathrm{~cm}$ (see Appendix A for further discussion). The PC $4(10,000$ year) rock DBE response spectral shape was developed with the PGA $(0.215 \mathrm{~g})$, an increasing acceleration (by selecting $0.249 \mathrm{~g}$ at $33 \mathrm{~Hz})$, peak spectral acceleration $(0.493 \mathrm{~g}$ ), and constant velocity defined by the PC 3 (2,000 years) UHS (Table 18). The peak spectral displacement was selected to be 6 inches or $15.24 \mathrm{~cm}$ (Appendix A). Appendix A shows the envelops of the response spectra to portions of the respective UHS used to develop the PC 3 and PC 4 DBE response spectral shapes for NRF. Figure 43 (a) and (b) show the PC 3 and PC 4 rock DBE 5\% damped response spectra compared to the PC 3 and PC 4 rock UHS at NRF, respectively. The PC 3 and PC 4 rock DBE response spectra envelop the PC 3 and PC 4 rock UHS.

The PC 3 (2,000 years) and PC 4 (10,000 years) rock DBE 5\% damped response spectra are shown in Figure 44 (a) and (b) compared to the modified RG 1.60 response spectra developed and recommended by Paul Rizzo Associates, Inc. (PCRA, 1998) for NRF. In Figure 44 (a) the modified RG 1.60 response spectrum is tied to $0.15 \mathrm{~g}$ and in Figure 44 (b) the modified RG 1.60 response spectrum tied is to $0.24 \mathrm{~g}$ (PCRA, 1998). For both PC 3 and PC 4, the rock DBE response spectra has much lower spectral accelerations than the recommended modified RG 1.60 response spectra. PCRA modified the RG 1.60 response spectra by extending the $9 \mathrm{~Hz}$ corner frequency out to $25 \mathrm{~Hz}$ to conservatively account for the deterministic response spectra produced by (WCC, 1990). 
Table 17. Spectral accelerations for the horizontal PC 3 (2,000 years) 5\% damped rock UHS at NRF.

\begin{tabular}{|c|c|}
\hline $\begin{array}{c}\text { Frequency } \\
(\mathrm{Hz})\end{array}$ & $\begin{array}{c}\text { Horizontal } \\
\text { Spectral Acceleration } \\
(\mathrm{g})\end{array}$ \\
\hline 50.00 & 0.125 \\
\hline 33.33 & 0.145 \\
\hline 20.00 & 0.177 \\
\hline 10.00 & 0.242 \\
\hline 5.00 & 0.283 \\
\hline 3.33 & 0.262 \\
\hline 2.50 & 0.235 \\
\hline 2.00 & 0.210 \\
\hline 1.00 & 0.129 \\
\hline 0.50 & 0.067 \\
\hline
\end{tabular}

a. URSG-WCFS (2000a).

Table 18. Spectral accelerations for the horizontal PC 4 (10,000 years) 5\% damped rock UHS at NRFa

Horizontal

Spectral Acceleration

\begin{tabular}{|c|c|}
\hline $\begin{array}{l}\text { Frequency } \\
(\mathrm{Hz})\end{array}$ & $\begin{array}{c}\text { Spectral Acceleration } \\
(\mathrm{g})\end{array}$ \\
\hline 50.00 & 0.215 \\
\hline 33.33 & 0.249 \\
\hline 20.00 & 0.306 \\
\hline 10.00 & 0.417 \\
\hline 5.00 & 0.493 \\
\hline 3.33 & 0.457 \\
\hline 2.50 & 0.411 \\
\hline 2.00 & 0.367 \\
\hline 1.00 & 0.234 \\
\hline 0.50 & 0.125 \\
\hline
\end{tabular}


(a)

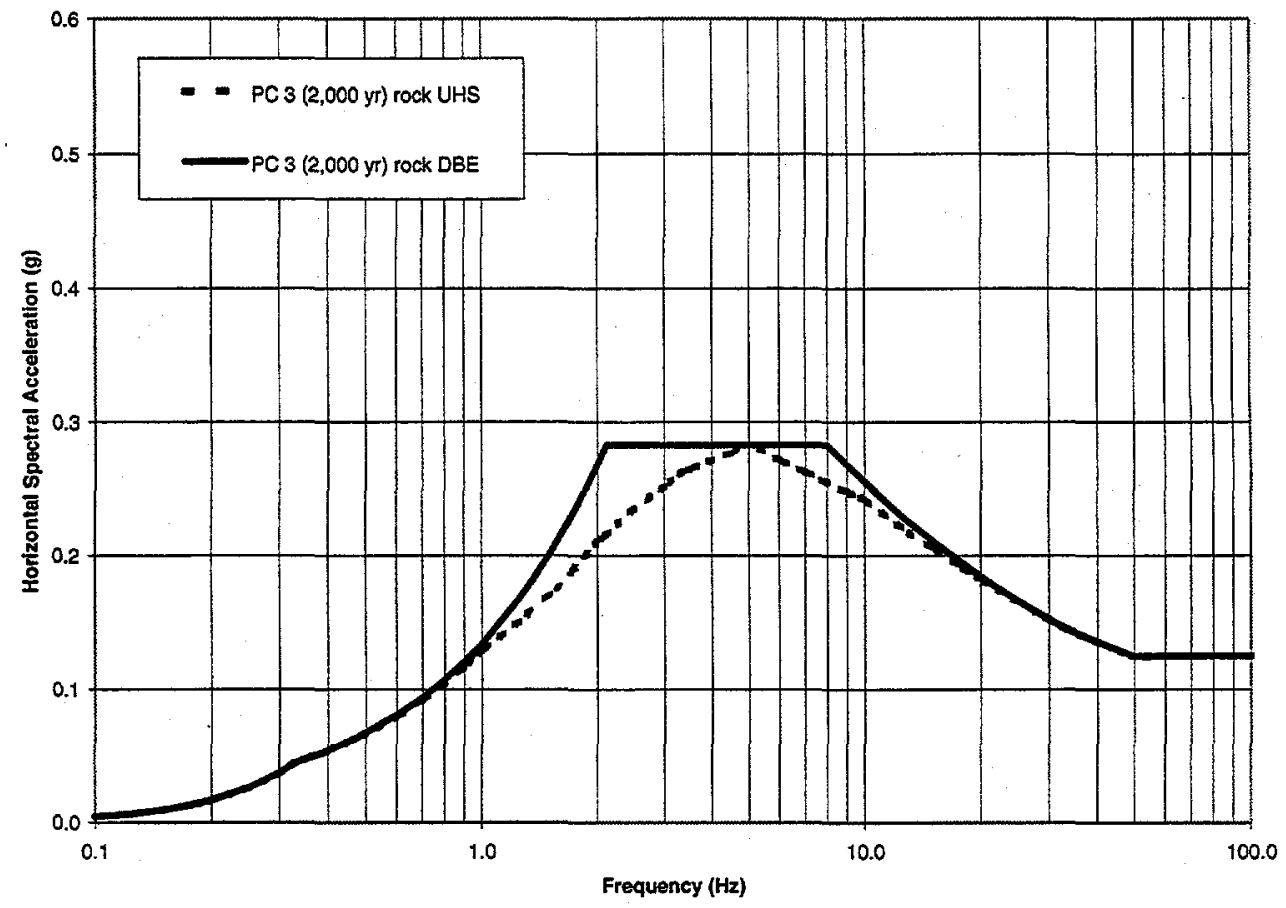

(b)

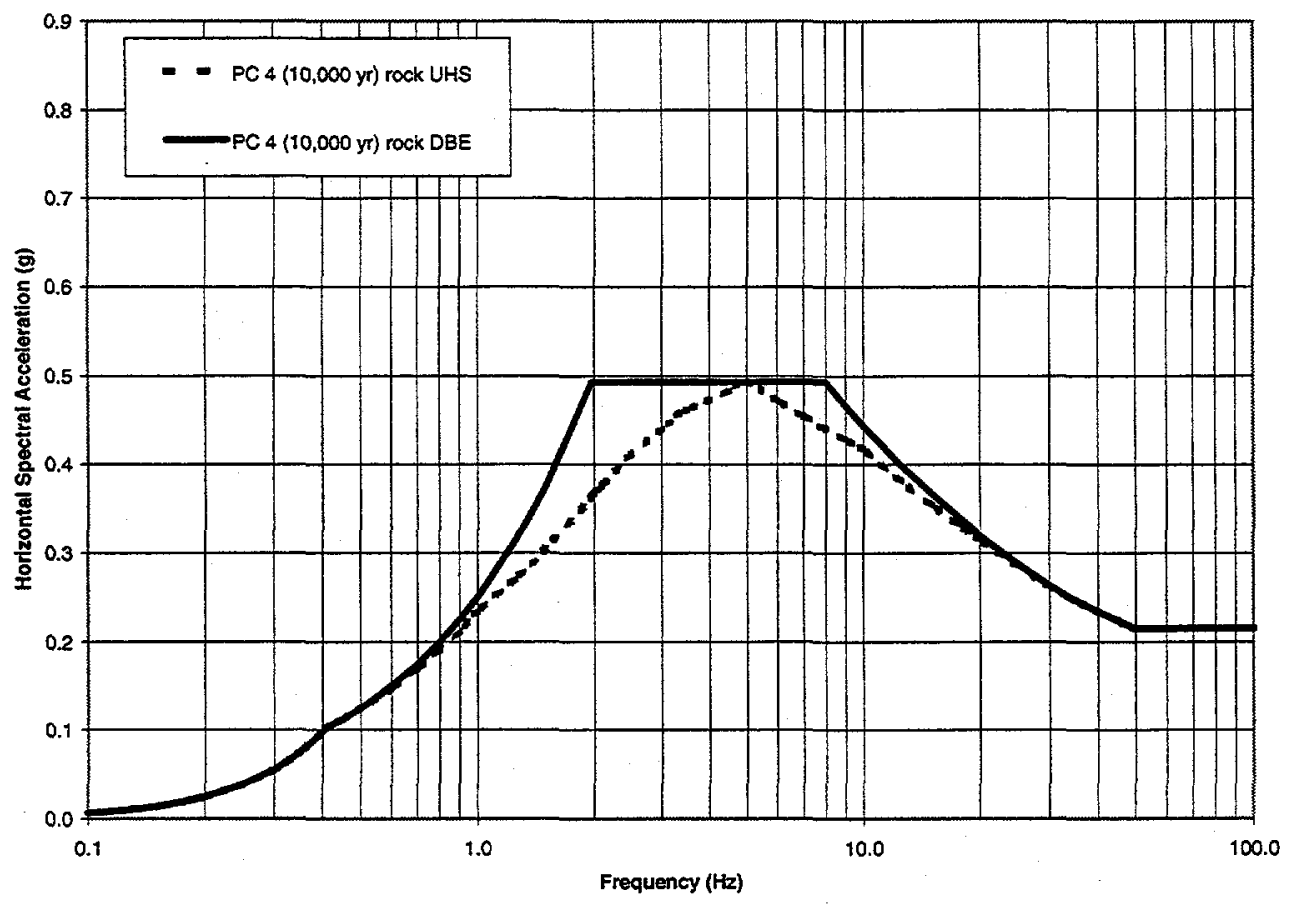

Figure 43. Comparison of the NRF horizontal rock DBE 5\% damped response spectra and the horizontal rock UHS developed by URSG-WCFS (2000a) at (a) PC 3 (2,000 years) and (b) PC 4 (10,000 years). 
(a)

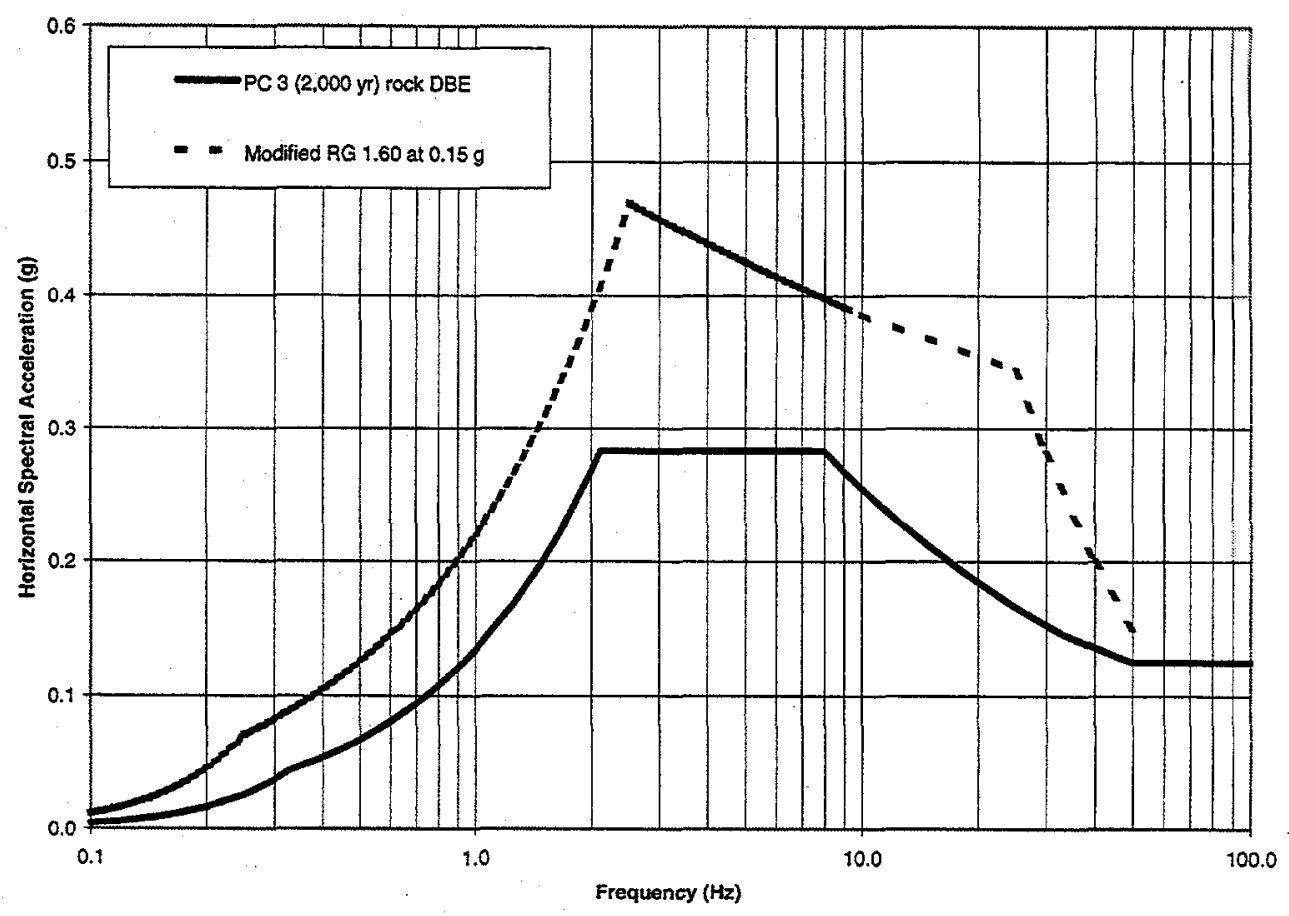

(b)

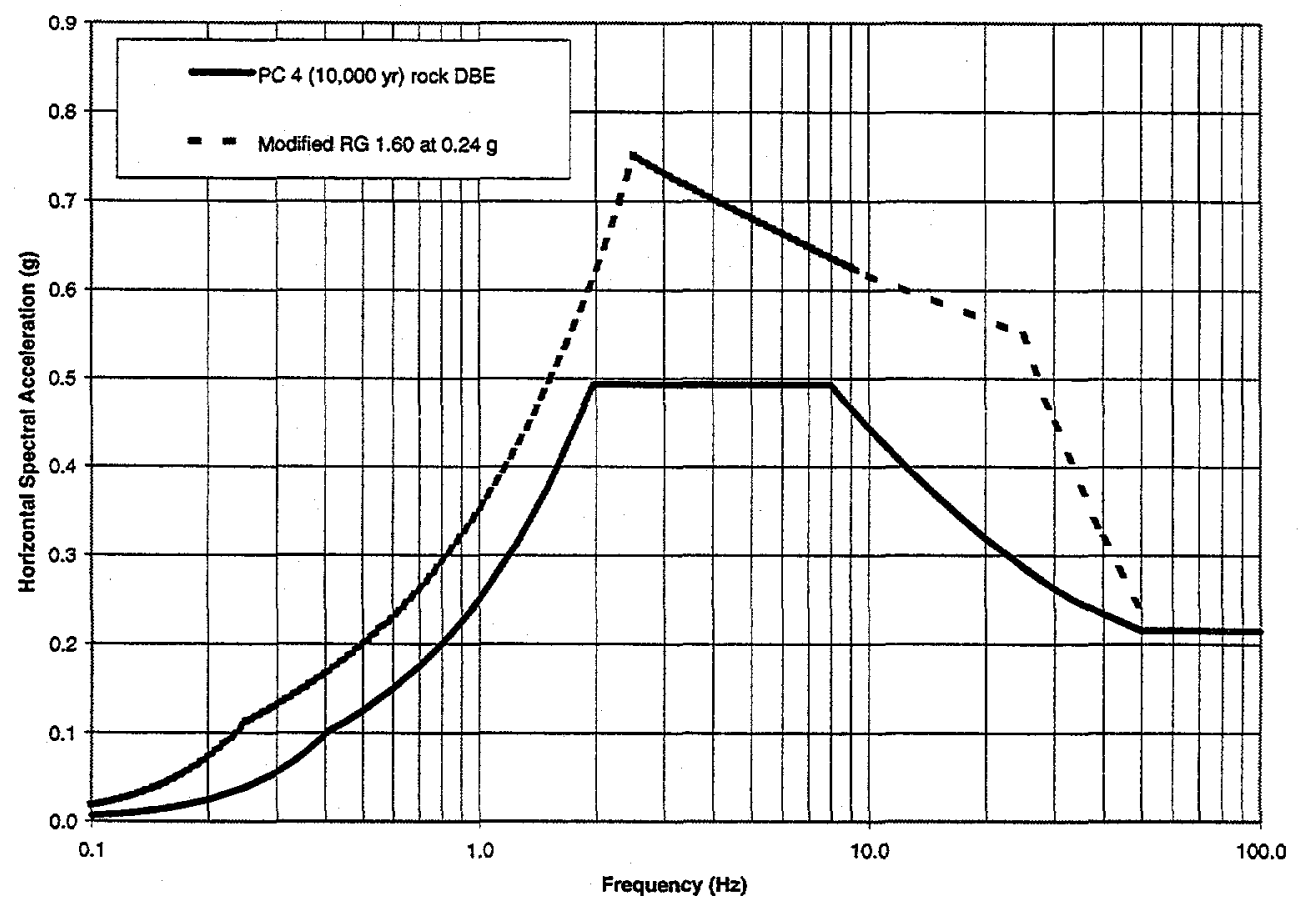

Figure 44. Comparison of the NRF PC 3 (2,000 years) and PC 4 (10,000 years) horizontal rock DBE 5\% damped response spectra with design criteria developed by PCRA (1998) for NRF. 


\subsection{Development of the PC 3 and PC 4 Vertical Rock DBE}

The PC 3 and PC 4 horizontal rock 5\% damped UHS were used to develop the vertical rock DBE response spectra for PC 3 and PC 4 at NRF, respectively. URSG-WCFS (1999) developed a ratio for the vertical to horizontal (V/H) ground motions applicable to INEEL (see Appendix B for discussion of development method). To derive the PC 3 and PC 4 vertical rock DBE response spectra, the horizontal rock UHS spectral accelerations shown in Tables 17 and 18 were multiplied by the $\mathrm{V} / \mathrm{H}$ spectral ratio (Figure 10) to produce vertical UHS. The constant acceleration, velocity, and displacement portions of the vertical DBE response spectra were determined by enveloping the vertical UHS. The envelopes of the vertical response spectra for the PC 3 and PC 4 vertical rock DBE response spectra are shown in Appendix A.

A comparison between the PC 3 and PC 4 vertical rock DBE response spectra and the vertical design spectra as recommended by PCRA (1998) are shown in Figure 45 (a) and (b). The PCRA (1998) recommended DBE are shown as two-thirds of the horizontal modified RG 1.60 response spectra. In Figure 45 (a), the modified RG 1.60 vertical response spectrum is tied to $0.10 \mathrm{~g}$. In Figure 45 (b), the RG 1.60 vertical response spectrum is tied to $0.16 \mathrm{~g}$. The modified RG 1.60 vertical response spectra exceed the PC 3 and PC 4 vertical rock DBE response spectra developed in this report. 
(a)

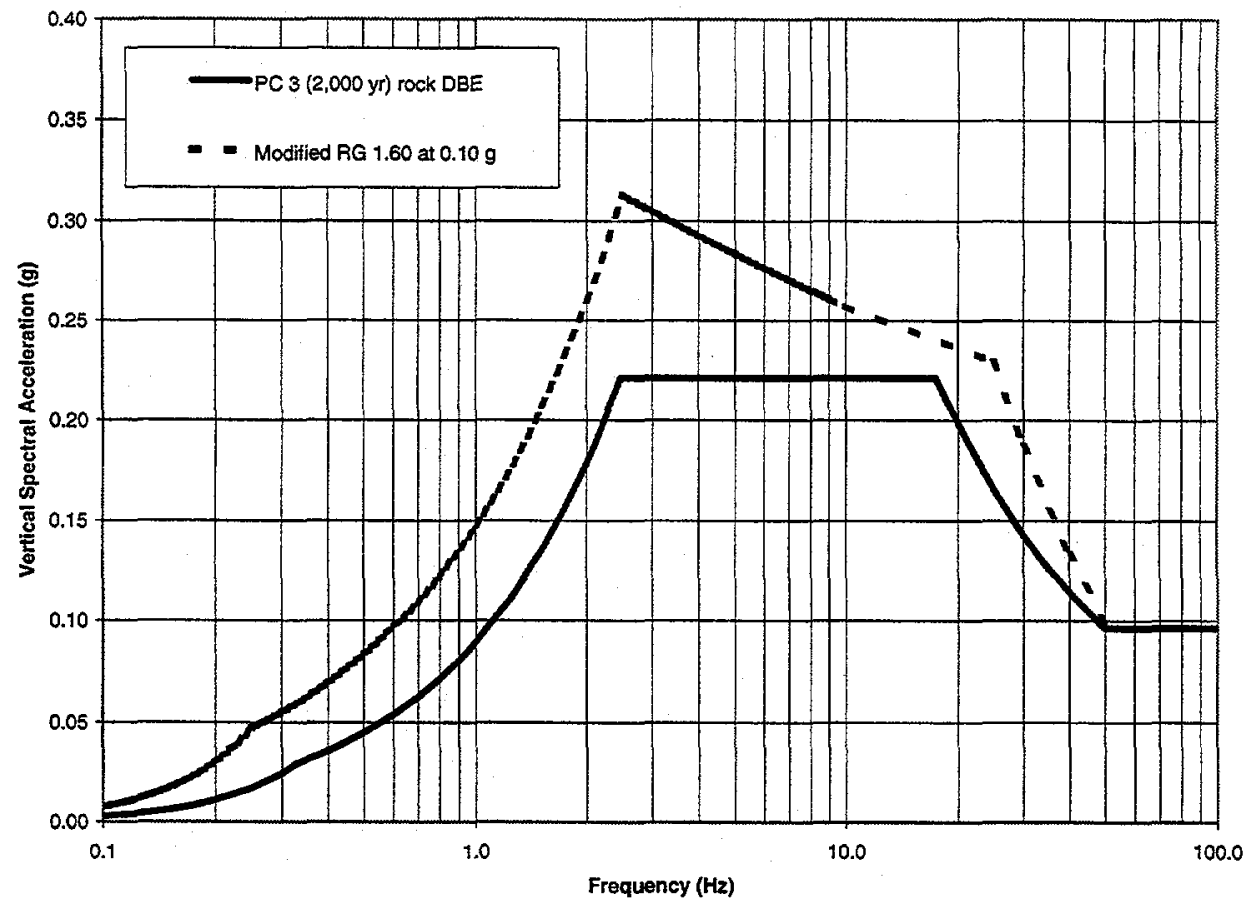

(b)

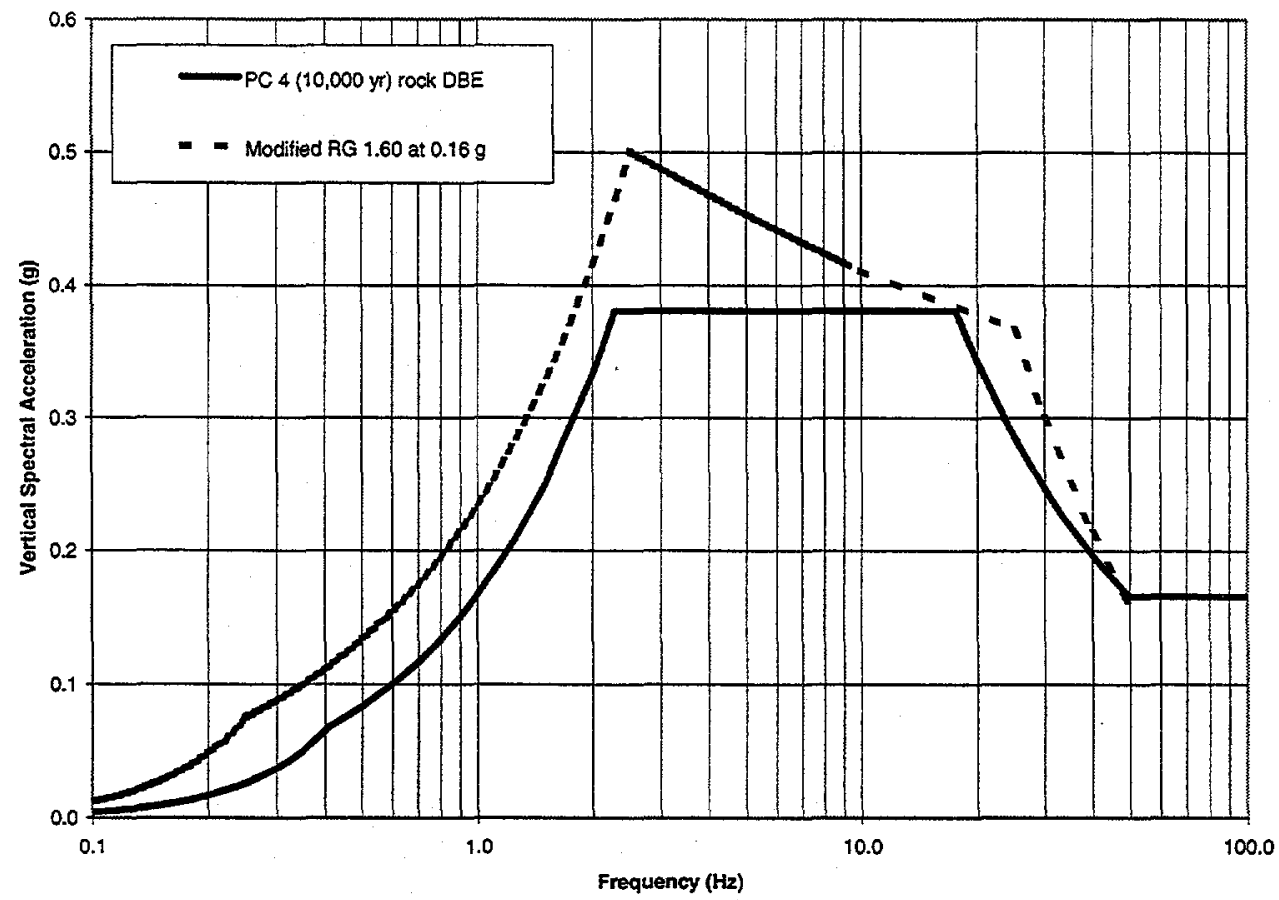

Figure 45. Comparison of the NRF PC 3 (2,000 years) and PC 4 (10,000 years) vertical rock DBE 5\% damped response spectra with vertical design criteria developed by PCRA (1998) for NRF. 


\subsection{Use of the PC 3 and PC 4 Rock DBE}

The PC 3 and PC 4 rock horizontal and vertical DBE 5\% damped response shown in Figures 46 and 47 are recommended for use at NRF for seismic design and evaluations at rock outcrop surface conditions. The PC 3 and PC 4 vertical rock DBE response spectra slightly exceed the horizontal rock $\mathrm{DBE}$ response spectra from 12.5 to $25 \mathrm{~Hz}$ because of the higher spectral ratios over this frequency range where the $\mathrm{V} / \mathrm{H}$ ratio exceeds 1.00 . The $\mathrm{DBE}$ horizontal and vertical spectral accelerations for 5\% damping are listed in Tables 19 and 20. The PC 3 and PC 4 DBE are also plotted on tripartite graphs in Figures 48 and 49.

The horizontal and vertical PC 3 (2,000 years) rock DBE response spectra (Figure 48) and PC 4 (10,000 years) rock DBE response spectra (Figure 49) are also recommended for use in development of time histories for input to soil response and SSI. It is recommended that the time histories be developed consistent with the top of the subsurface geologic (or Vs) profile used by URSG-WCFS (2000a) to develop the PC 3 and PC 4 rock UHS. The motion at the top of the rock without the soil present is referred to as bedrock outcrop. The bedrock outcrop time histories should be adjusted for the higher seismic velocities found in rock at the base of the soil at NRF with consideration of the Vs profile used by URSG-WCFS (2000a). This Vs profile is documented in WCFS (1996) in Appendix E "Site-specific Geologic Profiles." Because a site-specific V/H ratio has been developed for INEEL (Figure 10), it is recommended that the vertical soil response be determined by multiplying the horizontal soil response by the $\mathrm{V} / \mathrm{H}$ ratio and not propagating vertical waves through the soil column. Section 2.7 suggests steps to develop a vertical soil response. 
Table 19. Spectral accelerations for the PC $3(2,000$ year) and PC $4(10,000)$ horizontal rock DBE 5\% damped response spectra for NRF.

\begin{tabular}{|c|c|c|c|}
\hline $\begin{array}{l}\text { Frequency } \\
(\mathrm{Hz})\end{array}$ & $\begin{array}{l}\text { Horizontal Spectral } \\
\text { Acceleration }(\mathrm{g}) \\
\text { PC } 3(2,000 \mathrm{Yr}) \\
\end{array}$ & $\begin{array}{c}\text { Frequency } \\
(\mathrm{Hz})\end{array}$ & $\begin{array}{l}\text { Horizontal Spectral } \\
\text { Acceleration (g) } \\
\text { PC } 4(10,000 \mathrm{Yr})\end{array}$ \\
\hline 100.00 & 0.125 & 100.00 & 0.215 \\
\hline 90.00 & 0.125 & 90.00 & 0.215 \\
\hline 80.00 & 0.125 & 80.00 & 0.215 \\
\hline 70.00 & 0.125 & 70.00 & 0.215 \\
\hline 60.00 & 0.125 & 60.00 & 0.218 \\
\hline 50.00 & 0.125 & 50.00 & 0.215 \\
\hline 45.00 & 0.130 & 45.00 & 0.224 \\
\hline 40.00 & 0.136 & 40.00 & 0.234 \\
\hline 35.00 & 0.143 & 35.00 & 0.246 \\
\hline 33.33 & 0.146 & 33.33 & 0.252 \\
\hline 30.00 & 0.152 & 30.00 & 0.263 \\
\hline 25.00 & 0.166 & 25.00 & 0.287 \\
\hline 20.00 & 0.184 & 20.00 & 0.319 \\
\hline 17.50 & 0.196 & 17.50 & 0.340 \\
\hline 15.00 & 0.211 & 15.00 & 0.366 \\
\hline 12.50 & 0.229 & 12.50 & 0.399 \\
\hline 10.00 & 0.254 & 10.00 & 0.443 \\
\hline 9.00 & 0.268 & 9.00 & 0.466 \\
\hline 8.00 & 0.283 & 8.00 & 0.493 \\
\hline 7.00 & 0.283 & 7.00 & 0.493 \\
\hline 6.00 & 0.283 & 6.00 & 0.493 \\
\hline 5.00 & 0.283 & 5.00 & 0.493 \\
\hline 4.50 & 0.283 & 4.50 & 0.493 \\
\hline 4.00 & 0.283 & 4.00 & 0.493 \\
\hline 3.50 & 0.283 & 3.50 & 0.493 \\
\hline 3.33 & 0.283 & 3.33 & 0.493 \\
\hline 3.00 & 0.283 & 3.00 & 0.493 \\
\hline 2.50 & 0.283 & 2.50 & 0.493 \\
\hline 2.11 & 0.283 & 2.11 & 0.493 \\
\hline 2.05 & 0.275 & 2.05 & 0.493 \\
\hline
\end{tabular}


Table 15. (continued).

\begin{tabular}{|c|c|c|c|}
\hline $\begin{array}{c}\text { Frequency } \\
(\mathrm{Hz})\end{array}$ & $\begin{array}{c}\text { Horizontal Spectral } \\
\text { Acceleration (g) } \\
\text { PC } 3(2,000 \text { Yr) } \\
\end{array}$ & $\begin{array}{c}\text { Frequency } \\
(\mathrm{Hz})\end{array}$ & $\begin{array}{c}\text { Horizontal Spectral } \\
\text { Acceleration }(\mathrm{g}) \\
\text { PC } 4(10,000 \mathrm{Yr})\end{array}$ \\
\hline 2.00 & 0.268 & 2.00 & 0.493 \\
\hline 1.75 & 0.234 & 1.97 & 0.493 \\
\hline 1.50 & 0.201 & 1.50 & 0.375 \\
\hline 1.25 & 0.167 & 1.25 & 0.312 \\
\hline 1.00 & 0.134 & 1.00 & 0.250 \\
\hline 0.90 & 0.121 & 0.90 & 0.225 \\
\hline 0.80 & 0.107 & 0.80 & 0.200 \\
\hline 0.70 & 0.093 & 0.70 & 0.175 \\
\hline 0.60 & 0.080 & 0.60 & 0.150 \\
\hline 0.50 & 0.067 & 0.50 & 0.125 \\
\hline 0.45 & 0.060 & 0.45 & 0.112 \\
\hline 0.40 & 0.053 & 0.407 & 0.101 \\
\hline 0.39 & 0.052 & 0.39 & 0.094 \\
\hline 0.35 & 0.047 & 0.35 & 0.075 \\
\hline 0.327 & 0.043 & 0.327 & 0.066 \\
\hline 0.30 & 0.037 & 0.30 & 0.055 \\
\hline 0.25 & 0.025 & 0.25 & 0.038 \\
\hline 0.20 & 0.016 & 0.20 & 0.024 \\
\hline 0.175 & 0.012 & 0.175 & 0.018 \\
\hline 0.15 & 0.009 & 0.15 & 0.014 \\
\hline 0.125 & 0.006 & 0.125 & 0.009 \\
\hline 0.10 & 0.004 & 0.10 & 0.006 \\
\hline
\end{tabular}


Table 20. Spectral accelerations for the PC 3 (2,000 year) and PC $4(10,000)$ vertical rock DBE 5\% damped response spectra for NRF

\begin{tabular}{|c|c|c|c|}
\hline $\begin{array}{c}\text { Frequency } \\
(\mathrm{Hz})\end{array}$ & $\begin{array}{l}\text { Vertical Spectral } \\
\text { Acceleration (g) } \\
\text { PC } 3(2,000 \mathrm{Yr}) \\
\end{array}$ & $\begin{array}{c}\text { Frequency } \\
(\mathrm{Hz})\end{array}$ & $\begin{array}{l}\text { Vertical Spectral } \\
\text { Acceleration }(\mathrm{g}) \\
\text { PC } 4(10,000 \mathrm{Yr})\end{array}$ \\
\hline 100.00 & 0.096 & 100.00 & 0.165 \\
\hline 90.00 & 0.096 & 90.00 & 0.165 \\
\hline 80.00 & 0.096 & 80.00 & 0.165 \\
\hline 70.00 & 0.096 & 70.00 & 0.165 \\
\hline 60.00 & 0.096 & 60.00 & 0.165 \\
\hline 50.00 & 0.096 & 50.00 & 0.165 \\
\hline 45.00 & 0.104 & 45.00 & 0.179 \\
\hline 40.00 & 0.114 & 40.00 & 0.196 \\
\hline 35.00 & 0.126 & 35.00 & 0.218 \\
\hline 33.33 & 0.132 & 33.33 & 0.228 \\
\hline 30.00 & 0.143 & 30.00 & 0.246 \\
\hline 25.00 & 0.165 & 25.00 & 0.285 \\
\hline 20.00 & 0.198 & 20.00 & 0.342 \\
\hline 17.50 & 0.221 & 17.50 & 0.381 \\
\hline 15.00 & 0.221 & 15.00 & 0.381 \\
\hline 12.50 & 0.221 & 12.50 & 0.381 \\
\hline 10.00 & 0.221 & 10.00 & 0.381 \\
\hline 9.00 & 0.221 & 9.00 & 0.381 \\
\hline 8.00 & 0.221 & 8.00 & 0.381 \\
\hline 7.00 & 0.221 & 7.00 & 0.381 \\
\hline 6.00 & 0.221 & 6.00 & 0.381 \\
\hline 5.00 & 0.221 & 5.00 & 0.381 \\
\hline 4.50 & 0.221 & 4.50 & 0.381 \\
\hline 4.00 & 0.221 & 4.00 & 0.381 \\
\hline 3.50 & 0.221 & 3.50 & 0.381 \\
\hline 3.33 & 0.221 & 3.33 & 0.381 \\
\hline 3.00 & 0.221 & 3.00 & 0.381 \\
\hline 2.50 & 0.221 & 2.50 & 0.381 \\
\hline 2.47 & 0.221 & 2.28 & 0.381 \\
\hline 2.11 & 0.189 & 2.11 & 0.352 \\
\hline
\end{tabular}


Table 16. (continued).

\begin{tabular}{|c|c|c|c|}
\hline $\begin{array}{l}\text { Frequency } \\
(\mathrm{Hz})\end{array}$ & $\begin{array}{l}\text { Vertical Spectral } \\
\text { Acceleration (g) } \\
\text { PC } 3(2,000 \text { Yr) }\end{array}$ & $\begin{array}{c}\text { Frequency } \\
(\mathrm{Hz})\end{array}$ & $\begin{array}{l}\text { Vertical Spectral } \\
\text { Acceleration (g) } \\
\text { PC } 4(10,000 \text { Yr) }\end{array}$ \\
\hline 2.05 & 0.183 & 2.05 & 0.342 \\
\hline 2.00 & 0.178 & 2.00 & 0.333 \\
\hline 1.75 & 0.156 & 1.97 & 0.329 \\
\hline 1.50 & 0.134 & 1.50 & 0.250 \\
\hline 1.25 & 0.112 & 1.25 & 0.208 \\
\hline 1.00 & 0.084 & 1.00 & 0.167 \\
\hline 0.90 & 0.080 & 0.90 & 0.150 \\
\hline 0.80 & 0.071 & 0.80 & 0.133 \\
\hline 0.70 & 0.062 & 0.70 & 0.117 \\
\hline 0.60 & 0.053 & 0.60 & 0.100 \\
\hline 0.50 & 0.044 & 0.50 & 0.083 \\
\hline 0.45 & 0.040 & 0.45 & 0.075 \\
\hline 0.40 & 0.036 & 0.407 & 0.068 \\
\hline 0.39 & 0.035 & 0.39 & 0.062 \\
\hline 0.35 & 0.031 & 0.35 & 0.050 \\
\hline 0.327 & 0.029 & 0.327 & 0.044 \\
\hline 0.30 & 0.024 & 0.30 & 0.037 \\
\hline 0.25 & 0.017 & 0.25 & 0.025 \\
\hline 0.20 & 0.011 & 0.20 & 0.016 \\
\hline 0.175 & 0.008 & 0.175 & 0.012 \\
\hline 0.15 & 0.006 & 0.15 & 0.009 \\
\hline 0.125 & 0.004 & 0.125 & 0.006 \\
\hline 0.10 & 0.003 & 0.10 & 0.004 \\
\hline
\end{tabular}


Table 21. Peak Accelerations for NRF

Recommended DBE Peak Acceleration ${ }^{\mathrm{a}}$

(g)

2,000 Year Return $\quad 10,000$ Year Return Period

Component

Horizontal

Vertical

0.12

0.09

a. This report.
PCRA (1998) Peak Acceleration (g)

\section{2,000 Year Return $\quad 10,000$ Year Return} Period Period

$\begin{array}{lll}0.21 & 0.15 & 0.24 \\ 0.16 & 0.10 & 0.16\end{array}$




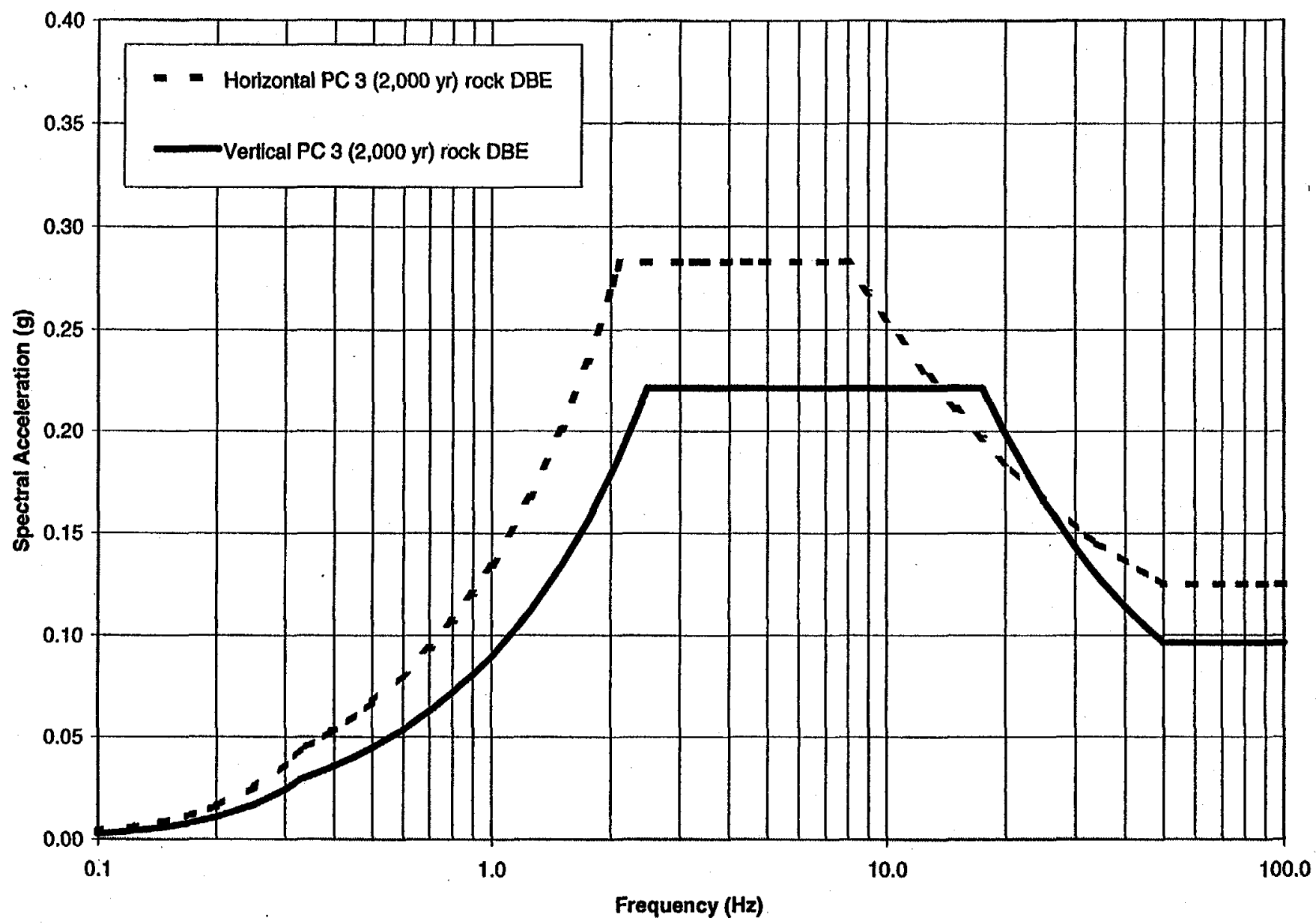

Figure 46. The recommended PC 3 (2,000 years) horizontal and vertical rock DBE 5\% damped response spectra to be used for seismic design and evaluations at NRF. 


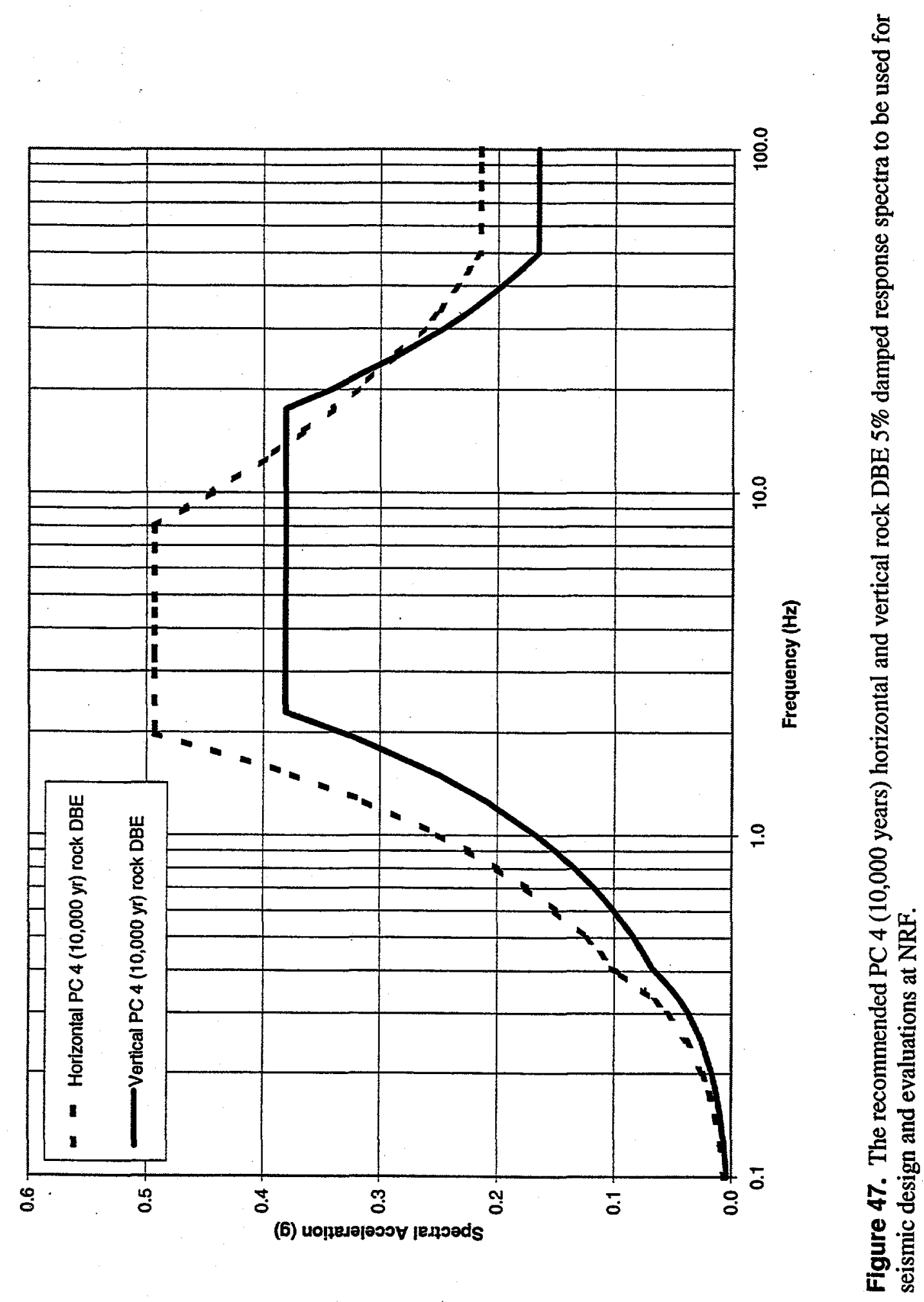




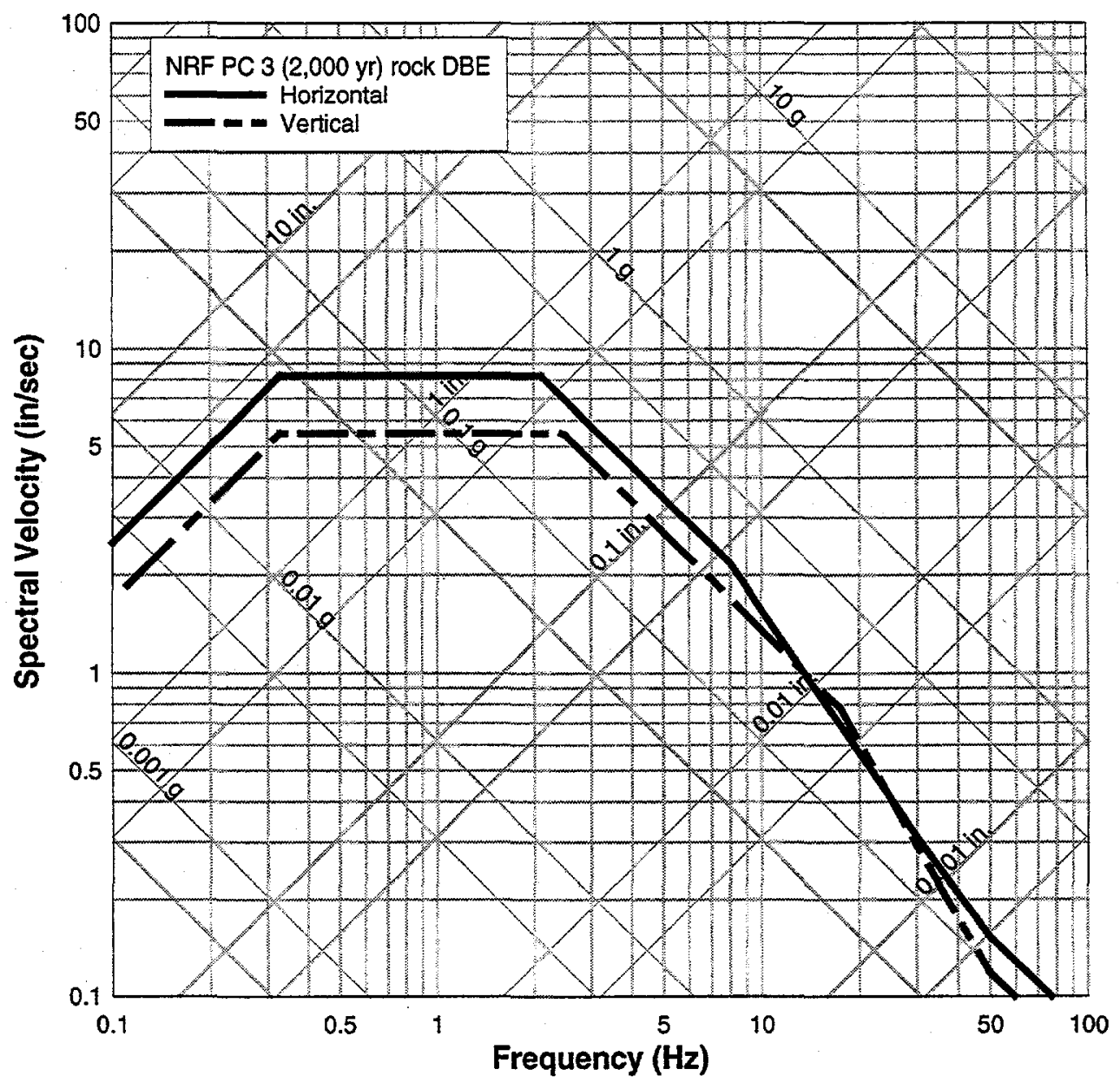

Figure 48. Tripartite graph of the horizontal and vertical PC 3 (2,000 years) rock DBE 5\% damped response spectra for NRF (see Appendix C, Tables C-11 and C-12 for spectral velocities). 


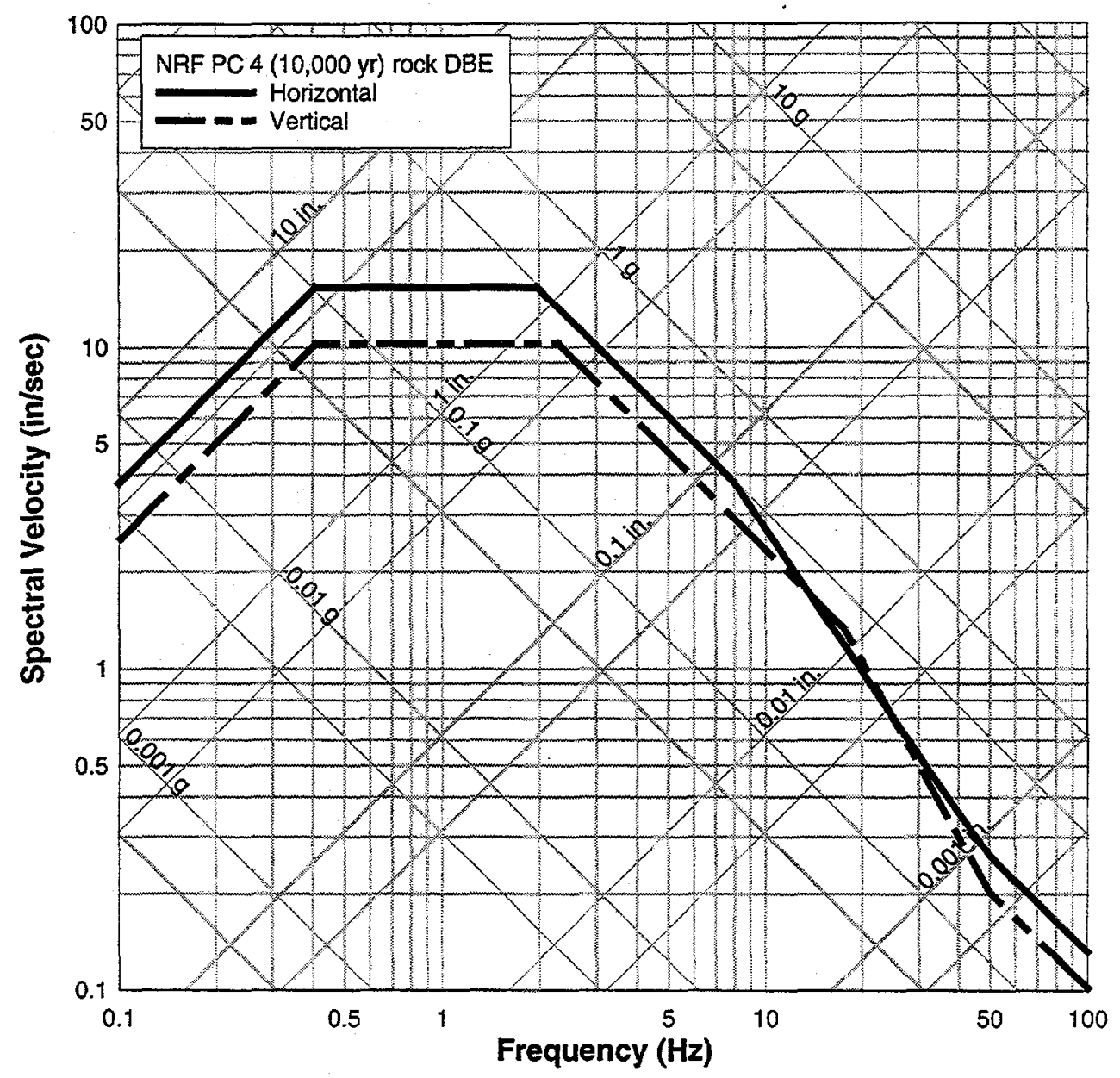

Figure 49. Tripartite graph of the horizontal and vertical PC 4 (10,000 years) rock DBE 5\% damped response spectra for NRF (see Appendix C, Tables C-11 and C-12 for spectral velocities). 


\section{REFERENCES}

Abrahamson, N. A. and W. J. Silva (1999), Empirical response spectral attenuation relations for shallow crustal earthquakes, Seismological Research Letters, v. 68, p. 94-127.

ASCE (1986), Seismic Analysis of Safety-Related Nuclear Structures and Commentary, American Society of Civil Engineers Standard 4.

ASCE (1998), Seismic Analysis of Safety-Related Nuclear Structures and Commentary, American Society of Civil Engineers Standard 4, draft.

ASME (1997), Quality Assurance Requirements for Nuclear Facility Applications, The American Society of Mechanical Engineers, ASME NQA-1-1997.

DOE (1994), Natural Phenomena Hazards Design and Evaluation Criteria for Department of Energy Facilities, U.S. Department of Energy, DOE Standard, DOE-STD-1020-94.

DOE (1995), Natural Phenomena Hazards Assessment Criteria, U.S. Department of Energy, DOE Standard, DOE-STD-1023-95.

DOE-ID (1998), DOE-ID Architectural Engineering Standards, U.S. Department of Energy Idaho Operations Office, Idaho Falls, Idaho, Issue Number 25, December.

EPRI (1993), Guidelines for determining design basis ground motions, Volume 1: Method and guidelines for estimating earthquake ground motion in eastern North America, prepared by Electric Power Research Institute, EPRI TR-102293, Project 3302, November.

GEOVision Geophysical Services (1997), Downhole Seismic Logging at the TMI-2 Independent Spent Fuel Storage Installation at the Idaho Chemical Processing Plant, INEL, GEOVision Geophysical Services, Division of Agbabian Associates, Corona California, Report number 98-210-01.

Kaiser Engineering (1964), Engineering report on soils investigation for Loss of Fluid Test Facility, prepared for U.S. Atomic Energy Commission, Idaho Operations Office, Idaho, Report No. 64-35$\mathrm{R}, 20 \mathrm{p}$.

Newmark, N.M. and W.J. Hall (1978), Development of Criteria for Seismic Review of Selected Nuclear Power Plants, Office of Nuclear Reactor Regulation, U.S. Nuclear Regulatory Commission, NUREG/CR-0098.

NUREG-0800 (1981), Standard Review Plan for the Review of Safety Analysis Reports for Nuclear Power Plants, Office of Nuclear Reactor Regulation, U.S. Nuclear Regulatory Commission.

Paul C. Rizzo Associates, Inc. (1998), Recommendations for Seismic Design Ground Motions at the Expended Core Facility Site Idaho National Engineering and Environmental Laboratory, Report prepared for Westinghouse Electric Corporation, West Mifflen, Pennsylvania, Project No. 93-1350.

Rollins, K. M., M.D. Evans, N. B. Diehl, and W. D. Daily (1998), Shear modulus and damping relationships for gravels, Journal of Geotechnical and Geoenvironmental Engineering Division, ASCE, May, p. 396-405. 
Silva, W.J., N. Abrahamson, G. Toro, and C. Costantino (1997), Description and validation of the stochastic ground motion model, unpublished report prepared for Brookhaven National Laboratory, Associated Universities, Inc, Pacific Engineering and Analysis, PE\&A 94PJ20, November.

Smith, R.P., H. C. Bean, G. S. Carpenter, and S. C. Minkin (1994), INEL Alternative Playa Resource Investigation, Lockheed Idaho Technologies Company Informal Report, INEL-94/0234, December.

Spudich, P., J.B. Fletcher, M. Hellweg, J. Boatwright, C. Sullivan, W.B. Joyner, T.C. Hanks, D.M. Boore, A. McGarr, L.M. Baker, and A.G. Lindh (1997), SEA97 - A new predictive relation for earthquake ground motions in extensional tectonic regimes, Seismological Research Letters, v. 68, p. 190-198.

Spudich, P., J.B. Fletcher, M. Hellweg, J. Boatwright, C. Sullivan, W.B. Joyner, T.C. Hanks, D.M. Boore, A. McGarr, L.M. Baker, and A.G. Lindh (1999), SEA97 - A revised ground motion predicition relation for use in extensional tectonic regimes, Bulletin of the Seismological Society of America, v. 89 , p. $1156-1170$.

Woodward-Clyde Consultants (1990), Earthquake Strong Ground Motion Estimates for the Idaho National Engineering Laboratory Final Report, EG\&G Idaho Informal Report EGG-BG-9350, Idaho Falls, Idaho, Three Volumes, November.

Woodward-Clyde Consultants (1992), Earthquake ground motion evaluations for the proposed New Production Reactor at the Idaho National Engineering Laboratory, Volume I: Deterministic Evaluation and Volume II: Probabilistic Evaluation, EG\&G Idaho Informal Report EGG-GEO10304, Idaho Falls, Idaho, June.

Woodward-Clyde Federal Services (1996), Site-specific Seismic Hazard Analyses for the Idaho National Engineering Laboratory, Volume I Final Report and Volume 2 Appendix, Lockheed Idaho Technologies Company Informal Report, INEL-95/0536, May.

Woodward-Clyde Federal Services (1998), Development of Design Basis Earthquake Parameters for the Argonne National Laboratory-West, Idaho National Engineering and Environmental Laboratory, Final Report, submitted to Argonne National Laboratory, March.

URS Greiner Woodward-Clyde Federal Services (1999), Final Report: Development of Design Basis Earthquake Parameters for TMI-2 Independent Spent Fuel Storage Installation at the INEEL, Bechtel BWXT Idaho, LLC. External Report INEEL/EXT-99-00619, November.

URS Greiner Woodward-Clyde Federal Services (2000a). Recomputation of the Seismic Hazard at the Idaho National Engineering and Environmental Laboratory, Bechtel BWXT Idaho, LLC. External Report INEEL/EXT-99-00786, February.

URS Greiner Woodward-Clyde Federal Services (2000b). Development of Time Histories for Design Basis Earthquake Response Spectra at the Idaho National Engineering and Environmental Laboratory, Bechtel BWXT Idaho, LLC. External Report, INEEL/EXT-99-01276, April. 
Appendix A

Background for Development of PC 3 and PC 4 DBE Response Spectra 


\section{Appendix A}

\section{Background for Development of PC 3 and PC 4 DBE Response Spectra}

\section{A.1 Adjustment Factors for PC 3 and PC 4 UHS}

Table A-1 shows the adjustment factors for the spectral ratios for the higher motions at TRA and RWMC for the 2,000- and 10,000-year return periods, and for the 2,500-year return period (discussed below). The spectral accelerations for the INTEC 2,000-year mean 5\% damped UHS were multiplied by adjustment factors for the 2,500-year return period and the spectral ratios at TRA and RWMC to determine the adjusted PC 3 rock UHS. The spectral accelerations for the INTEC 10,000-year mean 5\% damped UHS were multiplied by the adjustment factors for the spectral ratios at TRA and RWMC to determine the adjusted PC 4 rock UHS.

Since URSG-WCFS $(1999 ; 2000$ a) was not requested to develop design basis earthquake results at a 2,500-year return period for INTEC, TRA, RWMC, and PBF, the INTEC 2,000-year return period rock UHS supplemented for dominant earthquakes was adjusted by an appropriate factor to account for higher motions at the longer return period. As mentioned in Section 2.1 of the report, the UHS for INTEC was deaggregated and adjusted for contributions from dominant earthquakes. These changes were minor according to URSG-WCFS (1999). URSG-WCFS (2000a) deaggregated the seismic hazard results for TRA, RWMC, and PBF, but did not supplement their respective UHS with the dominant earthquakes because no significant increases were anticipated for TRA, RWMC, and PBF based on the similarities for dominant earthquake contributors and the minor increases determined for INTEC.

The seismic hazard curves for INTEC were evaluated to determine which frequency would produce the largest slope from which to estimate the largest factor. Table A-2 lists the spectral accelerations as a function of frequency for the UHS at return periods of $1,000,2,000$, and 10,000 years. A ratio of the 1,000 year $/ 10,000$ year spectral accelerations show that the largest factor would occur for a spectral frequency of $1 \mathrm{~Hz}$. Figure A-1 shows a plot of the seismic hazard curve at $1 \mathrm{~Hz}$ for the return periods and corresponding accelerations. Using the equation for the line shown in Figure A-1, an acceleration of $0.126 \mathrm{~g}$ is estimated for the 2,500-year return period. A ratio of the accelerations at 2,500-year $(0.126 \mathrm{~g})$ to 2,000 -year $(0.117 \mathrm{~g})$ results in a factor of 1.08 or $8 \%$. The scale factors for the ratio of $2,500 / 2,000$ years range from 1.07 to 1.08 which results in very little conservatism using 1.08 for all frequencies.

The adjusted PC 3 rock UHS at 2,500 years (also adjusted for higher motions at TRA and RWMC) is compared to the site-specific UHS at 2,500 years for TRA and RWMC in Figure A-2. The TRA and RWMC 2,500-year UHS were not supplemented for the dominant earthquakes (URSG-WCFS, 2000a). The adjusted PC 3 rock UHS at the 2,500-year return period is close to the same spectral accelerations for the TRA UHS at 2,500 years. An $8 \%$ increase applied to the 2,000-year return period rock UHS appears to be a reasonable adjustment to estimate spectral accelerations at 2,500 years. The 1.08 factor was assumed to be applicable to the 2,000-year soil UHS. 
Table A-1. Factors used to adjust the INTEC 2,000- and 10,000-year return period rock mean 5\% damped UHS.

\begin{tabular}{cccc}
\hline $\begin{array}{c}\text { Factors to Adjust the } \\
(\mathrm{Hz})\end{array}$ & $\begin{array}{c}\text { INTEC 2,000 Year Return } \\
\text { Period for Higher Motions } \\
\text { At TRA and RWMC }\end{array}$ & $\begin{array}{c}\text { Factors to Adjust the } \\
\text { INTEC 2,000 Year } \\
\text { Return Period for } \\
2,500 \text { Years }\end{array}$ & $\begin{array}{c}\text { Factors to Adjust the } \\
\text { INTEC 10,000 Year Return } \\
\text { Period for Higher Motions } \\
\text { At TRA and RWMC }\end{array}$ \\
\hline 50.00 & $1.02^{\mathrm{a}}$ & 1.08 & $1.02^{\mathrm{a}}$ \\
33.33 & $1.04^{\mathrm{a}}$ & 1.08 & $1.11^{\mathrm{a}}$ \\
20.00 & $1.09^{\mathrm{b}}$ & 1.08 & $1.15^{\mathrm{b}}$ \\
10.00 & $1.04^{\mathrm{b}}$ & 1.08 & $1.03^{\mathrm{b}}$ \\
5.00 & $1.08^{\mathrm{a}}$ & 1.08 & $1.07^{\mathrm{a}}$ \\
3.33 & $1.08^{\mathrm{a}}$ & 1.08 & $1.07^{\mathrm{a}}$ \\
2.50 & $1.06^{\mathrm{a}}$ & 1.08 & $1.07^{\mathrm{a}}$ \\
2.00 & $1.04^{\mathrm{a}}$ & 1.08 & $1.05^{\mathrm{a}}$ \\
1.00 & $1.00^{\mathrm{a}}$ & 1.08 & $1.05^{\mathrm{a}}$ \\
0.50 & $1.07^{\mathrm{a}}$ & 1.08 & $1.10^{\mathrm{a}}$ \\
\hline
\end{tabular}

a. Spectral Ratio TRAINTEC.

b. Spectral Ratio RWMC/INTEC.

Table A-2. Spectral ratios for the INTEC mean UHS.

\begin{tabular}{|c|c|c|c|c|}
\hline \multirow{2}{*}{$\begin{array}{c}\text { Frequency } \\
(\mathrm{Hz})\end{array}$} & \multicolumn{3}{|c|}{ Spectral Accelerations (g) for Return Periods } & \multirow{2}{*}{$\begin{array}{c}\text { Ratio of } \\
1,000 \text { Year } \\
10,000 \text { Year }\end{array}$} \\
\hline & 1,000 Year & 2,000 Year & 10,000 Year & \\
\hline 50.00 & 0.090 & 0.114 & 0.186 & $2: 066$ \\
\hline 33.33 & 0.112 & 0.142 & 0.242 & 2.160 \\
\hline 20.00 & 0.141 & 0.184 & 0.305 & 2.163 \\
\hline 10.00 & 0.174 & 0.226 & 0.370 & 2.126 \\
\hline 5.00 & 0.208 & 0.270 & 0.457 & 2.197 \\
\hline 3.33 & 0.191 & 0.249 & 0.426 & 2.230 \\
\hline 2.50 & 0.167 & 0.221 & 0.382 & 2.287 \\
\hline 2.00 & 0.147 & 0.196 & 0.339 & 2.306 \\
\hline 1.00 & 0.089 & 0.117 & 0.209 & 2.348 \\
\hline 0.50 & 0.048 & 0.062 & 0.111 & 2.312 \\
\hline
\end{tabular}




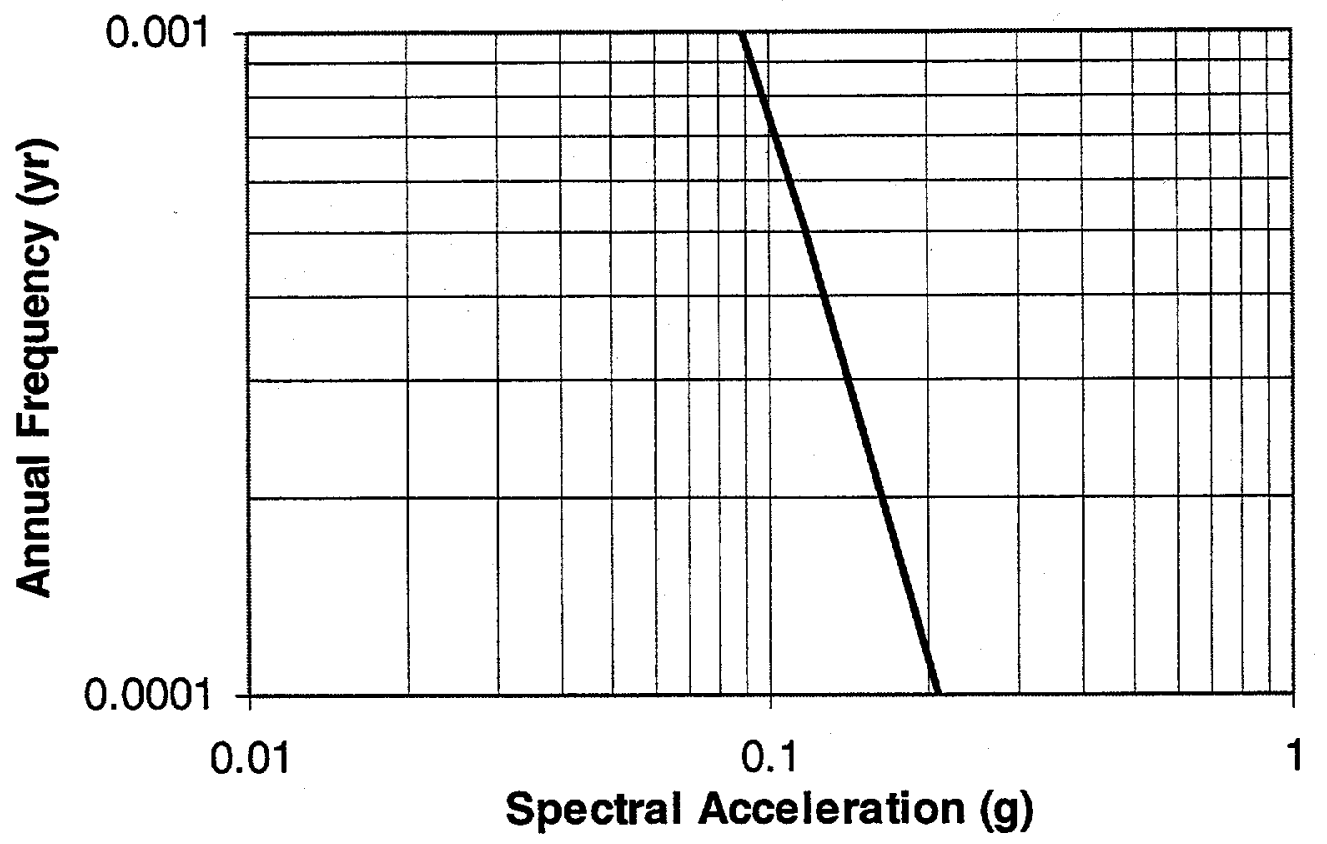

Figure A-1. Plot of the slope for the seismic hazard curves $(1,000,2,000$, and 10,000 year return periods) at $1.0 \mathrm{~Hz}$ for INTEC (URSG-WCFS, 1999). 


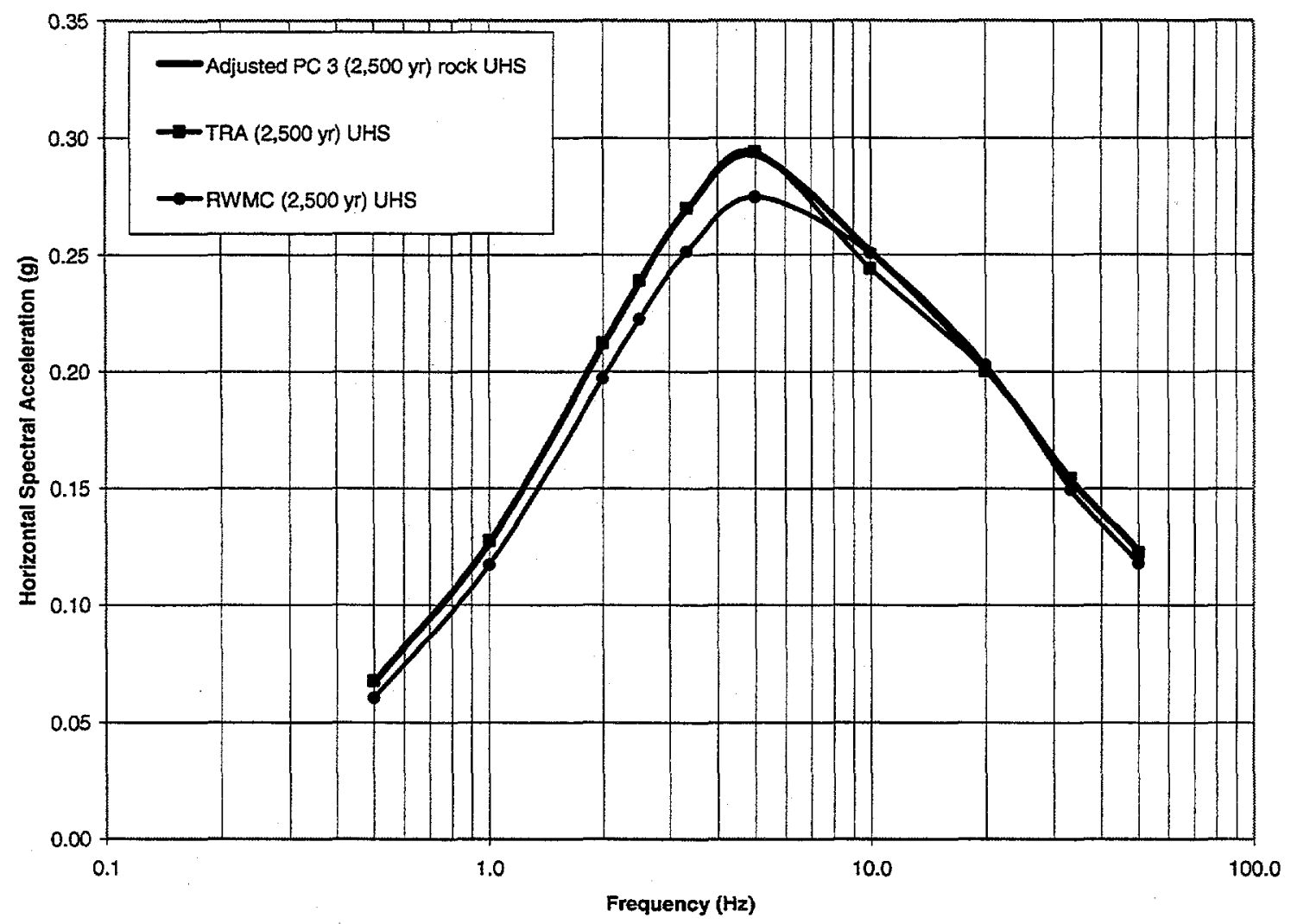

Figure A-2. Comparison of the adjusted PC 3 rock UHS at 2,500 years (including adjustments for higher motions at TRA and RWMC) to the site-specific UHS at 2,500 years for TRA and RWMC developed by URSG-WCFS (2000a). 


\section{A.2 Adequacy of the Site-specific UHS for Development of the DBE}

Newmark and Hall (1978) median amplification factors were used to check the adequacy of the DBE response spectra since they were developed using the site-specific UHS. The dominant earthquakes determined from the URSG-WCFS evaluation are used to link to an empirical spectral shape. The seismic hazard calculated by URSG-WCFS $(1999 ; 2000 \mathrm{~b})$ were deaggregated to define the dominant earthquake magnitude and distances for INEEL facility areas at 2,000 and 10,000 year return periods shown in Table A-3. The dominant magnitudes and distances were then used to select empirical amplification factors for a similar magnitude and distance. Table A-4 lists the empirical factors (i.e., v/a and $\mathrm{ad} / \mathrm{v}^{2}$ ) for a magnitude 7.0 at distances of 30 to $50 \mathrm{~km}$ on rock from Newmark and Hall (1978) and the ongoing work of NRC (Per. Comm. J. Kimball, 1999). Empirically derived median amplification factors are compared to amplification factors determined using the DBE response spectra to ensure that the DBE response spectra represent an adequate frequency range to accommodate the possible range of earthquake ground motions (Newmark and Hall, 1978).

Three comparisons were made using the peak spectral acceleration (A), peak spectral velocity (V), peak spectral displacement (D) from the DBE response spectra. The acceleration amplification factors for the DBE response spectra were calculated by taking a ratio of the peak spectral acceleration (at $5.0 \mathrm{~Hz})$ to the PGA at $50 \mathrm{~Hz}$. The resulting factors were compared to the median acceleration amplification factor derived by Newmark and Hall (1978), recognizing that Newmark and Hall (1978) chose PGA at $33 \mathrm{~Hz}$. The PC 3 and PC 4 rock DBE response spectra for INTEC, TRA, RWMC, and PBF, NRF and TAN have acceleration amplification factors (Table A-5) that are greater than the Newmark and Hall (1978) median acceleration amplification factor of 2.12 (Table A-4). An assumption was made that the median amplification factors for rock (Table A-4) could be applied to shallow soil sites $(<100 \mathrm{ft})$. The acceleration amplification factor calculated using the PC 3 and PC 4 DBE response spectra for INTEC soil conditions (30-50ft) exceed the median amplification factor of 2.12 .

A peak spectral velocity $\left(\mathrm{PSV}_{\mathrm{E}}\right)$ using the median velocity amplification factors of listed in Table A-4 was compared to the peak spectral velocity $\left(\mathrm{PSV}_{\mathrm{D}}\right)$ derived for the DBE response spectra. An assumption was made that the spectral acceleration at $0.5 \mathrm{~Hz}$ of the rock DBE response spectra and spectral acceleration at $3 \mathrm{~Hz}$ of the soil DBE response spectra represent the peak spectral velocity portion of the DBE response spectra. The peak spectral velocities were calculated using the following equations:

$$
\begin{aligned}
& P S V_{E}=a \times 70 \mathrm{~cm} / \mathrm{s} / \mathrm{g} \times 1.65 \\
& P S V_{D}=\left(A_{F} \times 981 \mathrm{~cm} / \mathrm{s}^{2} / \mathrm{g} \times \mathrm{F}\right) / 2 \pi
\end{aligned}
$$

Where:

$a$ is the PGA of the DBE response spectra;

$A_{F}$ is the spectral acceleration at a defined frequency for the DBE response spectra $(0.5$ $\mathrm{Hz}$ for rock and $3 \mathrm{~Hz}$ for soil);

$F$ is frequency for the spectral acceleration.

For the PC 3 and PC 4 rock and soil DBE response spectra, $P_{D} V_{D}$ exceeds $P_{S V}$ listed in Table A5. The comparisons using the peak acceleration and peak velocity amplification factors indicate that the rock and soil DBE response spectra are adequate in terms of peak spectral acceleration and peak spectral 
velocity, representing an adequate frequency range to accommodate the possible range of ground motions.

Peak displacements for the PC 3 and PC 4 rock and soil DBE response spectra were selected for the DBE response spectra based discussions DOE had with the DNFSB (Per. Comm. J. Kimball, 1999). Knowing the displacements selected to develop the DBE response spectra would probably be conservative for INEEL when compared to the site-specific UHS, the INEEL NPHC agreed to be consistent with the discussions DOE had with the DNFSB regarding other DOE sites. Table A-5 shows the selected peak displacements have been conservatively chosen since they exceed the displacements $\left(D_{E}\right)$ calculated using the empirical amplification factor for $\mathrm{ad} / \mathrm{v}^{2}$ (Table $\left.\mathrm{A}-4\right)$ and the following equation:

$D_{E}=\left(\left(4.25 \times P S V_{E}^{2}\right) / a\right) \times 1.39$

Where:

$\mathrm{PSV}_{\mathrm{E}}$ is the peak spectral velocity derived from empirical amplification factors listed in Table A-4;

$a$ is the PGA of the DBE response spectra. 
Table A-3. Dominant earthquake magnitudes and distances.

\begin{tabular}{|c|c|c|c|}
\hline Source & $\begin{array}{l}\text { Frequency Range } \\
\qquad(\mathrm{Hz})\end{array}$ & $\begin{array}{l}\text { Dominant Magnitude }-M_{\text {bar }} \\
\qquad\left(\mathrm{M}_{\mathrm{w}}\right)\end{array}$ & $\begin{array}{c}\text { Dominant Distance Range }-D_{\text {bar }} \\
(\mathrm{km})\end{array}$ \\
\hline \multirow{2}{*}{$\begin{array}{l}\text { INTEC } 2,000 \text { and } \\
10,000 \text { Year Events }\end{array}$} & 5 to 10 & 6.4 to 6.5 & 26 to 34 \\
\hline & 1 to 2.5 & 6.7 to 6.8 & 31 to 43 \\
\hline \multirow{2}{*}{$\begin{array}{l}\text { NRF 2,000 and } \\
10,000 \text { Year Events }\end{array}$} & 5 to 10 & 6.3 to 6.4 & 20 to 25 \\
\hline & 1 to 2.5 & 6.6 to 6.8 & 23 to 30 \\
\hline \multirow{2}{*}{$\begin{array}{l}\text { TAN 2,000 and } \\
10,000 \text { Year Events }\end{array}$} & 5 to 10 & 6.1 to 6.5 & 12 to 16 \\
\hline & 1 to 2.5 & 6.2 to 6.6 & 15 to 22 \\
\hline $\begin{array}{l}\text { NRC draft guidance } \\
\text { for rock sites }\end{array}$ & - & 7.0 & 30 to 50 \\
\hline \multicolumn{4}{|l|}{ a. URSG-WCFS (1999). } \\
\hline \multicolumn{4}{|l|}{ b. URSG-WCFS (2000a). } \\
\hline $\mathrm{mn}$ & J. Kimball (1999). & & \\
\hline
\end{tabular}

Table A-4. Empirical amplification factors.

\begin{tabular}{|c|c|c|}
\hline Type & Empirical Amplification Factor & Reference \\
\hline $\mathrm{v} / \mathrm{a}$ & $70 \mathrm{~cm} / \mathrm{sec} / \mathrm{g}$ & Ongoing work of the NRC (Personal \\
\hline $\mathrm{ad} / \mathrm{v}^{2}$ & 4.25 & Communications; J. Kimball, 1999) \\
\hline Spectral Acceleration & 2.12 & \multirow{3}{*}{$\begin{array}{l}\text { Median }(50 \%) \text { spectrum amplification factors } \\
\text { for a horizontal elastic 5\% damped response } \\
\text { (Newmark and Hall, 1978) }\end{array}$} \\
\hline Spectral Velocity & 1.65 & \\
\hline Spectral Displacement & 1.39 & \\
\hline
\end{tabular}


Table A-5. Comparison of amplification factors derived using the DBE response spectra with empirical median amplification factors.

\begin{tabular}{|c|c|c|c|c|c|c|}
\hline $\begin{array}{c}\text { Site-specific } \\
\text { UHS } \\
\end{array}$ & $\begin{array}{c}\text { Acceleration } \\
\text { Amplification } \\
\text { Factor for } \mathrm{DBE}^{\mathrm{a}}\end{array}$ & $\begin{array}{c}\text { PSV }_{\mathrm{E}} \\
\text { Peak Spectral } \\
\text { Velocity Based on } \\
\text { Median Velocity } \\
\text { Amplification Factor } \\
(\mathrm{cm} / \mathrm{sec}) \\
\end{array}$ & $\begin{array}{c}\mathrm{PSV}_{\mathrm{D}} \\
\text { Peak Spectral } \\
\text { Velocity Based on } \\
\mathrm{DBE}^{\mathrm{c}}(\mathrm{cm} / \mathrm{sec}) \\
\end{array}$ & $\begin{array}{l}\text { Peak Displacement } \\
\text { Based on Empirical } \\
\text { Displacement } \\
\text { Amplification } \\
\text { Factor }^{d} \\
(\mathrm{~cm}) \\
\end{array}$ & $\begin{array}{c}\begin{array}{c}\text { Peak Displacement } \\
\text { Selected for DBE } \\
(\mathrm{cm})\end{array} \\
\end{array}$ & $\begin{array}{c}\text { Represents } \\
\text { Adequate } \\
\text { Frequency } \\
\text { Range } \\
\end{array}$ \\
\hline $\begin{array}{l}\text { Adjusted PC } 3 \\
(2,500 \mathrm{yr}) \text { Rock }\end{array}$ & 2.38 & 14.20 & 20.93 & 3.63 & 10.16 & Yes \\
\hline $\begin{array}{l}\text { Adjusted PC } 4 \\
\text { (10,000 yr) Rock }\end{array}$ & 2.44 & 21.60 & 34.67 & 5.52 & 15.24 & Yes \\
\hline $\begin{array}{l}\text { NRF PC } 3 \\
(2,000 \text { yr }) \text { Rock }\end{array}$ & 2.26 & 14.44 & 20.93 & 3.69 & 10.16 & Yes \\
\hline $\begin{array}{l}\text { NRF PC } 4 \\
(10,000 \text { yr) Rock }\end{array}$ & 2.29 & 24.83 & 39.05 & 6.34 & 15.24 & Yes \\
\hline $\begin{array}{l}\text { TAN PC } 3 \\
(2,500 \text { yr) Rock }\end{array}$ & 2.22 & 18.48 & 22.81 & 4.72 & 10.16 & Yes \\
\hline $\begin{array}{l}\text { TAN PC } 4 \\
(10,000 \text { yr) Rock }\end{array}$ & 2.23 & 31.18 & 39.06 & 7.97 & 15.24 & Yes \\
\hline $\begin{array}{l}\text { INTEC PC } 3 \\
(2,500 \text { Year }) \text { Soil }\end{array}$ & 3.01 & 29.34 & 31.19 & 7.49 & 27.35 & Yes \\
\hline $\begin{array}{l}\text { INTEC PC } 4 \\
(10,000 \text { Year) } \\
\text { Soil }\end{array}$ & 3.01 & 41.73 & 49.35 & 10.92 & 30.48 & Yes \\
\hline \multicolumn{7}{|c|}{ a. Peak spectral acceleration/PGA of the DBE. } \\
\hline \multicolumn{7}{|c|}{ b. PGA of the DBE $\times 70 \mathrm{~cm} / \mathrm{s} / \mathrm{g} \times 1.65$. } \\
\hline \multicolumn{7}{|c|}{ c. (Peak Spectral Acceleration of the DBE $\times 981 \mathrm{~cm} / \mathrm{s} / \mathrm{g}) / 2 \pi \times$ Frequency. } \\
\hline \multicolumn{7}{|c|}{ d. $\left(\left(4.25 \times \mathrm{PSV}_{\mathrm{E}}^{2}\right) /(\mathrm{PGA} \times 981 \mathrm{~cm} / \mathrm{s} / \mathrm{g})\right) \times 1.39}$. \\
\hline
\end{tabular}




\section{A.3 Comparison of the DBE Response Spectra and UHS}

The DBE response spectra were developed by incorporating smoothed broadened regions of the peak accelerations, velocities, and displacements defined by the site-specific UHS. Portions of the DBE response spectra were adjusted to ensure conservatism for the structural design process. The DBE response spectral shape was developed with the PGA, an increasing acceleration (by selecting the spectral acceleration at $33 \mathrm{~Hz}$ ), peak spectral acceleration, and constant velocity defined by the site-specific UHS. The peak spectral displacement was selected based on discussions DOE had with the DNFSB (Appendix A, Section A.2). Figures A-3 through A-16 show envelops of the response spectra to portions of the sitespecific UHS used to develop the DBE response spectral shapes. 
(a)

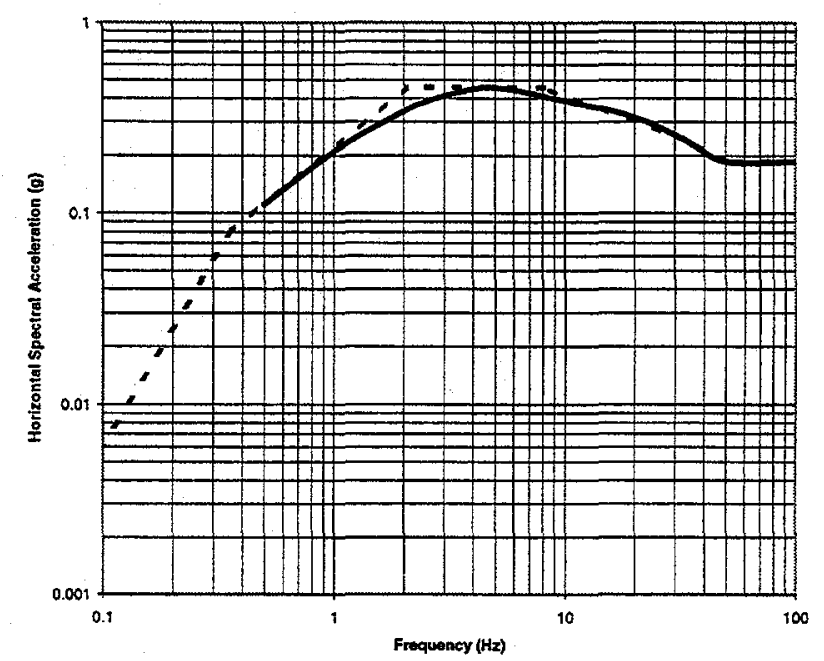

(b)

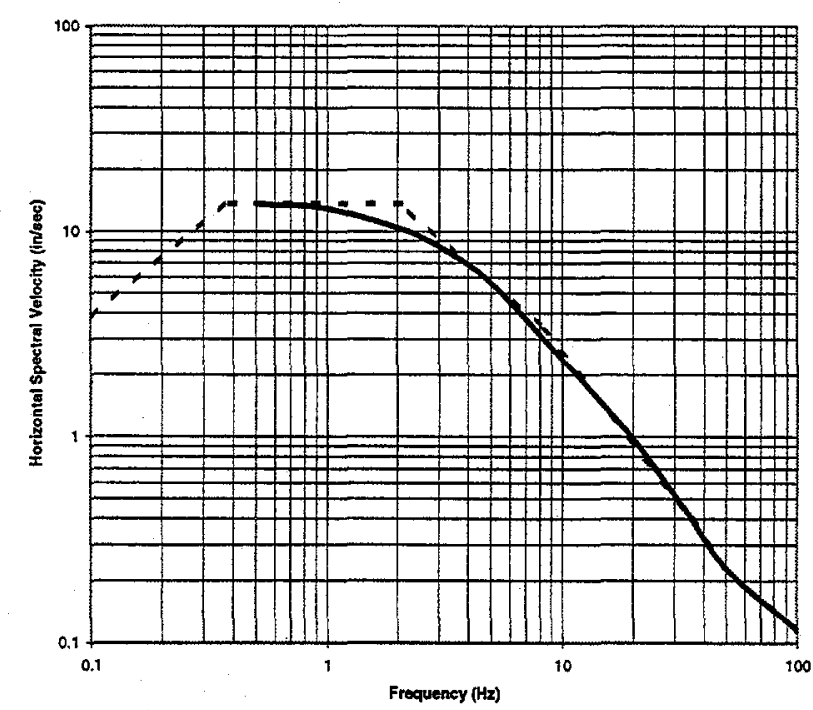

(c)

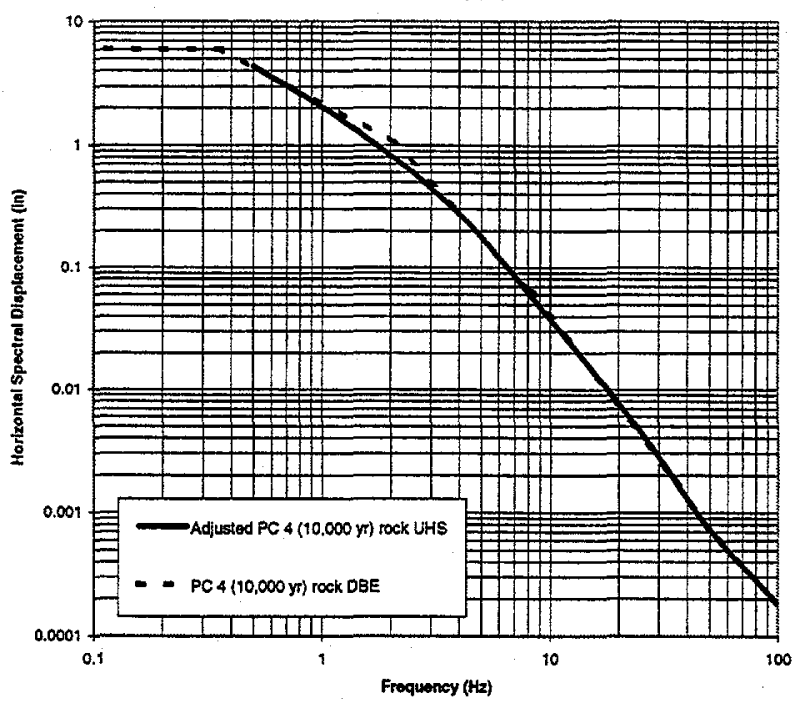

Figure A-3. Envelopes of the horizontal response spectra, (a) acceleration, (b) velocity, and (c) displacement, to portions of the adjusted PC 4 rock UHS used to develop the PC 4 (10,000 years) horizontal rock DBE response spectral shape for INTEC, TRA, RWMC, and PBF. 


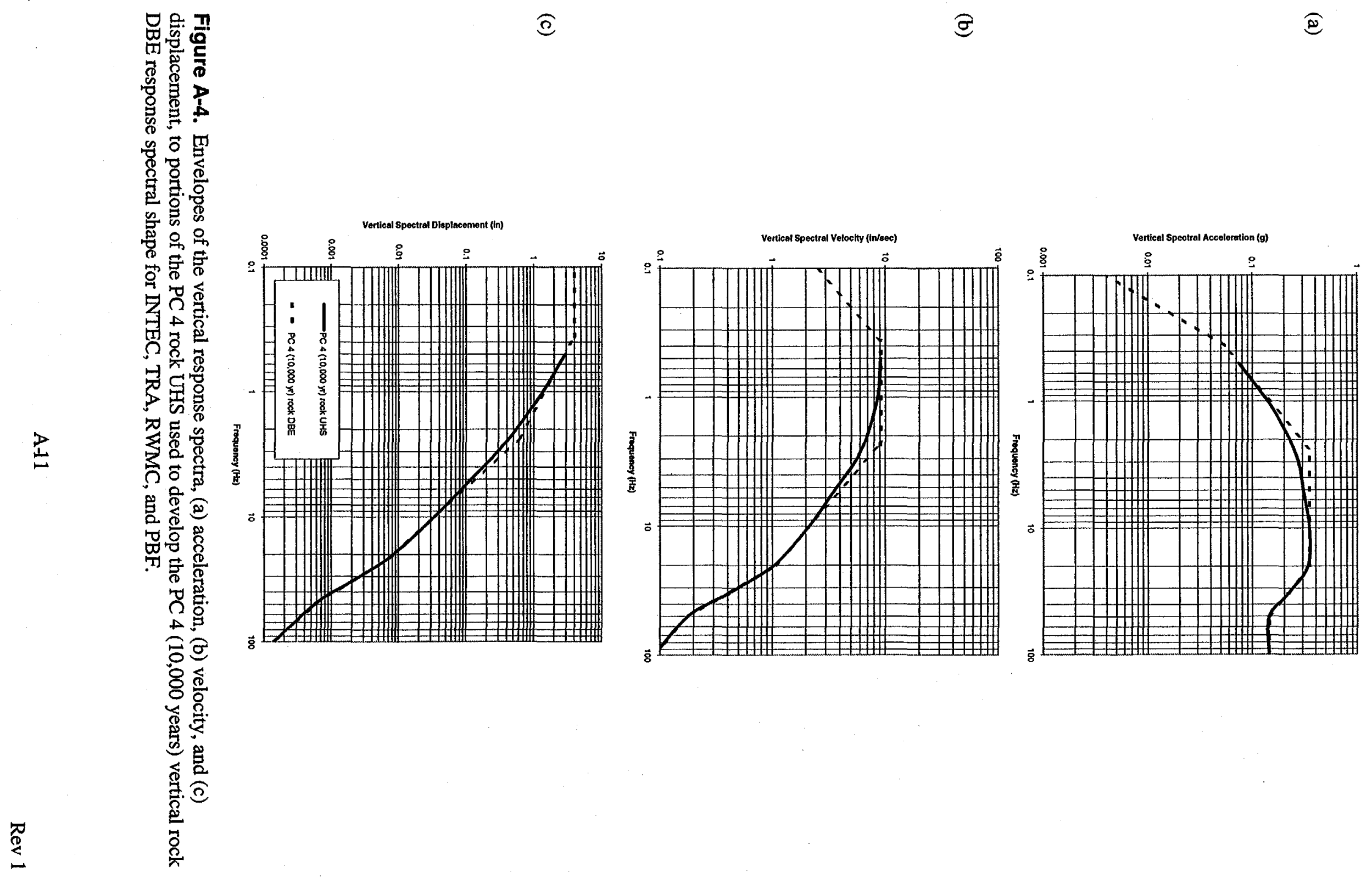


(a)

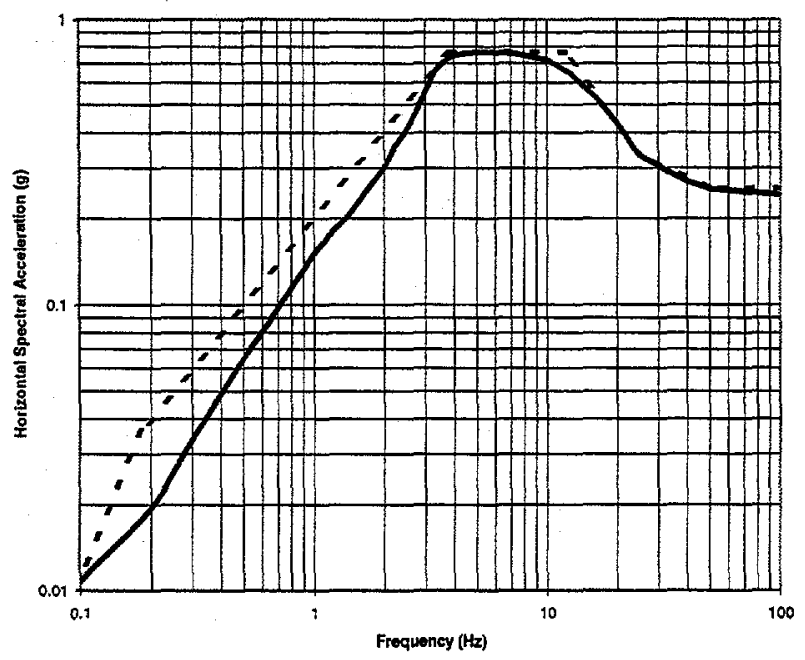

(b)

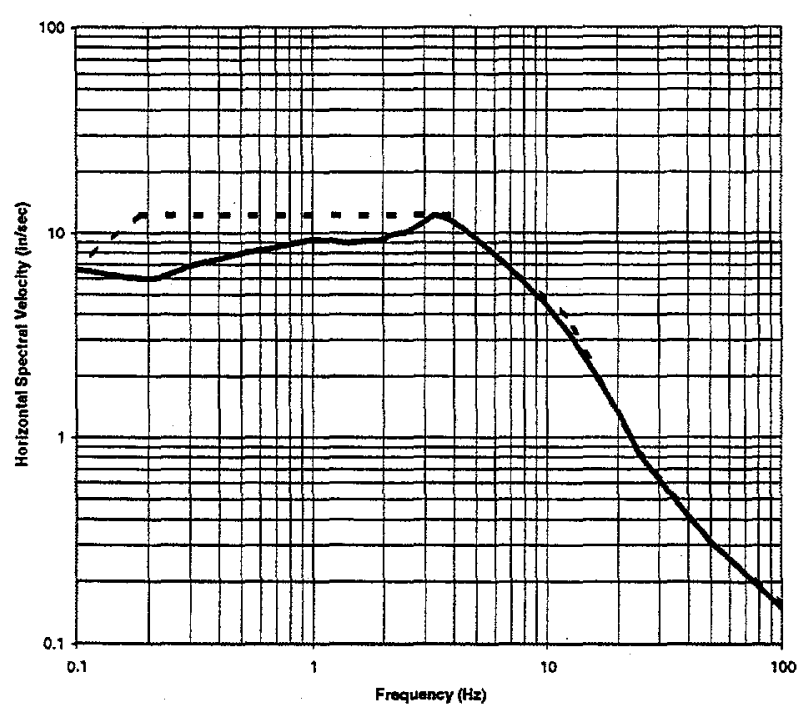

(c)

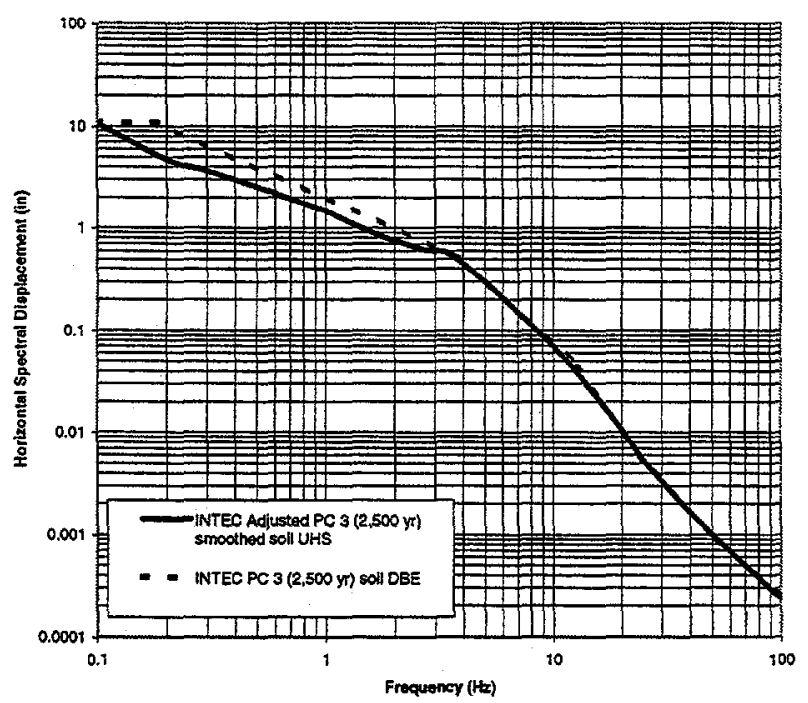

Figure A-5. Envelopes of the horizontal response spectra, (a) acceleration, (b) velocity, and (c) displacement, to portions of the adjusted PC 3 smoothed soil UHS used to develop the PC 3 (2,500 years) horizontal soil DBE response spectral shape for INTEC. 
(a)

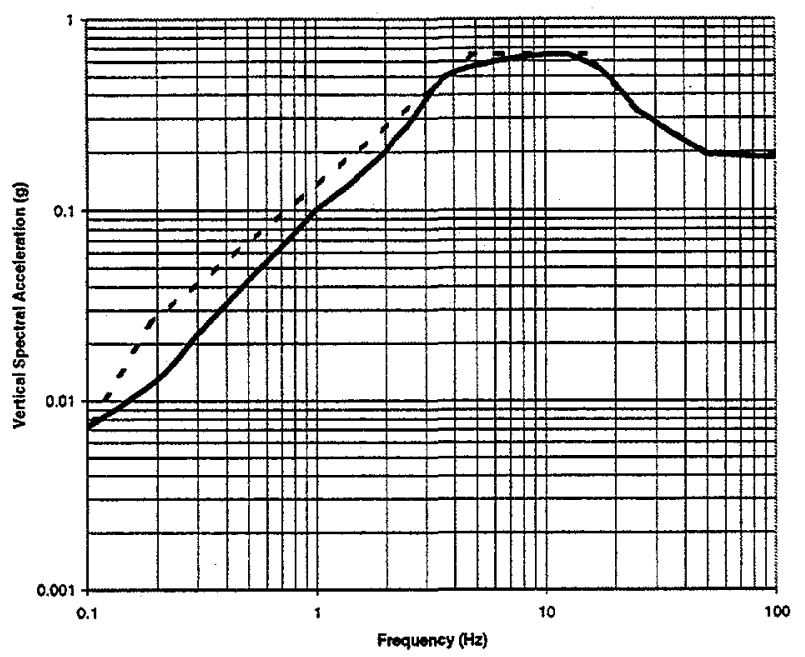

(b)

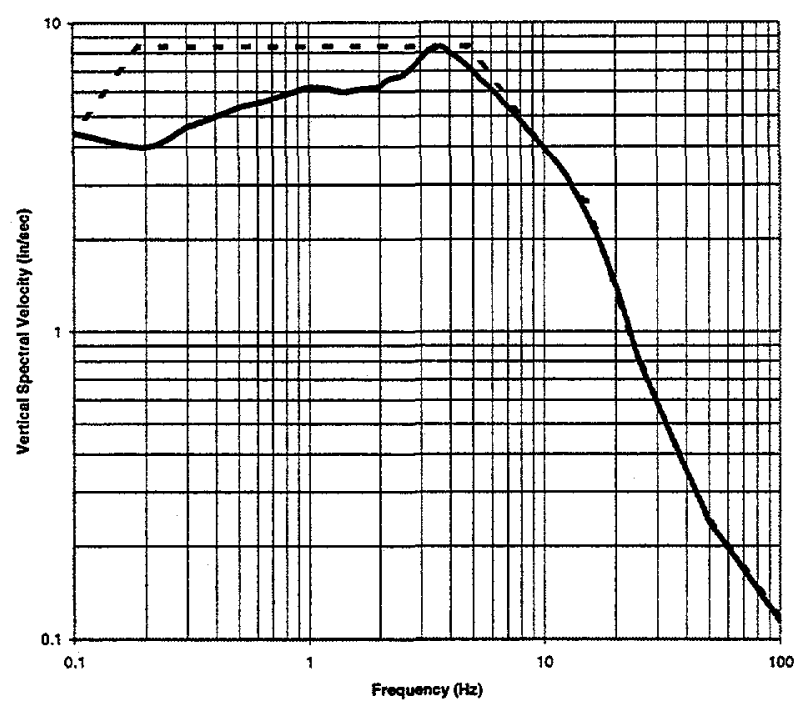

(c)

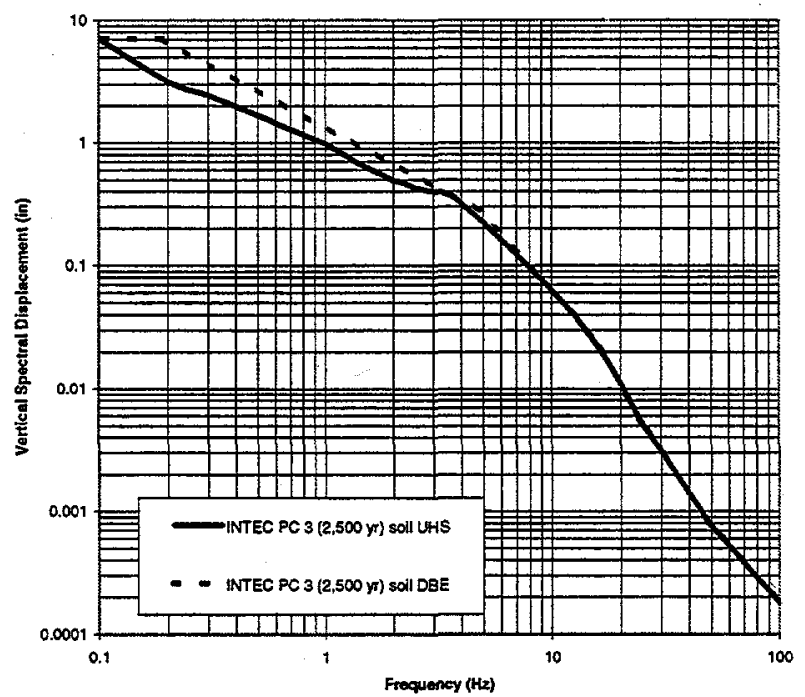

Figure A-6. Envelopes of the vertical response spectra, (a) acceleration, (b) velocity, and (c) displacement, to portions of the PC 3 soil UHS used to develop the PC 3 (2,500 years) vertical soil DBE response spectral shape for INTEC. 
(a)

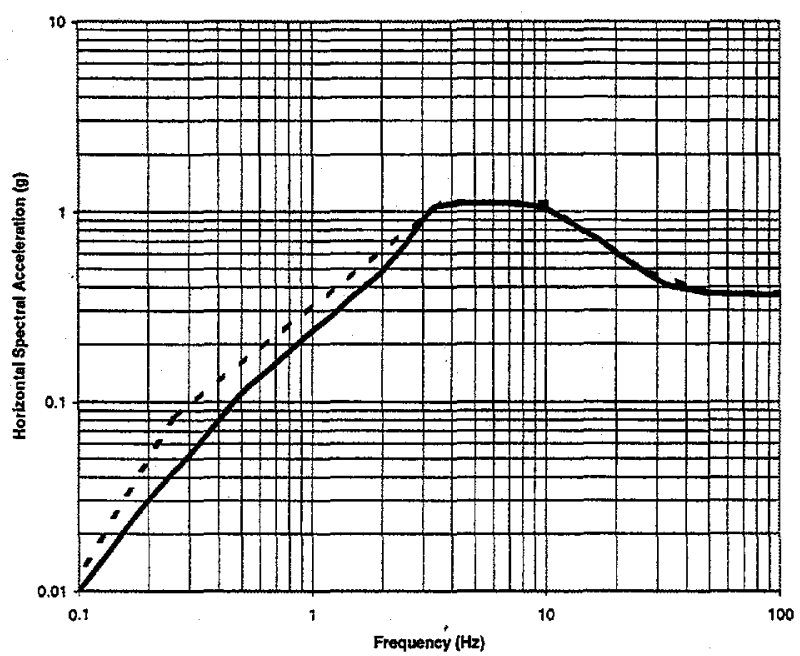

(b)

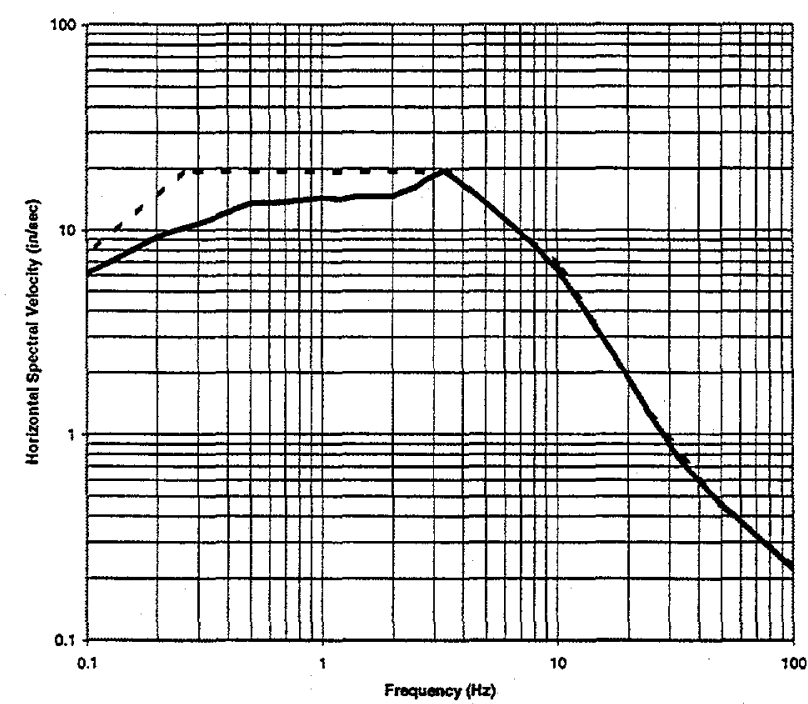

(c)

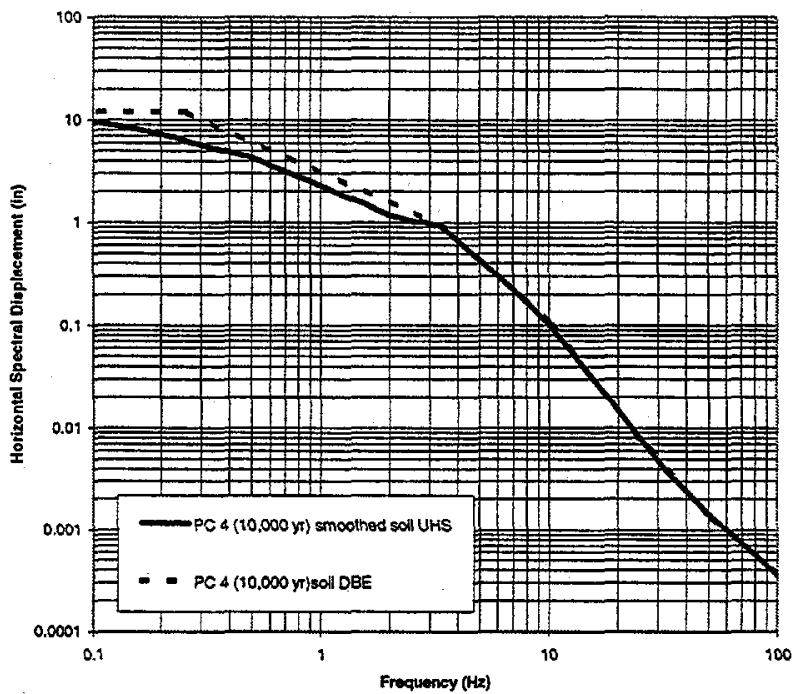

Figure A-7. Envelopes of the horizontal response spectra, (a) acceleration, (b) velocity, and (c) displacement, to portions of the PC 4 smoothed soil UHS used to develop the PC 4 (10,000 years) horizontal soil DBE response spectral shape for INTEC. 
(a)

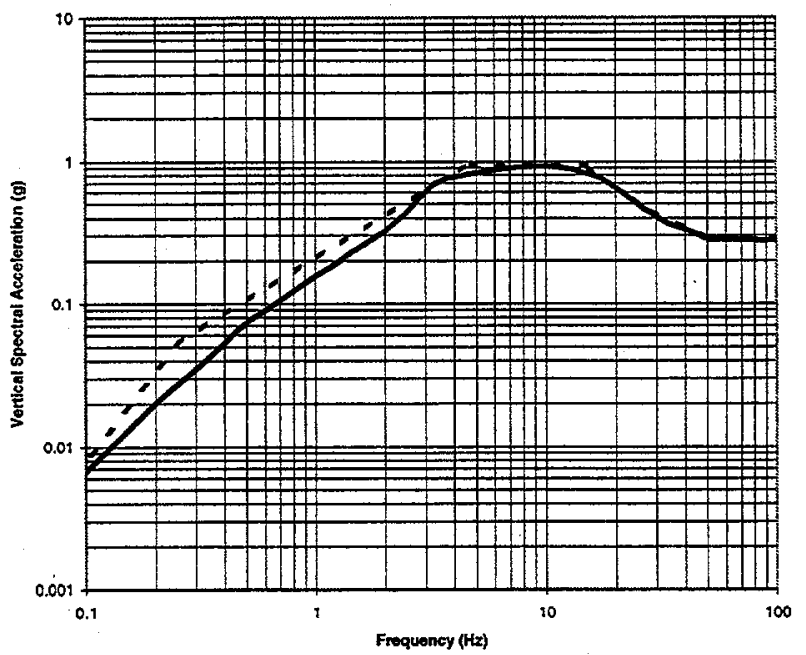

(b)

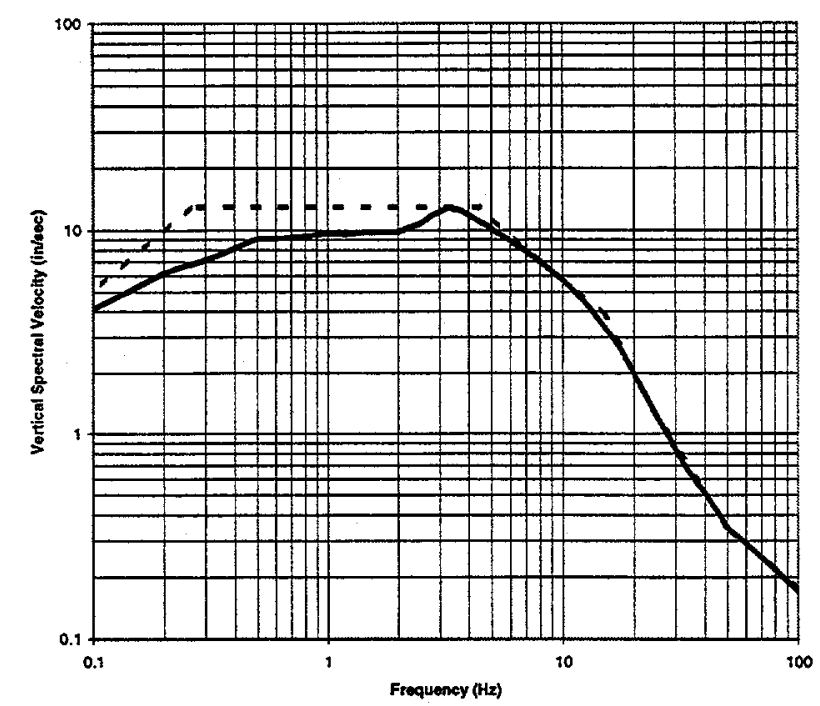

(c)

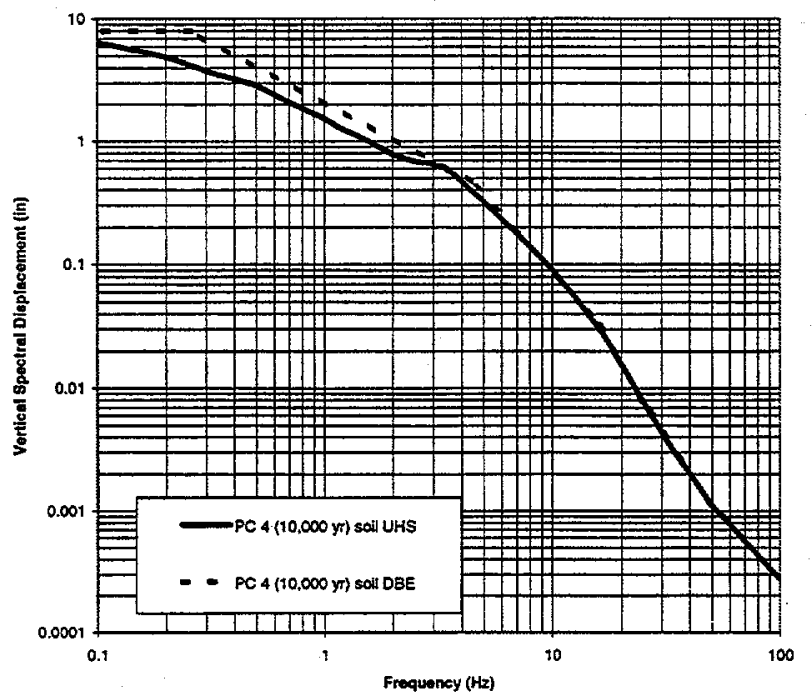

Figure A-8. Envelopes of the vertical response spectra, (a) acceleration, (b) velocity, and (c) displacement, to portions of the PC 4 soil UHS used to develop the PC $4(10,000$ years) vertical soil DBE response spectral shape for INTEC. 
(a)

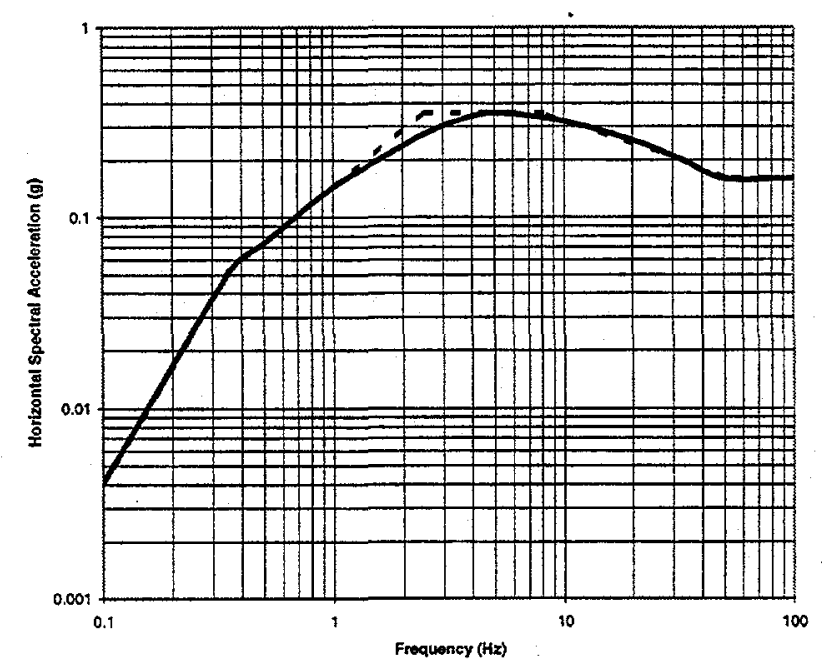

(b)

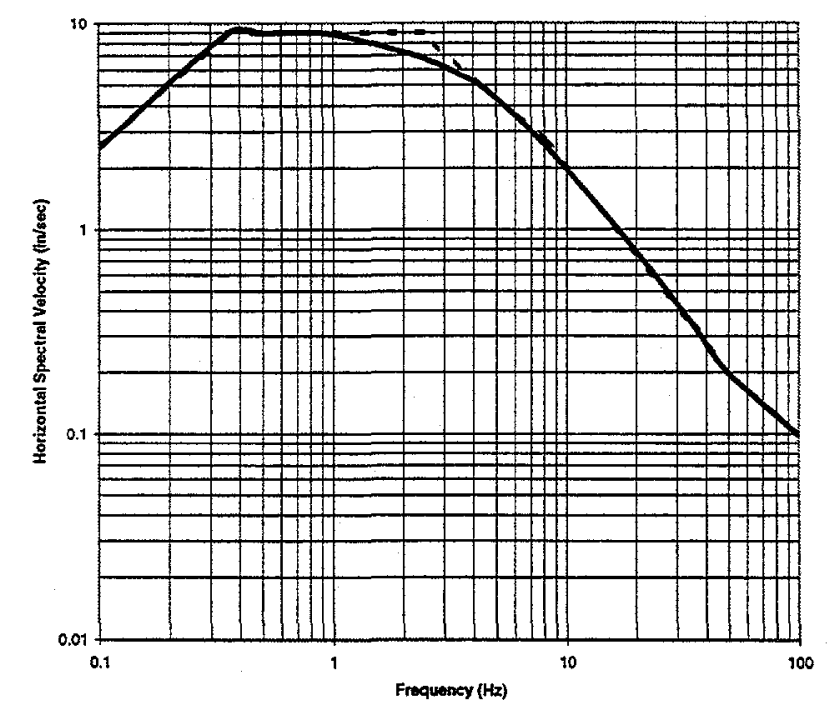

(c)

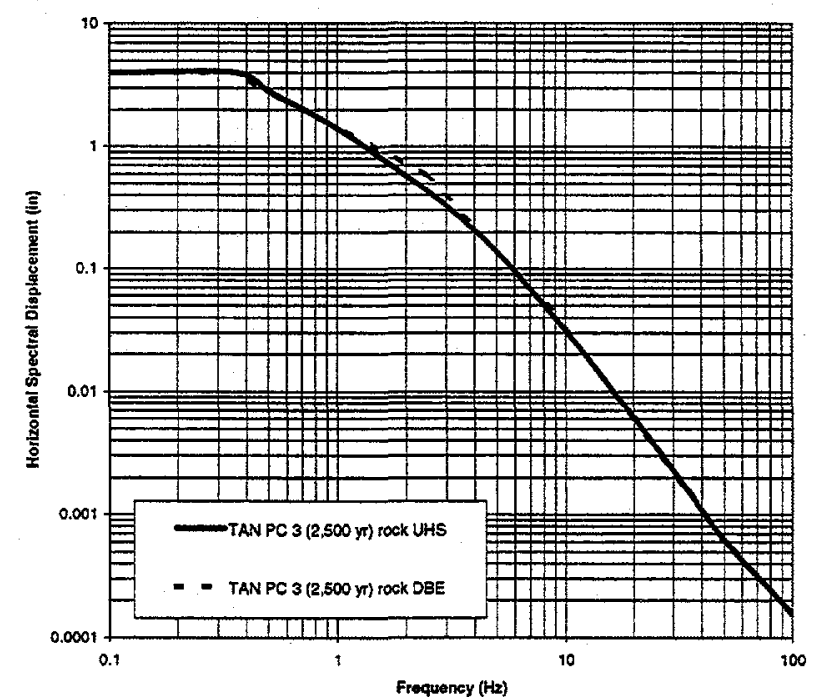

Figure A-9. Envelopes of the horizontal response spectra, (a) acceleration, (b) velocity, and (c) displacement, to portions of the PC 3 rock UHS used to develop the PC 3 (2,500 years) horizontal rock DBE response spectral shape for TAN. 


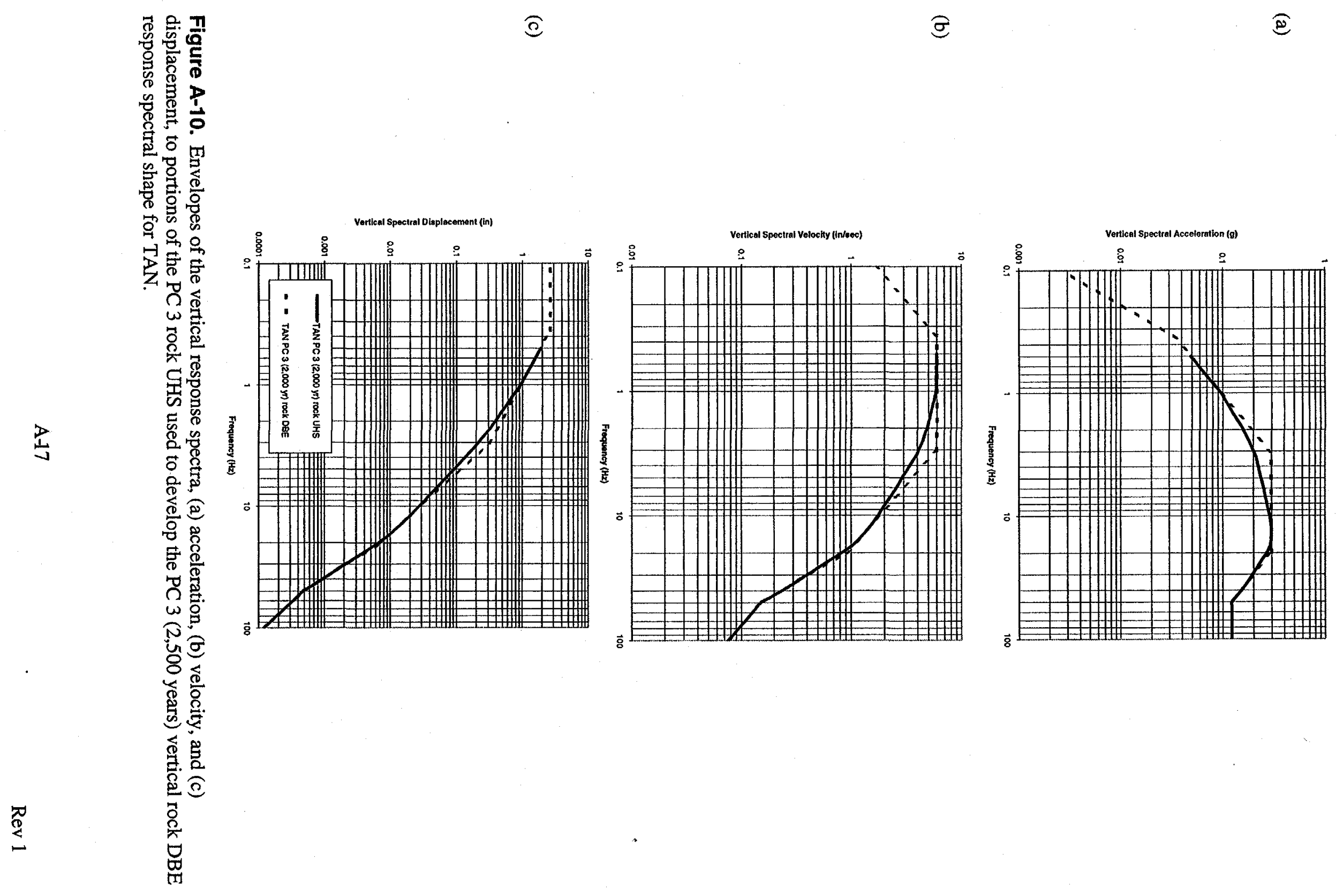


(a)

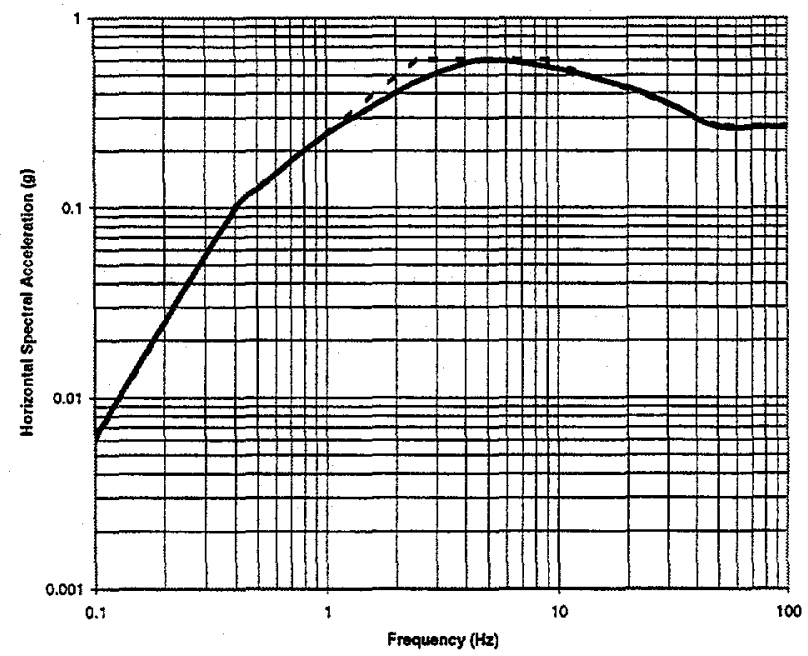

(b)

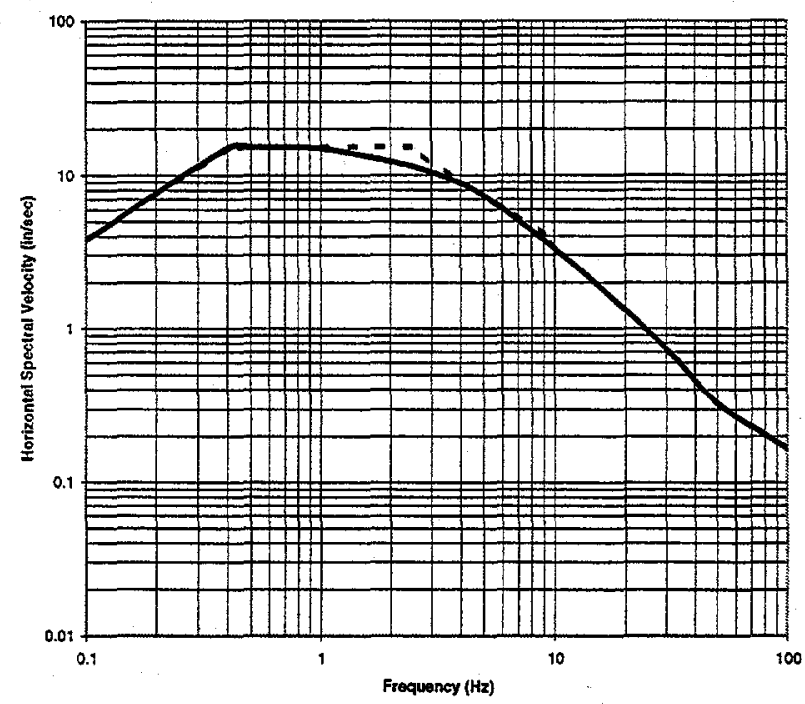

(c)

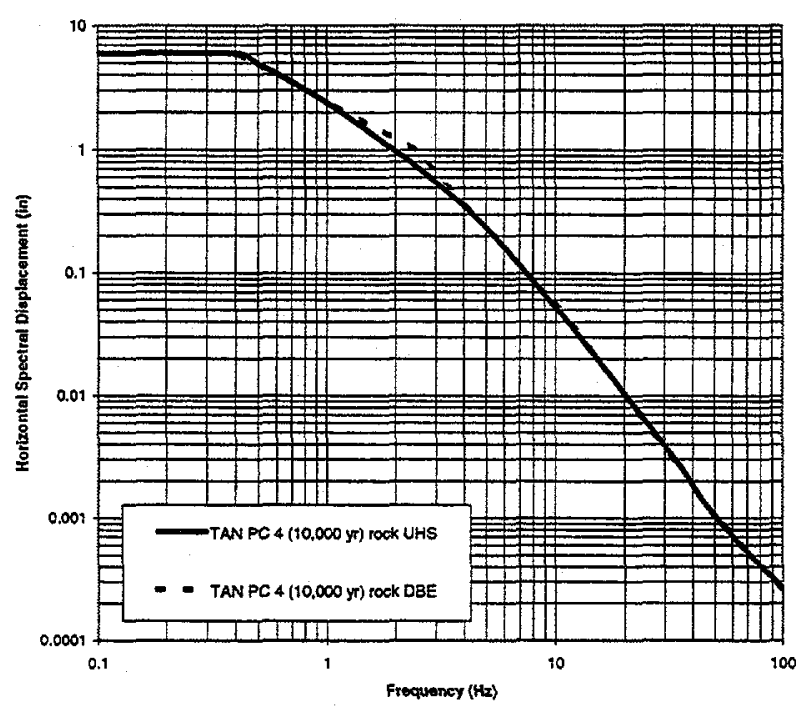

Figure A-11. Envelopes of the horizontal response spectra, (a) acceleration, (b) velocity, and (c) displacement, to portions of the PC 4 rock UHS used to develop the PC 4 (10,000 years) horizontal rock DBE response spectral shape for TAN. 
(a)

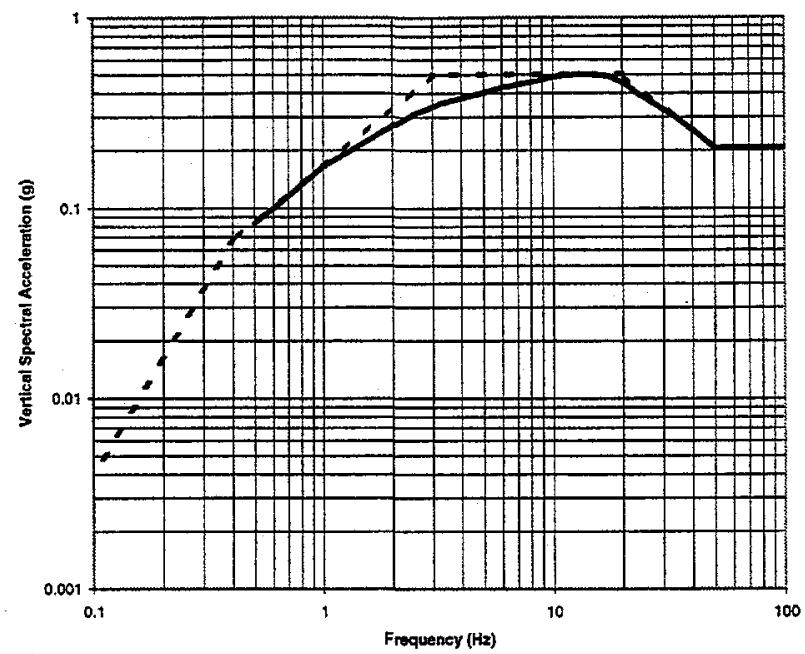

(b)

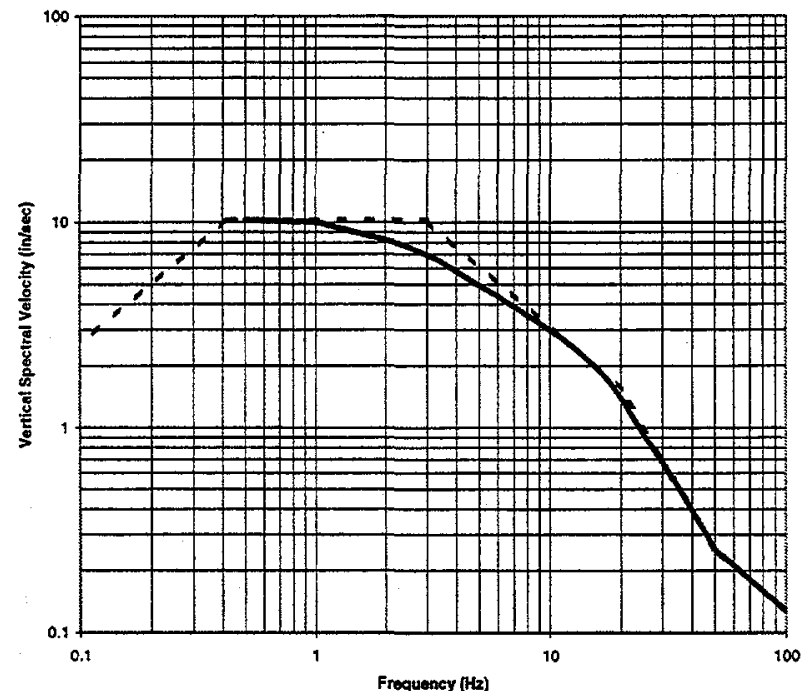

(c)

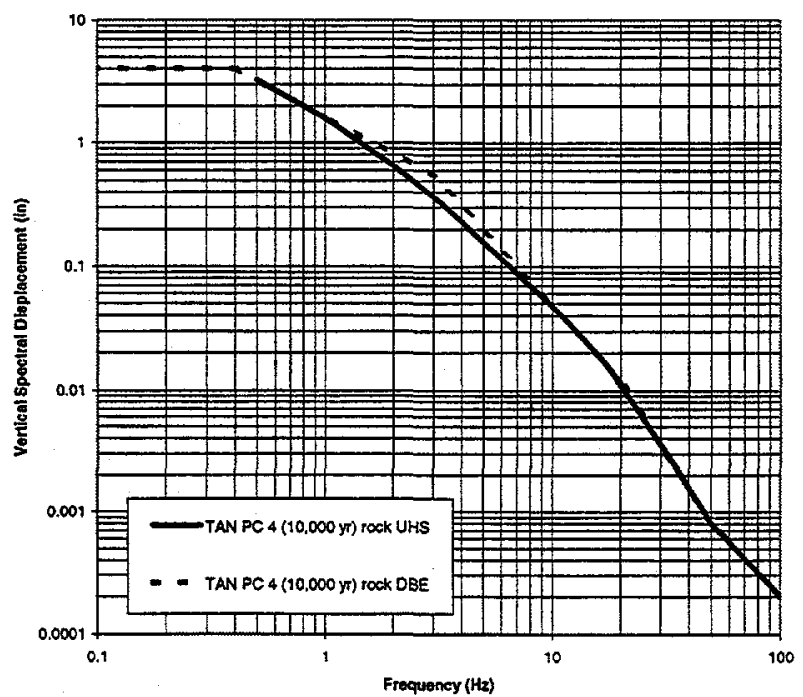

Figure A-12. Envelopes of the vertical response spectra, (a) acceleration, (b) velocity, and (c) displacement, to portions of the PC 4 rock UHS used to develop the PC 4 (10,000 years) vertical rock DBE response spectral shape for TAN. 
(a)

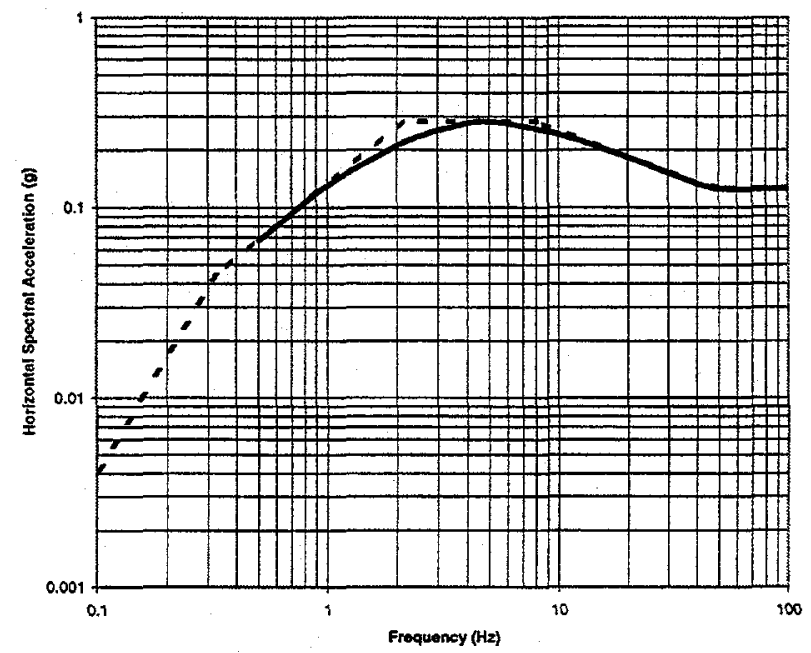

(b)

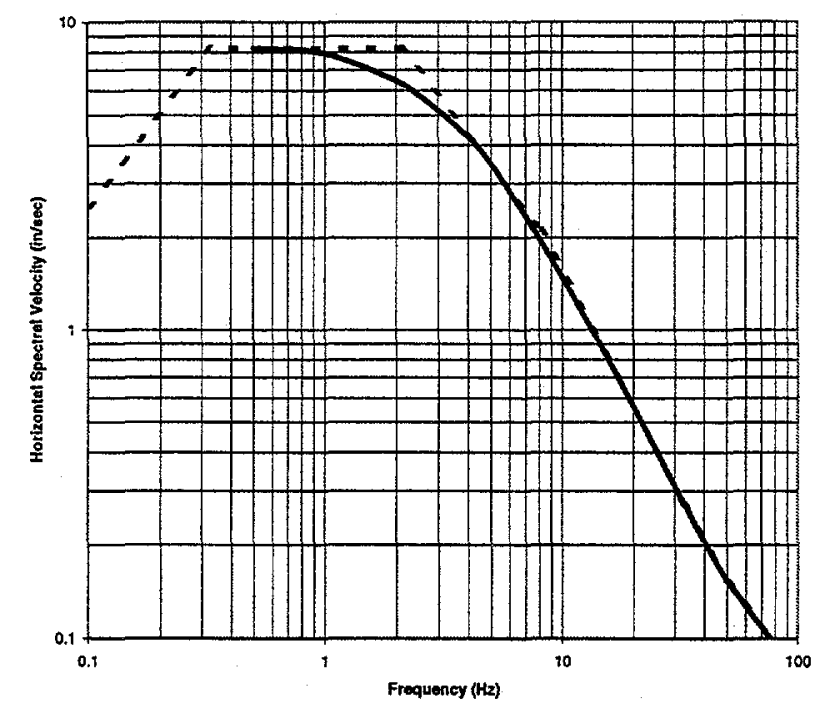

(c)

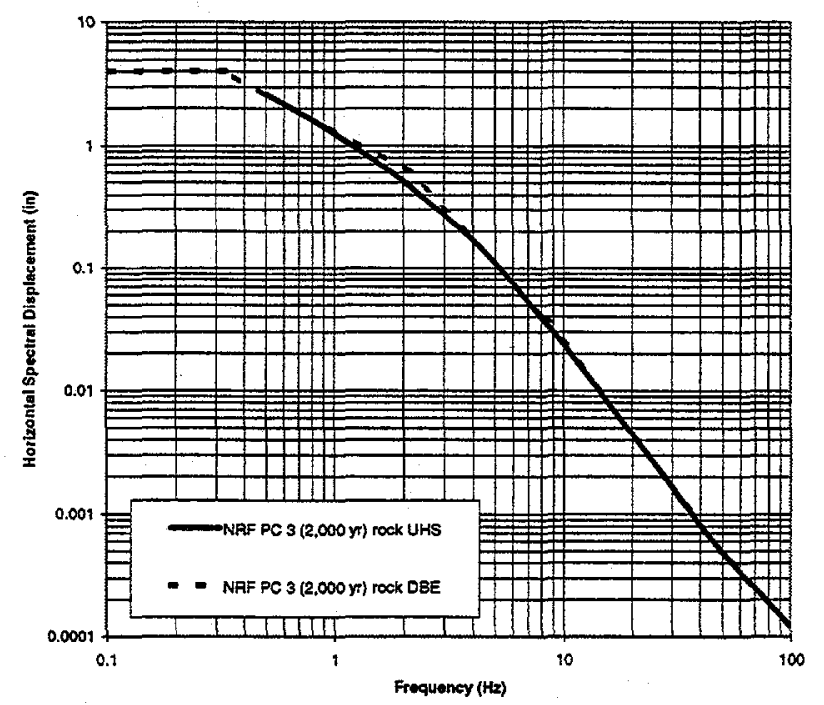

Figure A-13. Envelopes of the horizontal response spectra, (a) acceleration, (b) velocity, and (c) displacement, to portions of the PC 3 rock UHS used to develop the PC 3 (2,000 years) horizontal rock DBE response spectral shape for NRF. 
(a)

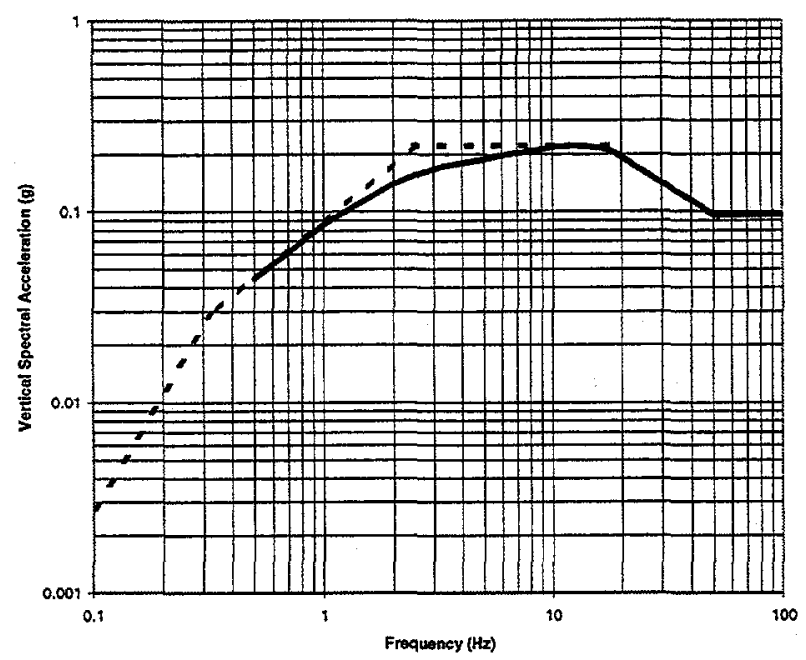

(b)

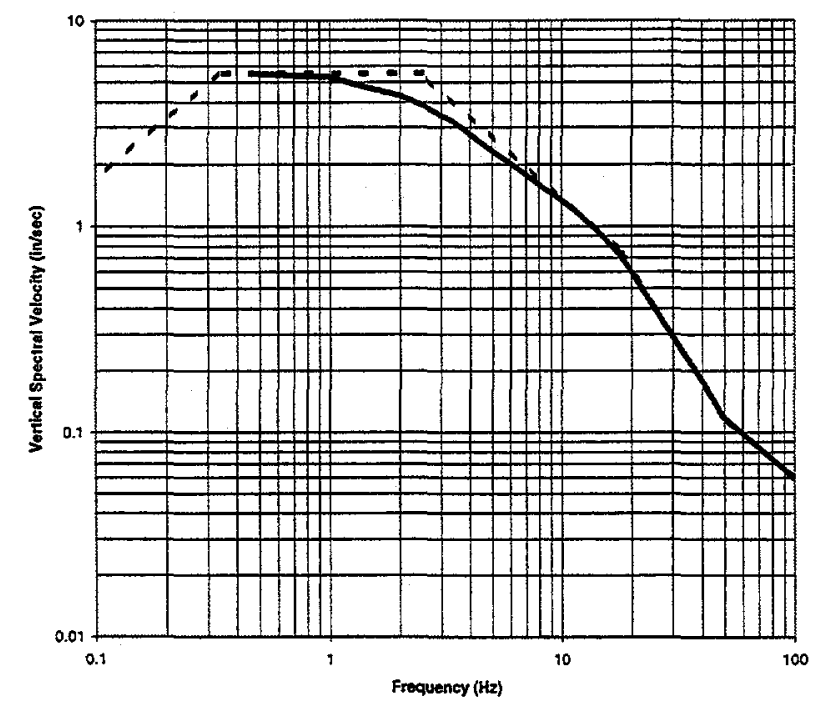

(c)

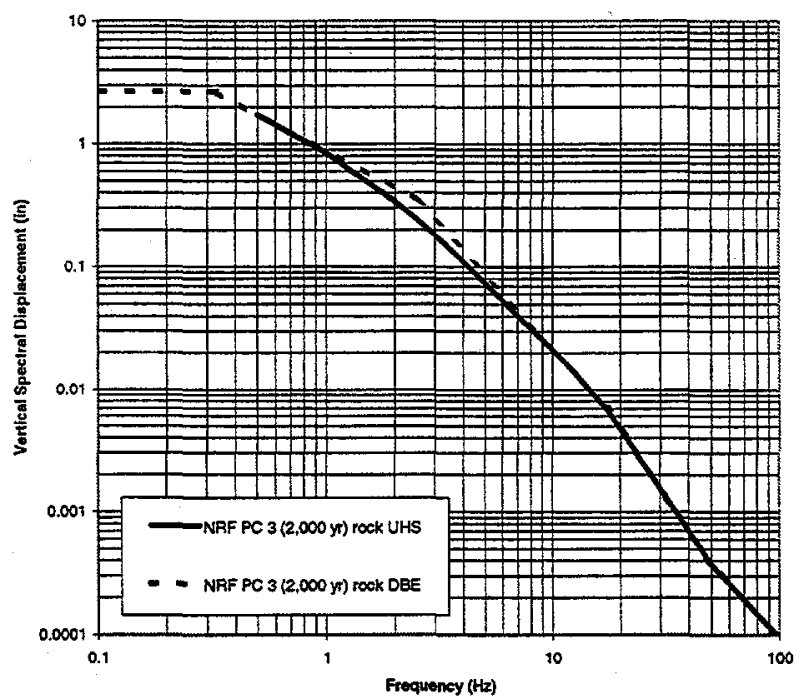

Figure A-14. Envelopes of the vertical response spectra, (a) acceleration, (b) velocity, and (c) displacement, to portions of the PC 3 rock UHS used to develop the PC 3 (2,000 years) vertical rock DBE response spectral shape for NRF. 
(a)

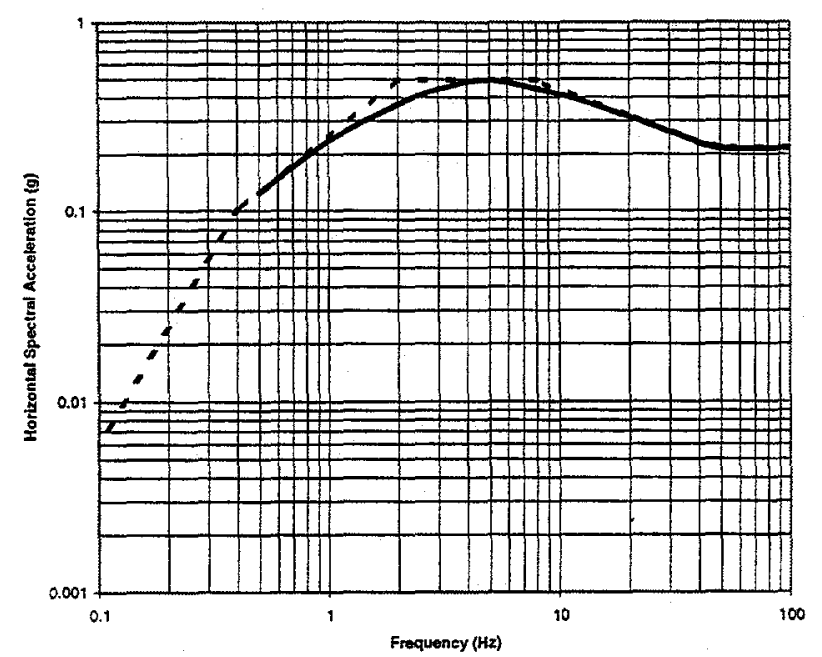

(b)

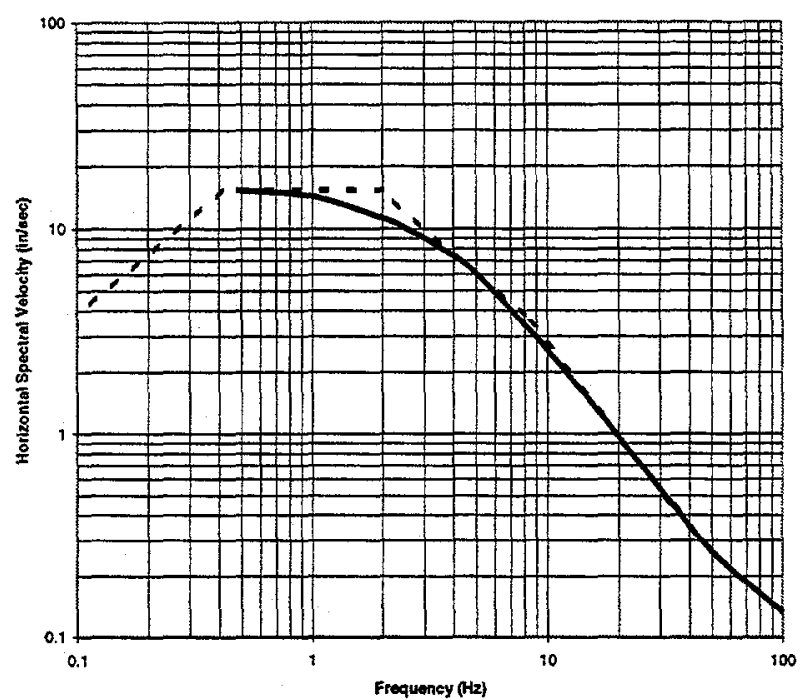

(c)

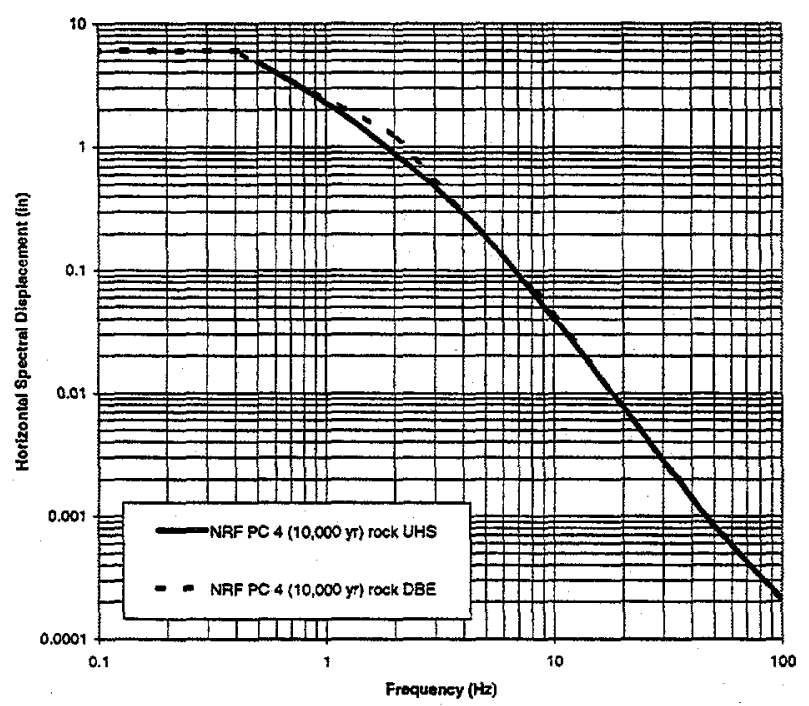

Figure A-15. Envelopes of the horizontal response spectra, (a) acceleration, (b) velocity, and (c) displacement, to portions of the PC 4 rock UHS used to develop the PC $4(10,000$ years) horizontal rock DBE response spectral shape for NRF. 
(a)

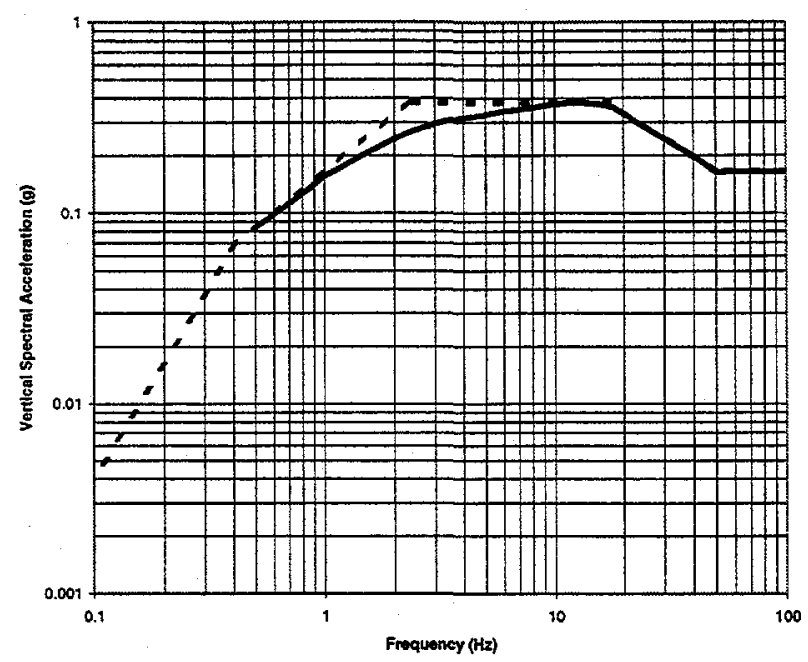

(b)

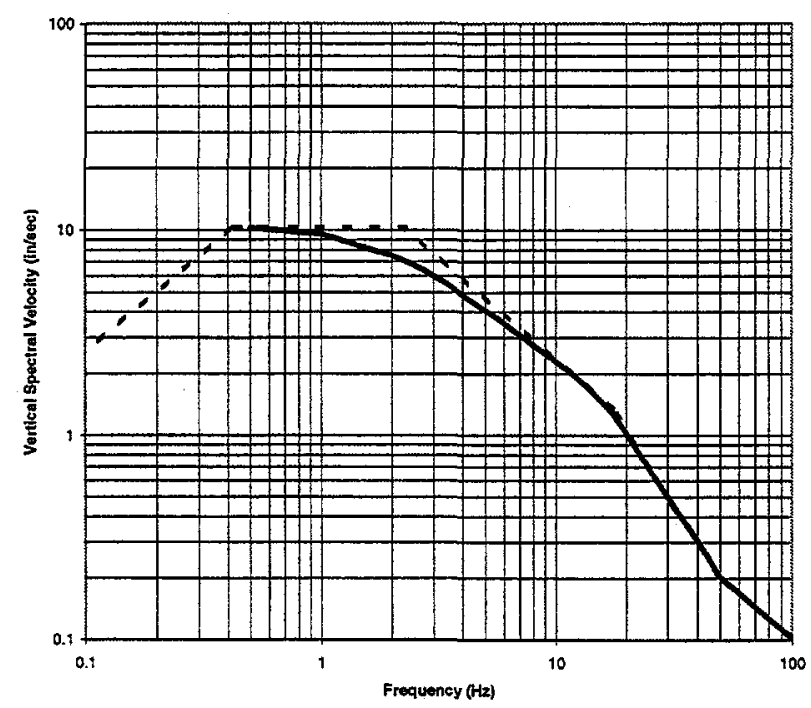

(c)

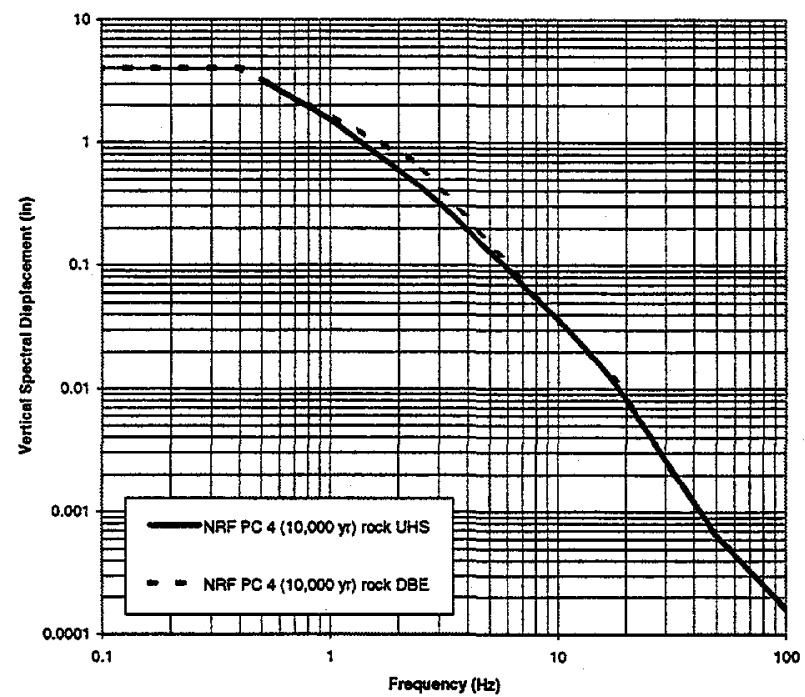

Figure A-16. Envelopes of the vertical response spectra, (a) acceleration, (b) velocity, and (c) displacement, to portions of the PC 4 rock UHS used to develop the PC 4 (10,000 years) vertical rock DBE response spectral shape for NRF. 


\section{A.4 Comparison of the DBE Response Spectra and DOE-ID Architectural Engineering Standards}

Figures A-17 through A-20 show comparisons of the PC 3 and PC 4 rock DBE response spectra for INTEC, TRA, RWMC, and PBF with the current horizontal and vertical design criteria in the DOE-ID AE Standards (DOE, 1998) for RWMC and PBF. 
(a)

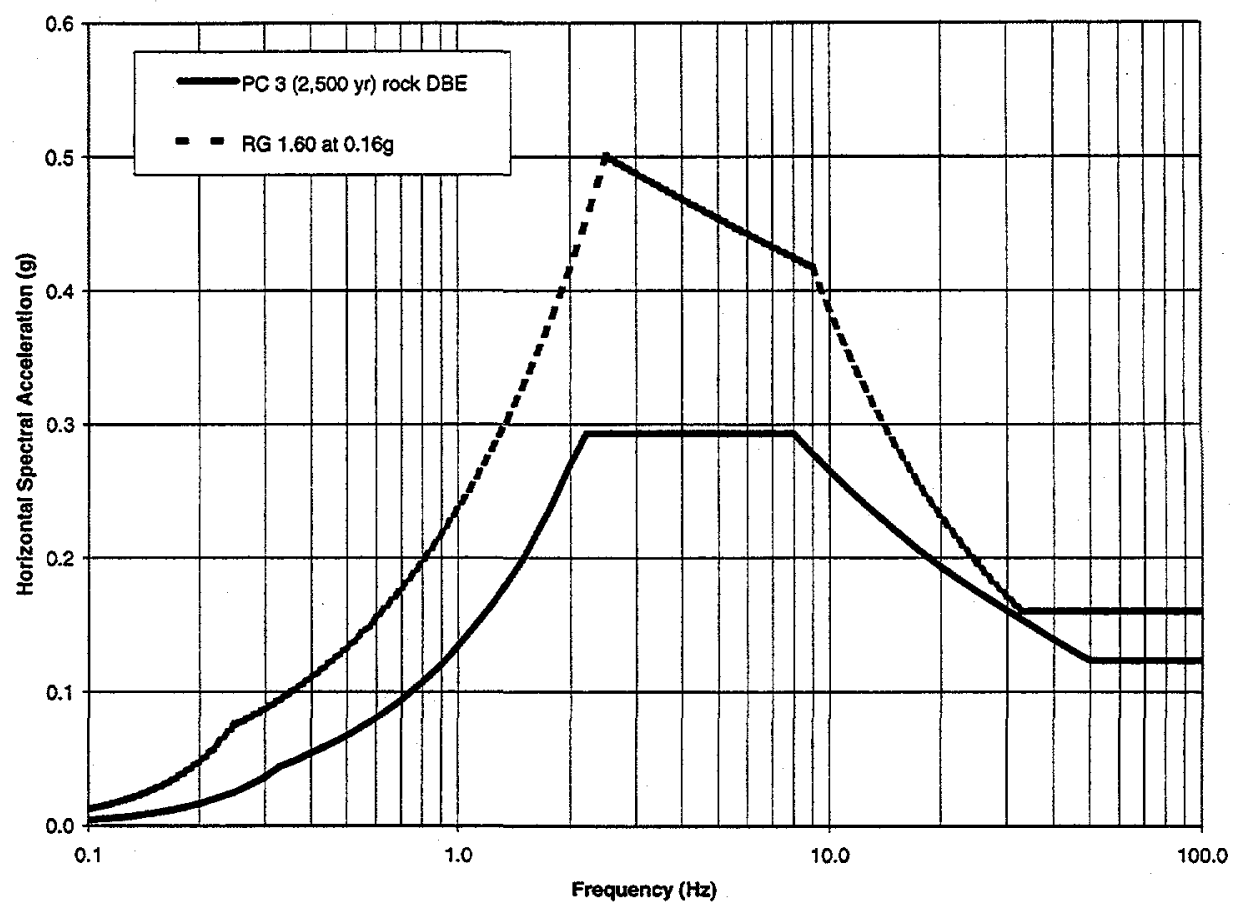

(b)

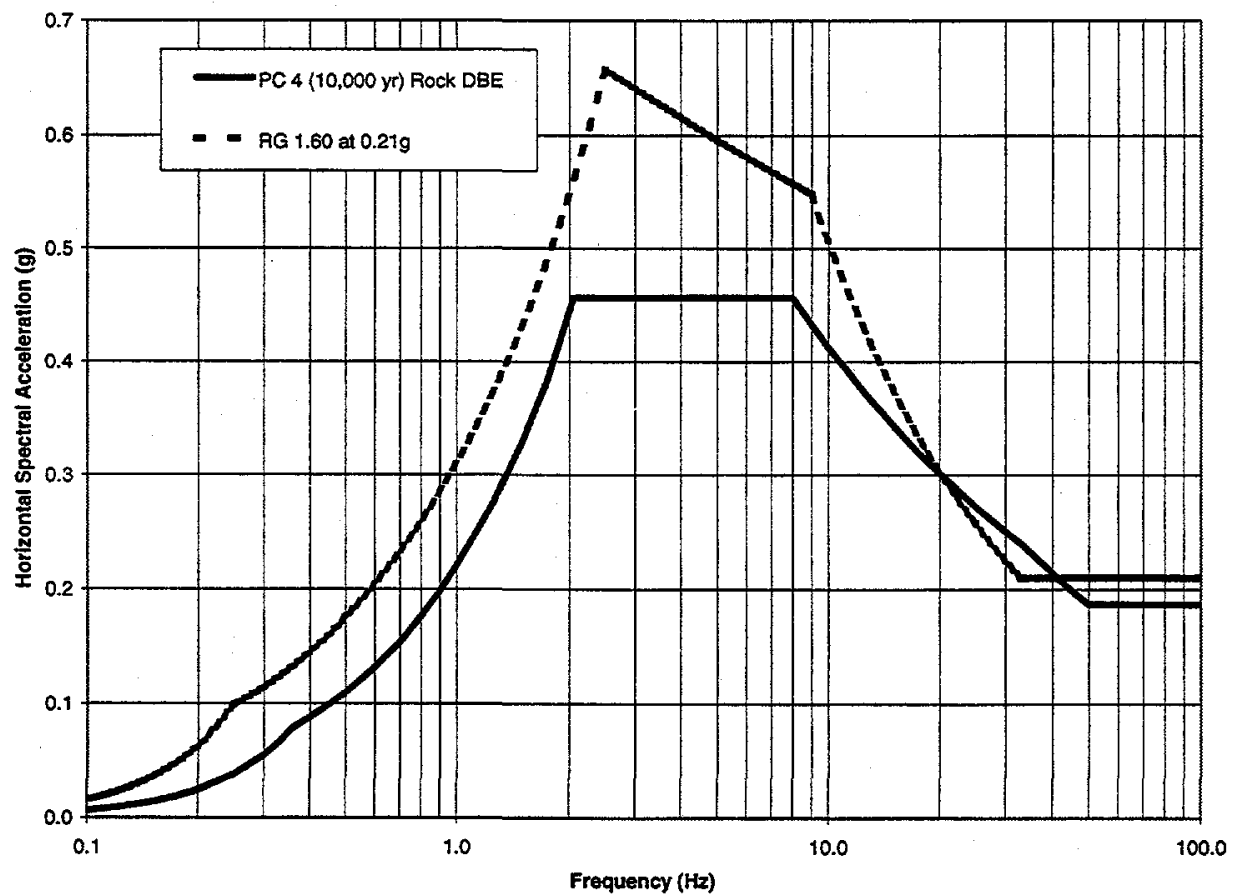

Figure A-17. Comparison of the PC 3 (2,500 years) and PC 4 (10,000 years) horizontal rock DBE response spectra for INTEC, TRA, RWMC, and PBF with the current horizontal design criteria in the DOE-ID AE Standards for RWMC (DOE-ID, 1998). 
(a)

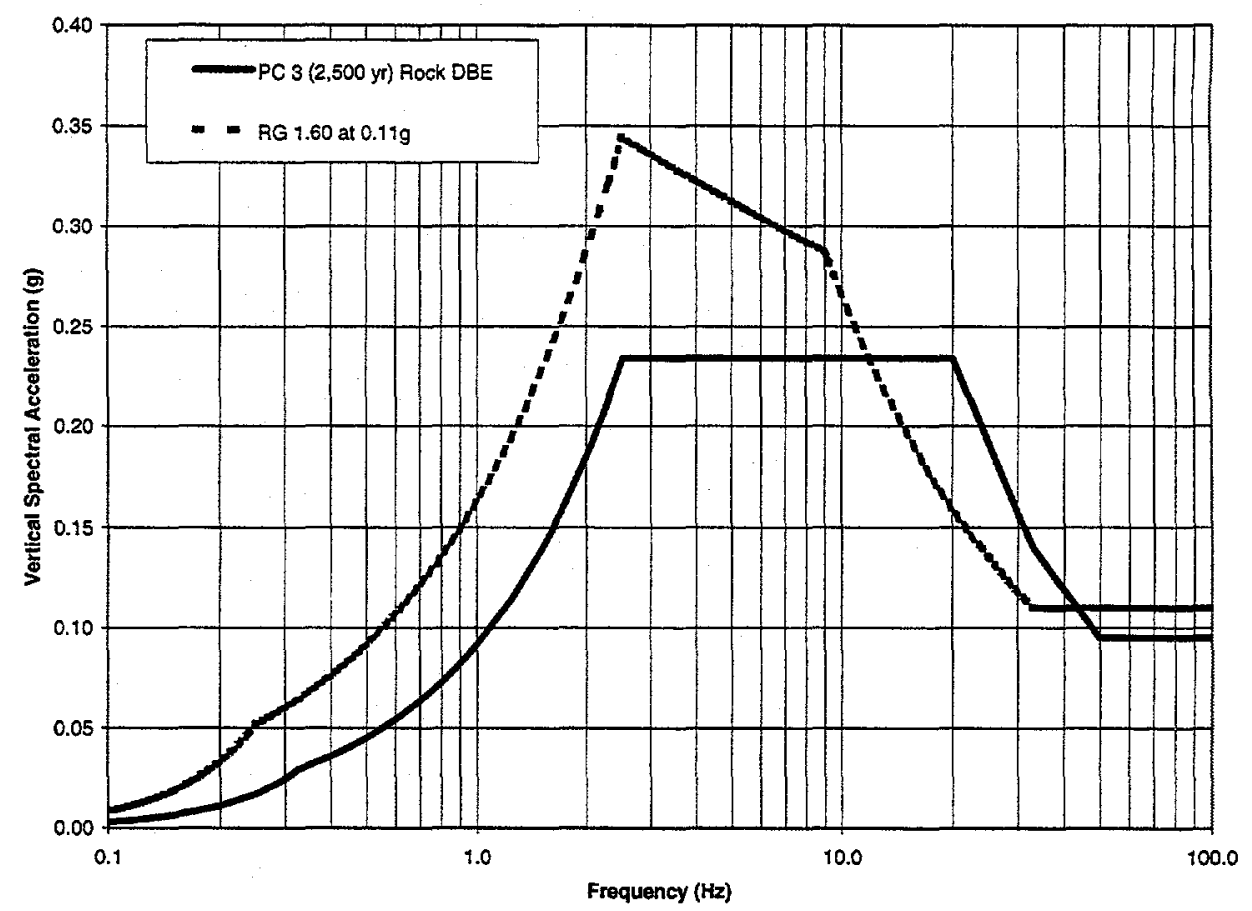

(b)

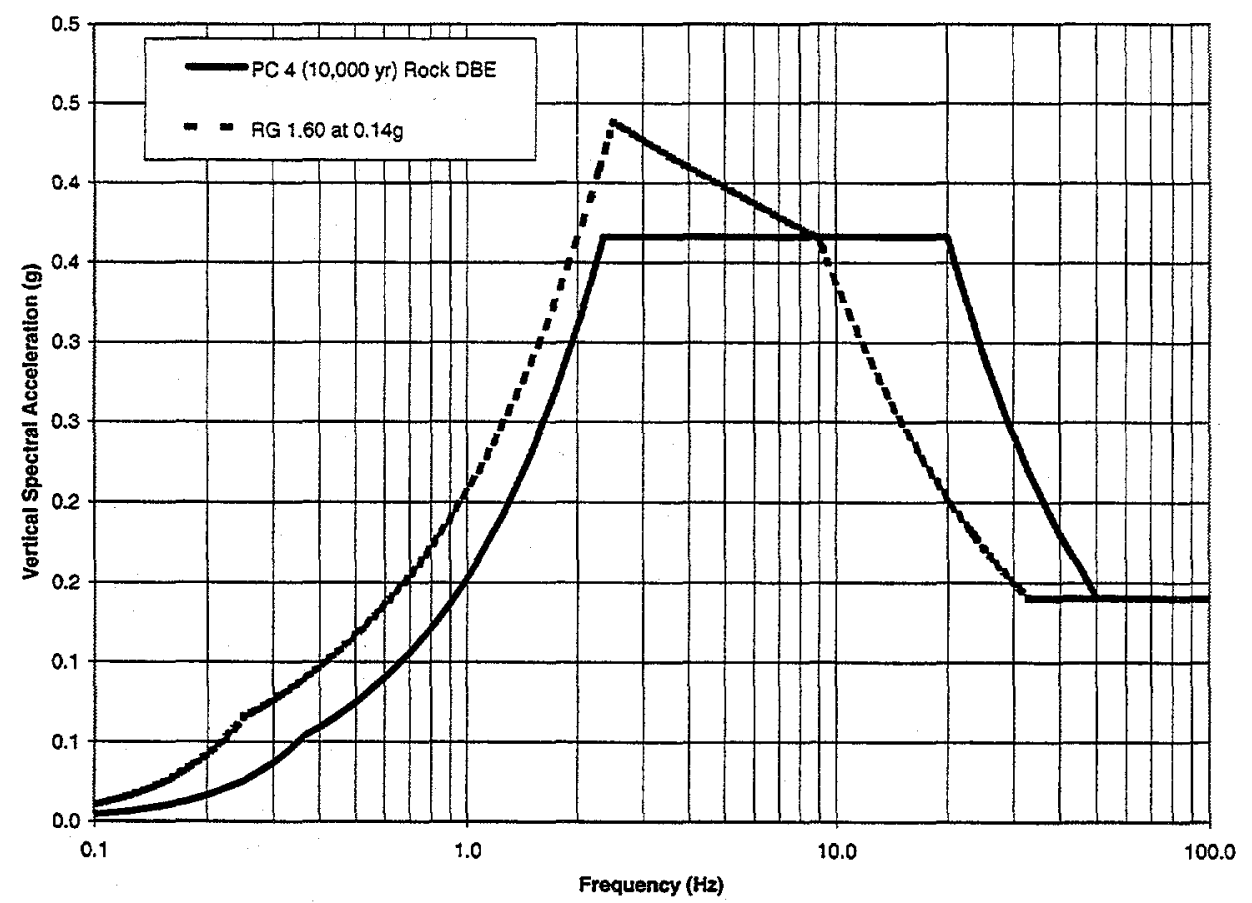

Figure A-18. Comparison of the PC 3 (2,500 years) and PC 4 (10,000 years) vertical rock DBE response spectra for INTEC, TRA, RWMC, and PBF with current vertical design criteria in the DOE-ID AE Standards for RWMC (DOE-ID, 1998). 
(a)

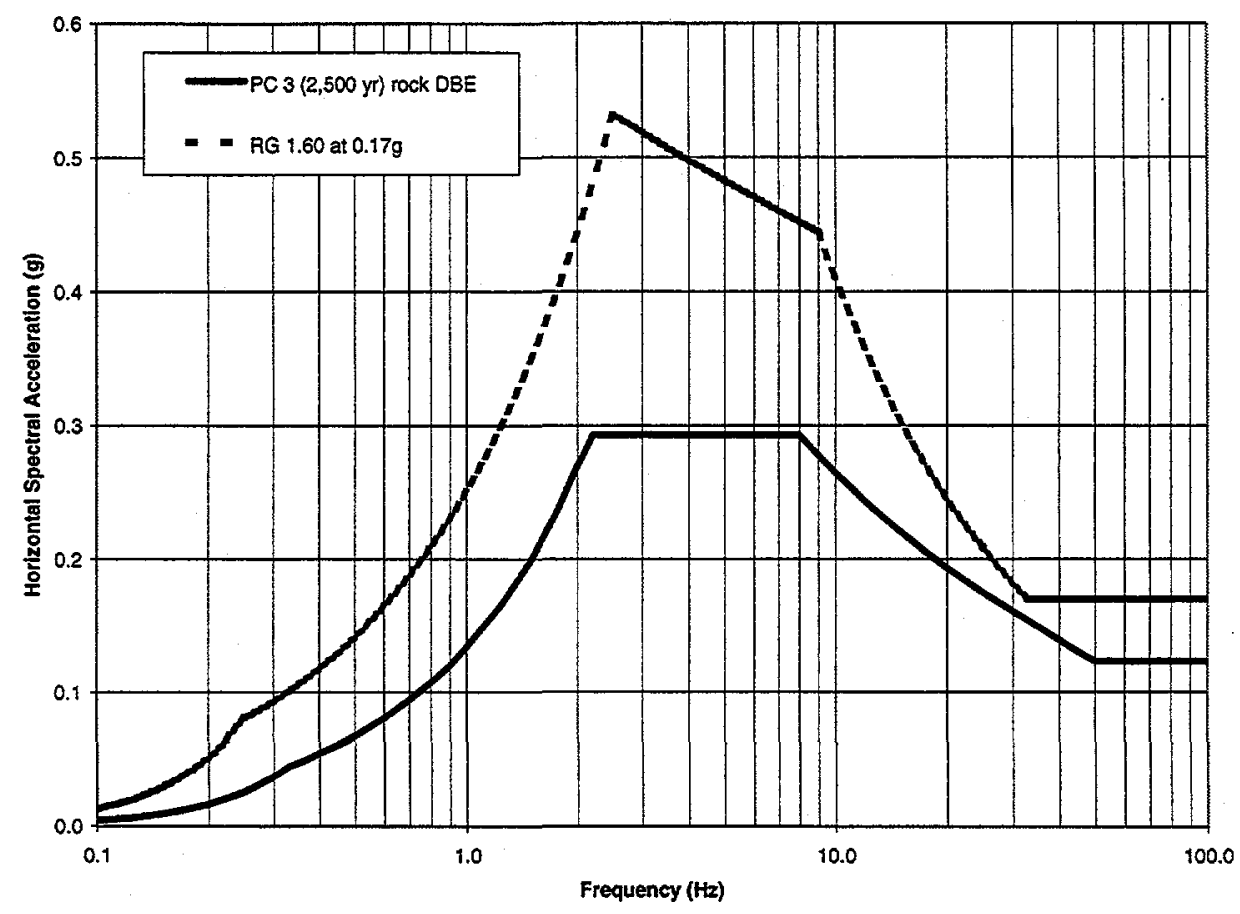

(b)

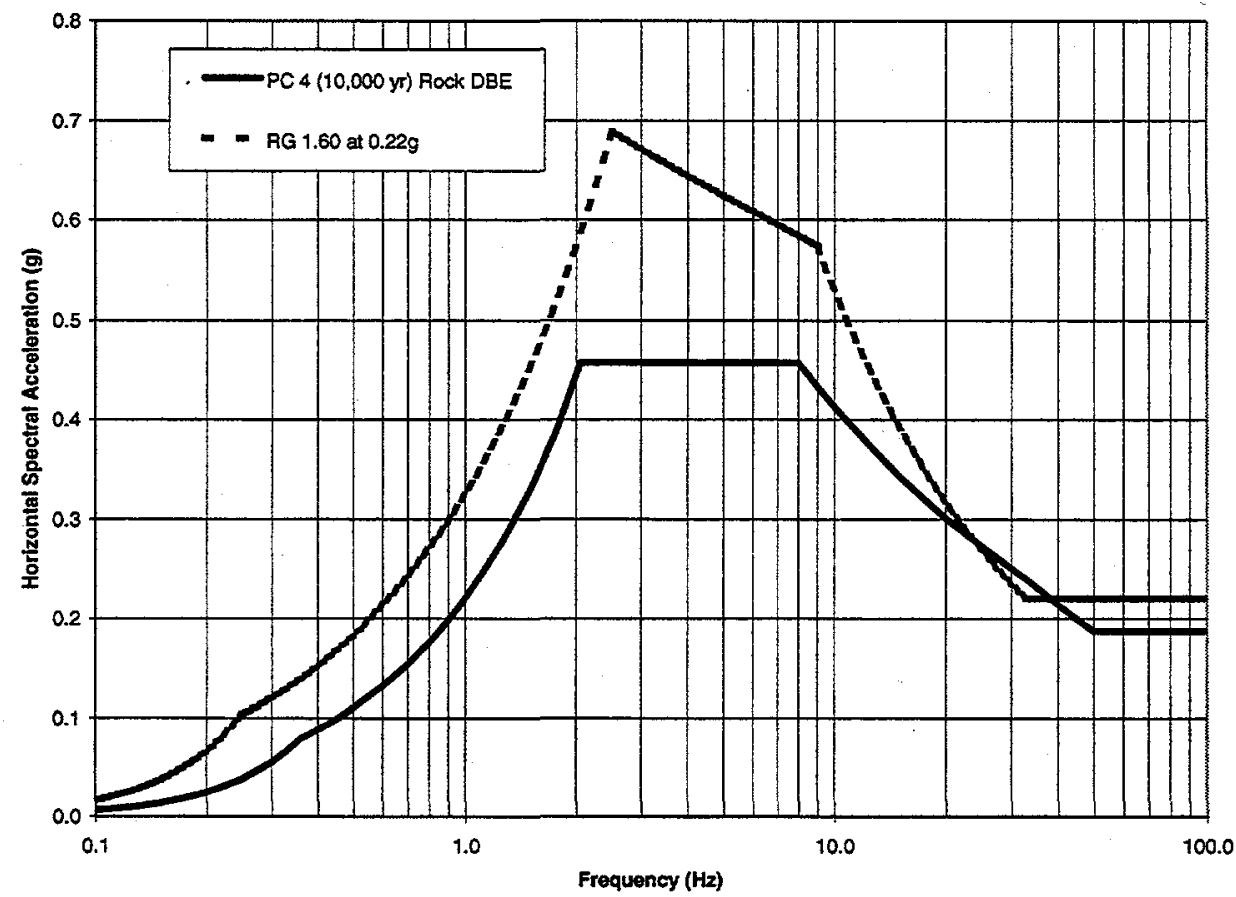

Figure A-19. Comparison of the PC 3 (2,500 years) and PC 4 (10,000 years) horizontal rock DBE response spectra for INTEC, TRA, RWMC, and PBF with the current horizontal design criteria in the DOE-ID AE Standards for PBF (DOE-ID, 1998). 
(a)

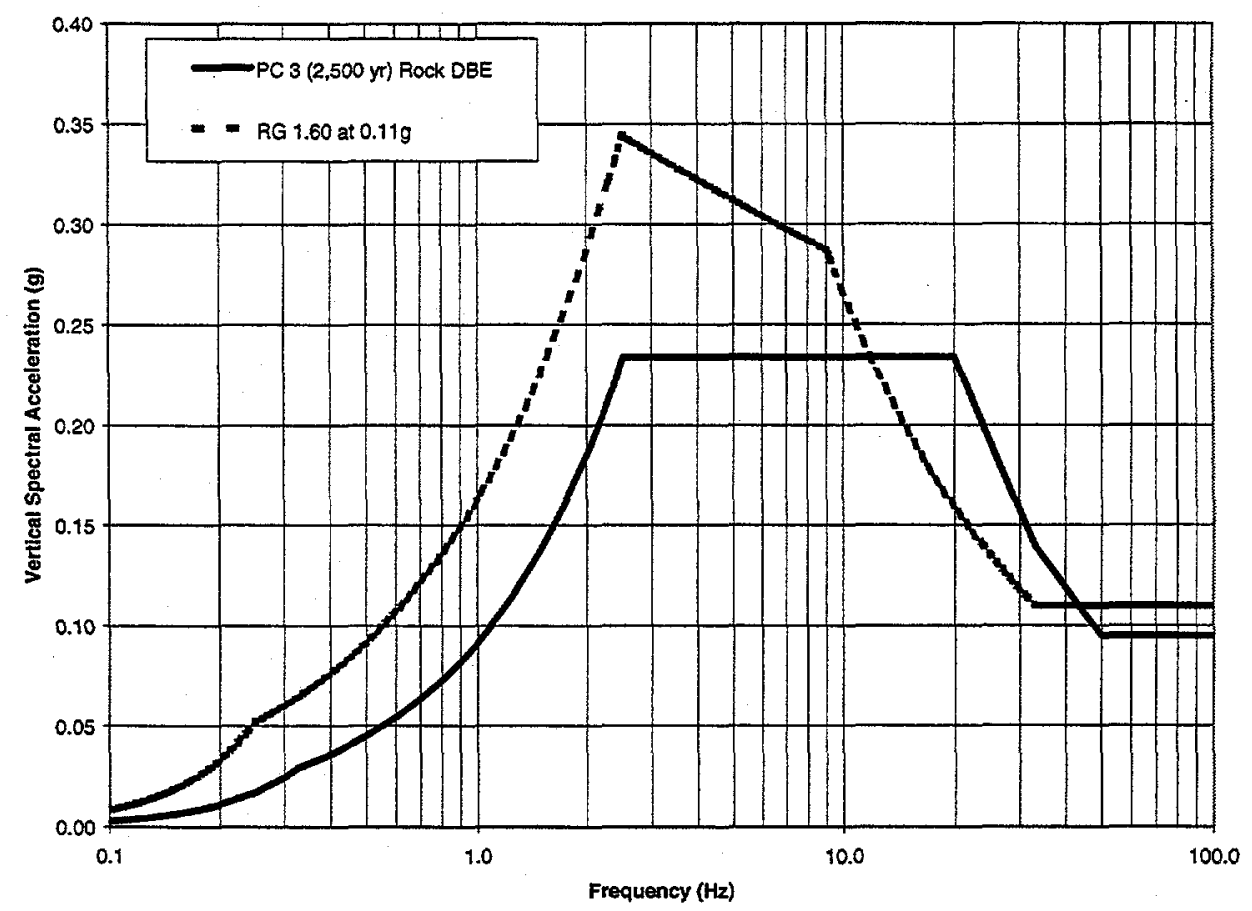

(b)

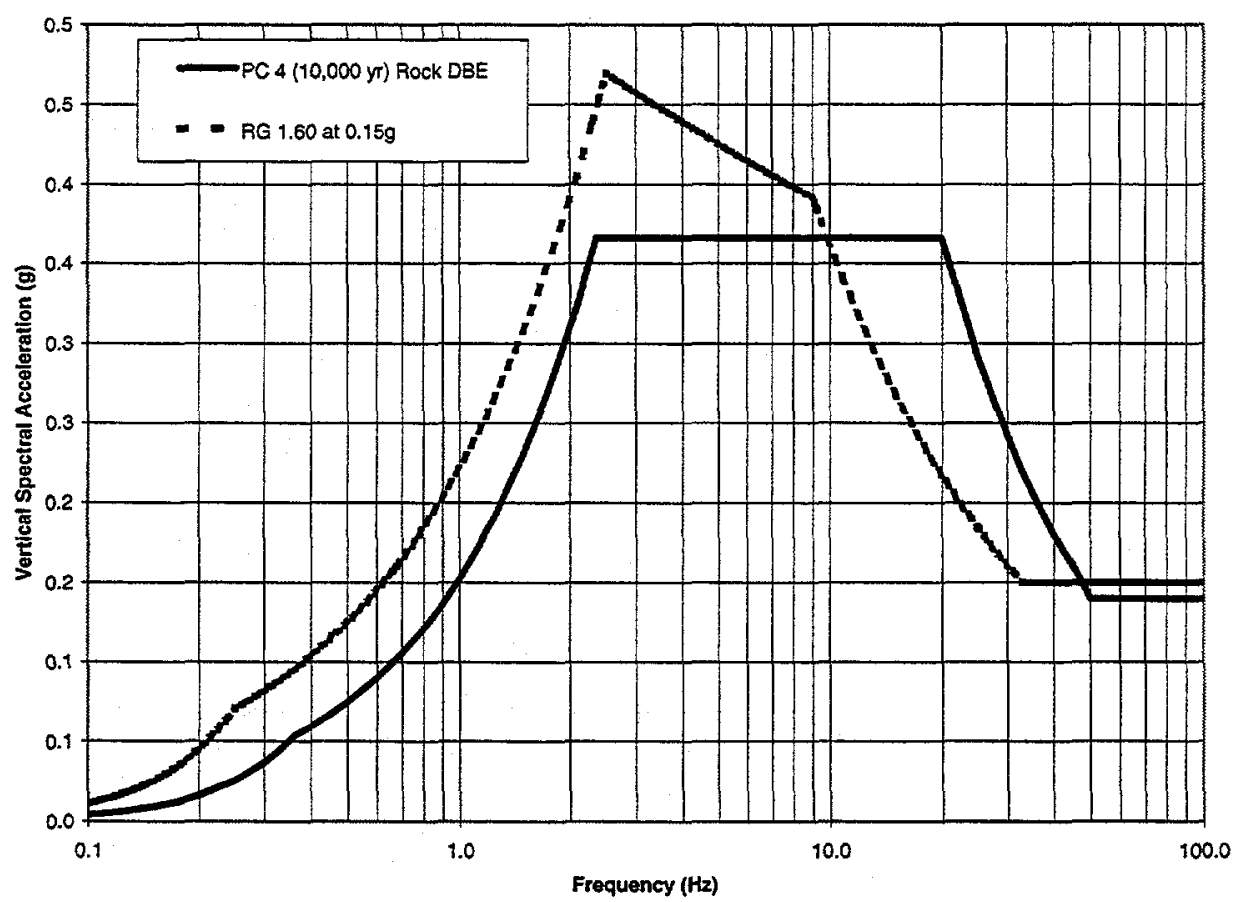

Figure A-20. Comparison of the PC 3 (2,500 years) and $\mathrm{PC} 4$ (10,000 years) vertical rock DBE response spectra for INTEC, TRA, RWMC, and PBF with current vertical design criteria in the DOE-DD AE Standards for PBF (DOE-ID, 1998). 


\section{Appendix B}

Spectral Ratios for the Vertical to Horizontal Motions Used to Develop the Vertical DBE 


\section{Appendix B}

\section{Spectral Ratios for the Vertical to Horizontal Motions Used to Develop the Vertical DBE}

Typically, the vertical component is considered to be $2 / 3$ of the horizontal component. For some critical structures and structures within a short distance of the earthquake source, the vertical spectra can be equal or slightly larger than the horizontal spectra at frequencies greater than $2 \mathrm{~Hz}$. Ideally to develop vertical design spectra, actual recorded earthquake motions (two horizontal and one vertical component) obtained at close distances to the source would be used in the analysis. However, this process cannot be applied because of the scarcity of recorded earthquake motions at INEEL (URSG-WCFS, 1999). Thus, URSG-WCFS (1999) was requested to develop a relationship between horizontal and vertical motions for INEEL.

To develop the V/H ratio, URSG-WCFS (1999) modeled vertical ground motions to compare with empirical predictions. In this implementation of an equivalent-linear approach, the horizontal component analyses were performed for vertically propagating S-waves (P-SV) using random vibration theory (RVT). The vertical motions were computed from a linear analysis of incident inclined P-SV waves using low-strain, $\mathrm{P}$ - and S-wave velocities. Also, the P-wave damping is assumed to be equal to the low strain $S$-wave damping. The horizontal component and vertical component analyses are assumed to be independent (URSG-WCFS, 1999). The approach by URSG-WCFS (1999) has been validated with recordings of the $1989 \mathrm{M}_{\mathrm{w}} 6.9$ Loma Prieta, California earthquake at 20 sites (EPRI, 1993).

The $\mathrm{V} / \mathrm{H}$ ratios as a function of frequency and a dominant earthquake $\left(\mathrm{M}_{\mathrm{w}} 6.9\right.$ at $\left.17 \mathrm{~km}\right)$ were computed using a site-specific $\mathrm{P}$-wave velocity (Vp) profile for soil and underlying rock (URSG-WCFS, 1999). The RVT modeling results, the recommended ratio value of $2 / 3$, and empirical ratios for rock or shallow soil developed by Abrahamson and Silva (1997) were compared by URSG-WCFS (1999). At frequencies less than $10 \mathrm{~Hz}$, the RVT modeling and empirical ratios are less than the standard $2 / 3$ value. A minimum ratio of $2 / 3$ was chosen for frequencies up to $6 \mathrm{~Hz}$ by URSG-WCFS (1999) as required by STD-DOE-1020-94. For frequencies of $6 \mathrm{~Hz}$ and above, URSG-WCFS (1999) chose the empirical ratios of Abrahamson and Silva (1997) because they envelop the RVT modeling results and are conservative. The V/H ratio developed by URSG-WCFS (1999) is shown in Figure 10 of the report and the spectral ratios are listed in Table B-1. The $\mathrm{V} / \mathrm{H}$ ratio is applicable to rock and shallow soil sites $(<100 \mathrm{ft}$; Per. Comm. W. Silva, 2000) since it incorporates the empirical ratios of Abrahamson and Silva (1997). The V/H ratios (Table B-1) were used to develop the vertical DBE response spectra for both rock and soil sites at INEEL (see report for further details). 


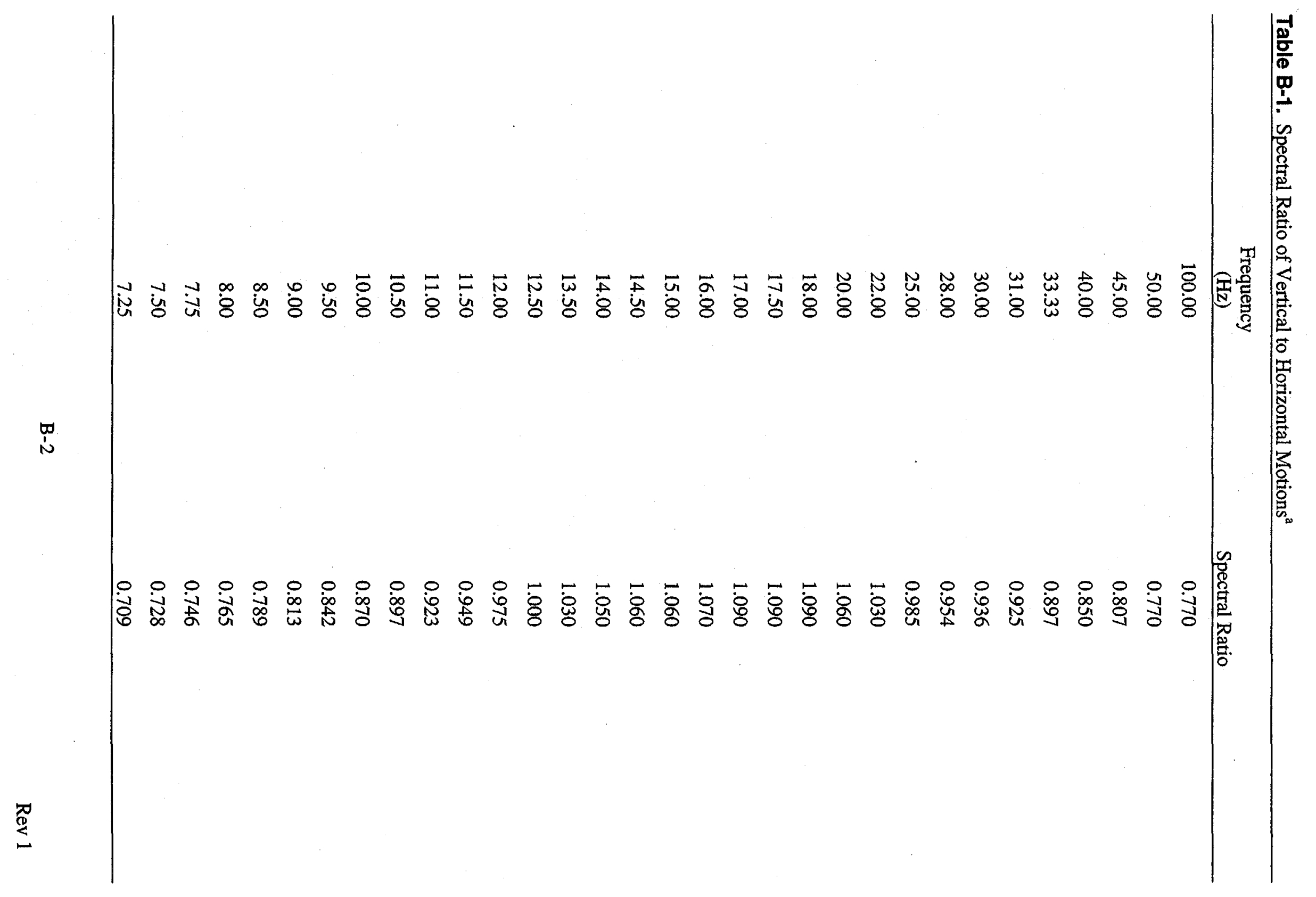


Table C-1. (continued).

Frequency

$(\mathrm{Hz})$

7.00

6.75

6.50

6.25

6.00

1.00

0.10
Spectral Ratio
0.690
0.685
0.679
0.673
0.667
0.667
0.667

a. URSG-WCFS (1999). 


\section{Appendix C}

PC 3 and PC 4 DBE Spectral Accelerations and Velocities 


\section{Appendix C}

\section{PC 3 and PC 4 DBE Spectral Accelerations and Velocities \\ C.1 PC 3 and PC 4 Rock DBE Response Spectra at 2, 3, 5, 7, and $10 \%$ Damping at INTEC, TRA, RWMC, and PBF}

Tables C-1 through C-4 are of spectral accelerations for PC 3 (2,500 years) and PC $4(10,000$ years) horizontal and vertical rock DBE response spectra at 2, 3, 5, 7 and 10\% damping for INTEC, TRA, RWMC, and PBF. The spectral accelerations for the damping values were calculated from the time histories (URSG-WCFS, 2000b) shown in Figures 18 through 23 in Section 2.6 of the report. 
Table C-1. PC 3 (2,500 years) horizontal rock DBE response spectra at 5, 2, 3, 7 and 10\% damping for INTEC, TRA, RWMC, and PBF.

\begin{tabular}{|c|c|c|c|c|}
\hline \multirow[b]{2}{*}{ Damping } & \multirow[b]{2}{*}{ Frequency $(\mathrm{Hz})$} & \multicolumn{3}{|c|}{ Horizontal Spectral } \\
\hline & & Acceleration $(\mathrm{g})$ & Velocity (in/sec) & Displacement (in) \\
\hline \multirow[t]{7}{*}{$5 \%$} & 100 & 0.1230 & 0.0756 & 0.0001 \\
\hline & 50 & 0.1230 & 0.1513 & 0.0005 \\
\hline & 33 & 0.1540 & 0.2870 & 0.0014 \\
\hline & 8 & 0.2930 & 2.2523 & 0.0448 \\
\hline & 2.1866 & 0.2930 & 8.2407 & 0.5998 \\
\hline & 0.3279 & 0.0439 & 8.2407 & 4.0000 \\
\hline & 0.1 & 0.0041 & 2.5133 & 4.0000 \\
\hline \multirow[t]{7}{*}{$2 \%$} & 100 & 0.1230 & 0.0756 & 0.0001 \\
\hline & 50 & 0.1230 & 0.1513 & 0.0005 \\
\hline & 36.3969 & 0.1873 & 0.2870 & 0.0014 \\
\hline & 9.8038 & 0.4400 & 2.7602 & 0.0448 \\
\hline & 2.3868 & 0.4400 & 11.3375 & 0.7560 \\
\hline & 0.3983 & 0.0734 & 11.3375 & 4.5300 \\
\hline & 0.1 & 0.0046 & 2.8463 & 4.5300 \\
\hline \multirow[t]{7}{*}{$3 \%$} & 100 & 0.1230 & 0.0756 & 0.0001 \\
\hline & 50 & 0.1230 & 0.1513 & 0.0005 \\
\hline & 34.7947 & 0.1712 & 0.2870 & 0.0014 \\
\hline & 8.9764 & 0.3689 & 2.5272 & 0.0448 \\
\hline & 2.2734 & 0.3689 & 9.9786 & 0.6986 \\
\hline & 0.3734 & 0.0606 & 9.9786 & 4.2532 \\
\hline & 0.1 & 0.0043 & 2.6724 & 4.2532 \\
\hline \multirow[t]{7}{*}{$7 \%$} & 100 & 0.1230 & 0.0756 & 0.0001 \\
\hline & 50 & 0.1230 & 0.1513 & 0.0005 \\
\hline & 32.1148 & 0.1458 & 0.2870 & 0.0014 \\
\hline & 7.4931 & 0.2570 & 2.1096 & 0.0448 \\
\hline & 2.1963 & 0.2570 & 7.1974 & 0.5216 \\
\hline & 0.2976 & 0.0348 & 7.1974 & 3.8496 \\
\hline & 0.1 & 0.0039 & 2.4188 & 3.8496 \\
\hline
\end{tabular}

C-2 
Table C-1. (continued).

Horizontal Spectral

\begin{tabular}{ccccc} 
Damping & Frequency $(\mathrm{Hz})$ & Acceleration $(\mathrm{g})$ & Velocity (in/sec) & Displacement (in) \\
\hline $10 \%$ & 100 & 0.1230 & 0.0756 & 0.0001 \\
& 50 & 0.1230 & 0.1513 & 0.0005 \\
& 31.3957 & 0.1394 & 0.2870 & 0.0014 \\
7.0659 & 0.2286 & 1.9893 & 0.0448 \\
& 2.2623 & 0.2286 & 6.2135 & 0.4371 \\
& 0.2622 & 0.0265 & 6.2135 & 3.7716 \\
& 0.1 & 0.0039 & 2.3698 & 3.7716 \\
\hline
\end{tabular}

C-3 
Table C-2. PC 3 (2,500 years) vertical rock DBE response spectra at 5, 2, 3, 7 and 10\% damping for INTEC, TRA, RWMC, and PBF.

\begin{tabular}{|c|c|c|c|c|}
\hline \multirow[b]{2}{*}{ Damping } & \multirow[b]{2}{*}{ Frequency $(\mathrm{Hz})$} & \multicolumn{3}{|c|}{ Vertical Spectral } \\
\hline & & Acceleration $(\mathrm{g})$ & Velocity (in/sec) & Displacement (in) \\
\hline \multirow[t]{7}{*}{$5 \%$} & 100 & 0.0947 & 0.0582 & 0.0001 \\
\hline & 50 & 0.0947 & 0.1165 & 0.0004 \\
\hline & 33 & 0.1395 & 0.2600 & 0.0013 \\
\hline & 20 & 0.2250 & 0.6918 & 0.0055 \\
\hline & 2.5174 & 0.2250 & 5.4965 & 0.3475 \\
\hline & 0.3279 & 0.0293 & 5.4965 & 2.6680 \\
\hline & 0.1 & 0.0027 & 1.6764 & 2.6680 \\
\hline \multirow[t]{7}{*}{$2 \%$} & 100 & 0.0947 & 0.0582 & 0.0001 \\
\hline & 50 & 0.0947 & 0.1165 & 0.0004 \\
\hline & 35.6885 & 0.1632 & 0.2600 & 0.0013 \\
\hline & 24.1975 & 0.3294 & 0.8370 & 0.0055 \\
\hline & 2.8014 & 0.3294 & 7.2301 & 0.4108 \\
\hline & 0.3995 & 0.0470 & 7.2301 & 2.8804 \\
\hline & 0.1 & 0.0029 & 1.8098 & 2.8804 \\
\hline \multirow[t]{7}{*}{$3 \%$} & 100 & 0.0947 & 0.0582 & 0.0001 \\
\hline & 50 & 0.0947 & 0.1165 & 0.0004 \\
\hline & 34.4498 & 0.1521 & 0.2600 & 0.0013 \\
\hline & 22.3213 & 0.2803 & 0.7721 & 0.0055 \\
\hline & 2.6671 & 0.2803 & 6.4623 & 0.3856 \\
\hline & 0.3679 & 0.0387 & 6.4623 & 2.7958 \\
\hline & 0.1 & 0.0029 & 1.7567 & 2.7958 \\
\hline \multirow[t]{7}{*}{$7 \%$} & 100 & 0.0947 & 0.0582 & 0.0001 \\
\hline & 50 & 0.0947 & 0.1165 & 0.0004 \\
\hline & 32.1238 & 0.1322 & 0.2600 & 0.0013 \\
\hline & 18.5116 & 0.1928 & 0.6404 & 0.0055 \\
\hline & 2.4194 & 0.1928 & 4.8996 & 0.3223 \\
\hline & 0.3013 & 0.0240 & 4.8996 & 2.5882 \\
\hline & 0.1 & 0.0026 & 1.6262 & 2.5882 \\
\hline
\end{tabular}

C-4 
Table C-2. (continued).

Vertical Spectral

Damping

Frequency $(\mathrm{Hz})$

Acceleration (g) Velocity (in/sec) Displacement (in)

$10 \%$

100

50

0.0947

0.0582

0.0001

31.3491

0.0947

0.1165

0.0004

17.1254

0.1259

0.2600

0.0013

2.3718

0.1650

0.5924

0.0055

0.2699

0.1650

4.2774

0.2870

0.1

0.0188

4.2774

2.5223

0.0026

1.5848

2.5223

C-5 
Table C-3. PC 4 (10,000 years) horizontal rock DBE response spectra at 5, 2,3, 7 and $10 \%$ damping for INTEC, TRA, RWMC, and PBF.

\begin{tabular}{|c|c|c|c|c|}
\hline \multirow[b]{2}{*}{ Damping } & \multirow{2}{*}{ Frequency $(\mathrm{Hz})$} & \multicolumn{3}{|c|}{ Horizontal Spectral } \\
\hline & & Acceleration $(\mathrm{g})$ & Velocity (in/sec) & Displacement (in) \\
\hline \multirow[t]{7}{*}{$5 \%$} & 100 & 0.1870 & 0.1150 & 0.0002 \\
\hline & 50 & 0.1870 & 0.2300 & 0.0007 \\
\hline & 33 & 0.2420 & 0.4510 & 0.0022 \\
\hline & 8 & 0.4570 & 3.5130 & 0.0699 \\
\hline & 2.0586 & 0.4570 & 13.6524 & 1.0555 \\
\hline & 0.3621 & 0.0804 & 13.6524 & 6.0000 \\
\hline & 0.1 & 0.0061 & 3.7699 & 6.0000 \\
\hline \multirow[t]{7}{*}{$2 \%$} & 100 & 0.1870 & 0.1150 & 0.0002 \\
\hline & 50 & 0.1870 & 0.2300 & 0.0007 \\
\hline & 36.3843 & 0.2942 & 0.4510 & 0.0022 \\
\hline & 9.8097 & 0.6871 & 4.3077 & 0.0699 \\
\hline & 2.2486 & 0.6871 & 18.7926 & 1.3301 \\
\hline & 0.4421 & 0.1351 & 18.7926 & 6.7656 \\
\hline & 0.1 & 0.0069 & 4.2510 & 6.7656 \\
\hline \multirow[t]{7}{*}{$3 \%$} & 100 & 0.1870 & 0.1150 & 0.0002 \\
\hline & 50 & 0.1870 & 0.2300 & 0.0007 \\
\hline & 34.7944 & 0.2690 & 0.4510 & 0.0022 \\
\hline & 8.9832 & 0.5762 & 3.9448 & 0.0699 \\
\hline & 2.1376 & 0.5762 & 16.5782 & 1.2344 \\
\hline & 0.4158 & 0.1121 & 16.5782 & 6.3462 \\
\hline & 0.1 & 0.0065 & 3.9874 & 6.3462 \\
\hline \multirow[t]{7}{*}{$7 \%$} & 100 & 0.1870 & 0.1150 & 0.0002 \\
\hline & 50 & 0.1870 & 0.2300 & 0.0007 \\
\hline & 32.1192 & 0.2293 & 0.4510 & 0.0022 \\
\hline & 7.4919 & 0.4008 & 3.2899 & 0.0699 \\
\hline & 2.0656 & 0.4008 & 11.9322 & 0.9194 \\
\hline & 0.3279 & 0.0636 & 11.9322 & 5.7912 \\
\hline & 0.1 & 0.0059 & 3.6387 & 5.7912 \\
\hline
\end{tabular}

C-6

Rev 1 
Table C-3. (continued).

Horizontal Spectral

\begin{tabular}{ccccc} 
Damping & Frequency $(\mathrm{Hz})$ & Acceleration $(\mathrm{g})$ & Velocity (in/sec) & Displacement (in) \\
\hline $10 \%$ & 100 & 0.1870 & 0.1150 & 0.0002 \\
50 & 0.1870 & 0.2300 & 0.0007 \\
& 31.3857 & 0.2189 & 0.4510 & 0.0022 \\
7.0523 & 0.3551 & 3.0969 & 0.0699 \\
2.1157 & 0.3551 & 10.3226 & 0.7765 \\
& 0.2876 & 0.0483 & 10.3226 & 5.7132 \\
& 0.1 & 0.0058 & 3.5897 & 5.7132 \\
\hline
\end{tabular}

C-7 
Table C-4. PC 4 (10,000 years) vertical rock DBE response spectra at 5, 2, 3, 7 and 10\% damping for INTEC, TRA, RWMC, and PBF.

Vertical Spectral

\begin{tabular}{|c|c|c|c|c|}
\hline Damping & Frequency $(\mathrm{Hz})$ & Acceleration $(\mathrm{g})$ & Velocity (in/sec) & Displacement (in) \\
\hline \multirow[t]{7}{*}{$\mathbf{5 \%}$} & 100 & 0.1440 & 0.0886 & 0.0001 \\
\hline & 50 & 0.1440 & 0.1771 & 0.0006 \\
\hline & 33 & 0.2193 & 0.4086 & 0.0020 \\
\hline & 20 & 0.3478 & 1.0695 & 0.0085 \\
\hline & 2.3489 & 0.3478 & 9.1062 & 0.6170 \\
\hline & 0.3623 & 0.0537 & 9.1062 & 4.0000 \\
\hline & 0.1 & 0.0041 & 2.5133 & 4.0000 \\
\hline \multirow[t]{7}{*}{$2 \%$} & 100 & 0.1440 & 0.0886 & 0.0001 \\
\hline & 50 & 0.1440 & 0.1771 & 0.0006 \\
\hline & 35.6595 & 0.2560 & 0.4086 & 0.0020 \\
\hline & 24.2173 & 0.5100 & 1.2950 & 0.0085 \\
\hline & 2.6018 & 0.5100 & 12.0538 & 0.7374 \\
\hline & 0.4458 & 0.0874 & 12.0538 & 4.3036 \\
\hline & 0.1 & 0.0044 & 2.7040 & 4.3036 \\
\hline \multirow[t]{7}{*}{$3 \%$} & 100 & 0.1440 & 0.0886 & 0.0001 \\
\hline & 50 & 0.1440 & 0.1771 & 0.0006 \\
\hline & 34.4295 & 0.2387 & 0.4086 & 0.0020 \\
\hline & 22.3258 & 0.4334 & 1.1938 & 0.0085 \\
\hline & 2.4729 & 0.4334 & 10.7781 & 0.6937 \\
\hline & 0.4107 & 0.0720 & 10.7781 & 4.1768 \\
\hline & 0.1 & 0.0043 & 2.6244 & 4.1768 \\
\hline \multirow[t]{7}{*}{$7 \%$} & 100 & 0.1440 & 0.0886 & 0.0001 \\
\hline & 50 & 0.1440 & 0.1771 & 0.0006 \\
\hline & 32.1474 & 0.2081 & 0.4086 & 0.0020 \\
\hline & 18.5278 & 0.2985 & 0.9907 & 0.0085 \\
\hline & 2.2665 & 0.2985 & 8.0990 & 0.5687 \\
\hline & 0.3318 & 0.0437 & 8.0990 & 3.8844 \\
\hline & 0.1 & 0.0040 & 2.4406 & 3.8844 \\
\hline
\end{tabular}

C-8 
Table C-4. (continued).

Vertical Spectral

\begin{tabular}{ccccc}
\cline { 3 - 4 } Damping & Frequency $(\mathrm{Hz})$ & Acceleration $(\mathrm{g})$ & Velocity $(\mathrm{in} / \mathrm{sec})$ & Displacement (in) \\
\hline \multirow{2}{*}{$10 \%$} & 100 & 0.1440 & 0.0886 & 0.0001 \\
& 50 & 0.1440 & 0.1771 & 0.0006 \\
& 31.3748 & 0.1982 & 0.4086 & 0.0020 \\
17.1219 & 0.2549 & 0.9156 & 0.0085 \\
& 2.2216 & 0.2549 & 7.0564 & 0.5055 \\
& 0.2957 & 0.0339 & 7.0564 & 3.7984 \\
& 0.1 & 0.0039 & 2.3866 & 3.7984 \\
\hline
\end{tabular}

C-9 


\section{C.2 Spectral Velocities for the PC 3 and PC 4 DBE Response Spectra}

Tables C-5 and C-6 are of spectral velocities for PC 3 (2,500-year) and PC 4 (10,000-year) rock DBE 5\% damped response spectra at INTEC, TRA, RWMC, and PBF used to plot the tripartite graphs in Figures 15 and 16, Section 2.6 in the report. Tables C-7 and C-8 are of spectral velocities for PC 3 (2,500-year) and PC 4 (10,000-year) soil DBE 5\% damped response spectra at INTEC used to plot the tripartite graphs in Figures 32 and 33, Section 3.4 in the report. Tables C-9 and C-10 are of spectral velocities for PC 3 (2,500-year) and PC 4 (10,000-year) rock DBE 5\% damped response spectra at TAN used to plot the tripartite graphs in Figures 40 and 41, Section 4.4 in the report. Tables C-11 and C-12 are of spectral velocities for PC 3 (2,000-year) and PC 4 (10,000-year) rock DBE 5\% damped response spectra at NRF used to plot the tripartite graphs in Figures 48 and 49 , Section 5.4 in the report. 
Table C-5. Spectral velocities for the horizontal rock DBE 5\% damped response spectra for PC $3(2,500$ years) and PC $4(10,000$ years) at INTEC, TRA, RWMC, and PBF.

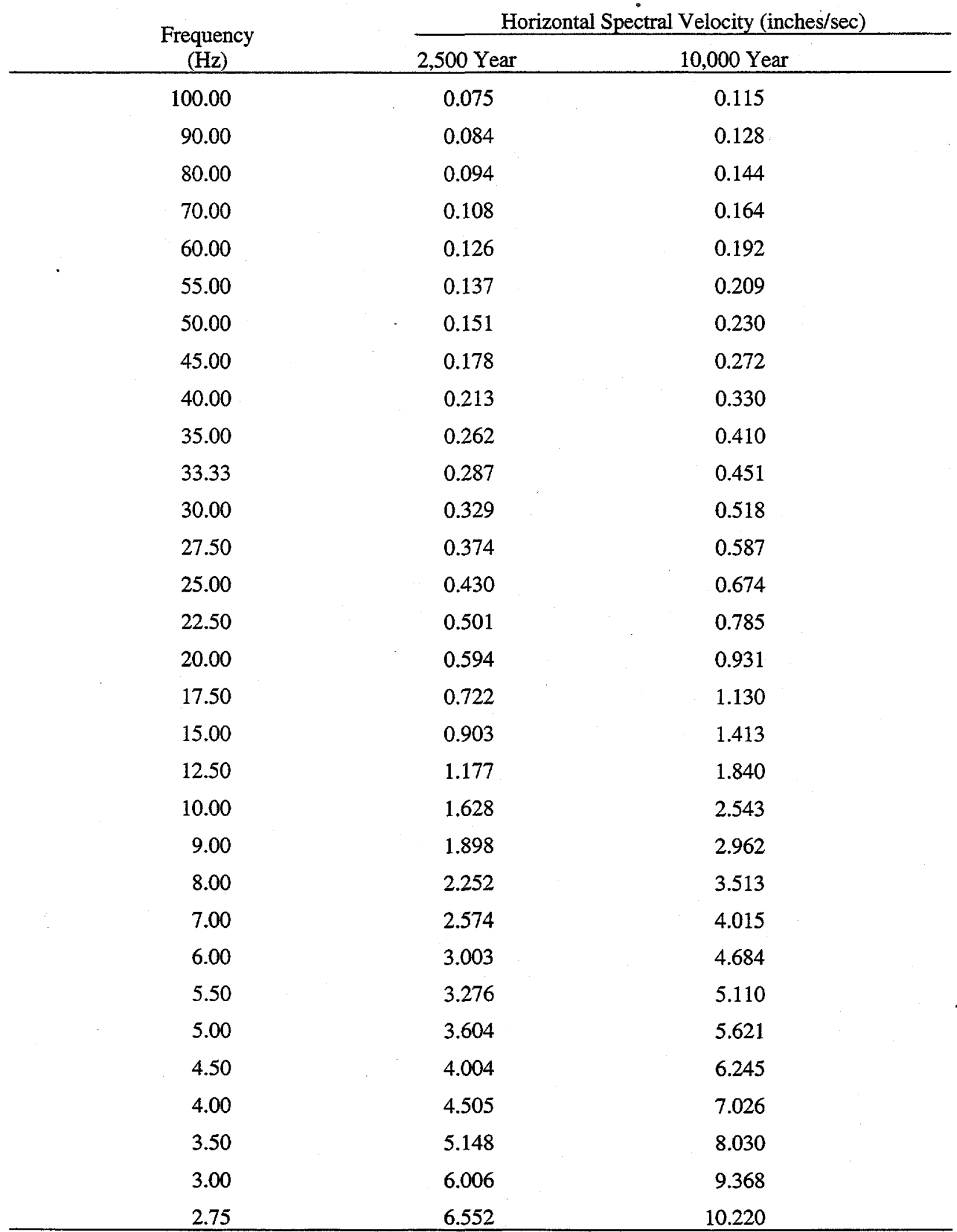

C-11 


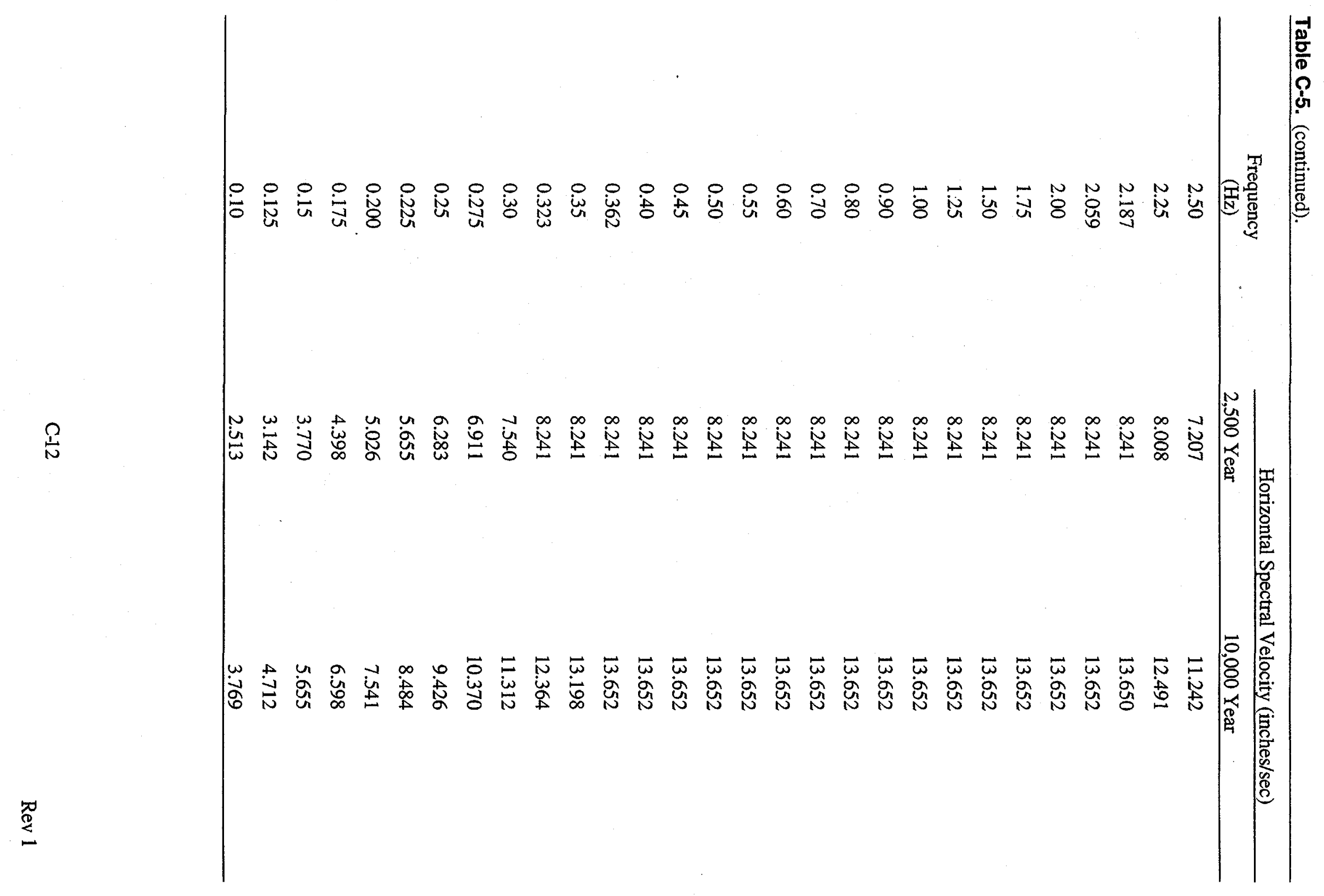


Table C-6. Spectral velocities for the vertical rock DBE 5\% damped response spectra for PC 3 (2,500 years) and PC 4 (10,000 years) at INTEC, TRA, RWMC, and PBF.

\begin{tabular}{|c|c|c|}
\hline \multirow{2}{*}{$\begin{array}{c}\text { Frequency } \\
(\mathrm{Hz})\end{array}$} & \multicolumn{2}{|c|}{ Horizontal Spectral Velocity (inches/sec) } \\
\hline & 2,500 Year & 10,000 Year \\
\hline 100.00 & 0.058 & 0.088 \\
\hline 90.00 & 0.065 & 0.098 \\
\hline 80.00 & 0.073 & 0.111 \\
\hline 70.00 & 0.083 & 0.126 \\
\hline 60.00 & 0.097 & 0.147 \\
\hline 55.00 & 0.106 & 0.161 \\
\hline 50.00 & 0.116 & 0.177 \\
\hline 45.00 & 0.143 & 0.219 \\
\hline 40.00 & 0.179 & 0.277 \\
\hline 35.00 & 0.232 & 0.363 \\
\hline 33.33 & 0.260 & 0.409 \\
\hline 30.00 & 0.313 & 0.491 \\
\hline 27.50 & 0.371 & 0.580 \\
\hline 25.00 & 0.447 & 0.696 \\
\hline 22.50 & 0.550 & 0.853 \\
\hline 20.00 & 0.692 & 1.069 \\
\hline 17.50 & 0.791 & 1.222 \\
\hline 15.00 & 0.922 & 1.426 \\
\hline 12.50 & 1.107 & 1.711 \\
\hline 10.00 & 1.628 & 2.139 \\
\hline 9.00 & 1.537 & 2.376 \\
\hline 8.00 & 1.729 & 2.673 \\
\hline 7.00 & 1.977 & 3.055 \\
\hline 6.00 & 2.306 & 3.565 \\
\hline 5.50 & 2.516 & 3.889 \\
\hline 5.00 & 2.767 & 4.278 \\
\hline 4.50 & 3.075 & 4.753 \\
\hline 4.00 & 3.459 & 5.347 \\
\hline 3.50 & 3.953 & 6.111 \\
\hline 3.00 & 4.612 & 7.129 \\
\hline 2.75 & 5.031 & 7.778 \\
\hline
\end{tabular}


Table C-6. (continued).

\begin{tabular}{|c|c|c|}
\hline \multirow{2}{*}{$\begin{array}{c}\text { Frequency } \\
(\mathrm{Hz})\end{array}$} & \multicolumn{2}{|c|}{ Horizontal Spectral Velocity (inches/sec) } \\
\hline & 2,500 Year & 10,000 Year \\
\hline 2.517 & 5.496 & 8.498 \\
\hline 2.50 & 5.496 & 8.555 \\
\hline 2.349 & 5.496 & 9.106 \\
\hline 2.25 & 5.496 & 9.106 \\
\hline 2.00 & 5.496 & 9.106 \\
\hline 1.75 & 5.496 & 9.106 \\
\hline 1.50 & 5.496 & 9.106 \\
\hline 1.25 & 5.496 & 9.106 \\
\hline 1.00 & 5.496 & 9.106 \\
\hline 0.90 & 5.496 & 9.106 \\
\hline 0.80 & 5.496 & 9.106 \\
\hline 0.70 & 5.496 & 9.106 \\
\hline 0.60 & 5.496 & 9.106 \\
\hline 0.55 & 5.496 & 9.106 \\
\hline 0.50 & 5.496 & 9.106 \\
\hline 0.45 & 5.496 & 9.106 \\
\hline 0.40 & 5.496 & 9.106 \\
\hline 0.362 & 5.496 & 9.106 \\
\hline 0.35 & 5.496 & 8.797 \\
\hline 0.328 & 5.496 & 8.242 \\
\hline 0.30 & 5.029 & 7.540 \\
\hline 0.275 & 4.610 & 6.912 \\
\hline 0.25 & 4.911 & 6.284 \\
\hline 0.225 & 3.772 & 5.655 \\
\hline 0.200 & 3.353 & 5.027 \\
\hline 0.175 & 2.934 & 4.398 \\
\hline 0.15 & 2.514 & 3.770 \\
\hline 0.125 & 2.095 & 3.142 \\
\hline 0.10 & 1.676 & 2.513 \\
\hline
\end{tabular}


Table C-7. Spectral velocities for the horizontal soil DBE 5\% damped response spectra for PC 3 (2,500 years) and PC 4 (10,000 years) at INTEC.

\begin{tabular}{|c|c|c|c|}
\hline $\begin{array}{l}\text { Frequency } \\
(\mathrm{Hz})\end{array}$ & $\begin{array}{l}\text { Horizontal Spectral } \\
\text { Velocity (inches/sec) } \\
\text { PC } 3(2,500 \text { Year) }\end{array}$ & $\begin{array}{c}\text { Frequency } \\
(\mathrm{Hz})\end{array}$ & $\begin{array}{l}\text { Horizontal Spectral } \\
\text { Velocity (inches/sec) } \\
\text { PC } 4 \text { (10,000 Year) }\end{array}$ \\
\hline 100.00 & 0.156 & 100.00 & 0.228 \\
\hline 90.00 & 0.173 & 90.00 & 0.253 \\
\hline 80.00 & 0.195 & 80.00 & 0.284 \\
\hline 70.00 & 0.223 & 70.00 & 0.325 \\
\hline 60.00 & 0.260 & 60.00 & 0.379 \\
\hline 55.00 & 0.284 & 55.00 & 0.414 \\
\hline 50.00 & 0.312 & 50.00 & 0.455 \\
\hline 45.00 & 0.362 & 45.00 & 0.530 \\
\hline 40.00 & 0.427 & 40.00 & 0.629 \\
\hline 35.00 & 0.514 & 35.00 & 0.763 \\
\hline 30.00 & 0.638 & 30.00 & 0.954 \\
\hline 27.50 & 0.721 & 27.50 & 1.082 \\
\hline 25.00 & 0.824 & 25.00 & 1.242 \\
\hline 22.50 & 1.030 & 22.50 & 1.512 \\
\hline 20.00 & 1.323 & 20.00 & 1.882 \\
\hline 17.50 & 1.758 & 17.50 & 2.414 \\
\hline 15.00 & 2.439 & 15.00 & 3.217 \\
\hline 12.50 & 3.593 & 12.50 & 4.517 \\
\hline 12.00 & 3.918 & 10.00 & 6.845 \\
\hline 10.00 & 4.702 & 9.00 & 7.605 \\
\hline 9.00 & 5.225 & 8.00 & 8.556 \\
\hline 8.00 & 5.878 & 7.00 & 9.778 \\
\hline 7.00 & 6.717 & 6.00 & 11.408 \\
\hline 6.00 & 7.837 & 5.50 & 12.445 \\
\hline 5.50 & 8.549 & 5.00 & 13.689 \\
\hline 5.00 & 9.404 & 4.50 & 15.210 \\
\hline 4.50 & 10.449 & 4.00 & 17.112 \\
\hline 4.00 & 11.755 & 3.523 & 19.429 \\
\hline 3.823 & 12.280 & 3.50 & 19.429 \\
\hline 3.50 & 12.280 & 3.00 & 19.429 \\
\hline
\end{tabular}


Table C-7. (continued).

\begin{tabular}{|c|c|c|c|}
\hline $\begin{array}{c}\text { Frequency } \\
(\mathrm{Hz})\end{array}$ & $\begin{array}{l}\text { Horizontal Spectral } \\
\text { Velocity (inches/sec) } \\
\text { PC } 3(2,500 \text { Year) }\end{array}$ & $\begin{array}{c}\text { Frequency } \\
(\mathrm{Hz})\end{array}$ & $\begin{array}{l}\text { Horizontal Spectral } \\
\text { Velocity (inches/sec) } \\
\text { PC 4 (10,000 Year) }\end{array}$ \\
\hline 3.00 & 12.280 & 2.75 & 19.429 \\
\hline 2.75 & 12.280 & 2.50 & 19.429 \\
\hline 2.50 & 12.280 & 2.25 & 19.429 \\
\hline 2.25 & 12.280 & 2.00 & 19.429 \\
\hline 2.00 & 12.280 & 1.75 & 19.429 \\
\hline 1.75 & 12.280 & 1.50 & 19.429 \\
\hline 1.50 & 12.280 & 1.25 & 19.429 \\
\hline 1.25 & 12.280 & 1.00 & 19.429 \\
\hline 1.00 & 12.280 & 0.90 & 19.429 \\
\hline 0.90 & 12.280 & 0.80 & 19.429 \\
\hline 0.80 & 12.280 & 0.70 & 19.429 \\
\hline 0.70 & 12.280 & 0.60 & 19.429 \\
\hline 0.60 & 12.280 & 0.55 & 19.429 \\
\hline 0.55 & 12.280 & 0.50 & 19.429 \\
\hline 0.50 & 12.280 & 0.45 & 19.429 \\
\hline 0.45 & 12.280 & 0.40 & 19.429 \\
\hline 0.40 & 12.280 & 0.35 & 19.429 \\
\hline 0.35 & 12.280 & 0.30 & 19.429 \\
\hline 0.30 & 12.280 & 0.275 & 19.429 \\
\hline 0.275 & 12.280 & 0.2577 & 19.429 \\
\hline 0.25 & 12.280 & 0.25 & 18.850 \\
\hline 0.225 & 12.280 & 0.225 & 16.965 \\
\hline 0.20 & 12.280 & 0.20 & 15.080 \\
\hline 0.1815 & 12.280 & 0.175 & 13.195 \\
\hline 0.175 & 11.383 & 0.15 & 11.310 \\
\hline 0.15 & 10.147 & 0.125 & 9.425 \\
\hline 0.125 & 8.456 & 0.10 & 7.540 \\
\hline 0.10 & 6.765 & & \\
\hline
\end{tabular}

a. The horizontal PC 3 and PC 4 DBE response spectra do not have an equal number of data points. 
Table C-8. Spectral velocities for the vertical soil DBE 5\% damped response spectra for PC $3(2,500$ years) and PC 4 (10,000 years) at INTEC.

\begin{tabular}{|c|c|c|c|}
\hline $\begin{array}{c}\text { Frequency } \\
(\mathrm{Hz})\end{array}$ & $\begin{array}{c}\text { Vertical Spectral } \\
\text { Velocity (inches/sec) } \\
\text { PC } 3(2,500 \text { Year) }\end{array}$ & $\begin{array}{c}\text { Frequency } \\
(\mathrm{Hz})\end{array}$ & $\begin{array}{c}\text { Vertical Spectral } \\
\text { Velocity (inches/sec) } \\
\text { PC } 4 \text { (10,000 Year) }\end{array}$ \\
\hline 100.00 & 0.120 & 100.00 & 0.175 \\
\hline 90.00 & 0.134 & 90.00 & 0.195 \\
\hline 80.00 & 0.150 & 80.00 & 0.219 \\
\hline 70.00 & 0.172 & 70.00 & 0.250 \\
\hline 60.00 & 0.200 & 60.00 & 0.292 \\
\hline 55.00 & 0.219 & 55.00 & 0.319 \\
\hline 50.00 & 0.240 & 50.00 & 0.350 \\
\hline 45.00 & 0.289 & 45.00 & 0.424 \\
\hline 40.00 & 0.356 & 40.00 & 0.524 \\
\hline 35.00 & 0.449 & 35.00 & 0.667 \\
\hline 30.00 & 0.589 & 30.00 & 0.881 \\
\hline 27.50 & 0.686 & 27.50 & 1.030 \\
\hline 25.00 & 0.811 & 25.00 & 1.224 \\
\hline 22.50 & 1.036 & 22.50 & 1.548 \\
\hline 20.00 & 1.362 & 20.00 & 2.013 \\
\hline 17.50 & 1.858 & 17.50 & 2.710 \\
\hline 15.00 & 2.658 & 15.00 & 3.822 \\
\hline 12.50 & 3.190 & 12.50 & 4.587 \\
\hline 10.00 & 3.988 & 10.00 & 5.733 \\
\hline 9.00 & 4.431 & 9.00 & 6.370 \\
\hline 8.00 & 4.984 & 8.00 & 7.167 \\
\hline 7.00 & 5.697 & 7.00 & 8.190 \\
\hline 6.00 & 6.646 & 6.00 & 9.555 \\
\hline 5.50 & 7.250 & 5.50 & 10.242 \\
\hline 5.00 & 7.975 & 5.00 & 11.466 \\
\hline 4.764 & 8.371 & 4.50 & 12.741 \\
\hline 4.50 & 8.371 & 4.425 & 12.956 \\
\hline 4.00 & 8.371 & 4.00 & 12.956 \\
\hline 3.50 & 8.371 & 3.50 & 12.956 \\
\hline 3.00 & 8.371 & 3.00 & 12.956 \\
\hline
\end{tabular}


Table C-8. (continued).

\begin{tabular}{|c|c|c|c|}
\hline $\begin{array}{c}\text { Frequency } \\
(\mathrm{Hz})\end{array}$ & $\begin{array}{c}\text { Vertical Spectral } \\
\text { Velocity (inches/sec) } \\
\text { PC } 3(2,500 \text { Year) }\end{array}$ & $\begin{array}{c}\text { Frequency } \\
(\mathrm{Hz})\end{array}$ & $\begin{array}{c}\text { Vertical Spectral } \\
\text { Velocity (inches/sec) } \\
\text { PC } 4 \text { (10,000 Year) }\end{array}$ \\
\hline 2.75 & 8.371 & 2.75 & 12.956 \\
\hline 2.50 & 8.371 & 2.50 & 12.956 \\
\hline 2.25 & 8.371 & 2.25 & 12.956 \\
\hline 2.00 & 8.371 & 2.00 & 12.956 \\
\hline 1.75 & 8.371 & 1.75 & 12.956 \\
\hline 1.50 & 8.371 & 1.50 & 12.956 \\
\hline 1.25 & 8.371 & 1.25 & 12.956 \\
\hline 1.00 & 8.371 & 1.00 & 12.956 \\
\hline 0.90 & 8.371 & 0.90 & 12.956 \\
\hline 0.80 & 8.371 & 0.80 & 12.956 \\
\hline 0.70 & 8.371 & 0.70 & 12.956 \\
\hline 0.60 & 8.371 & 0.60 & 12.956 \\
\hline 0.55 & 8.371 & 0.55 & 12.956 \\
\hline 0.50 & 8.371 & 0.50 & 12.956 \\
\hline 0.45 & 8.371 & 0.45 & 12.956 \\
\hline 0.40 & 8.371 & 0.40 & 12.956 \\
\hline 0.35 & 8.371 & 0.35 & 12.956 \\
\hline 0.30 & 8.371 & 0.30 & 12.956 \\
\hline 0.275 & 8.371 & 0.275 & 12.956 \\
\hline 0.25 & 8.371 & 0.2577 & 12.956 \\
\hline 0.225 & 8.371 & 0.25 & 12.566 \\
\hline 0.20 & 8.371 & 0.225 & 11.310 \\
\hline 0.189 & 8.371 & 0.20 & 10.053 \\
\hline 0.175 & 7.753 & 0.175 & 8.797 \\
\hline 0.15 & 6.645 & 0.15 & 7.540 \\
\hline 0.125 & 5.538 & 0.125 & 6.283 \\
\hline 0.10 & 4.430 & 0.10 & 5.027 \\
\hline
\end{tabular}


Table C-9. Spectral velocities for the horizontal rock DBE 5\% damped response spectra for PC 3 (2,500 years) and PC 4 (10,000 years) at TAN.

\begin{tabular}{|c|c|c|c|}
\hline $\begin{array}{c}\text { Frequency } \\
(\mathrm{Hz})\end{array}$ & $\begin{array}{l}\text { Horizontal Spectral } \\
\text { Velocity (inches/sec) } \\
\text { PC } 3(2,500 \text { Year) }\end{array}$ & $\begin{array}{c}\text { Frequency } \\
(\mathrm{Hz})\end{array}$ & $\begin{array}{l}\text { Horizontal Spectral } \\
\text { Velocity (inches/sec) } \\
\text { PC } 4 \text { (10,000 Year) }\end{array}$ \\
\hline 100.00 & 0.098 & 100.00 & 0.165 \\
\hline 90.00 & 0.109 & 90.00 & 0.184 \\
\hline 80.00 & 0.123 & 80.00 & 0.207 \\
\hline 70.00 & 0.141 & 70.00 & 0.236 \\
\hline 60.00 & 0.164 & 60.00 & 0.276 \\
\hline 55.00 & 0.179 & 55.00 & 0.301 \\
\hline 50.00 & 0.197 & 50.00 & 0.331 \\
\hline 45.00 & 0.231 & 45.00 & 0.389 \\
\hline 40.00 & 0.277 & 40.00 & 0.467 \\
\hline 35.00 & 0.341 & 35.00 & 0.575 \\
\hline 33.33 & 0.367 & 33.33 & 0.620 \\
\hline 30.00 & 0.426 & 30.00 & 0.722 \\
\hline 27.50 & 0.481 & 27.50 & 0.819 \\
\hline 25.00 & 0.550 & 25.00 & 0.940 \\
\hline 22.50 & 0.638 & 22.50 & 1.095 \\
\hline 20.00 & 0.753 & 20.00 & 1.298 \\
\hline 17.50 & 0.908 & 17.50 & 1.575 \\
\hline 15.00 & 1.128 & 15.00 & 1.968 \\
\hline 12.50 & 1.457 & 12.50 & 2.562 \\
\hline 10.00 & 1.994 & 10.00 & 3.538 \\
\hline 9.00 & 2.313 & 9.00 & 4.120 \\
\hline 8.00 & 2.729 & 8.00 & 4.635 \\
\hline 7.00 & 3.119 & 7.00 & 5.298 \\
\hline 6.00 & 3.639 & 6.00 & 6.181 \\
\hline 5.50 & 3.969 & 5.50 & 6.742 \\
\hline 5.00 & 4.366 & 5.00 & 7.417 \\
\hline 4.50 & 4.852 & 4.50 & 8.241 \\
\hline 4.00 & 5.458 & 4.00 & 9.271 \\
\hline 3.50 & 6.238 & 3.5 & 10.595 \\
\hline 3.00 & 7.277 & 3.00 & 12.361 \\
\hline
\end{tabular}


Table C-7. (continued).

\begin{tabular}{|c|c|c|c|}
\hline $\begin{array}{c}\text { Frequency } \\
(\mathrm{Hz})\end{array}$ & $\begin{array}{l}\text { Horizontal Spectral } \\
\text { Velocity (inches/sec) } \\
\text { PC } 3(2,500 \text { Year) }\end{array}$ & $\begin{array}{c}\text { Frequency } \\
(\mathrm{Hz})\end{array}$ & $\begin{array}{l}\text { Horizontal Spectral } \\
\text { Velocity (inches/sec) } \\
\text { PC 4 (10,000 Year) }\end{array}$ \\
\hline 2.75 & 7.939 & 2.75 & 13.485 \\
\hline 2.50 & 8.733 & 2.50 & 14.833 \\
\hline 2.43 & 8.980 & 2.41 & 15.380 \\
\hline 2.25 & 8.980 & 2.25 & 15.380 \\
\hline 2.00 & 8.980 & 2.00 & 15.380 \\
\hline 1.75 & 8.980 & 1.75 & 15.380 \\
\hline 1.50 & 8.980 & 1.50 & 15.380 \\
\hline 1.25 & 8.980 & 1.25 & 15.380 \\
\hline 1.00 & 8.980 & 1.00 & 15.380 \\
\hline 0.90 & 8.980 & 0.90 & 15.380 \\
\hline 0.80 & 8.980 & 0.80 & 15.380 \\
\hline 0.70 & 8.980 & 0.70 & 15.380 \\
\hline 0.60 & 8.980 & 0.60 & 15.380 \\
\hline 0.55 & 8.980 & 0.55 & 15.380 \\
\hline 0.50 & 8.980 & 0.50 & 15.380 \\
\hline 0.45 & 8.980 & 0.45 & 15.380 \\
\hline 0.40 & 8.980 & 0.408 & 15.380 \\
\hline 0.357 & 8.980 & 0.40 & 15.088 \\
\hline 0.35 & 8.799 & 0.35 & 19.429 \\
\hline 0.30 & 7.542 & 0.30 & 11.314 \\
\hline 0.275 & 6.913 & 0.275 & 10.371 \\
\hline 0.25 & 6.285 & 0.25 & 9.428 \\
\hline 0.225 & 5.656 & 0.225 & 8.485 \\
\hline 0.20 & 5.028 & 0.20 & 7.542 \\
\hline 0.175 & 4.399 & 0.175 & 6.599 \\
\hline 0.15 & 3.770 & 0.15 & 5.656 \\
\hline 0.125 & 3.142 & 0.125 & 4.713 \\
\hline 0.10 & 2.513 & 0.10 & 3.770 \\
\hline
\end{tabular}


Table C-10. Spectral velocities for the vertical rock DBE 5\% damped response spectra for PC 3 (2,500 years) and PC 4 (10,000 years) at TAN.

\begin{tabular}{|c|c|c|c|}
\hline $\begin{array}{c}\text { Frequency } \\
(\mathrm{Hz})\end{array}$ & $\begin{array}{c}\text { Vertical Spectral } \\
\text { Velocity (inches/sec) } \\
\text { PC } 3(2,500 \text { Year) }\end{array}$ & $\begin{array}{c}\text { Frequency } \\
(\mathrm{Hz})\end{array}$ & $\begin{array}{c}\text { Vertical Spectral } \\
\text { Velocity (inches/sec) } \\
\text { PC } 4 \text { (10,000 Year) } \\
\end{array}$ \\
\hline 100.00 & 0.076 & 100.00 & 0.127 \\
\hline 90.00 & 0.084 & 90.00 & 0.142 \\
\hline 80.00 & 0.095 & 80.00 & 0.159 \\
\hline 70.00 & 0.108 & 70.00 & 0.182 \\
\hline 60.00 & 0.126 & 60.00 & 0.212 \\
\hline 55.00 & 0.138 & 55.00 & 0.232 \\
\hline 50.00 & 0.152 & 50.00 & 0.255 \\
\hline 45.00 & 0.186 & 45.00 & 0.313 \\
\hline 40.00 & 0.233 & 40.00 & 0.393 \\
\hline 35.00 & 0.302 & 35.00 & 0.510 \\
\hline 33.33 & 0.332 & 33.33 & 0.560 \\
\hline 30.00 & 0.409 & 30.00 & 0.691 \\
\hline 27.50 & 0.486 & 27.50 & 0.821 \\
\hline 25.00 & 0.587 & 25.00 & 0.992 \\
\hline 22.50 & 0.723 & 22.50 & 1.222 \\
\hline 20.00 & 0.914 & 20.00 & 1.544 \\
\hline 17.50 & 1.044 & 17.50 & 1.764 \\
\hline 15.00 & 1.218 & 15.00 & 2.059 \\
\hline 12.50 & 1.462 & 12.50 & 2.470 \\
\hline 10.00 & 1.827 & 10.00 & 3.088 \\
\hline 9.00 & 2.030 & 9.00 & 3.431 \\
\hline 8.00 & 2.284 & 8.00 & 3.860 \\
\hline 7.00 & 2.610 & 7.00 & 4.411 \\
\hline 6.00 & 3.045 & 6.00 & 5.146 \\
\hline 5.50 & 3.322 & 5.50 & 5.614 \\
\hline 5.00 & 3.654 & 5.00 & 6.176 \\
\hline 4.50 & 4.060 & 4.50 & 6.862 \\
\hline 4.00 & 4.568 & 4.00 & 7.720 \\
\hline 3.50 & 5.220 & 3.50 & 8.822 \\
\hline 3.05 & 5.988 & 3.01 & 10.255 \\
\hline
\end{tabular}


Table 10. Continued.

\begin{tabular}{|c|c|c|c|}
\hline $\begin{array}{c}\text { Frequency } \\
(\mathrm{Hz})\end{array}$ & $\begin{array}{c}\text { Vertical Spectral } \\
\text { Velocity (inches/sec) } \\
\text { PC } 3(2,500 \text { Year) }\end{array}$ & $\begin{array}{c}\text { Frequency } \\
(\mathrm{Hz})\end{array}$ & $\begin{array}{l}\text { Vertical Spectral } \\
\text { Velocity (inches/sec) } \\
\text { PC 4 (10,000 Year) }\end{array}$ \\
\hline 3.00 & 5.988 & 3.00 & 10.255 \\
\hline 2.75 & 5.988 & 2.75 & 10.255 \\
\hline 2.50 & 5.988 & 2.50 & 10.255 \\
\hline 2.25 & 5.988 & 2.25 & 10.255 \\
\hline 2.00 & 5.988 & 2.00 & 10.255 \\
\hline 1.75 & 5.988 & 1.75 & 10.255 \\
\hline 1.50 & 5.988 & 1.50 & 10.255 \\
\hline 1.25 & 5.988 & 1.25 & 10.255 \\
\hline 1.00 & 5.988 & 1.00 & 10.255 \\
\hline 0.90 & 5.988 & 0.90 & 10.255 \\
\hline 0.80 & 5.988 & 0.80 & 10.255 \\
\hline 0.70 & 5.988 & 0.70 & 10.255 \\
\hline 0.60 & 5.988 & 0.60 & 10.255 \\
\hline 0.55 & 5.988 & 0.55 & 10.255 \\
\hline 0.50 & 5.988 & 0.50 & 10.255 \\
\hline 0.45 & 5.988 & 0.45 & 10.255 \\
\hline 0.40 & 5.988 & 0.408 & 12.956 \\
\hline 0.357 & 5.988 & 0.40 & 10.053 \\
\hline 0.35 & 5.864 & 0.35 & 8.797 \\
\hline 0.30 & 5.027 & 0.30 & 7.540 \\
\hline 0.275 & 4.608 & 0.275 & 6.912 \\
\hline 0.25 & 4.189 & 0.25 & 6.283 \\
\hline 0.225 & 3.770 & 0.225 & 5.655 \\
\hline 0.20 & 3.351 & 0.20 & 5.027 \\
\hline 0.175 & 2.932 & 0.175 & 4.398 \\
\hline 0.15 & 2.514 & 0.15 & 3.770 \\
\hline 0.125 & 2.095 & 0.125 & 3.142 \\
\hline 0.10 & 1.676 & 0.10 & 2.513 \\
\hline
\end{tabular}


Table C-11. Spectral velocities for the horizontal rock DBE 5\% damped response spectra for PC 3 (2,000 years) and PC 4 (10,000 years) at NRF.

\begin{tabular}{|c|c|c|c|}
\hline $\begin{array}{c}\text { Frequency } \\
(\mathrm{Hz})\end{array}$ & $\begin{array}{c}\text { Horizontal Spectral } \\
\text { Velocity (inches/sec) } \\
\text { PC } 3(2,000 \text { Year) }\end{array}$ & $\begin{array}{c}\text { Frequency } \\
(\mathrm{Hz})\end{array}$ & $\begin{array}{l}\text { Horizontal Spectral } \\
\text { Velocity (inches/sec) } \\
\text { PC } 4 \text { (10,000 Year) }\end{array}$ \\
\hline 100.00 & 0.077 & 100.00 & 0.132 \\
\hline 90.00 & 0.085 & 90.00 & 0.147 \\
\hline 80.00 & 0.096 & 80.00 & 0.165 \\
\hline 70.00 & 0.110 & 70.00 & 0.189 \\
\hline 60.00 & 0.128 & 60.00 & 0.220 \\
\hline 50.00 & 0.154 & 50.00 & 0.264 \\
\hline 45.00 & 0.178 & 45.00 & 0.306 \\
\hline 40.00 & 0.209 & 40.00 & 0.360 \\
\hline 35.00 & 0.251 & 35.00 & 0.433 \\
\hline 33.33 & 0.272 & 33.33 & 0.470 \\
\hline 30.00 & 0.313 & 30.00 & 0.540 \\
\hline 25.00 & 0.409 & 25.00 & 0.707 \\
\hline 20.00 & 0.567 & 20.00 & 0.982 \\
\hline 17.50 & 0.690 & 17.50 & 1.196 \\
\hline 15.00 & 0.865 & 15.00 & 1.501 \\
\hline 12.50 & 1.130 & 12.50 & 1.963 \\
\hline 10.00 & 1.568 & 10.00 & 2.728 \\
\hline 9.00 & 1.830 & 9.00 & 3.186 \\
\hline 8.00 & 2.175 & 8.00 & 3.790 \\
\hline 7.00 & 2.486 & 7.00 & 4.331 \\
\hline 6.00 & 2.900 & 6.00 & 5.053 \\
\hline 5.00 & 3.481 & 5.00 & 6.064 \\
\hline 4.50 & 3.867 & 4.50 & 6.737 \\
\hline 4.00 & 4.351 & 4.00 & 7.579 \\
\hline 3.50 & 4.972 & 3.50 & 8.662 \\
\hline 3.33 & 5.222 & 3.33 & 9.096 \\
\hline 3.00 & 5.801 & 3.00 & 10.106 \\
\hline 2.50 & 6.961 & 2.50 & 12.127 \\
\hline 2.11 & 8.241 & 2.11 & 14.355 \\
\hline 2.05 & 8.241 & 2.05 & 14.759 \\
\hline
\end{tabular}


Table C-11. (continued).

\begin{tabular}{|c|c|c|c|}
\hline $\begin{array}{c}\text { Frequency } \\
(\mathrm{Hz})\end{array}$ & $\begin{array}{c}\text { Horizontal Spectral } \\
\text { Velocity (inches/sec) } \\
\text { PC } 3 \text { (2,000 Year) }\end{array}$ & $\begin{array}{c}\text { Frequency } \\
(\mathrm{Hz})\end{array}$ & $\begin{array}{l}\text { Horizontal Spectral } \\
\text { Velocity (inches/sec) } \\
\text { PC } 4 \text { (10,000 Year) }\end{array}$ \\
\hline 2.00 & 8.241 & 2.00 & 15.159 \\
\hline 1.75 & 8.241 & 1.97 & 15.374 \\
\hline 1.50 & 8.241 & 1.50 & 15.374 \\
\hline 1.25 & 8.241 & 1.25 & 15.374 \\
\hline 1.00 & 8.241 & 1.00 & 15.374 \\
\hline 0.90 & 8.241 & 0.90 & 15.374 \\
\hline 0.80 & 8.241 & 0.80 & 15.374 \\
\hline 0.70 & 8.241 & 0.70 & 15.374 \\
\hline 0.60 & 8.241 & 0.60 & 15.374 \\
\hline 0.50 & 8.241 & 0.50 & 15.374 \\
\hline 0.45 & 8.241 & 0.45 & 15.374 \\
\hline 0.40 & 8.241 & 0.407 & 15.374 \\
\hline 0.39 & 8.241 & 0.39 & 14.759 \\
\hline 0.35 & 8.241 & 0.35 & 13.195 \\
\hline 0.327 & 8.241 & 0.327 & 12.361 \\
\hline 0.30 & 7.540 & 0.30 & 11.310 \\
\hline 0.25 & 6.283 & 0.25 & 9.425 \\
\hline 0.20 & 5.026 & 0.20 & 7.540 \\
\hline 0.175 & 4.398 & 0.175 & 6.597 \\
\hline 0.15 & 3.770 & 0.15 & 5.655 \\
\hline 0.125 & 3.141 & 0.125 & 4.712 \\
\hline 0.10 & 2.513 & 0.10 & 3.770 \\
\hline
\end{tabular}


Table C-12. Spectral velocities for the vertical rock DBE 5\% damped response spectra for PC 3 (2,000 years) and PC 4 (10,000 years) at NRF.

\begin{tabular}{|c|c|c|c|}
\hline $\begin{array}{l}\text { Frequency } \\
(\mathrm{Hz})\end{array}$ & $\begin{array}{c}\begin{array}{c}\text { Vertical Spectral Velocity } \\
\text { (inches/sec) }\end{array} \\
\text { PC } 3(2,000 \text { Year) }\end{array}$ & $\begin{array}{c}\text { Frequency } \\
(\mathrm{Hz})\end{array}$ & $\begin{array}{c}\begin{array}{c}\text { Vertical Spectral Velocity } \\
\text { (inches/sec) }\end{array} \\
\text { PC } 4(10,000 \text { Year) } \\
\end{array}$ \\
\hline 100.00 & 0.059 & 100.00 & 0.102 \\
\hline 90.00 & 0.066 & 90.00 & 0.113 \\
\hline 80.00 & 0.074 & 80.00 & 0.127 \\
\hline 70.00 & 0.084 & 70.00 & 0.145 \\
\hline 60.00 & 0.099 & 60.00 & 0.170 \\
\hline 50.00 & 0.118 & 50.00 & 0.203 \\
\hline 45.00 & 0.142 & 45.00 & 0.245 \\
\hline 40.00 & 0.175 & 40.00 & 0.302 \\
\hline 35.00 & 0.222 & 35.00 & 0.383 \\
\hline 33.33 & 0.246 & 33.33 & 0.425 \\
\hline 30.00 & 0.293 & 30.00 & 0.505 \\
\hline 25.00 & 0.407 & 25.00 & 0.703 \\
\hline 20.00 & 0.610 & 20.00 & 1.052 \\
\hline 17.50 & 0.777 & 17.50 & 1.339 \\
\hline 15.00 & 0.907 & 15.00 & 1.562 \\
\hline 12.50 & 1.088 & 12.50 & 1.874 \\
\hline 10.00 & 1.360 & 10.00 & 2.343 \\
\hline 9.00 & 1.511 & 9.00 & 2.603 \\
\hline 8.00 & 1.700 & 8.00 & 2.929 \\
\hline 7.00 & 1.943 & 7.00 & 3.347 \\
\hline 6.00 & 2.267 & 6.00 & 3.905 \\
\hline 5.00 & 2.720 & 5.00 & 4.686 \\
\hline 4.50 & 3.023 & 4.50 & 5.207 \\
\hline 4.00 & 3.400 & 4.00 & 5.857 \\
\hline 3.50 & 3.886 & 3.50 & 6.694 \\
\hline 3.33 & 4.081 & 3.33 & 7.030 \\
\hline 3.00 & 4.534 & 3.00 & 7.810 \\
\hline 2.50 & 5.441 & 2.50 & 9.372 \\
\hline 2.47 & 5.496 & 2.28 & 10.254 \\
\hline 2.11 & 5.496 & 2.11 & 10.254 \\
\hline
\end{tabular}


Table C-12. (continued).

\begin{tabular}{|c|c|c|c|}
\hline $\begin{array}{c}\text { Frequency } \\
(\mathrm{Hz})\end{array}$ & $\begin{array}{c}\text { Vertical Spectral Velocity } \\
\text { (inches/sec) } \\
\text { PC } 3(2,000 \text { Year) }\end{array}$ & $\begin{array}{c}\text { Frequency } \\
(\mathrm{Hz})\end{array}$ & $\begin{array}{c}\text { Vertical Spectral Velocity } \\
\text { (inches/sec) } \\
\text { PC } 4(10,000 \text { Year) }\end{array}$ \\
\hline 2.05 & 5.496 & 2.05 & 10.254 \\
\hline 2.00 & 5.496 & 2.00 & 10.254 \\
\hline 1.75 & 5.496 & 1.97 & 10.254 \\
\hline 1.50 & 5.496 & 1.50 & 10.254 \\
\hline 1.25 & 5.496 & 1.25 & 10.254 \\
\hline 1.00 & 5.496 & 1.00 & 10.254 \\
\hline 0.90 & 5.496 & 0.90 & 10.254 \\
\hline 0.80 & 5.496 & 0.80 & 10.254 \\
\hline 0.70 & 5.496 & 0.70 & 10.254 \\
\hline 0.60 & 5.496 & 0.60 & 10.254 \\
\hline 0.50 & 5.496 & 0.50 & 10.254 \\
\hline 0.45 & 5.496 & 0.45 & 10.254 \\
\hline 0.40 & 5.496 & 0.407 & 10.254 \\
\hline 0.39 & 5.496 & 0.39 & 9.844 \\
\hline 0.35 & 5.496 & 0.35 & 8.801 \\
\hline 0.327 & 5.496 & 0.327 & 8.243 \\
\hline 0.30 & 5.029 & 0.30 & 7.543 \\
\hline 0.25 & 4.191 & 0.25 & 6.286 \\
\hline 0.20 & 3.353 & 0.20 & 5.029 \\
\hline 0.175 & 2.933 & 0.175 & 4.400 \\
\hline 0.15 & 2.514 & 0.15 & 3.772 \\
\hline 0.125 & 2.095 & 0.125 & 3.143 \\
\hline 0.10 & 1.676 & 0.10 & 2.514 \\
\hline
\end{tabular}


Appendix D

Applicable INEEL Region for PC 3 and PC 4 Rock DBE at INTEC, TRA, RWMC, and PBF 


\section{Appendix D}

\section{Applicable INEEL Region for PC 3 and PC 4 Rock DBE at INTEC, TRA, RWMC, and PBF}

The INTEC PC 3 and PC 4 UHS were adjusted to account for higher motions at TRA and RWMC so that the resulting PC 3 and PC 4 rock DBE response spectra would be applicable to multiple facility areas (Section 2.2 of the report). The adjusted PC 3 and PC 4 rock UHS are applicable to the region between the facility areas of INTEC, TRA, RWMC, and PBF. The steps listed below were used to derive the region where the $\mathrm{PC} 3$ and $\mathrm{PC} 4$ rock DBE response spectra would be applicable (Figure 17 in Section 2.6). Definition of the boundary to the west of the TRA and RWMC facility areas and north of the TRA facility area is critical to ensure applicability of the rock DBE response spectra. The further the facility area is from Basin and Range faults, the lower the ground motions which implies that the rock DBE response spectra will be more conservative in some areas such as the region east of PBF.

To establish the boundary to the west, the seismic hazard results for PC 3 and PC 4 at NRF were used as a guide. The recomputation of the seismic hazard for NRF indicates the spectral accelerations at the 2,000-year and 10,000-year return periods are higher than for INTEC, TRA, RWMC, and PBF at frequencies less than $15 \mathrm{~Hz}$. Between 15 to $33 \mathrm{~Hz}$, the spectral accelerations for TRA and RWMC are slightly higher. NRF has the highest PGA of TRA, RWMC, and INTEC (Figures 2 and 3 in the report). Using the results for NRF as a guide, the boundary to the west could not be placed any closer to the Basin and Range faults than the distance from NRF to the Lemhi fault. For additional conservatism, the position of the INEL-1 drill hole was chosen to define the closest distance to the Basin and Range faults because its stratigraphy is used to characterize the deep sections of the geologic profiles at TRA and INTEC and it lies between TRA and NRF. The INEL-1 drill hole is further from the Basin and Range faults than NRF. The INEL-1 drill hole was used to define the position of the boundary to the north.

Steps used to derive the INEEL region that $\mathrm{PC} 3$ and $\mathrm{PC} 4$ rock $\mathrm{DBE}$ response spectra can be used (see Figure 17 in Section 2.6):

1. The map projection of the southern end of the inferred rupture plane of the Howe segment of the Lemhi Fault was plotted on a map of INEEL and critical facilities (INTEC, TRA, RWMC, PBF, CFA, and NRF). The rupture plane dips at about $45^{\circ}$ to the southwest and extends to a depth of $16 \mathrm{~km}$.

2. The distance from the rupture plane to drill hole INEL-1 was chosen as the closest distance for which the INTEC seismic design parameters are applicable. This is because INEL-1 stratigraphy is used to characterize the deep stratigraphy in the TRA-INTEC areas. A cross section through INEL-1 and the rupture plane was constructed in order to measure the distance from to the earth's surface at the location of INEL-1 to the rupture plane. This distance was determined to be about $21.5 \mathrm{~km}$.

3. Starting at INEL-1, a line of constant $21.5 \mathrm{~km}$ distance from the southern end of the fault segment was drawn. This line extends almost due east of INEL-1 and continuously diverges from the surface projection of the southern end of the segment because the rupture plane is $16 \mathrm{~km}$ below the surface at the southwestern-most extent of the plane and climbs to the surface at the surface trace of the fault.

4. The two scenarios for the southern end of the Arco segment of the Lost River fault were plotted on the map. Since the scenarios are weighted almost evenly in the probabilistic 
seismic hazards assessment, a point midway between them was chosen as the closest approach of the rupture plane of the fault to INEEL facilities. From the midway point an arc of about the same radius $(22 \mathrm{~km})$ as used for the Lemhi fault $(21.5 \mathrm{~km})$ was drawn. This arc comes within about $1.6 \mathrm{~km}$ of RWMC.

5. A circle tangent to the $22 \mathrm{~km}$ radius from the Arco segment and the position of INEL-1 was drawn around TRA. This circle has a radius of about $4 \mathrm{~km}$.

6. The northern and western boundaries of the area of applicability of the PC 3 and PC 4 rock DBE response spectra is defined as shown in the figure by the lines and arcs constructed. From southwest to northeast, the area is defined by the $22 \mathrm{~km}$ arc from the midpoint of the Arco segment scenarios, the TRA circle, and the line of constant $21.5 \mathrm{~km}$ distance from the southern end of the Howe segment. 
Appendix E

Soil and Rock Properties

$\operatorname{Rev} 1$ 


\section{Appendix E}

\section{Soil and Rock Properties}

\section{E.1 Soil and Rock Properties Used to Develop the Soil UHS for INTEC}

Soil properties used by URSG-WCFS (1999) to develop the site-specific soil PC 3 and PC 4 UHS for INTEC include:

- Table E-1, Average seismic velocities measured in the boreholes at the TMI-2 ISFSI.

- Table E-2, Shear wave velocity profile for the base case used in the TMI-2 ISFSI soil response analyses.

- Figure E-1, Borehole locations at the TMI-2 ISFSI.

- Figure E-2, Borehole locations for of other Vs profiles considered in development of the TMI-2 ISFSI base case Vs profile.

- Figures E-3, E-4, and E-5, Vs profiles used in the soil response analyses.

- Figure E-6, Shear modulus reduction and damping curves used in the soil response analyses. See Section E.2 for appropriate degradation models for the specified soil conditions at INTEC and for applicability to other facility areas at INEEL.

- WCFS (1996) Appendix E for table of shear-wave velocities for CPP.

For the soil response analyses, URSG-WCFS (1999) placed the soil profile (Figure E-3) at the top of the Vs profile for INTEC (Figure E-4). The Vs for basalt, extending 13 to $37 \mathrm{~m}$ (43 ft to $123 \mathrm{ft}$; Figure E-3) was modified to match the Vs values obtained in the boreholes. Figure E-4 shows the step in the velocity profile near the very top of the INTEC profile where the base case Vs profile was added above. This step was taken because energy will be transmitted back up through the soil by reflectors in the basalt and will affect the soil response. URSG-WCFS (1999) then calculated power spectra derived by spectrally matching their horizontal rock UHS and propagating them through the one-dimensional soil and shallow rock profile (the uppermost 1-km of the combined soil surface and modified INTEC profile) using a frequency-domain equivalent linear formulation similar to the program SHAKE. They deconvolved the rock power spectra from the soil-rock interface down to a depth of $1 \mathrm{~km}$ and then propagated them back up through the rock and soil profile (for details, see URSG-WCFS, 1999).

URSG-WCFS (1999) used a poisson's ratio of 0.35 for the interbed sediments to estimate the S-wave velocities shown in the site-specific profile in Figure E-4 (WCFS, 1996). For the basalt rock, URSG-WCFS (1999) used a poisson's ratio of 0.30 (WCC, 1992). 
Table E-1. Average downhole $\mathrm{P}$ - and S-wave velocities $(\mathrm{m} / \mathrm{sec}$ ) for boreholes at the TMI-2 ISFSI from GEOVision Geophysical Services (1997).

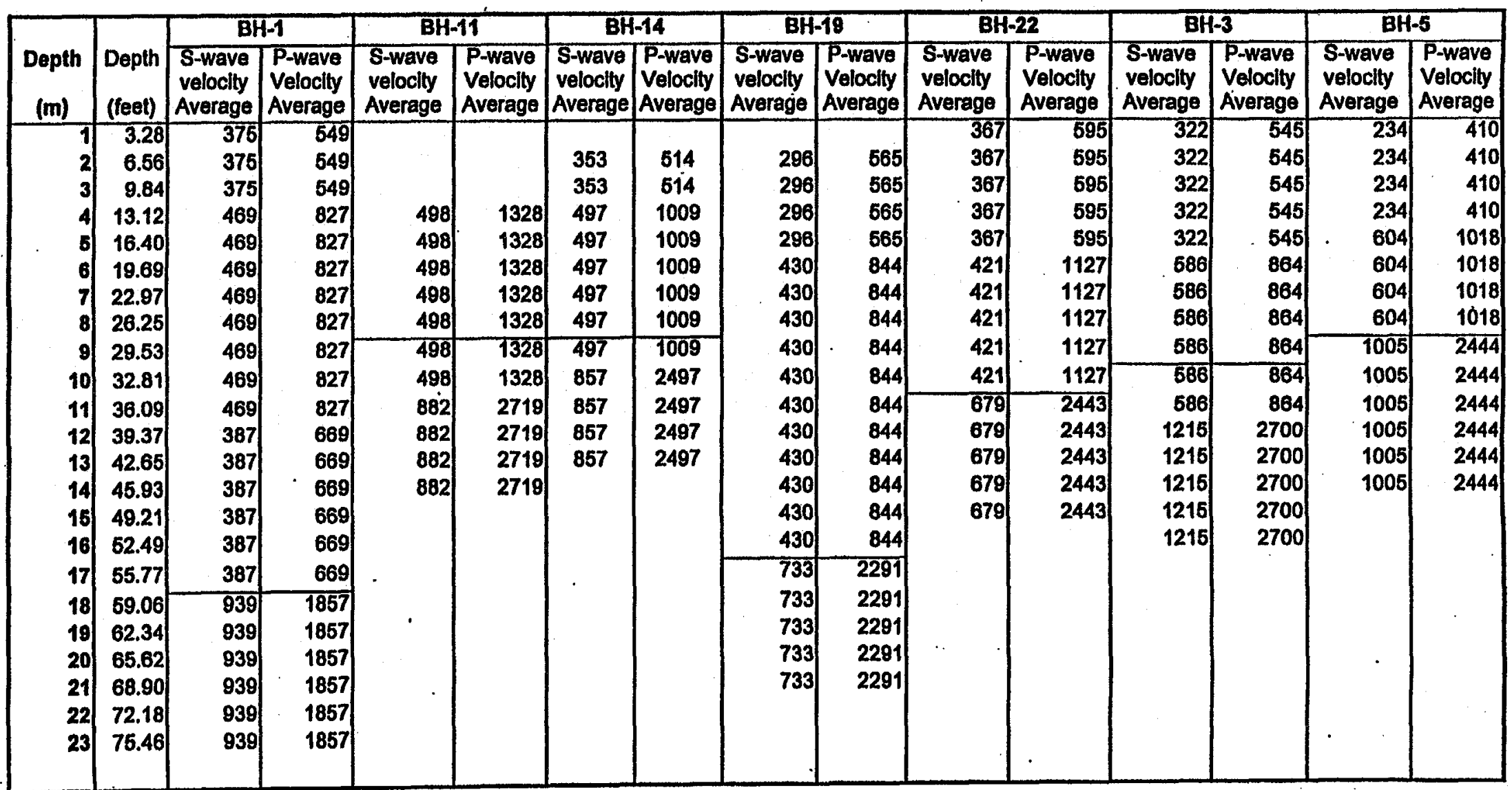


Table E-2. TMI-2 ISFSI base case S-wave velocity profile for soil thickness of $19.8 \mathrm{~m}$ (or $65 \mathrm{ft}$ ).

\begin{tabular}{lc}
$\begin{array}{c}\text { Depth Range } \\
(\mathrm{m})\end{array}$ & $\begin{array}{c}\text { Velocity } \\
(\mathrm{m} / \mathrm{sec})\end{array}$ \\
\hline 0 to 3.05 & 320.0 \\
3.05 to 3.96 & 341.4 \\
3.96 to 5.02 & 374.9 \\
5.02 to 6.08 & 405.4 \\
6.08 to 19.80 & 420.6 \\
$>19.80$ & 1106.4 \\
\hline
\end{tabular}




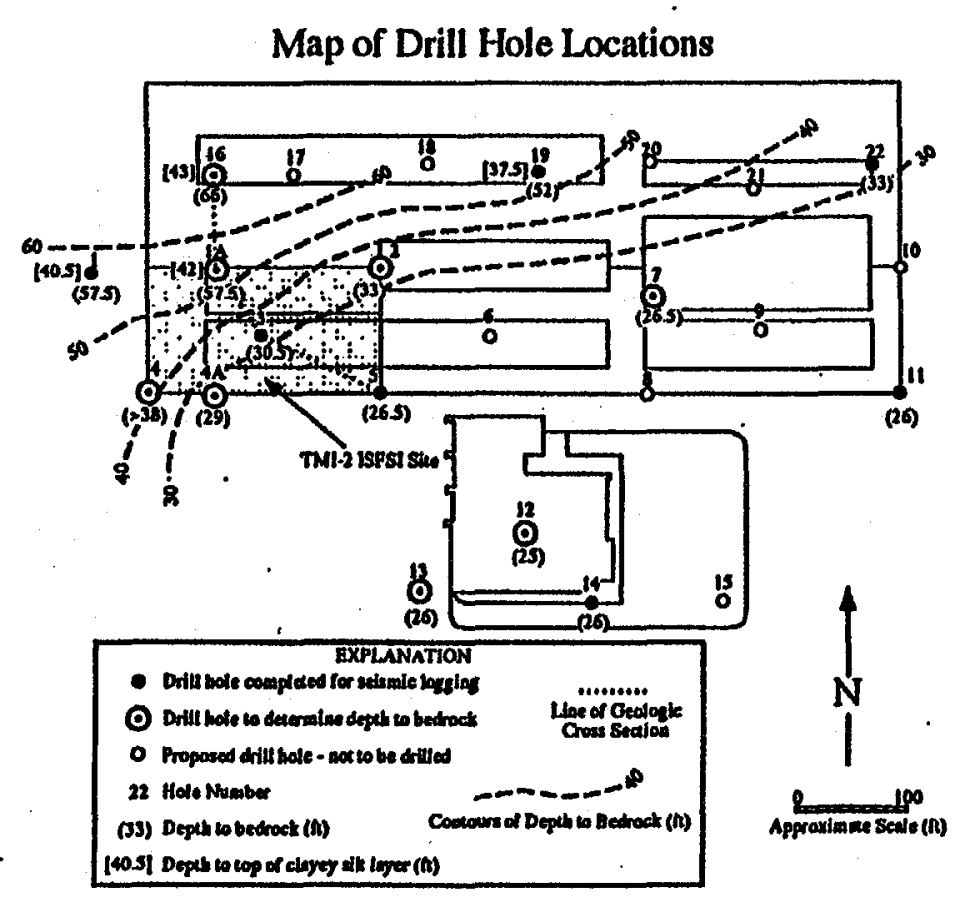

Geologic Cross Section through Drill Holes 5, 3, 1A, and 16
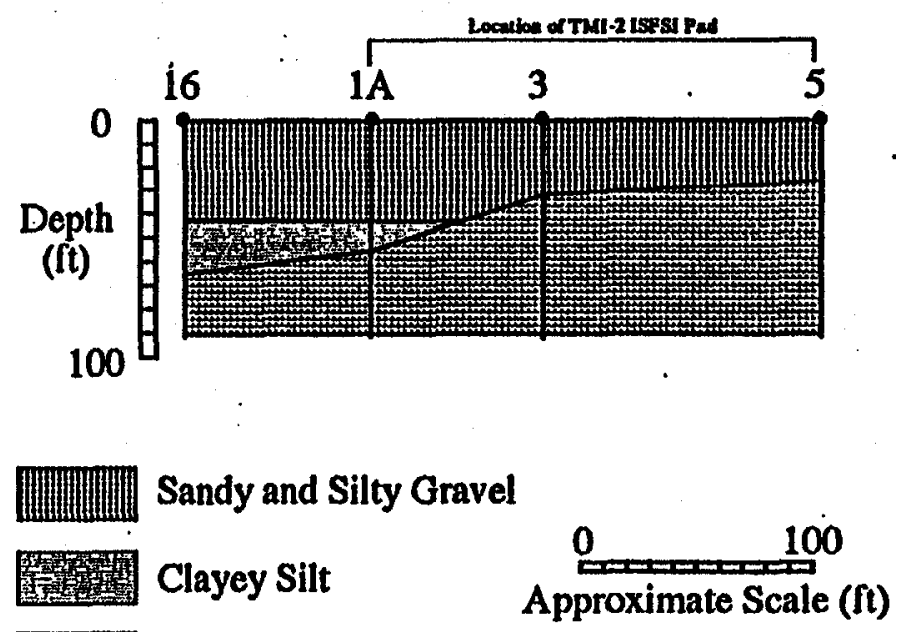

Basalt

Approximate Scale (ft)

Figure E-1. Locations of boreholes at the TMI-2 ISFSI and the interpreted geologic cross section based on the boreholes (URSG-WCFS, 1999). 


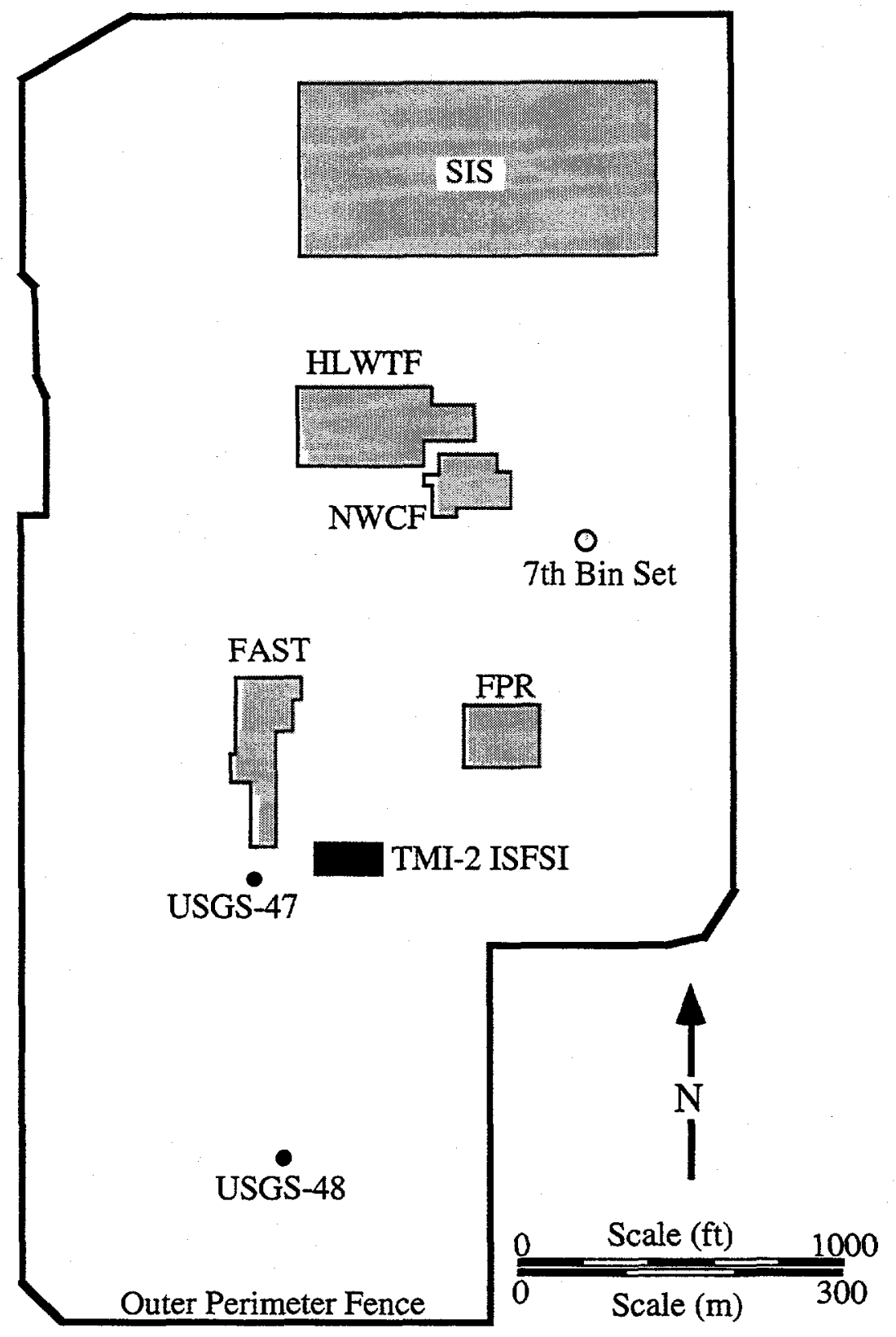

Figure E-2. Location of facilities at INTEC. Boreholes with measured velocities that were used to develop the TMI-2 ISFSI base case Vs profile are located at SIS - Special Isotope Separator; HLWTF - High Level Waste Treatment Facility; NWCF - New Waste Calciner Facility and the $7^{\text {th }}$ Bin Set (7BS). For reference, other facilities shown at INTEC are FAST - Flourinel And Fuel Storage Facilities and FPR - Fuel Processing Restoration and the U.S. Geological Survey (USGS-\#) boreholes. 


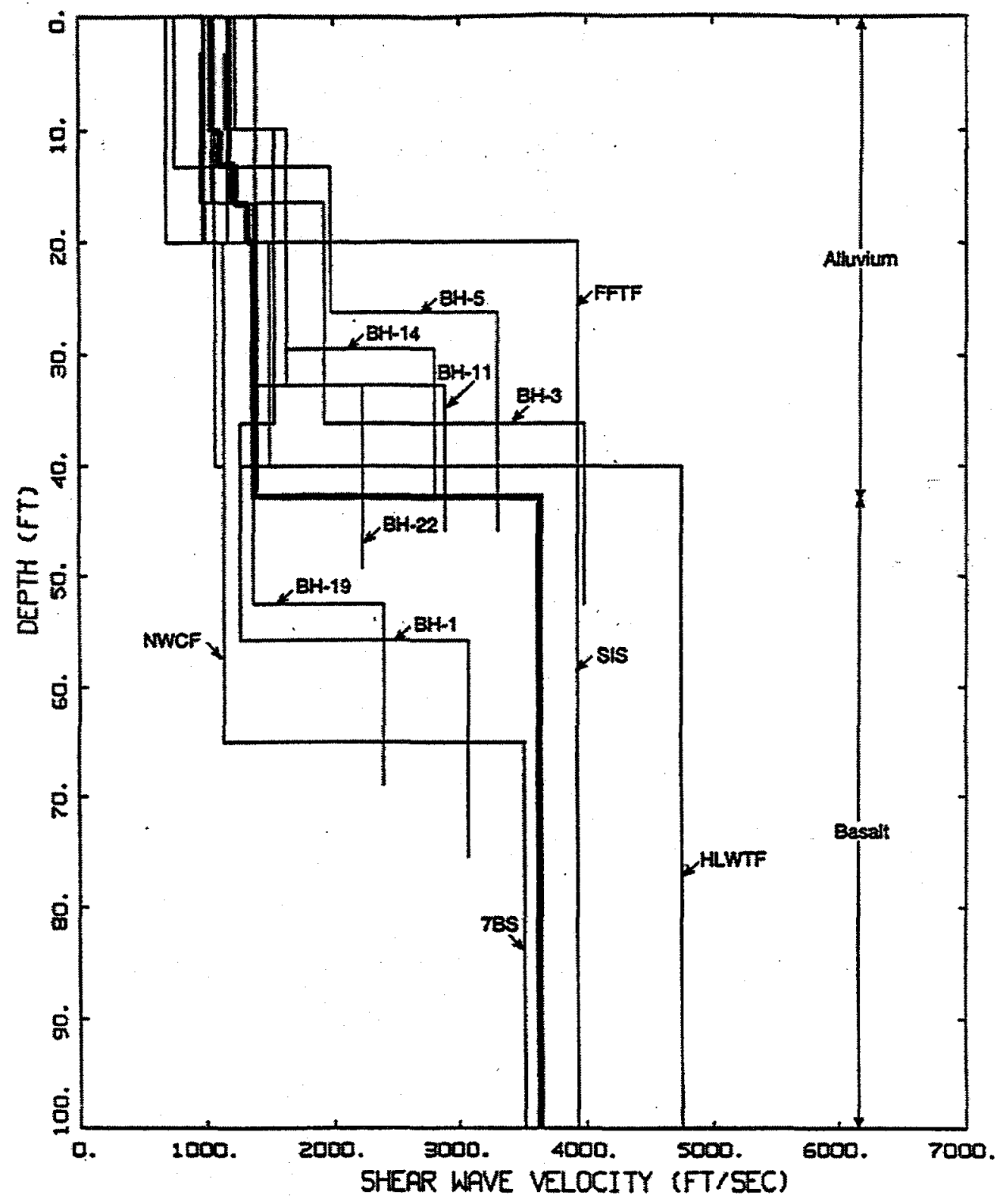

\section{LEGEND}

Base Case

$V_{S}$ Protiles

Figure E-3. The shear wave velocity base case profile for TMI-2 ISFSI compared to the shear wave velocity profiles from boreholes at the TMI-2 ISFSI (shown in Figure E-1) and at other locations around INTEC (Figure E-2) (URSG-WCFS, 1999). 


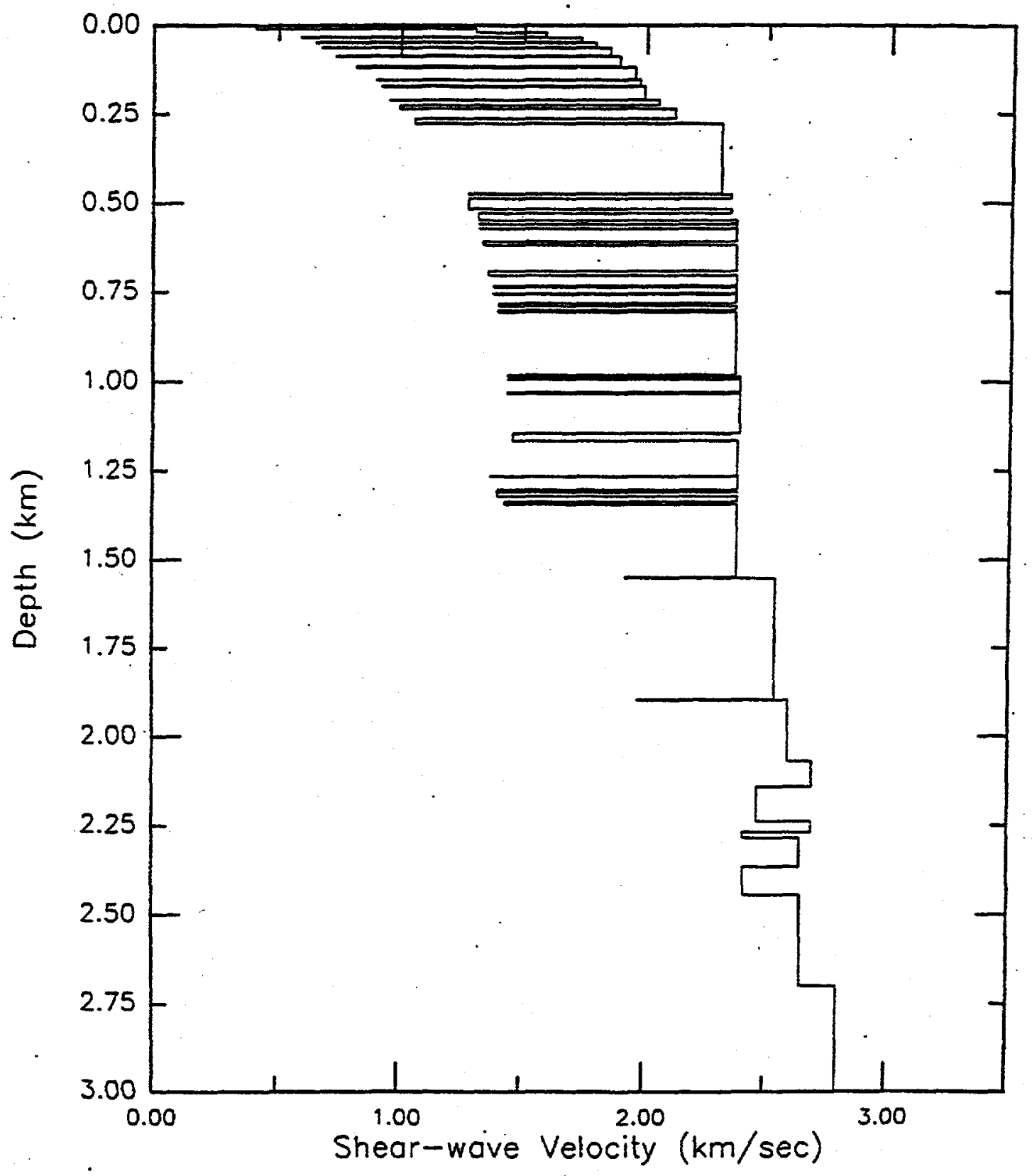

Figure E-4. The shear wave velocity profile for INTEC (WCFS, 1996). 


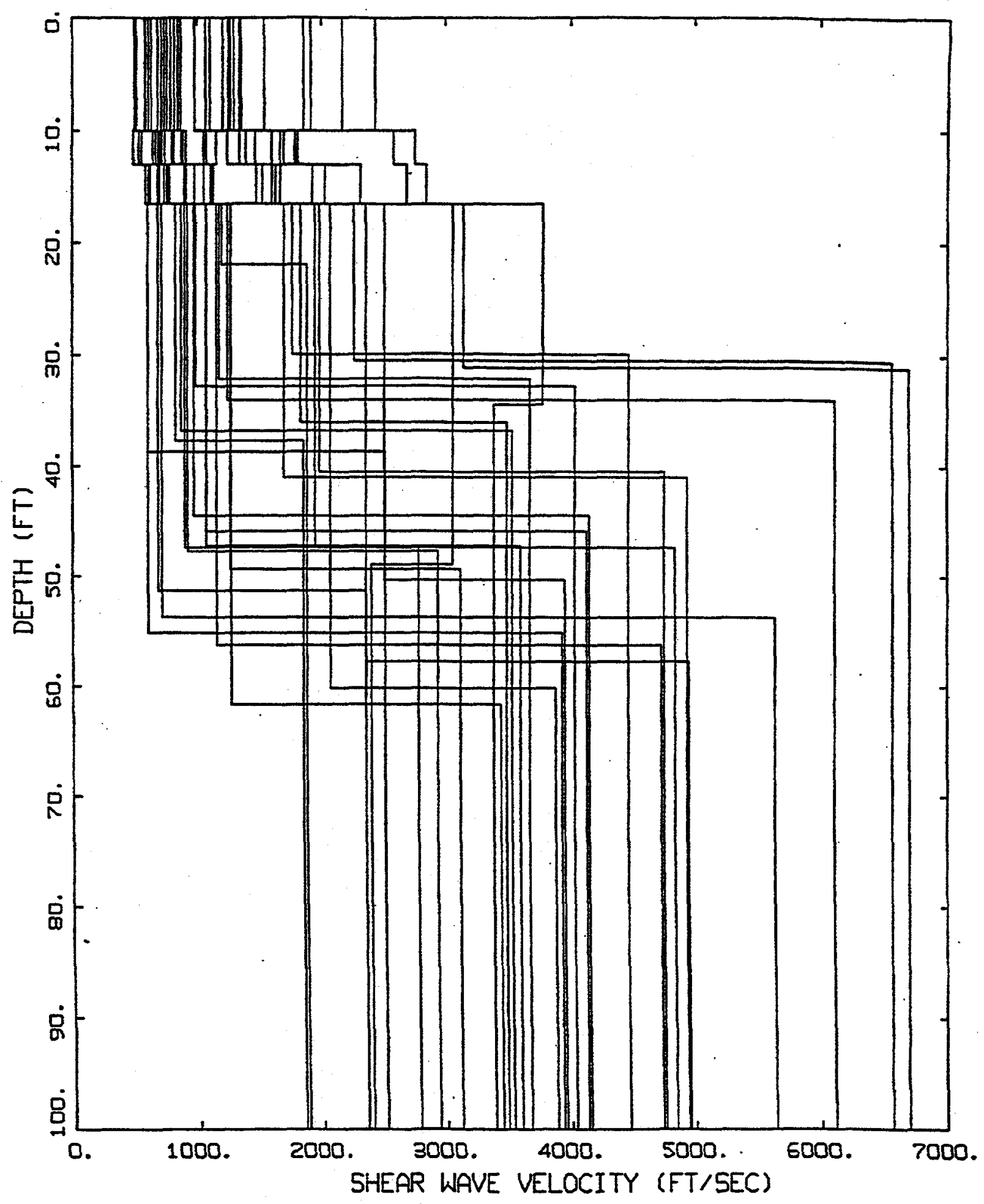

Figure E-5. Shear wave velocity profile variations for 30 randomized soil runs compared to the TMI-2 ISFSI shear wave velocity base case (URSG-WCFS, 1999). 
(a)

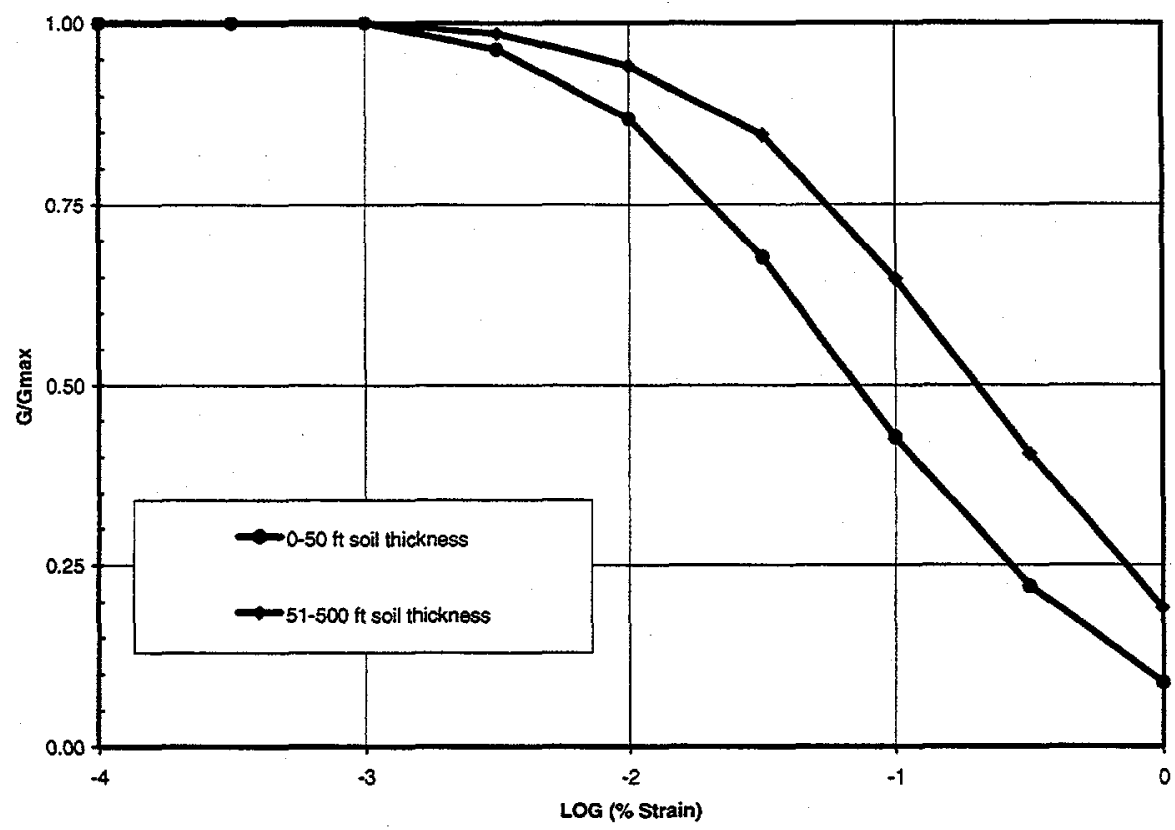

(b)

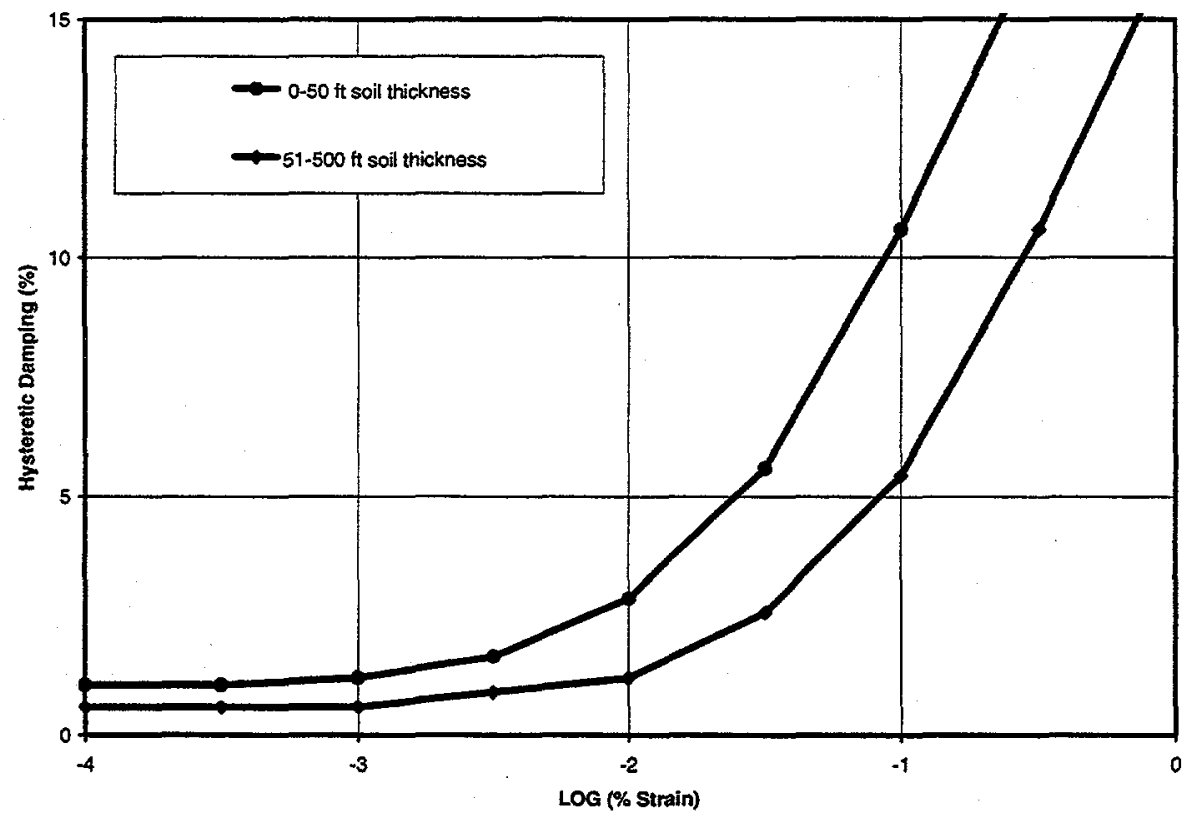

Figure E-6. (a) Shear modulus (G) reduction and (b) damping curves for low plasticity-index, cohesionless, generic soils (Silva et al., 1997) used by URSG-WCFS (1999) to characterize the strain-dependent behavior of the soil in the TMI-2 ISFSI soil response analyses. 


\section{E.2 Degradation Models for Soil Response Analysis at INTEC}

An evaluation of two degradation models (Silva et al., 1997 and EPRI, 1993) was performed to recommend appropriate shear modulus reduction and damping curves for INTEC. The degradation models of Silva et al. (1997) are for low plasticity-index, cohesionless, generic soils such as clean sands and silts, and were used by URSG-WCFS (1999) for the TMI-2 ISFSI soil response analysis. The EPRI (1993) degradation models are more appropriate for coarsegrained materials such as gravel. First, the two degradation models were compared to the recent work of Rollins et al. (1998) which developed shear modulus and damping relationships for gravels. Second, the mean soil responses of 30 randomized soil profiles using the two degradation models were compared. The results of the comparisons were used to recommend appropriate shear modulus reduction and damping curves for various soil conditions at INTEC and other facility areas at INEEL with similar soil conditions.

This evaluation considers soil conditions at INTEC that are typically described as alluvial silty and sandy gravels. Most soils at INTEC can be generally described as sandy gravels that have gravel content exceeding $50 \%$ by weight of the soil samples examined. However, some samples are noted to have gravel content slightly less than $50 \%$. A relatively thin silty clay layer has been encountered beneath the gravels at a few locations in the INTEC area. The evaluations of site response at INTEC have considered soil degradation models appropriate for either silty sands or sandy gravels, as described below. Based on engineering judgment, these results are considered appropriate for cases where the silty clay layer: 1) is less than $15 \mathrm{ft}$ thick; 2) has plasticity index (PI) values less than about 20 ; and 3 ) is encountered over no more than $25 \%$ of the facility foundation area. Whenever these limiting criteria are exceeded, a site-specific evaluation should be performed using appropriate degradation models that properly account for the existence of the silty clay layer.

The degradation models were compared to the recent work of Rollins et al., (1998) who developed shear modulus reduction and damping relationships from 15 investigations where cyclic shear tests were performed on gravels. The data from the 15 investigations were used to develop a best-fit curve and the $15^{\text {th }}$ and $84^{\text {th }}$ percentile curves or at One Standard Deviation. Figures E-7a and E-8a show that the shear modulus reduction curves ranging over soil depths of $0-120 \mathrm{ft}$ for EPRI (1993) are within the One Standard Deviation, $15^{\text {th }}$ and $84^{\text {th }}$ percentiles curves, developed by Rollins et al. (1998) for gravel. The shear modulus reduction curve for $0-50 \mathrm{ft}$ from Silva et al. (1997) is consistent with the $84^{\text {th }}$ percentile curve of Rollins et al (1998) in Figure E$7 \mathrm{a}$, but the shear modulus reduction curve for $51-500 \mathrm{ft}$ is beyond the $84^{\text {th }}$ percentile curve shown in Figure E-8a. Figures E-7b and E-8b show the damping curves ranging over soil depths of 0 $120 \mathrm{ft}$ for EPRI (1993) are within the $15^{\text {th }}$ and $84^{\text {th }}$ percentile curves developed by Rollins et al. (1998) for gravel. The damping curve for $0-50 \mathrm{ft}$ from Silva et al. (1997) is somewhat within the $15^{\text {th }}$ and $84^{\text {th }}$ percentile curves of Rollins et al (1998) in Figure E-7b, but the damping curve for $51-500 \mathrm{ft}$ is beyond the $15^{\text {th }}$ percentile curve shown in Figure E- $8 \mathrm{~b}$. The EPRI (1993) shear modulus reduction and damping curves for soil depths of $0-120 \mathrm{ft}$ are more consistent with the $15^{\text {th }}$ and $84^{\text {th }}$ percentile curves developed by Rollins et al (1998) for gravel than the Silva et al (1997) shear modulus reduction and damping curves.

The soil responses using the degradation models for low plasticity-index, cohesionless, generic soils of Silva et al. (1997) and the more nonlinear degradation model of EPRI (1993) were compared. URSG-WCFS was requested to use the EPRI (1993) degradation models (for soil depths of $0-20$ and $20-50 \mathrm{ft}$ ) in 30 soil randomized runs at the 10,000 year return period as 
was used in analysis of the TMI-2 ISFSI at INTEC. Figure E-9 shows the mean soil response using the degradation model of Silva et al. (1997) envelope the mean soil response using the degradation model of EPRI (1993) except at 2-3 Hz. The mean soil responses for both models are within $10 \%$ of each other. The use of the Silva et al (1997) degradation models for alluvial sandy silty soils with greater than $50 \%$ gravel results in conservative estimates of the mean soil response at INTEC (URSG-WCFS, 1999).

Based on these comparisons, degradation models (shear modulus reduction and damping curves) shown in Figures E-10 through E -14 are recommended for soil response and SSI analyses at INTEC. The degradation models are for alluvial sandy and silty gravel with greater than $50 \%$ gravel content, with less than $50 \%$ gravel content, and for ranges of soil thickness up to $120 \mathrm{ft}$. For other facility areas at INEEL (such as TRA, RWMC, PBF, NRF, and TAN) an evaluation of the soil properties should be performed to select the appropriate degradation models. The DOE-ID AE Standards will specify the criteria to be used to determine similarities in soil properties at other facility areas to those at INTEC. 
(a)

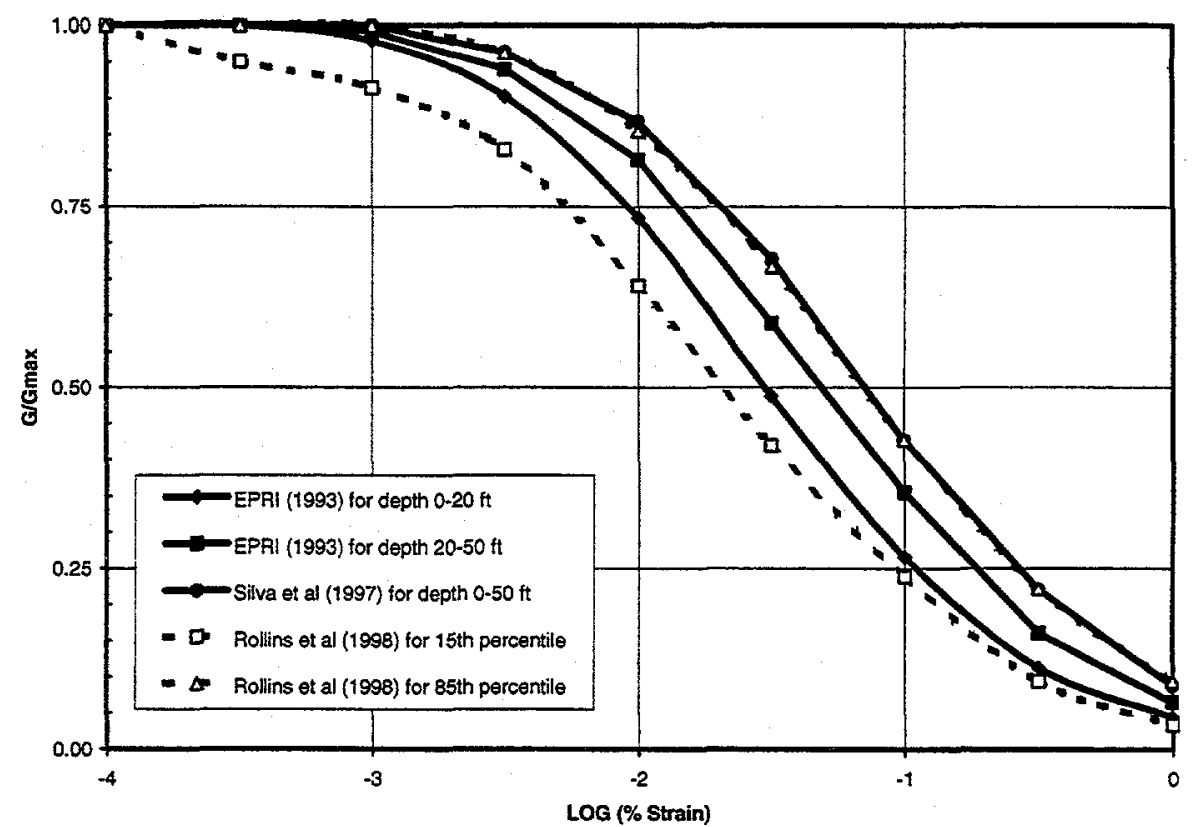

(b)

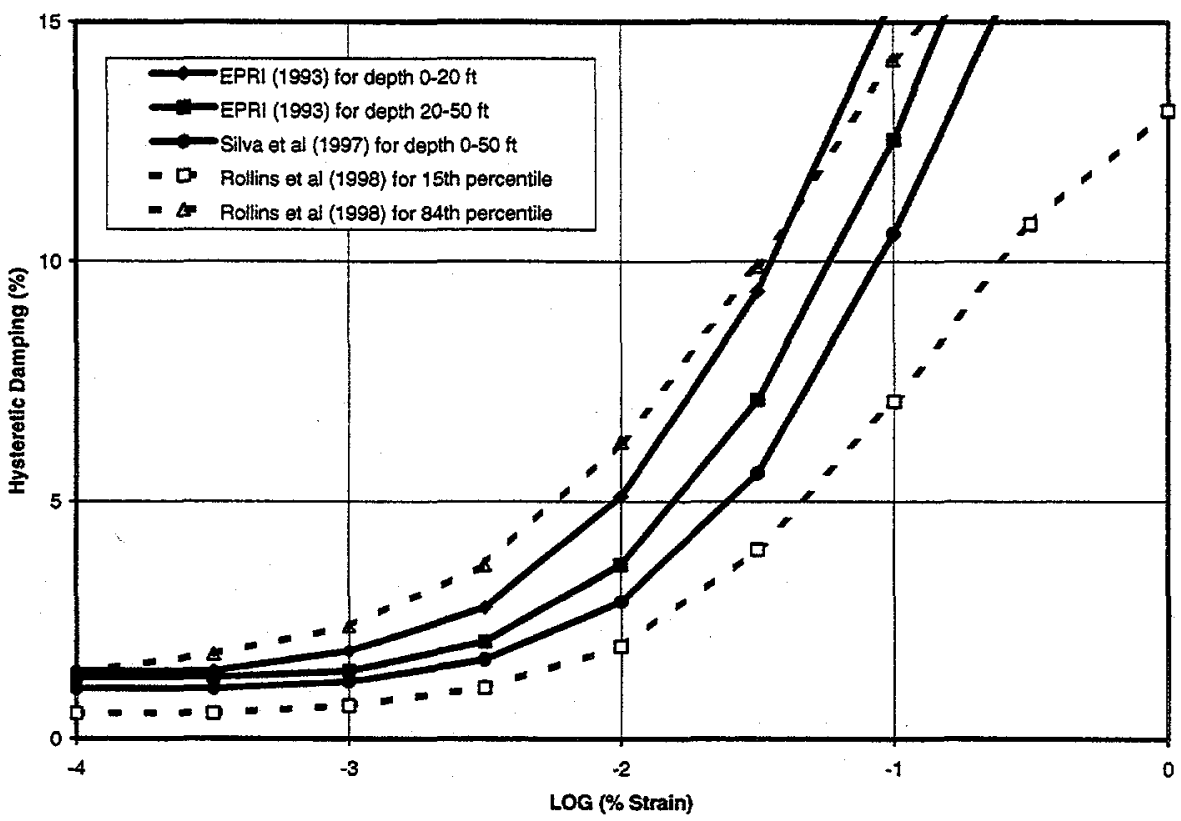

Figure E-7. Comparison of the (a) shear modulus reduction and (b) damping curves of EPRI (1993) and Silva et al. (1997) for 0 to $50 \mathrm{ft}$ soil thickness to the standard deviation boundaries of curves developed by Rollins et al. (1998) for gravels. 
(a)

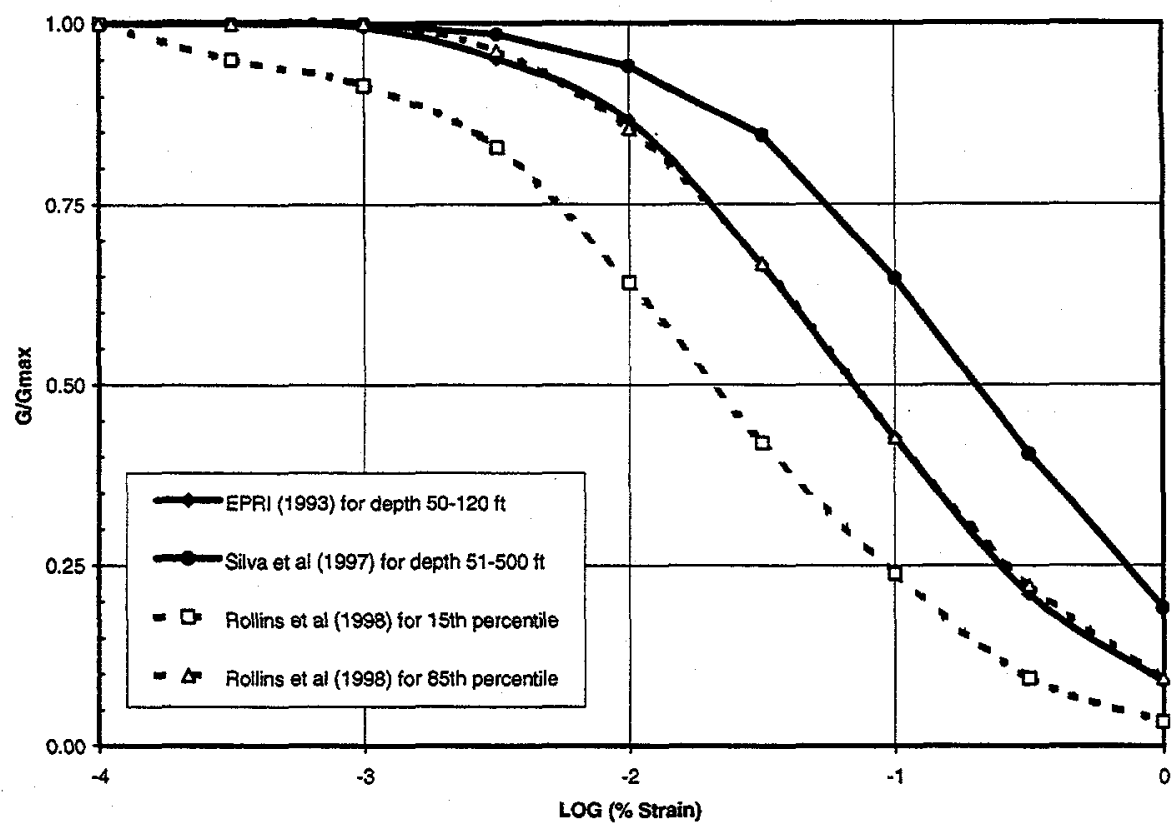

(b)

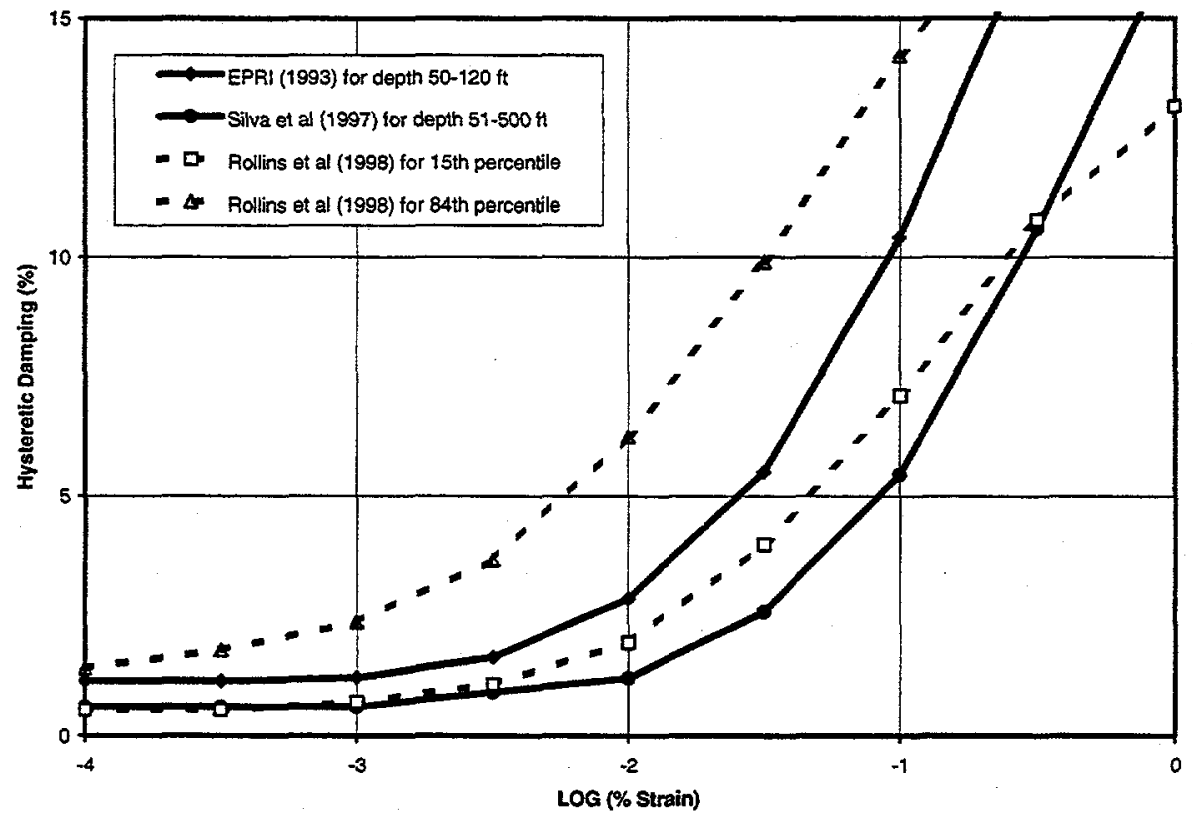

Figure E-8. Comparison of the (a) shear modulus reduction and (b) damping curves of EPRI (1993) and Silva et al. (1997) for greater than $50 \mathrm{ft}$ soil thickness to the standard deviation boundaries of curves developed by Rollins et al. (1998) for gravels. 


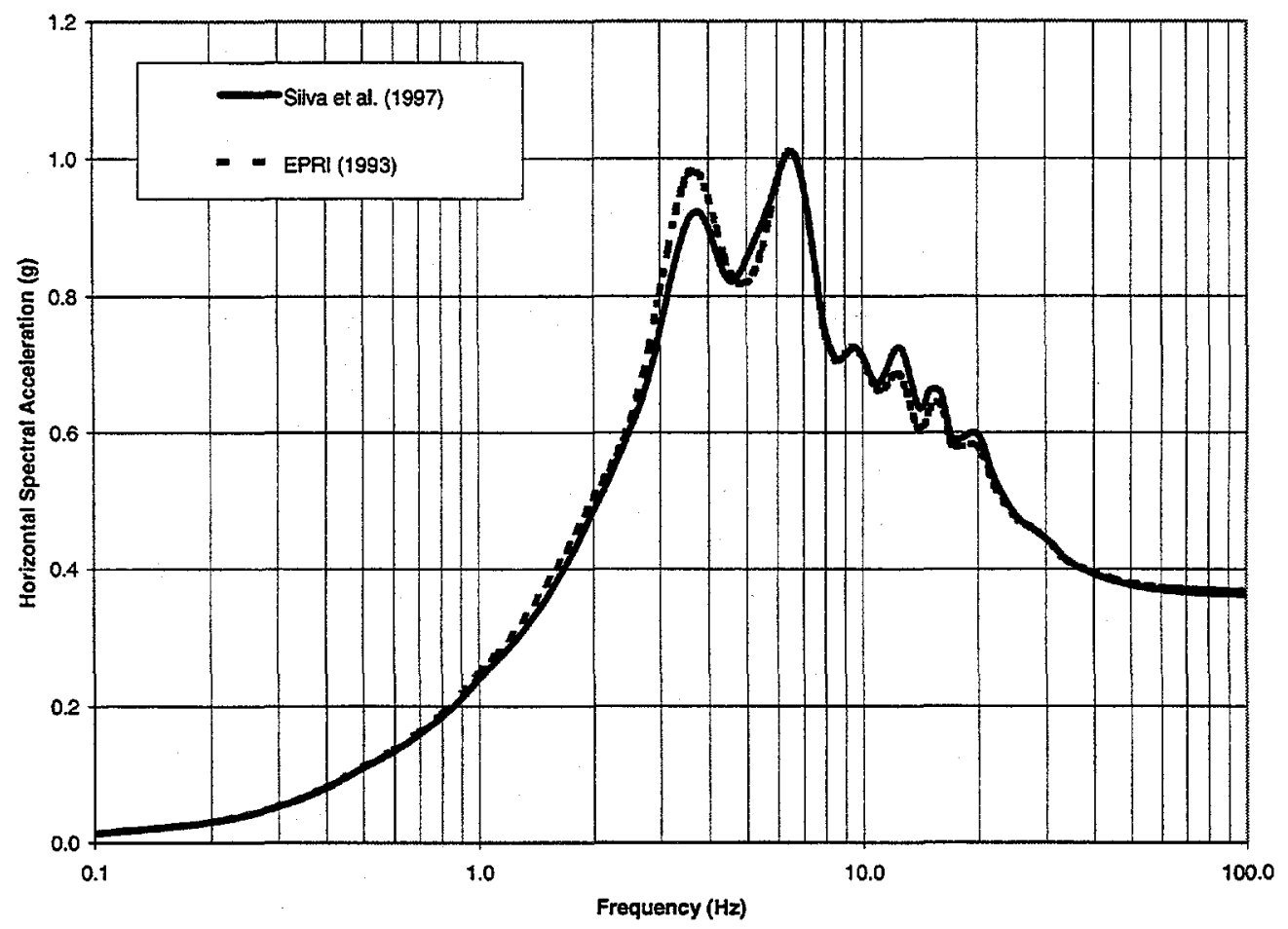

Figure E-9. Comparison of thirty runs for soil response analyses at INTEC using the degradation models of Silva et al. (1997) and EPRI (1993). The mean soil responses are shown for the 10,000-year return period at INTEC. 
(a)

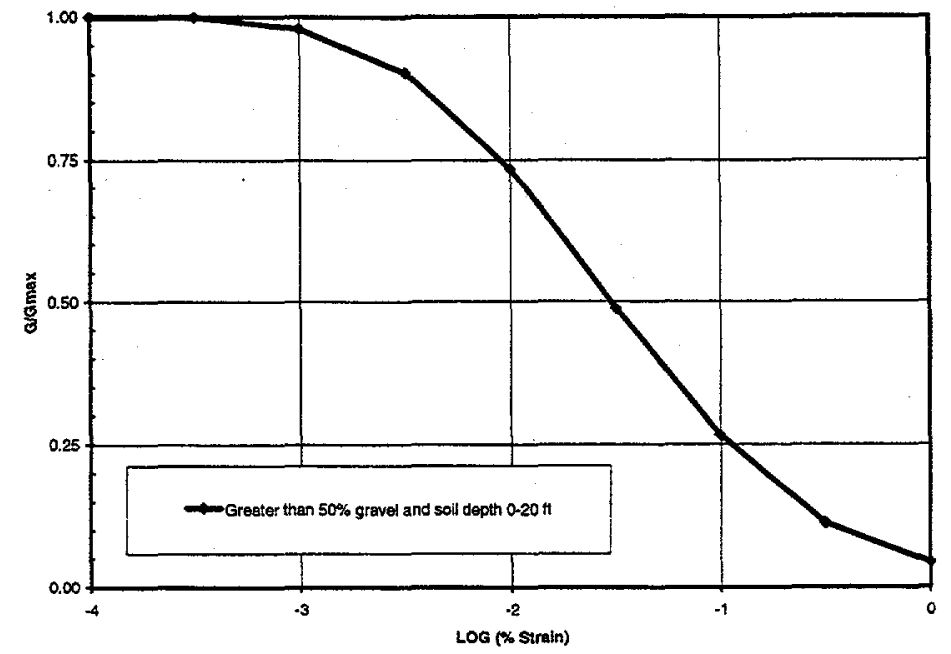

(b)

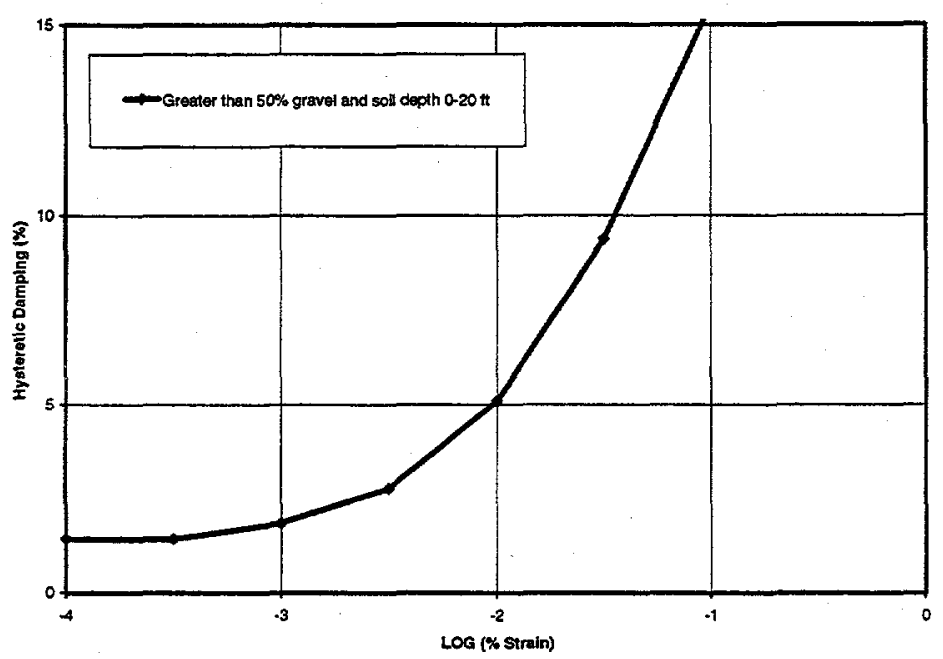

(a)

\begin{tabular}{ccccc}
\multicolumn{2}{c}{ (a) } & & \multicolumn{2}{c}{ (b) } \\
\cline { 4 - 5 } \% Strain & G/Gmax & & \% Strain & $\begin{array}{c}\text { Hysteretic } \\
\text { Damping (\%) }\end{array}$ \\
\hline-4 & 1 & -4 & 1.43 \\
-3.5 & 1 & -3.5 & 1.43 \\
-3 & 0.979 & -3 & 1.84 \\
-2.5 & 0.903 & -2.5 & 2.76 \\
-2 & 0.734 & -2 & 5.10 \\
-1.5 & 0.488 & -1.5 & 9.39 \\
-1 & 0.266 & -1 & 15.51 \\
-0.5 & 0.113 & & \\
0 & 0.044 & & & \\
\hline
\end{tabular}

Figure E-10. (a) Shear modulus (G) reduction and (b) damping curves (EPRI, 1993) for alluvial sandy and silty gravel with greater than $50 \%$ gravel and soil thickness of $0-20 \mathrm{ft}$ at INTEC. 
(a)

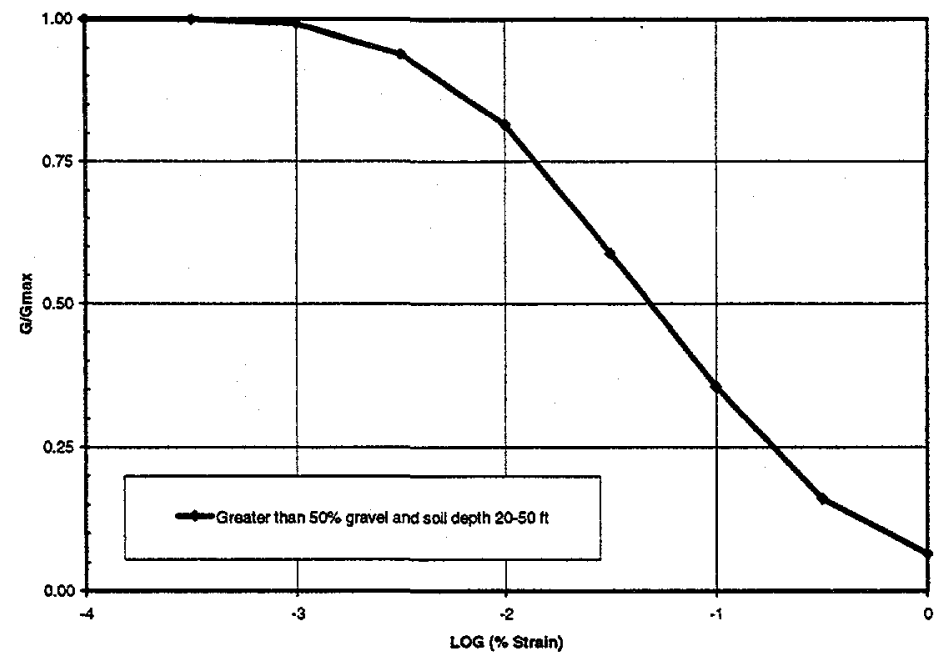

(b)

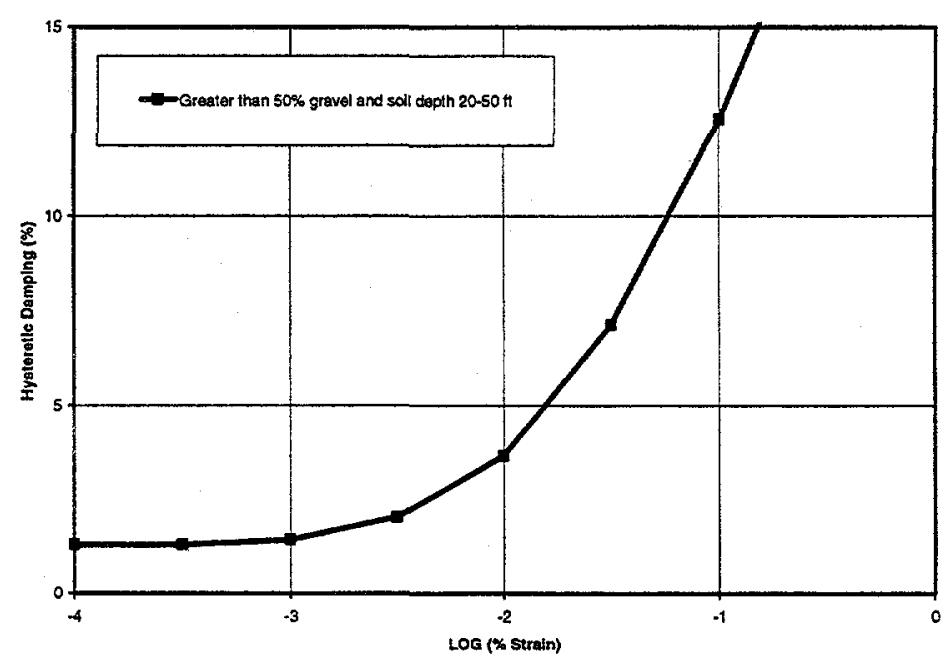

(a)

(b)

Hysteretic

\begin{tabular}{cccc} 
\% Strain & G/Gmax & \% Strain & Damping (\%) \\
\hline-4 & 1 & -4 & 1.30 \\
-3.5 & 1 & -3.5 & 1.30 \\
-3 & 0.992 & -3 & 1.43 \\
-2.5 & 0.940 & -2.5 & 2.04 \\
-2 & 0.815 & -2 & 3.67 \\
-1.5 & 0.589 & -1.5 & 7.14 \\
-1 & 0.355 & -1 & 12.55 \\
-0.5 & 0.161 & -0.5 & 19.39 \\
0 & 0.065 & & \\
\hline
\end{tabular}

Figure E-11. (a) Shear modulus (G) reduction and (b) damping curves (EPRI, 1993) for alluvial sandy and silty gravel with greater than $50 \%$ gravel and soil thickness of $20-50 \mathrm{ft}$ at INTEC. 
(a)

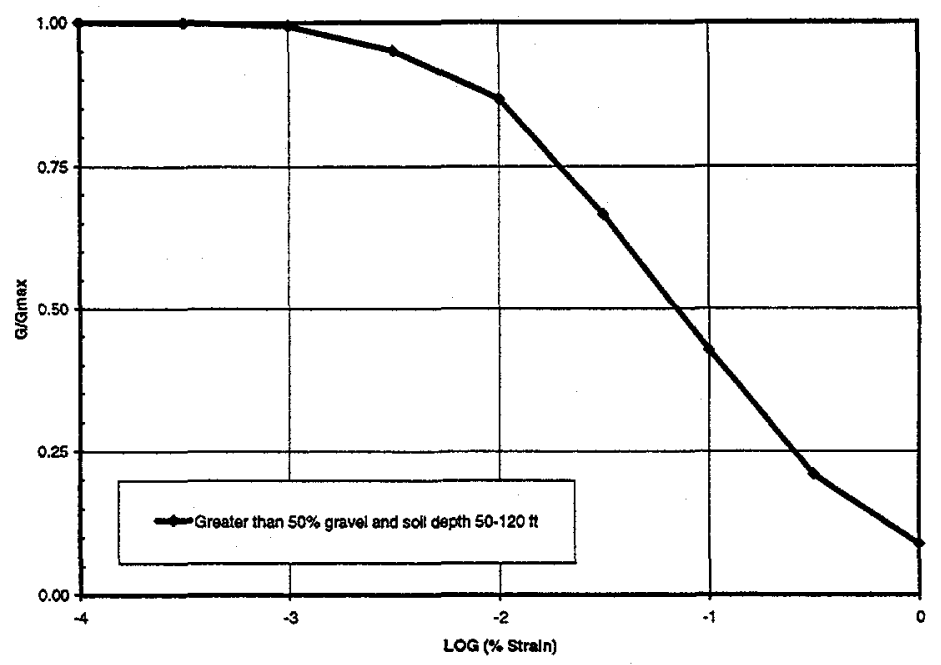

(b)

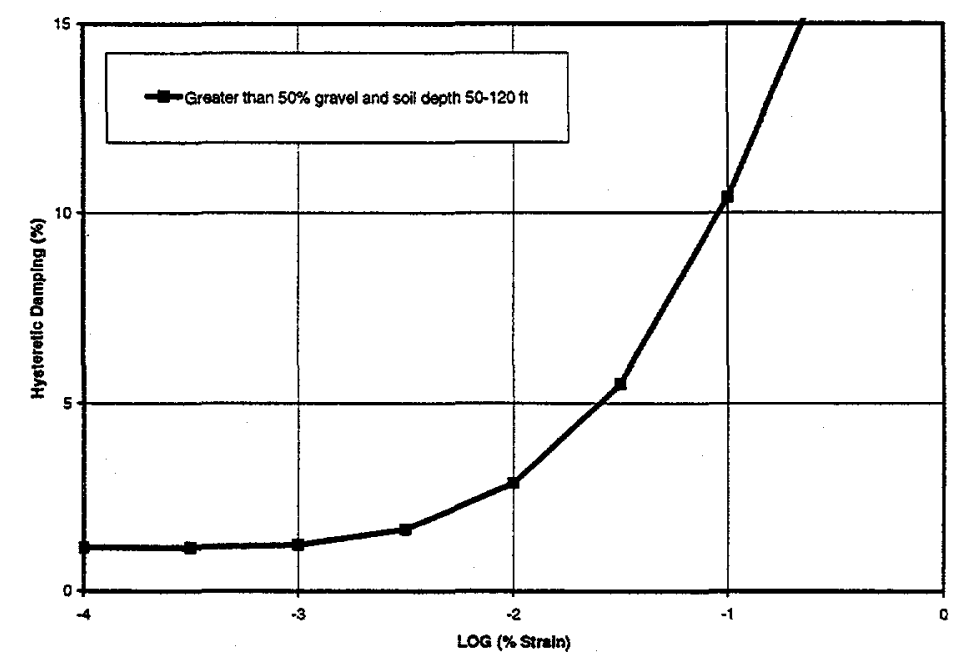

(a)

(b)

Hysteretic

\begin{tabular}{cccc} 
\% Strain & G/Gmax & \% Strain & Damping (\%) \\
\hline-4 & 1 & -4 & 1.15 \\
-3.5 & 1 & -3.5 & 1.15 \\
-3 & 0.995 & -3 & 1.22 \\
-2.5 & 0.951 & -2.5 & 1.63 \\
-2 & 0.867 & -2 & 2.86 \\
-1.5 & 0.665 & -1.5 & 5.51 \\
-1 & 0.427 & -1 & 10.41 \\
-0.5 & 0.210 & -0.5 & 17.04 \\
0 & 0.089 & & \\
\hline
\end{tabular}

Figure E-12. (a) Shear modulus (G) reduction and (b) damping curves (EPRI, 1993) for alluvial sandy and silty gravel with greater than $50 \%$ gravel and soil thickness of $50-120 \mathrm{ft}$ at INTEC. 
(a)

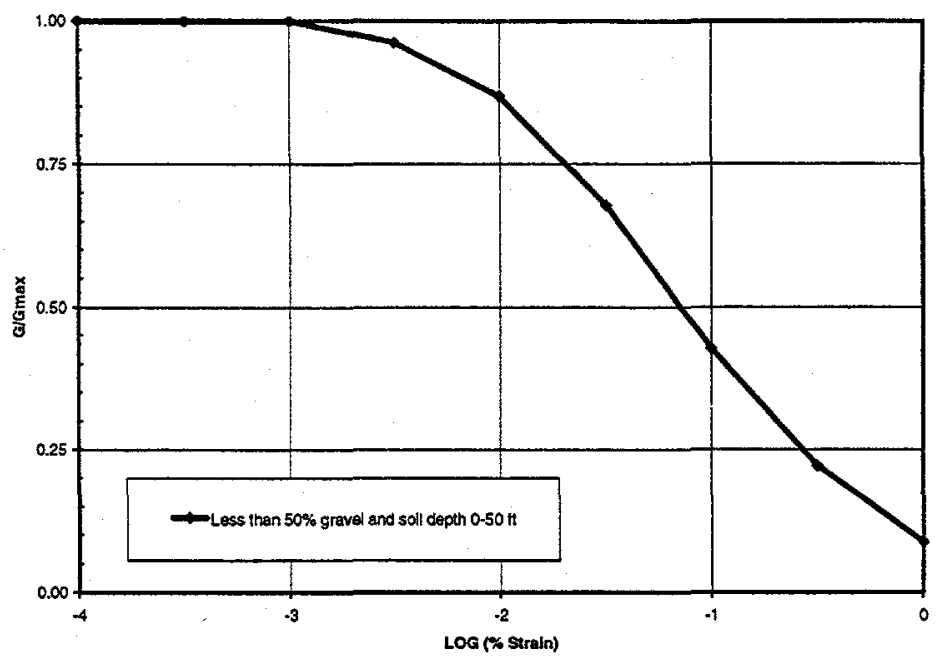

(b)

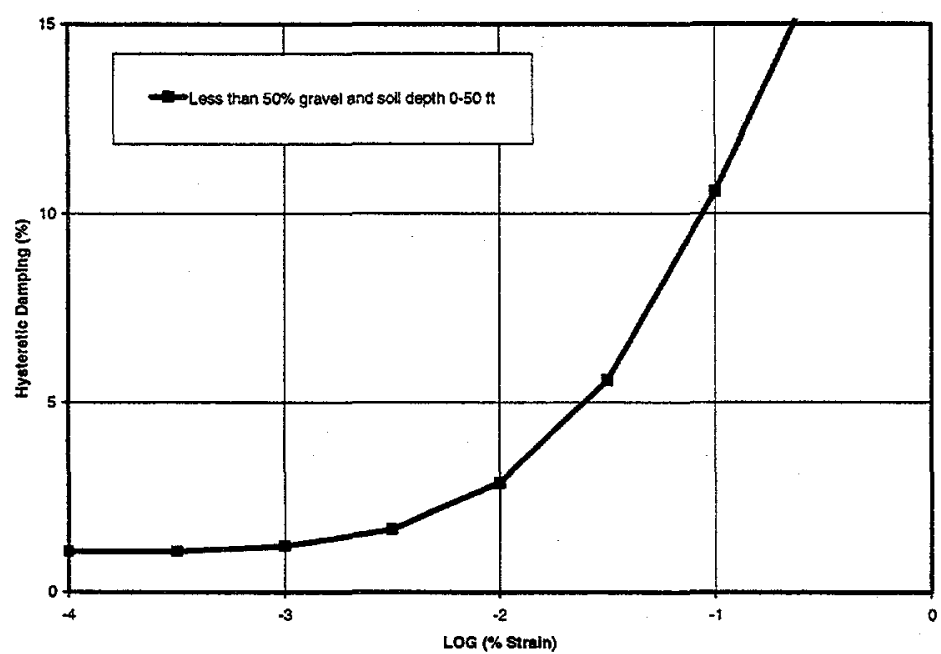

(a)

(b)

Hysteretic

\begin{tabular}{cccc} 
\% Strain & G/Gmax & \% Strain & Damping (\%) \\
\hline-4 & 1 & -4 & 1.06 \\
-3.5 & 1 & -3.5 & 1.06 \\
-3 & 1 & -3 & 1.21 \\
-2.5 & 0.963 & -2.5 & 1.66 \\
-2 & 0.868 & -2 & 2.88 \\
-1.5 & 0.677 & -1.5 & 5.60 \\
-1 & 0.427 & -1 & 10.59 \\
-0.5 & 0.221 & -0.5 & 16.65 \\
0 & 0.088 & & \\
\hline
\end{tabular}

Figure E-13. (a) Shear modulus (G) reduction and (b) damping curves (Silva et al., 1997) for alluvial sandy and silty gravel with less than $50 \%$ gravel and soil thickness of 0-50 ft at INTEC. 
(a)

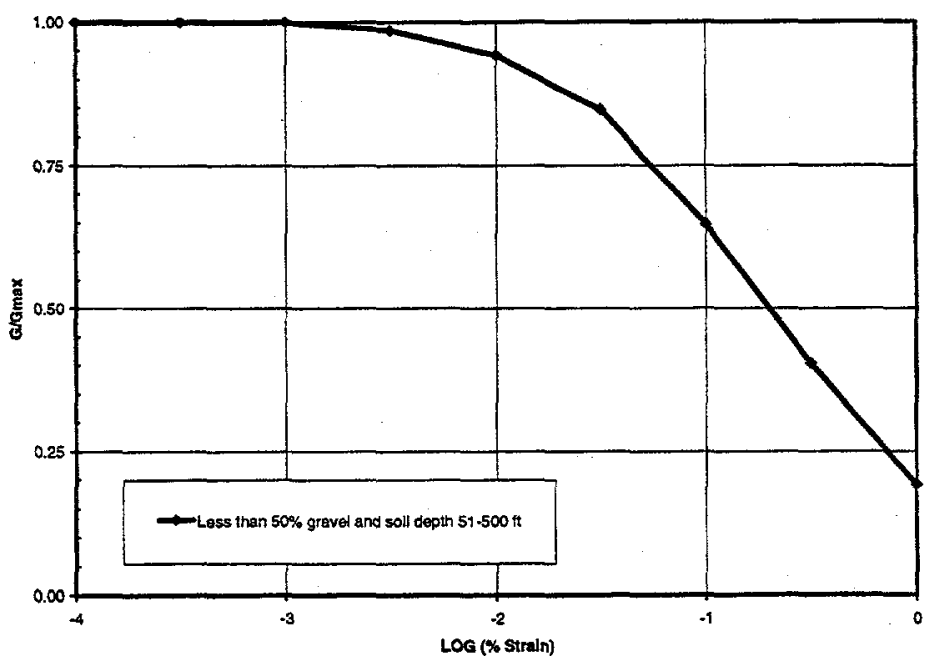

(b)

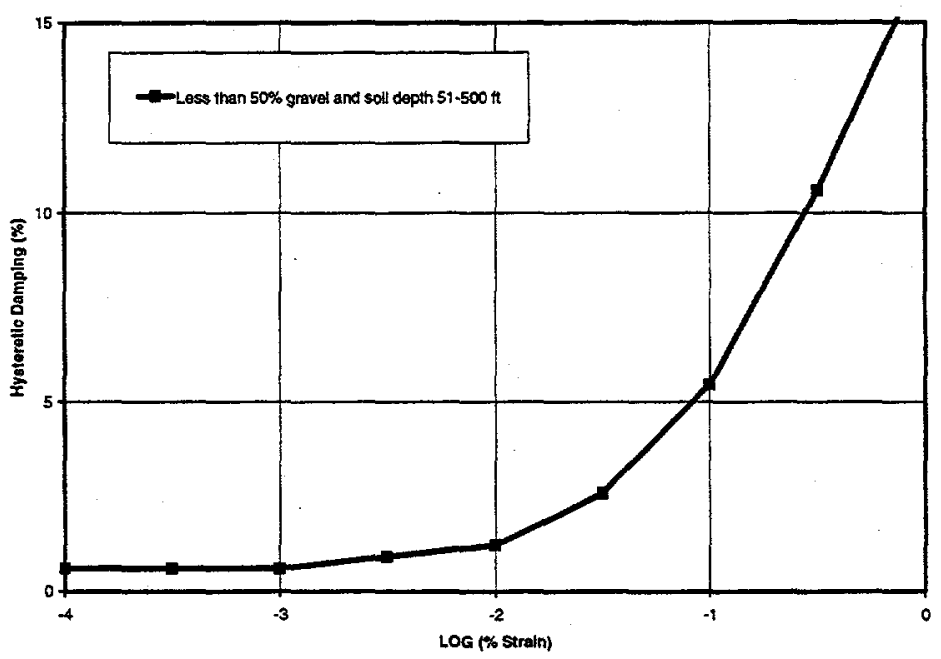

(a)

(b)

Hysteretic

\begin{tabular}{cccc} 
\% Strain & G/Gmax & \% Strain & Damping (\%) \\
\hline-4 & 1 & -4 & 0.60 \\
-3.5 & 1 & -3.5 & 0.60 \\
-3 & 1 & -3 & 0.60 \\
-2.5 & 0.985 & -2.5 & 0.91 \\
-2 & 0.941 & -2 & 1.21 \\
-1.5 & 0.846 & -1.5 & 2.58 \\
-1 & 0.647 & -1 & 5.45 \\
-0.5 & 0.404 & -0.5 & 10.59 \\
0 & 0.191 & 0 & 16.65 \\
\hline
\end{tabular}

Figure E-14. (a) Shear modulus (G) reduction and (b) damping curves (Silva et al., 1997) for alluvial sandy and silty gravel with less than $50 \%$ gravel and soil thickness of $51-500 \mathrm{ft}$ at INTEC. 